\title{
Skills Development in Sub-Saharan
} Africa

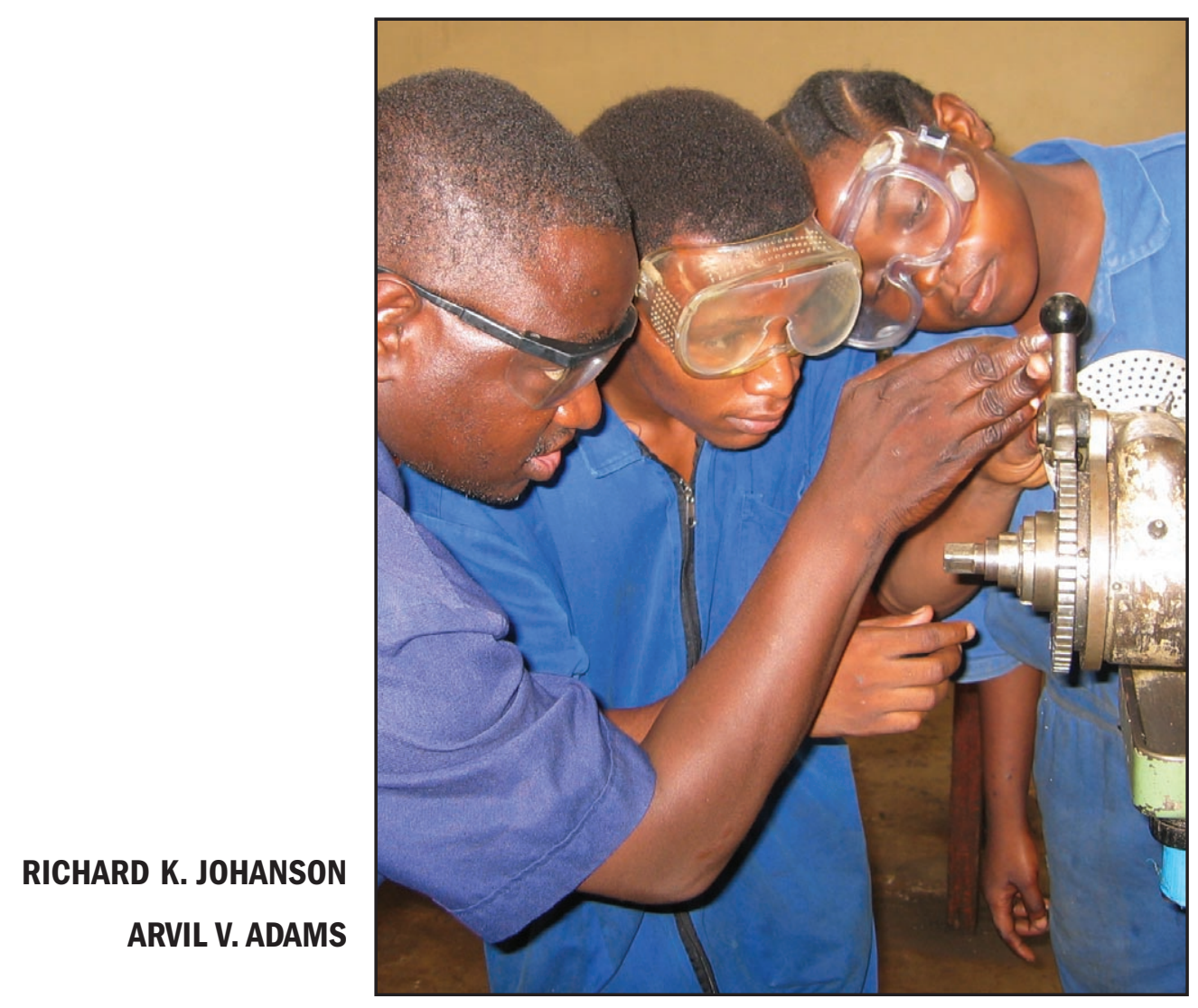



Skills Development in Sub-Saharan Africa

WORLD BANK

REgIONAL AND

SECTORAL STUDIES 



\section{Skills Development in Sub-Saharan Africa}

Richard K. Johanson

Arvil V. Adams

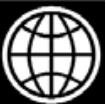

THE WORLD BANK

Washington, D.C. 
(C) 2004 The International Bank for Reconstruction and Development / The World Bank

The World Bank

1818 H Street, NW

Washington, DC 20433

Telephone 202-473-1000

Internet www.worldbank.org

E-mail feedback@worldbank.org

All rights reserved.

\section{4}

The findings, interpretations, and conclusions expressed herein are those of the author(s) and do not necessarily reflect the views of the Board of Executive Directors of the World Bank or the governments they represent.

The World Bank does not guarantee the accuracy of the data included in this work. The boundaries, colors, denominations, and other information shown on any map in this work do not imply any judgment on the part of the World Bank concerning the legal status of any territory or the endorsement or acceptance of such boundaries.

\section{Rights and Permissions}

The material in this work is copyrighted. Copying and/or transmitting portions or all of this work without permission may be a violation of applicable law. The World Bank encourages dissemination of its work and will normally grant permission promptly.

For permission to photocopy or reprint any part of this work, please send a request with complete information to the Copyright Clearance Center, Inc., 222 Rosewood Drive, Danvers, MA 01923, USA, telephone 978-750-8400, fax 978-750-4470, www.copyright.com.

All other queries on rights and licenses, including subsidiary rights, should be addressed to the Office of the Publisher, World Bank, 1818 H Street NW, Washington, DC 20433, USA, fax 202-522-2422, e-mail pubrights@worldbank.org.

ISBN 0-8213-5680-1

e-ISBN 0-8213-5681-X

Cover photo: Second-year trainees in machine fitting, working on milling machine; VETA Regional Vocational Training Center, Chan'gombe, Dar Es Salaam, Tanzania; Mr. Mayira Skada, instructor. Photo by Richard K. Johanson, World Bank.

\section{Library of Congress Cataloging-in-Publication Data}

Johanson, Richard K.

Skills development in Sub-Saharan Africa / Richard K. Johanson, Arvil V. Adams

p. cm - (World Bank regional and sectoral studies)

Includes bibliographical references and index.

ISBN 0-8213-5680-1

1. Vocational education-Africa, Sub-Saharan. 2. Technical education-Africa, Sub-Saharan. I. Adams, Arvil V. II. Title. III. Series. 


\section{Contents}

Foreword $\quad$ xi

$\begin{array}{ll}\text { Preface } & \text { XV }\end{array}$

Acknowledgments xix

Abbreviations and Acronyms xxi

Executive Summary $\quad 1$

Understanding the Labor Market Context and Developments 3

Making Reforms Work in Public Training 4

Opening Markets for Nongovernment Training Institutions 6

$\begin{array}{ll}\text { Recognizing Formal Sector Enterprises as Trainers } & 7\end{array}$

Building Skills for the Informal Economy $\quad 8$

Promoting Training Reforms with Financing 9

Moving Forward with Reforms 11

$\begin{array}{ll}\text { Note } & 14\end{array}$

1. Introduction and Background 15

$\begin{array}{ll}\text { Introduction } & 15\end{array}$

$\begin{array}{ll}\text { The Rationale for Training } & 15\end{array}$ 
Importance of Training in Sub-Saharan Africa Today 16

Issues Surrounding TVET $\quad 17$

Highlights of Developments in the 1990s 19

International Assistance for Skills Development 21

Highlights of the Literature $\quad 26$

Modeling Training Decisions $\quad 28$

Questions of Particular Relevance to Sub-Saharan Africa 32

The Africa Regional Review of Skills Development 32

Notes 37

2. Labor Market Context and Developments 39

Introduction $\quad 39$

Income and Poverty $\quad 40$

Labor Supply $\quad 44$

Labor Demand $\quad 47$

The Informal Sector 51

Labor Market Information $\quad 57$

Notes 61

3. Making Reforms Work In Public Training 63

Introduction 63

An Assessment of State-Sponsored Training 65

Making Reforms Work $\quad 72$

Priorities and Policy Issues $\quad 84$

4. Opening Markets for Nongovernment Training Institutions 91

Introduction 91

Scope and Characteristics of Nongovernment Training 93

Financing and Costs 96

Effectiveness 99

Regulation of Nongovernment Training Providers 104

Issues $\quad 106$

$\begin{array}{ll}\text { Notes } & 108\end{array}$

5. Recognizing Formal-Sector Enterprises as Trainers 109

Introduction 109

Background 110

Importance of Enterprise-Based Training 111

Pattern and Determinants of Enterprise-Based Training 111

Benefits of Enterprise-Based Training 118

$\begin{array}{ll}\text { Recruitment Practices } & 120\end{array}$

Types of Training 121

Public-Private Partnerships 124

Collective Support Services $\quad 124$

Coping with HIV/AIDS

Notes 125 
6. Building Skills for the Informal Economy 127

$\begin{array}{ll}\text { Introduction } & 127\end{array}$

Traditional Apprenticeship Training 129

Initiatives to Support Training Markets 135

$\begin{array}{ll}\text { Policies } & 142\end{array}$

Training Strategies for the Informal Sector 142

Toward a Strategy to Improve Traditional Apprenticeship

$\begin{array}{ll}\text { Training } & 145\end{array}$

$\begin{array}{ll}\text { Issues } & 147\end{array}$

Role of External Agencies $\quad 148$

$\begin{array}{ll}\text { Notes } & 148\end{array}$

7. Promoting Reforms with Training Finance 149

$\begin{array}{ll}\text { Introduction } & 149\end{array}$

Resource Mobilization $\quad 150$

Sale of Goods and Services $\quad 159$

Allocation Mechanisms 162

$\begin{array}{ll}\text { Notes } & 176\end{array}$

8. Moving Forward with Reforms 177

$\begin{array}{ll}\text { The Assessment } & 177\end{array}$

Government's Role $\quad 183$

Role of International Partners 186

$\begin{array}{ll}\text { A Research Agenda } & 187\end{array}$

\section{Appendixes}

Guide to Appendixes

A. Mali and Senegal: Rationale for Private Provision of Technical-Vocational Education

B. Mali: Private Technical-Vocational TrainingMain Findings

C. Senegal: Private TVE-Main Findings

D. Benin: BAA-Improving Traditional Apprenticeship Training

E. Cameroon: APME-Micro Enterprise Support and Promotion Program

F. Cameroon: GIPA-One Association's Approach to Improving Traditional Apprenticeship Training

G. Kenya: Jua Kali Project: Micro and Small Enterprise Training and Technology

H. Kenya: SITE Project: Improving Traditional Apprenticeship Training

I. Senegal: FEDNAPH-A Trade Association Providing Skills Training

J. Tanzania: VETA/GTZ Project: Pilot Programs for Informal Sector Training 
K. Uganda: UNIDO/DANIDA/JICA Project:

Master Craftspersons Training 215

L. Zimbabwe: ISTARN-Traditional Apprenticeship Program 217

M. Training Funds in Selected Sub-Saharan African Countries 220

\section{Principal Sources}

\section{References and Selected Bibliography}

\section{Tables}

1.1 Distribution of Country and Case Studies

2.1 African Firms That Ranked the AIDS Epidemic as Having a Moderate or Major Impact on the Costs of Running Their Businesses

2.2 Labor Force Participation Rates, by Gender, 1980 and 1997

2.3 Benin: Time Use, by Women and Men

2.4 Adult Literacy Rates, Selected African Countries, 1985 and 199546

2.5 Gross Enrollment Rates in Africa, 1960-97

2.6 Education Levels of Household Heads, Selected African Countries, 1993-97

2.7 Public Sector Wage-Employment, Selected African Countries, 1993-99

3.1 Secondary Enrollments in Technical-Vocational Subjects

4.1 Obstacles to Nongovernment Technical-Vocational Training and Solutions

4.2 Annual Salaries of Public and Nongovernment TVE Instructors in CFA Francs, Mali and Senegal

4.3 Regulatory Frameworks for Nongovernment

Technical-Vocational Training, Mali and Senegal

5.1 Determinants of Enterprise Efficiency (percentage increase in value added)

6.1 Training Needs in the Informal Sector

6.2 Advantages and Disadvantages of Traditional Apprenticeship as a Means of Skills Development

7.1 Revenue-Generating Payroll Taxes in Sub-Saharan Africa

7.2 Tanzania: Sources of Incomes and Training Costs, Selected Church-Owned Training Centers

7.3 Mechanisms for Funding Diversification: Advantages and Risks

7.4 Income Sources of National Training Funds, Selected Sub-Saharan African Countries

7.5 Key Conditions for Training Fund Success

7.6 National Levy-Grant Schemes in Selected Sub-Saharan African Countries

7.7 Weaknesses Common to Levy-Grant Schemes 
7.8 Strengths and Weaknesses of Enterprise Training Schemes 175

8.1 Strengths and Weaknesses by Type of Training Provider 182

\section{Figures}

1.1 World Bank Lending for TVET, Total and Africa Region

1.2 TVET Lending as a Percentage of Total Education Lending

1.3 World Bank Education and Training Projects with Training Investments

1.4 Studies Included in the Review

2.1. Sub-Saharan Africa: Estimated Proportions of Formal and Informal Sector Employment

2.2. Labor Force Structure, by Major Economic Sector, Selected African Countries, 1997

2.3. Informal Sector Employment as a Share of Nonagricultural Employment, Selected African Countries (1990s)

2.4. Structure of the Urban Informal Sector, Selected Francophone Countries, 1980s/1990s

2.5. Steps in the Training Process

3.1 The Range of Public Training Provision by Ownership 64

3.2a Relevance

3.2b Quality (Effectiveness) $\quad 70$

3.2c Internal Efficiency 71

4.1 Diversity in Nongovernment Institution-Based Training 92

4.2 Tanzania: Vocational Training Places by Ownership 93

4.3 Zambia: Training Institutions by Ownership 94

4.4 Costs per Trainee, Nonpublic and Public TVE Institutions in CFA Francs

4.5 Mali: Examination Results, Nonpublic and National Totals, by Type of Diploma (1999-2000) 100

4.6 Senegal: Success Rates for State Diplomas, 2000

4.7 Zambia: Examination Passes in Nonpublic Institutions by Type of Examination, 1998-2001

4.8 Zambia: Training Institutions by Type Ranked by Level of Standards, 2001

5.1 Incidence of Formal Training by Industry: Kenya, Zambia, and Zimbabwe, 1995

5.2 Incidence of Informal Training by Industry: Kenya, Zambia, and Zimbabwe, 1995

5.3 International Comparison of Incidence of Informal and Formal Training: Selected Countries

5.4 African Enterprises Providing Informal Training by Firm Size, 1995

5.5 African Enterprises Providing Formal Training by Firm Size, 1995

5.6 Percentage of African Firms Providing Formal Training by Ownership, 1995 
5.7 Percentage of African Firms Providing Informal Training by Ownership, 1995

5.8 Informal and External Training by Exporting and Nonexporting Firms

5.9 Workers Receiving Training by Type and Job Category:

Kenya and Zimbabwe, 1995

\section{Boxes}

2.1 Cameroon: Pathways to Entrepreneurship in the Informal Sector

2.2 Constraints on Informal Sector Enterprises

2.3 Namibia: Using Labor Market Information for Flexible Training Delivery

3.1 Kenya: Evaluation of Public TVET

3.2 CONFEMEN Conference on TVET in Bamako, 1998

3.3 Employer-Owned and -Managed Training in Brazil

3.4 Zambia: Granting Autonomy to Public Training Institutions

3.5 Plans for the Ghanaian National Qualifications Framework

4.1 Forms of Regulation

4.2 Zambia: Playing Field Slanted against Nongovernment Providers

6.1 Senegal: Views on the Position of an Apprentice 132

6.2 The Role of Informal Sector Associations 137

6.3 Main Findings from Study on Literacy for Livelihood Skills $\quad 140$

6.4 Training Follow-Up in Ghana 141

6.5 Role of Government in Informal Sector Training 143

7.1 Zambia: A Tale of Two Community-Based Trade Schools and Their Fee Policies 158

7.2 Senegal: Introduction of Extra Courses on a Fee-Paying Basis 159

7.3 Togo: Income Mobilization by Renting Institutional Premises $\quad 160$

$\begin{array}{lll}7.4 & \text { Zambia: Traditional Budgeting } & 168\end{array}$

7.5 South Africa: Normative Financing Experiment with Technical Colleges

7.6 Mauritius: Vouchers for Small Enterprise Training 170

$\begin{array}{lll}7.7 & \text { Malawi: Apprenticeship Allowances } & 172\end{array}$ 


\section{Foreword}

At the close of the 1980s, considerable doubts had begun to emerge among international donor agencies regarding the cost-effectiveness of publicly owned and managed technical and vocational education and training (TVET). Based on extensive analysis, a 1991 World Bank Policy Paper on TVET found a diverse market for skills development globally with national training systems consisting of public training, private training, and enterprise-based training. The paper's recommendations called for a strategic policy role for governments, the opening of markets to private provision of TVET, and the diversification of sources of training finance. The study found weaknesses in public provision of TVET, but it also found that such provision could be costeffective when accompanied by new forms of organization, management, and financing.

A decade later, this review of TVET in Sub-Saharan Africa in the 1990s reinforces many of the findings of the 1991 policy paper. It comes at a critical time in African development. Economies are weak. Wage employment in the modern sector is largely stagnant, and unemployment among educated youth is substantial and increasing. The impact of HIV / AIDS on the work force, although yet to be documented, is huge, with much of the impact falling on the ranks of the educated and skilled work force. In this context, what can African governments do to ensure that the skills required for growth and equity are developed in a cost-effective way? 
Without being prescriptive, this review provides relevant and useful knowledge that should help African leaders and donor agencies find answers to this question. These answers will be specific to given country contexts, but the review provides lessons from experience in Africa over the last decade that constitute a good starting point for the development of country policies and programs, including, most importantly, a strategic role for governments. The wealth of information specific to Africa should be of value not only to African leaders but also to countries in other regions that are facing similar challenges.

Reforms begun early in the decade have led to positive changes in the management and financing of public TVET. Although not uniformly successful, the reforms have demonstrated that institutional autonomy and financing mechanisms can work if they establish incentives for both efficiency and effectiveness. Training funds, especially those that allocate resources through competition, can work although their administration is complex. Not only private but also public institutions are mobilizing funds through fees and a range of business practices.

This study provides new documentation of the extensive scope and characteristics of, and the constraints upon, private TVET. The finding that African enterprises provide a substantial amount of formal and informal training in patterns similar to those found in middle-income and developed countries could provide comfort to African leaders faced with opportunities to change government's role in training, focusing more on policy and less on provision. Private TVET is not without problems, however, as the study shows, drawing attention to issues of promoting equity and quality in private training. Addressing these issues and building on the potential of the private sector as a partner is recommended as part of a more strategic role for the public sector in the provision and financing of TVET.

This review does far more than confirm for Africa the global findings of the earlier World Bank policy paper. By focusing on Africa, it provides a deep and relevant view of the challenges facing skills development in Africa today. A particular case in point is the extensive treatment of training for the informal sector, especially reforms that have sought to move beyond traditional apprenticeship in an effort to raise informal sector productivity and earnings. These have been difficult reforms, but most employment in the region will continue to be in the informal sector. In order for skills training to contribute to poverty alleviation, high priority must be given to finding effective models for the informal sector.

The absence of good information on the impact of HIV/AIDS on the labor force and on skill requirements is sobering and worrisome. One hopes that this finding will help convince governments and donors to undertake the necessary analyses as a matter of priority. If the impact is as large as commonly understood, then addressing the issue will be an important challenge in developing training policies. Added to this challenge is the need for 
understanding the stagnant nature of job growth in Africa's formal economy. Analyses of both topics are needed as a guide to future paths for skills development.

Callisto Madavo Vice President

Africa Region

The World Bank 



\section{Preface}

A decade after publication of the 1991 World Bank policy paper on Technical and Vocational Education and Training, the subject of TVET and its impact on productive employment and opportunities for income generation continues to spark debate about the responsibility of governments for providing and financing it. During this decade, donor interest in TVET has waned, with increasing attention given to Education For All and the global initiatives for human development embodied in the Millennium Development Goals. Donor interest in TVET has moved away from large investments in state capacity to less costly support for policy reforms.

Getting the macroeconomic context right remains the essential first step in focusing on skills development. Training does not create jobs. Skills are a derived demand and that demand depends on policies for growth and employment creation. These points are emphasized at several points throughout the study and should be viewed as an overarching theme underpinning the guidance offered for TVET reforms. The best strategy for improving the quality and incidence of training is likely to be strong growth in the demand for skilled labor within firms. The incentives that this growth provides for financing and the provision of training are important to the successful reform of TVET.

In no region other than Africa is the trade-off drawn more sharply between the achievement of skills development with TVET and the provision of universal basic education. Both are important to economic growth 
and poverty reduction, but the fiscal and administrative capacity of the state to meet both goals is limited. The presence of HIV / AIDS and the attendant deskilling of the labor force compounds the problem. Defining the role of the state in the provision and financing of TVET more strategically is essential to achieving EFA and the poverty reduction goal of the Millennium Development Goals. Confronting this trade-off is the objective of this review of Sub-Saharan Africa.

The experience of the past decade confirms many of the lessons drawn from the 1991 policy paper, and further brings a note of optimism amid the persistent difficulties faced in reforming public TVET systems. The decade has seen new governance arrangements emerging to tackle system fragmentation. Increased institutional autonomy, along with performance-based budgeting and diversified financing, is introducing new accountability to TVET. Evidence of nongovernment capacity for TVET is reducing pressures on public spending and opening opportunities for partnership.

The role of governments in the provision and financing of TVET has been reshaped over the past decade, and opportunities exist to deepen these reforms in Sub-Saharan Africa with further international assistance. Public stakeholders in TVET criticized the 1991 policy paper for its perceived bias toward private training solutions. This review provides a clearer rationale for a public-private partnership by documenting the scope of nongovernment provision and financing of TVET and its selective coverage. This description of African training markets helps define a more strategic role for government to play in TVET, while it continues to work in partnerships with nongovernment providers, including enterprises. This message will doubtless resonate in other regions, as well.

The study sets out to update knowledge and explore issues and recent developments in TVET and to distill lessons as a guide for future skills development in the region. It is written to inform clients, donors, and World Bank staff about TVET experience over the past decade and build a dialogue from this experience. It is not intended as a prescriptive policy paper but as a knowledge product. The focus is on nonfarm employment, leaving aside skills development in agriculture, which merits a study of its own.

The focus of the analysis is on economic lessons. Provision and financing of TVET are examined through the lens of economic efficiency, balanced with attention to social equity. Assessments of skill providers are built upon issues of access, relevance, cost-effectiveness, internal efficiency, financing, and equity. TVET has important social objectives, but the attention here is on economic objectives and the contribution of skills development to enhanced productivity, earnings, and poverty reduction.

The regional context for the study is one of low economic growth, high population and labor force expansion, and large informal economies. Access to reliable data was an issue. Substantial investment has been made in developing new data from thematic and country case studies conducted in partnership with the U.N. Educational, Scientific, and Cultural Organization 
(UNESCO) International Institute for Educational Planning (IIEP), the International Labour Organisation (ILO) and its International Training Center, the German Adult Education Association, and the National Institute of Technology in Oslo, Norway. Numerous African scholars have been engaged in this effort. The thematic and country case studies have formed the largest portion of the cost of this study by virtue of the weak institutional capacity of countries throughout the region for routinely monitoring and evaluating TVET. 



\section{Acknowledgments}

Colleagues inside and outside the World Bank have contributed to this review through their own work in the field of technical and vocational education and training and by preparation of thematic and case studies and peer review of this work. David Atchoarena, Paul Esquieu, André Marcel Delluc, and Igor Kitaev of the United Nations Education, Scientific, and Cultural Organization (UNESCO) International Institute for Educational Planning (IIEP) prepared three studies on trends in public vocational education and training (VET) and private VET. Fred Fluitman, John Grierson, Kenneth King, Hans Christian Haan, and Nicholas Serriere completed four studies on labor markets, enterprise-based training, and informal sector training for the International Labour Organisation, International Training Center (ILO/ITC).

John Oxenham, Abdoul Diallo, Anne Katahoire, Anna PetrovikaMwangi, and Oumar Sall wrote the report on literacy and livelihoods for the Institute for International Cooperation of the German Adult Education Association (IIZ/DVV). Andrew Dabalen, Helena Skyt Nielsen, and Michel Rosholm completed studies on enterprise training in Africa. Halfdan Farstad was responsible for the review of entrepreneurship education and training for the National Institute of Technology in Oslo, Norway. Jon Lauglo, Albert K. Akyeampong, Kilemi Mwiria, and Sheldon G. Weeks prepared a paper on vocationalizing secondary education. Geoff Stevens authored a study on 
distance learning for TVET. Adrian Ziderman completed the review of financing TVET, and Robin de Pietro Jurand prepared a literature review.

Others who also served as peer reviewers of thematic and case studies included John Middleton, Amit Dar, Claudio de Moura Castro, Fred Fluitman, Paud Murphy, Adrian Verspoor, Rachidi Radji, Joseph Bredie, Kalanidhi Subbarao, William Steel, Zafiris Tzannatos, Hong Tan, Harry Patrinos, Terry Allsop, Julia Betts, Peter Materu, Vis Naidoo, Jacob Bregman, Donald C. Mead, and David Fretwell.

Mogens Jensen of DANIDA, Edda Grunwald and Friedrich Hammerschmidt of GTZ, and Malte Lipczinsky of the Swiss Agency for Development Cooperation supplied agency background on trends in TVET support.

Several international meetings produced feedback on early drafts of the study. Twelve bilateral and multilateral agencies participated, as did senior African policymakers and scholars from 14 countries. The events and their organizers included a seminar in Sussex, United Kingdom, June 2002, Christopher Colclough, Peter Williams; the International Working Group for Cooperation in Skills Development, Edinburgh, Scotland, October 2002, Donor Consultation, Kenneth King and Michel Carton; and the International Training Center of the ILO, Turin, Italy, November 2002, African Consultation, Fred Fluitman.

The study was made possible by financial support provided under the Norwegian Education Trust Fund, managed by Birger Fredriksen, and the U.K. Department for International Development (DfID) Trust Fund, managed by Toby Linden.

Technical production of the final report was done by Fabrice Houdart. Administrative arrangements for thematic and case studies were handled by Farida Reza. Angel Mattimore and Julia Anderson oversaw publication of interim reports, and Raidan Dillard placed all documents produced by the study on the Web site of the World Bank's Social Protection topic area, http:/ / www.worldbank.org/labormarkets. Koffi Edoh handled the translation into French of the interim report.

The study was conducted under the general direction of Birger Fredriksen and his successor, Ms. Oey A. Meesook, Sector Directors, Africa Human Development. The team responsible for the study was Arvil V. Adams (task manager) and Richard Johanson. 


\section{Abbreviations and Acronyms}

ACS

ADB

AFD

APDES

APME

ARIF

l'artisanat

BAA

BEP

BT

BTS

CERES

CAP
Association des Couturiers

African Development Bank

Agence Française de Développement

Association pour une Dynamique de Progrès Economique et Social (Senegal)

Programme d'Appui au Milieu Artisanal de Maroua

(Cameroon)

Association regionale interprofessionnelle (Regional employer association) (Madagascar)

Traditional crafts

Bureau d'Appui aux Artisans (Benin)

Brevet d'Etudes Professionnelles (Nondegree vocational studies)

Brevet Technique (Nondegree technical education)

Brevet de Technicien Supérieur (Nondegree postsecondary technical education)

Centre de Ressources des Personnels des Etablissements d'Enseignement Technique et Professionnel (Madagascar) Certificat d'Aptitude Professionnelle (Vocational Training Certificate) 
CFA

Communauté Financière Africaine (African Financial

Community)

Chambres Trade chambers

des Metiers

Compagnons

Apprentice graduates

CONALEP Colegio de Nacional Educación Profesional Técnica

CONFEMEN Conférence des Ministres de 1'Education des pays ayant le français en partage (Conference of Ministers of Education of countries sharing French)

COSDEC Community Skills Development Centers (Namibia)

CNFTP

Conseil National de la Formation Technique

Professionnelle (Madagascar)

DANIDA Danish International Development Agency

DfID

Department for International Development (U.K.)

DIT

Department of Industrial Training (Kenya)

DUT

Diplôme Universitaire de Technologie

$\begin{array}{ll}\text { E\&T } & \text { Education and training } \\ \text { EBT } & \text { Enterprise-based training } \\ \text { EC } & \text { European Commission }\end{array}$

FAC

Aid and Cooperation Fund

FEDNAPH Fédération National de Professionnels de l'Habillement (Senegal)

GIPA

Groupement Interprofessionnel des Artisans (Cameroon)

GDP

Gross domestic product

GNP

Gross national product

GRETA

Groupement d'Etablissements (France)

GTZ

Deutsche Gesellschaft für Technische Zusammenarbeit

(German aid agency)

ICT

Information and communications technology

IDB

Inter-American Development Bank

IEE

Integrated entrepreneurship education

IIEP

IIZ/DVV

International Institute for Educational Planning

(UNESCO)

Institute for International Cooperation of the German

Adult Education Association

ILO

International Labour Organisation

ILO/ITC International Training Center of the ILO

INAFOP Instituto Nacional de Acreditação da Formação

de Professores (National Vocational Training Agency)

(Angola) 
INTEP Integrated Training and Entrepreneurship Promotion (Tanzania)

ISA Informal sector association

ISF Institutional Support Fund (Mauritania)

IST Informal sector training

ISTARN Informal Sector Training and Resources Network Project (Zimbabwe)

IVTB Industrial Vocational Training Board (Mauritius)

JICA Japanese International Cooperation Agency

Jua Kali Informal sector enterprises (Kenya)

LMIS Labor market information systems

MINDIC Ministère du Développement Industrial et Commerce

NACVET National Council for Vocational Education and Training

(Ghana)

NEPAD New Economic Program for African Development

NGO Nongovernmental organization

NIVTC National Industrial Vocational Training Center (Kenya)

NQF

NSA

NTA

National qualifications framework

National Skills Authority (South Africa)

National training authority

OIC Opportunities Industrialization Council (Ghana)

PRSP Poverty Reduction Strategy Program

RASCOM Regional Africa Satellite Communication Organization RPED

Regional Program on Enterprise Development

SADC

Southern African Development Community

SEBRAE Serviço de Apoio às Micro e Pequenas Empresas (Support

Services for Micro and Small Enterprises)

SDC Swiss Agency for Development and Cooperation

SENAC Serviço Nacional de Aprendizagem Comercial (National Service for Commercial Apprenticeship)

SENAI Serviço Nacional de Aprendizagem Industrial (National Industrial Apprenticeship Service) (Brazil)

SENAR Serviço Nacional de Aprendizagem Rural (National Service for Rural Apprenticeship)

SENAT Serviço Nacional da Formação Profissional para os Transportes (National Vocational Training Service for Transport) 
SETA

SITE

SWAPs

TC

TELISA

TEVETA

TSF

TVE

TVET

UFAE

UNAIDS

UNDP

UNESCO

UNEVOC

UNHCR

UNIDO

USAID

VAT

VET

VETA

VSP

VTC

VTIs

VTT

YTTC

ZIMDEF
Sector Education and Training Authority (South Africa) Strengthening Informal Training and Enterprise (Kenya)

Sectorwide approaches

Training college

Technology Enhanced Learning Initiative of Southern

Africa

Technical Education and Vocational Education

and Training Authority (Zambia, Malawi)

Training Support Fund (Mauritania)

Technical and vocational education

Technical and vocational education and training

Units for Training and Support to Enterprises (Mali)

United Nations AIDS Prevention Agency

United Nations Development Programme

United Nations Educational, Scientific, and Cultural Organization

International Project on Technical and Vocational

Education, UNESCO

United Nations High Commission for Refugees

United Nations Industrial Development Organization

U.S. Agency for International Development

Value added tax

Vocational education and training

Vocational Education and Training Authority (Tanzania)

Vocational Skills Project (Ghana)

Vocational training center

Vocational training institutes

Vocational and technical training

Youth technical training center

Zimbabwe Manpower Development Fund 


\section{Executive Summary}

Education and training are sound investments for the individual, the employer, and the economy. Skills development for participants in the labor force is important in Sub-Saharan Africa today for several reasons. Technological change and the increased competition flowing from trade liberalization require higher skills and productivity among workers. Skilled workers are more readily able to adapt existing knowledge and processes. Growing, competitive economies benefit from their presence and their movement to more productive employment.

Investing in the productivity and skills of people raises the incomes of economically vulnerable groups, thereby reducing poverty. Skills development has also become more important and difficult as wars proliferate and health issues intensify in the region. In particular, HIV/AIDS is depleting scarce human capital and magnifies the need to replace skills lost across a wide range of occupations.

The 1991 World Bank Policy Paper on Technical and Vocational Education and Training (TVET) called for rationalizing the role of the public sector in training, expanding the role of the private sector, and diversifying sources of financing for training. It emphasized the importance of good-quality basic education for all as a foundation for equitable access to future skills development. Governments were encouraged to establish a policy environment that supported market-led skills development. The rationalization of the 
public sector's role in training anticipated a more strategic approach by governments to the provision and financing of skills development, built on an understanding of what the private sector could be encouraged to do as a development partner in a given country setting.

The priority for governments was getting the policies right for establishing competitive training markets that would provide a level playing field for all parties. However, in the middle to late 1990s donor interest in skills development seemed to wane, in part because of the higher priority accorded to basic education. The attention given by donors to TVET in this period focused on fostering sector reforms rather than making massive new investments in public capacity.

A decade after the 1991 Policy Paper, this review assesses progress in Sub-Saharan Africa and the lessons to be learned from recent experience. This review updates and puts into an African context the Bank's 1991 work on TVET, explores issues and recent developments, reviews recent literature and policy studies, and distills lessons and conclusions as a guide to future skills development in the region. It is not offered as a prescriptive policy paper but as a knowledge product intended to advise experts and policymakers in the region on best practices, build consensus among donors on these practices, and create capacity within the World Bank to assist TVET reforms. The term "TVET" is used in this review to refer to formal and informal sources for skills acquisition, excluding informal learning on the job. "Skills development" is used generically in referring to the outcome of the learning process and does not refer to the source of skills acquisition.

This review benefits from extensive collection of new data and analysis of skills provision and financing, enabling it to explore the strengths and weaknesses of different provider groups and the impact of management and financing reforms over the past decade. The review is based on a series of 14 thematic studies ${ }^{1}$ that include 20 country reviews and 70 case studies. Attention is focused on the provision and financing of TVET in urban and rural nonfarm employment, leaving aside skills development in agriculture, which merits a study of its own. The regional setting is one of low economic growth, high population and labor force expansion, and large informal economies.

The review addresses a list of questions that seem especially pertinent for skills development in Sub-Saharan Africa today, namely:

- What should be the role of training when there is not enough modern sector employment?

- Given the widespread decay in public training systems, what should be the role of the public sector in training?

- Are private training providers more cost-effective than public sector training providers?

- What is the capacity of private training providers to fill the gap left by declining public investment in training? 
- What is the relative importance of training within enterprises and does the state need to intervene to stimulate it?

- In view of shortages of public financing, how can needed skills development be financed?

- What role can financing mechanisms play in improving the effectiveness and efficiency of training?

Answers to these questions and others developed in each chapter are pursued by looking over the past decade at the structure of employment and the demand for skills; the experience of government and nongovernment providers of skills training, including enterprises; and the experience with financing of TVET and resource management. The findings yield a clear, strategic role for governments to play in skills development while deepening sector reforms. The actions, if taken, promise to support achievement of the Millennium Development Goals for poverty reduction and Education for All.

\section{Understanding the Labor Market Context and Developments}

The principal challenge for African economies over the next decade is to find productive employment for the 7 to 10 million annual new entrants to the labor force-a consequence of historical rapid population growth and a swelling of the labor force by today's school-leavers. Currently, as many as 500,000 young people enter the labor force each year in Kenya, and as many as 700,000 in Tanzania and 250,000 in Zimbabwe.

While real wages have fallen in many countries, wage employment in the modern sector has been largely stagnant, except in isolated cases; for example, Uganda, Ghana, and Mauritius. Most entrants to the labor market have no alternative but to seek work in the informal economy. Employment in the informal sector has risen sharply since the 1970s.

The informal sector today absorbs most of those unable to find wage employment. In a typical African country (excluding South Africa and Mauritius), as much as 85 percent of total employment is engaged in the informal economy, with most of this in smallholder agriculture. Up to one-third of the total is employed off the farm in rural and urban areas in the informal economy.

Crowding-in of employment in traditional trade, retail, and personal services in the informal sector is cutting into individual market share and serving to redistribute poverty. A small number of new entrants who have more education are seeking manufacturing and high-end service opportunities in the informal sector as a preferred choice.

Against this background, Sub-Saharan Africa's stock of human capital is exceedingly low-as evidenced by low enrollment ratios, literacy rates, and educational attainment. Women are active labor force participants, but their full absorption into labor markets is hindered by a lack of education and skills and by cultural impediments. 
The outlook for labor is influenced by the region's wars, diseases, and demand for economic reforms. The influence of HIV/AIDS on skills development alone is devastating. It reduces productivity while driving up the cost of labor. It deskills the work force while reducing incentives for investing in skills. Weak market institutions for conducting surveys and monitoring labor force activity make analysis and policy development difficult.

Skills development is shaped by this environment. Growth in the informal sector is probably a permanent feature of African labor markets for the foreseeable future. Micro and small enterprises will remain the backbone of many developing economies. Reaching the informal sector with skills development will be increasingly important to poverty reduction.

\section{Making Reforms Work in Public Training}

State-sponsored training systems play an important role in all countries in Sub-Saharan Africa. These institutions continue to fall short in assessments of their relevance to economic and social needs, their effectiveness in delivering skills, and their costs and efficiency. The challenge is how to reform these institutions to make them more responsive to markets and more effective in the use of resources.

Among the various providers of TVET, state-sponsored training frequently responds to the demand for more costly skills, particularly at the tertiary level, and provides better geographical coverage, but it also suffers from poor quality and a lack of connection with market needs. Budget pressures of the past decade have limited capital improvements and spending on instructor salaries and other operating expenses, with adverse consequences for quality.

Some promising reforms to the management of TVET systems have been introduced over the past decade. Recognition of the interest in skills development among the diverse stakeholders-employers, government and nongovernment training institutions, workers, and trainees-has led to new governance arrangements and the introduction of national coordinating bodies and national training authorities. These bodies have been most effective where stakeholders have been given authority for developing training markets and allocating resources.

The movement to provide individual training institutions and managers with increased autonomy and accountability for results has improved the relevance and quality of skills development. Rigid, centralized public training systems have become more responsive where individual training institutes have been given the freedom to set fees, adapt training to local needs, hire appropriate staff, and choose methods of instruction. The shift from financing inputs for training to financing performance and outcomes has helped change incentives for improvements.

Innovations in the delivery of new, shortened, competency-based programs providing skills training on schedules that accommodate the needs of clients have opened up new training markets for public training systems. 
These markets have provided additional revenues for public institutions, improving quality and reducing pressures on public spending. These markets are attracting other nongovernment providers, further reducing pressure for public expenditures.

Open unemployment among youths in urban areas continues to create pressure to smooth the transition from school to work by adding vocational content to the academic curriculum. Although occupational knowledge with broad application-such as an introduction to computers-can be useful, research thus far has failed to confirm the value of inserting a limited number of vocational courses in the curriculum to give an advantage to youths entering the labor market. A variation of this approach, which supports entrepreneurship, has yielded several promising strategies.

The emphasis on performance and outcomes in training markets has found support in efforts to set skill standards for measuring performance and to provide a common yardstick for appraising the effectiveness of different providers. Such efforts promote cost-effective choices in training. If trades testing and certification are not managed well, however, they reinforce rigidity in the curriculum. One of the newest innovations, national qualifications frameworks (NQFs), is proving difficult to implement for countries that have limited capacity. More limited competency-based systems appear effective and more feasible.

The role of governments in the provision and financing of skills development continues to be debated. Governments have a public interest in removing skills bottlenecks to economic development and in promoting access to skills for those who are socially and economically disadvantaged. However, governments cannot afford to provide all the skills needed in a modern market economy. State-sponsored training can work best when delivered in partnership with other providers to meet market needs and diversify financing, while governments support the development of training markets.

Governments can be proactive in the following areas: (1) developing policies, setting standards, investing in training materials and instructors, improving public information about the training system, and carrying out evaluations of training; (2) financing training to meet equity objectives and fill strategic skill gaps; and (3) providing skills training in priority areas where nongovernment providers are reluctant to invest (but exercising caution to avoid crowding out nongovernment providers).

Finding the right balance between government and nongovernment provision and financing of TVET is important to ensuring that public resources are available for other spending priorities, such as basic education. Basic education remains essential to building the capacity to acquire new skills over the life cycle. The balance to be struck will doubtless vary from country to country based on the incentives present for each stakeholder. For government, the highest priority is in getting the policies and incentives right. Economic analysis at the country level is needed to inform this balance. 


\section{Opening Markets for Nongovernment Training Institutions}

The nongovernment training sector is highly diverse in ownership and purposes. It includes nongovernmental organizations (NGOs), religious-based providers, and for-profit trainers. Its scope exceeds the goals of those searching for profit and includes the social objectives of those seeking to reach the disadvantaged and poor with skills development. These institutions are an important and growing source of supply for skills in Sub-Saharan Africa. In many cases, nongovernment provision of training eclipses the supply from public sources.

Reliable information on the scope and performance of nongovernment training is difficult to find in most countries. This is a gap that needs to be filled in order to better understand training markets and define the role of government in the provision and financing of TVET. The limited information available from surveys in a small number of countries suggests that nongovernment providers are more responsive to markets and have lower instructor costs, more intensive use of facilities, and larger class sizes.

For-profit trainers tend to be well attuned to the market and often provide a substantial amount of training for women in traditional areas of employment. These enterprises are typically located in urban centers, less commonly in rural communities, and focus on a narrow range of skills that are relatively inexpensive to develop; for example, information technology, commerce, and sewing and tailoring. Nongovernment organizations and religious institutions serve a wider array of social objectives in reaching the disadvantaged, but they tend to be less well connected with markets and employers.

The variance is high among nongovernment providers in the quality of training offered. Interventions are appropriate to inform consumers about differences in quality; however, government capacity to regulate providers is weak in most countries and overregulation in pursuit of controlling quality can establish barriers to entry. Providing information to clients about the performance of individual institutions is an effective form of consumer protection. Government monitoring of performance can provide this information, but so can support for associations of trainers to set standards voluntarily and to enforce these standards.

Government and nongovernment providers of skills development tend to serve different market segments, but where overlaps occur, they open opportunities to redirect public financing more strategically to fill gaps left by nongovernment providers. Analysis of these markets is necessary to building this partnership and defining its limits. In identifying barriers to expanding nongovernment provision, providers mention lack of start-up capital, access to land, and capacity of trainees to pay. Public financing to lower these barriers can replace the need for public provision of skills development. 


\section{Recognizing Formal Sector Enterprises as Trainers}

African enterprises also provide training, and they are an important component of supply in training markets. Using a sample of enterprises from the manufacturing sector to assess wage employment in five countries shows that these enterprises train at rates equal to or greater than those of enterprises in other regions. The combination of enterprise-based training and nongovernment training institutions represents substantially greater capacity for skills development than is found in state-sponsored training institutions.

Enterprise-based training is largely self-financing, self-regulating, and cost-effective. It occurs without much government help, apart from any tax benefits that may exist in specific countries. The economic benefits of this training are substantial in terms of wage growth and value added per worker. Access to such training, however, is selective. If not compensated for in other ways, it will lead to higher income inequality over the life cycle of workers.

As is true worldwide, larger enterprises train more than smaller enterprises. The difference is greater for formal modes of training than for informal on-the-job training. The latter is available in most firms, large and small. The rate of formal training in enterprises with more than 150 employees, however, can be 10 to 20 times higher than that for smaller enterprises with 10 or fewer workers. Not surprisingly, enterprises that produce for export and that are foreign-owned train at higher rates than others.

Those trained in enterprises tend to have more education and higher occupational status than those not selected for training. Thus, those who were fortunate to secure education early continue to enjoy this advantage at later stages of the life cycle through further access to training for increased productivity and incomes. These patterns of investment in training are consistent with patterns found in others developing and industrial countries.

In view of the extensive training that takes place within enterprises, mostly without government intervention, no blanket justification exists for general subsidies for skills development, at least among the larger enterprises that are active trainers. However, the argument can be made that present levels of training in these enterprises may still not be optimal in economic terms, and that the economic returns to training should be investigated. The case may be stronger for public subsidy of smaller enterprises, where the high cost of time away from production can lead to underinvestment, as can a lack of information about the benefits of training.

As with state-sponsored and nongovernment training, the training market served by enterprises is segmented. The reliance on any of these providers alone is likely to leave gaps in the provision of training. Reforms over the past decade, specifically using training funds as an intermediary to encourage enterprise training and help overcome the high transactions cost for smaller firms in the design of training, merit further use and targeting to smaller enterprises. 


\section{Building Skills for the Informal Economy}

As shown, smaller enterprises train less frequently, and when they do, often use traditional apprenticeships. Traditional apprenticeship training is selffinancing, self-regulating, and cost-effective, but it perpetuates traditional technologies and lacks standards and quality assurance. The informal sector is where most of the nonfarm poor work and where investments in skills development along with other complementary inputs-access to secure workplaces, credit, and technology - can play an important role in poverty reduction, particularly for women and vulnerable groups.

Experience over the past decade has shown how shifting financing to the demand side through training funds and vouchers for workers can elicit a new supply response from trainers for the informal sector, including nongovernment institutions and master craftspersons. State-sponsored formal training institutions have been slower to respond to incentives for this training. Support for training of master craftspersons can enhance the quality of the training they offer while raising awareness of new technologies.

Training interventions can have an added benefit in raising productivity and incomes in micro and small enterprises by acting as an entry point for upgrading the technology of enterprises. Interventions need to target niche markets that have growth prospects and avoid saturated trades and markets, which are unlikely to yield benefits for training. The Madagascar experience of targeting training to small suppliers of intermediate goods for processing and exporting is an example of finding these niche markets. Market studies are needed to achieve this goal.

Demand for training among micro and small enterprises in the informal sector is likely to be low and to require development activities in order to demonstrate the benefits of skills development. Informal sector associations can be helpful in raising awareness of skills shortages among members, as well as in addressing other shared needs. Literacy or the lack thereof is likely to be an issue for skills development in the informal sector. Successful examples are available of programs that combine learning for livelihoods with literacy training.

Training for the informal sector is necessarily different from that for the formal sector in its preference for merging technical skills with business management skills and delivering these courses with a flexible schedule. The training needs to have immediate application, since the poor can hardly afford long periods of training before seeing a payoff. Focusing on the evaluation of competencies achieved with training is important to quality assurance. Even poor people have shown a willingness to pay for good training. Full cost recovery is rarely attempted or achieved, however, and subsidies for training in the informal sector can be justified on the grounds of social equity and efficiency.

Donors have been active supporters of skills development for the informal sector and have shown that enterprises in the informal sector can be upgraded; however, taking these interventions to scale and sustaining them 
remains a challenge. The emergence of training markets with diverse sources of supply and ready demand remains in the distance. Developing these markets is possible, however, and can be facilitated by governments. Except at the high end of the informal sector, strengthening skills development does not ensure the transition of Sub-Saharan Africa from abundant manual labor to skill-based competitiveness. An increased focus on skills development for the informal sector should not detract from ensuring a reasonable amount of high-quality training for the modern sector.

\section{Promoting Training Reforms with Financing}

Resource mobilization must be an integral part of national training policy, in view of limitations on public financing. It needs to be matched with initiatives to improve the efficiency of existing expenditures on skills development. The past decade has shown increased diversification of financing for skills development and a movement toward new instruments that shift financing to the demand side of training markets in order to promote accountability for performance. The modalities of financing TVET are perhaps the most important instrument for promoting sector reforms, because of the incentives they provide.

\section{Resource Mobilization}

There are five options for mobilizing additional resources for skills development: (1) payroll levies on employers, (2) tuition and other fees paid by enterprises or trainees and their families, (3) production and sale of goods and services by training institutions, (4) community support and donations, and (5), indirectly, the expansion of nongovernment provision. Tax credits or deductions of expenses can also be used to encourage spending on training by enterprises and households, but the outcome largely depends on the efficiency of tax administration and the presence of income to be taxed, which tends to reduce the effectiveness of such measures in the informal sector.

Training levies are used in 12 countries in Sub-Saharan Africa to provide a stable source of financing for skills development, but not without problems. These problems include noncompliance among employers, particularly among smaller enterprises; diversion of resources to uses other than training; and potential generation of surpluses leading to misuse of funds. The weakness of this source rests in the limited industrial base of the modern sector in Sub-Saharan Africa.

Tuition and fees have expanded for skills development. Such fees currently cover up to one-quarter of recurrent costs but vary with the type and cost of the training, the willingness of clients to pay, political constraints on cost sharing, and policies for social equity. Where fees are used, targeted public financing can help provide access for the poor.

The sale of goods and services produced by training institutions has increased revenues for skills development. Finding the right balance 
between training and production is important to ensuring that an undue focus on production does not reduce the quality of training and lead to exploitation of trainees. Maintaining total revenues from this source of up to 15 percent at the institutional level can retain the right balance.

Actions to remove barriers to entry and expand nongovernment sources of skills development promise to bring additional private resources to the market. In some cases, communities are also willing to sponsor training institutions.

Combined, these sources can reduce pressures on public spending for skills development. Supplementary financing is not expected to replace public financing completely or even to mostly replace it, particularly where equity issues apply. What is important is building a financing strategy that combines these sources to create a mix of public and private financing for skills development. Incentives to do so are enhanced where local institutions are able to retain and use the additional revenues generated for quality improvements.

\section{Resource Allocation}

How funds are managed and training procured influences the behavior of training institutions and the outcomes of skills development. Allocation mechanisms for training resources are a powerful means to help the training system become more market-responsive and efficient.

Training funds are now found in 21 countries in Sub-Saharan Africa, managing resources from government budgets, training levies, and donors. These funds afford an opportunity to level the playing field for all providers by procuring training for target groups on a competitive basis. This encourages cost-effective delivery. Characteristics of effective training funds include transparent rules for allocation, good governance with employer and worker representation, sound management, effective targeting instruments, regular monitoring and evaluation of training results, and attention to fiscal sustainability.

An expansion of cost sharing increases consumer interest in the quality of training and demand to the provider for training relevance and cost-effectiveness. Empowerment of consumers with training vouchers can lead to an expansion of training supply from the different provider groups, more choices for trainees, increased relevance, and reductions in cost from competition. However, vouchers have proven complex to implement and control financially and may not fit in African countries where low administrative capacity is an issue.

The use of budgeting norms and performance criteria shows promise for improving training outcomes and is especially relevant to reshaping incentives and accountability for state-sponsored training. Norms for financing can be established using inputs, such as trainees enrolled; outputs, such as course completions; and outcomes, such as job placements. Combinations of 
these norms could be feasible in most African settings, provided that reliable measurement criteria and adequate information systems are developed, results are reported candidly, and political will exists to resist the vested interests that may lose from this application.

In countries that use a training levy, the proceeds can be returned to enterprises as a grant for training in proportion to their contribution to the levy or redistributed among enterprises that choose to train. The levy-grant system encourages efficient enterprise training and reduces demand for public spending but, like vouchers, requires administrative capacity for evaluating grant proposals and monitoring results.

Allocation mechanisms for procuring training services vary in complexity and administrative requirements and need to be tailored to local circumstances. The importance of these mechanisms is the incentive framework that they provide for improving the quality, cost-effectiveness, and relevance of training. These incentives can be applied to all providers to encourage competition. Mechanisms such as training funds, vouchers, and even budget performance criteria can also be used to achieve social equity objectives.

\section{Moving Forward with Reforms}

Five principal findings emerge from this review as guides to future TVET reforms in Sub-Saharan Africa:

1. The reform of skills development in the informal sector is essential to poverty alleviation.

2. The record of TVET reforms over the past decade has been promising.

3. Public training continues to face challenges in reform and will require sustained commitment.

4. Nongovernment training institutions and enterprises account for most of the regional capacity for skills development and should be part of the reform dialogue.

5. Management and finance provide powerful instruments for promoting reforms.

Encouraging trainers to respond to markets for skills development in informal economies, where many poor people are employed, can reduce poverty. The evidence of the past decade shows management and finance reforms that have improved access, relevance, cost-effectiveness, and reduced wastage in training but that also highlight the ongoing challenges facing the reform of state-sponsored training. Reforms require the consensus and sustained commitment of all stakeholders. What is most clear in this review is the substantial capacity of nongovernment providers for skills development, including in enterprises, and the potential for governments in Sub-Saharan Africa to adopt a more strategic role in the provision and financing of training. 
Confronted by budget pressures, governments cannot supply all the skills needed in a modern economy. They therefore need to adopt a more strategic role in the provision and financing of TVET, working in partnership with other stakeholders to meet skill needs. The first priority for governments is to get the policies and incentives right for skills development. The policies should foster the development of efficient training markets and provide incentives for performance. The most important of these policies is in shifting sector financing from an input-based to an outcomes-based model.

Policies adopted through government legislation and decrees need to address governance of the training system, licensing and regulation, standards and examinations, financing, and monitoring and evaluation. The roles and responsibilities of stakeholders need to be identified. Broad participation in policy development is essential to developing effective policies to which all parties can be committed. Building a consensus around these policies is expected to take time, as will their implementation.

Defining government's role in the provision and financing of skills development is part of the policy framework. Economic analysis of training markets, the demand and supply sides, is needed to inform decisions regarding this role. The most important part of the analysis is understanding who other than government provides training in an economy, how cost-effective this training is, and what barriers exist to enhancing and expanding this capacity to reduce pressure on public spending. The analysis needs to be country-specific in examining the performance and capacities of all stakeholders.

Governments have a clear role to play in removing barriers to skills development for the benefit of economic growth and poverty reduction while promoting social equity. As such, governments also have a role in the promotion of efficient training markets, addressing issues that these markets fail to address, and performing market functions that governments are uniquely equipped to perform. In many cases, these roles can be played through financing and working in partnership with nongovernment providers, but in some cases-such as reaching underserved geographic areas, adding tertiary and high-cost skills, training instructors, and developing essential skills for the growth of strategic industries-public provision of training may also be appropriate, subject to the rules of market accountability.

Governments especially need to give attention to institutions that promote the efficient operation of training markets. This attention extends from governance of training systems through national training authorities that integrate stakeholder interests to the definition and enforcement of appropriate market regulations. The shift to outcomes-based financing and the promotion of open training markets can be facilitated by engaging stakeholders in setting skills standards and examination systems. An important institutional gap presently is that of labor market information and analysis for policy development and management of training systems. 
Over the past decade international partners have shifted much of their assistance in Sub-Saharan Africa from investment in building the capacity of state-sponsored training to support of TVET reforms. This support should continue. Progress has been made, but reforms require a long-term commitment. TVET reforms should be part of a broader, sectorwide approach to the reform of education and training systems, where all options are on the table and all tradeoffs are visible.

Several partners, including the World Bank, have piloted activities over the past decade to reach the informal sector with skills development. Opportunities can be taken to scale up successful ventures, export them as appropriate to other country settings, and continue testing innovations that show promise for reaching this sector. Similar opportunities can be found in efforts to promote reforms in the governance of TVET systems and to support capacity building and development of institutions for the operation of efficient training markets. International assistance should follow the movement from financing inputs to financing outcomes.

Potential areas for international assistance to TVET include the following:

- Development and evaluation of experimental approaches to provide training services (as part of packages of assistance) to the informal sector and - the greatest challenge-scaling up successful approaches on a sustainable basis

- Development of public-private partnerships, with a view to supporting development of nongovernment programs

- Development of demand-responsive national training systems involving all stakeholders, recognizing that such development requires expertise in change management and may take decades to accomplish fully

- Decentralization of public skills development

- Development of information systems that evaluate the scope, performance, outputs, and impact of public and nongovernment skills provision

- Development and implementation of formula funding and normative financing systems for the public sector

- Development of associations-of nongovernment providers and trade and sector associations - both to advocate their interests and to deliver training relevant to their members.

Gaps in knowledge relevant to TVET still remain. Among them, the full implications of HIV / AIDS for skills development remain to be assessed, as do the causes of stagnation in the growth of wage employment in the modern sector. A fuller understanding is needed of NQFs and their suitability for developing countries and their potential in performance-based training systems. As future TVET reforms are planned, they should be based on the analysis of training markets and their performance at the country level. Country-specific analyses of TVET are needed to underpin future reform agendas. 


\section{Note}

1. The thematic studies cover labor market trends, World Bank assistance for TVET in the 1990s, training finance, trends in public training, two studies on private training markets, two studies on enterprise-based training, two studies on training for the informal sector, literacy and livelihood skills, distance teaching in TVET, vocationalization of secondary education, and entrepreneurship education and training. These documents can be found at the following Web site: http:/ /www.world bank.org/labormarkets under "Vocational Education and Training." See also the Bibliography for principal sources. 


\section{1}

\section{Introduction and Background}

Education and training are good investments-good for the individual, the employer, and the economy. Enterprises in Sub-Saharan Africa repeatedly report shortages of skilled labor, and many of them provide training for their own employees. Debate continues about the role that governments and private providers play in the provision and financing of training and how to get better value for the money spent on training. Donor interest in skills development has waned over the past decade, in part because of increased attention to basic education. Valuable experience has been gained, however, since the issues were last studied for the 1991 World Bank policy paper on technical and vocational education and training (TVET) (World Bank 1991). This review sets out to capture this experience in a study of technical and vocational education and training in Sub-Saharan Africa.

\section{Introduction}

Human capital development is a process that improves an individual's knowledge and skills, and therefore his or her productivity in the home, community, or workplace. Skills, representing the acquisition and mastery of knowledge and processes used to earn a living, may be acquired in a formal technical or vocational school at the secondary or tertiary levels; nonformally in a vocational training center (VTC) outside formal schooling; formally on the job through apprenticeship; or informally on the job through observation, unstructured learning activities, and practice.

The institutional sources used vary by the level of skills acquired. Semiskilled workers may acquire the rudiments of a craft or trade through prevocational education in a school setting, or by informal on-the-job methods. Skills from higher-level journeyman up to master craftsperson can be acquired informally but also can be obtained through combinations of formal vocational education, nonformal training, and apprenticeship. Technicians perform the highest level of skilled work below professionals, and they acquire their skills through experience and continuing education and training, or through formal technical education at secondary and, more often, tertiary levels. ${ }^{1}$

\section{The Rationale for Training}

Improving the knowledge and skills of workers is expected to increase an economy's output of goods and services and contribute to economic development. 
Education and training are a form of investment. For the individual, the economic returns on this investment accrue in the form of increased earnings. For companies, the economic returns are realized through gains in productivity and profits. For an economy, the returns are found in the expanded output of goods and services and economic growth.

Development of human capital not only leads to higher worker productivity but also facilitates the absorption of workers into the economy and improves their job mobility (ability to move into more productive jobs and sectors). Reducing skills bottlenecks significantly enhances the efficiency of the labor market. Investment in human capital also enhances business and technological innovation by improving the capacity of workers to apply and adapt existing knowledge and processes as well as make new discoveries.

Human capital is a critical input to determining the efficiency with which capital investments are utilized and production is carried out. Human capital accumulation is even more important than physical capital accumulation. Weak human capital in the form of generally low levels of educational attainment can constrain the ability of workers to acquire new skills as markets change and thus slow both investment and market adjustments to new technology.

\section{Importance of Training in Sub-Saharan Africa Today}

A comprehensive survey of modern enterprises of all sizes in three African countries found that companies repeatedly cite as a problem insufficiently skilled labor (Biggs, Shah, and Srivastava 1995a). Manufacturers in Kenya were found not to have the numbers of technical personnel at the certificate and diploma levels required to improve technical capacities. This is important from the company's perspective because industrial output is sensitive to small changes in the scarcest factors of production. ${ }^{2}$ Low levels of education and skills in the labor force can severely restrict labor market flexibility in the formal sector of African economies. If companies cannot find abundant and adaptive skilled labor, they cannot respond to opportunities presented by new technologies.

Skills development is important in Sub-Saharan Africa today for several reasons:

- Globalization and competition require higher skills and productivity among workers, both in modern companies and in the micro and small enterprises that support them. Companies have been downsizing and outsourcing in response to liberalized trade regimes and lowered import tariffs. However, having fewer employees has not meant less training. Quite the contrary-evidence suggests that qualification levels are increasing and training efforts are intensifying within enterprises in competitive environments. Moreover, entrepreneurial skills are of growing importance. Persons with more formal education outperform others in small enterprises. 
- In many countries in Sub-Saharan Africa, technological changes require richer cognitive content, higher skill levels in the labor force, and continued enhancement of work force skills. Exploiting the potential of information and communications technology (ICT) requires a strong skills base (as well as infrastructure and appropriate regulatory frameworks). Adoption of ICT is associated with the employment of more skilled workers. A labor force with a solid basic skills foundation is essential for countries to exploit the opportunities opened by technological change (Betcherman 2001).

- Many countries have undergone significant structural adjustment over the past decade. This often entails the sale or closing of lossmaking state-owned enterprises. Structural adjustment can lead to substantial downsizing of employment in the state and parastatal sectors as well as in private companies that face increased competition. Workers displaced by structural adjustment often need upgrading of their skills. The numbers can be significant.

- Poverty reduction requires investing in the productivity and skills of economically and socially vulnerable groups. This is one of the main messages of Can Africa Claim the 21st Century? (World Bank 2000). Investment in people is important for two reasons: Africa's future economic growth depends less on its natural resources, which are being depleted and are subject to long-run price declines, and more on its labor skills and its ability to accelerate a demographic transition. Investing in people promotes their individual development and enhances their ability to escape poverty. Improving human capital is thus crucial for Africa, both to reduce poverty and to improve people's lives. Efforts to boost human capital in the region must cover a broad front, including education, health, and skills development (World Bank 2000, pp. 3, 100, 103). Skills are an important means to increase incomes and sustainable livelihoods for the poor.

- Finally, skills development becomes both more important and more difficult as a result of HIV / AIDS. AIDS depletes scarce human capital and magnifies the need to replace skills lost across a wide range of occupations (World Bank 2000, p. 42). (See also chapter 2.)

\section{Issues Surrounding TVET}

Debate about TVET today revolves around the issues of balancing supply and demand, delineating the roles of the public and private sectors, and ensuring cost-effectiveness.

\section{Supply and Demand}

The fundamental issue in skills development is how best to balance the supply of skills with the demand in the labor market. What role does a training market play? If the demand is unsatisfied, skills bottlenecks impede growth 
and development. If the supply is not absorbed, unemployment and waste of scarce resources ensue. One of the earlier approaches to this issue attempted to balance supply and demand using manpower planning and requirements forecasting. Under manpower planning, skills requirements by sector were forecast 5 to 10 years ahead. Manpower plans were developed and implemented based on these forecasts. However, the forecasts proved uniformly unreliable, did not allow for labor or educational substitution, ignored costs and prices, and favored investment in secondary and higher education at the expense of primary schooling (Middleton, Ziderman, and Adams 1993, pp. 136-39).

Another approach to investment in skills development, and indirectly to balancing supply and demand, is rate-of-return analysis, which compares the discounted future income stream of graduates with the direct and indirect costs of producing their skills. Income streams are based indirectly on supply and demand, because skills in demand command higher incomes. Returns can be calculated for the individual (private rate of return) and for society (social rate of return) and compared for investments in various types of education and training. The advantage of rate-of-return analysis is it compares the costs as well as the benefits of acquiring education and training. These analyses typically show that education investments yield higher returns than physical investments; that returns are higher in countries at a lower stage of development and with a narrower base of education; and that returns on primary education are the highest among all educational levels, although this pattern has recently been challenged in Sub-Saharan Africa (Bennell 1996a) The rate-of-return methodology has its own drawbacks ${ }^{3}$ and does not completely substitute for manpower forecasting (Richards and Amjad 1994).

In the 1990s a third approach emerged, built around markets, to help balance supply and demand. Labor market signaling used the data provided by labor market information systems (LMIS) to analyze movements in demand and supply. Rates of return were among the "signals" used. Planners could take their cues about balances in supply and demand from key labor market indicators such as employment rates, waiting times for employment, and especially wages for various occupations. High relative wages, assuming they are free to float, indicate scarcity of skills, and low or declining wages point to oversupplies. Experience with the implementation of LMIS is taken up in chapter 2.

\section{Role of the Public and Private Sectors}

The issue of who should provide and pay for skills development continues to occupy policymakers. Should it be government's responsibility to finance skills development from public revenues and provide it in government-sponsored institutes? Or should those who capture the benefits-employers and trainees - pay for the training and should provision be left to the market and nongovernmental providers? In effect, should all training be turned over to employers or private sector providers, in view of the private benefits obtained? 
Historically, in industrial countries, virtually all middle-level skills training was shouldered by employers and provided on the job. Public interest in the skills of the work force and economic growth led governments to assume responsibility for providing technical and vocational training in dedicated schools. The thinking in the 1950s and 1960s was that governments in developing countries needed to invest in occupational skills training to complement investments in physical capital. With donor assistance, governments built, equipped, and staffed vocational schools and training centers to produce the skills needed for rapid industrialization and replacement of expatriate workers (localization).

TVET was infused with broad social objectives, including fighting youth unemployment, relieving demographic pressure on higher education institutions by diverting student aspirations, and serving academically less able students. Proponents maintained that government must remain involved to compensate for limited private training capacity and willingness to pursue these goals and to stimulate economic growth with supplies of trained workers (Middleton, Ziderman, and Adams 1993, p. 37). All too often, the supply of vocational skills became its own justification. This issue is pursued below in the discussion of modeling training decisions.

\section{Cost-Effectiveness}

By the 1980s serious questions were being raised about the cost-effectiveness of much pre-employment skills training. TVET is expensive-up to 14 times more expensive than general secondary education in Sub-Saharan Africa (Atchoarena and Delluc 2001, p. 37). The greater cost of TVET imposes a major constraint on its expansion and compels attention to its effects in the labor market. Critics of government-sponsored pre-employment training pointed to its inflexibility and inefficiency compared with training that is subject to market forces. Moreover, economic downturns and structural adjustment led to contraction in wage employment, especially in the public sector, and fiscal restraint led to difficulties in sustaining expensive public vocational training. TVET graduates could not find jobs. Governments could not afford to sustain the costly training programs (Middleton, Ziderman, and Adams 1993, pp. 37-38).

\section{Highlights of Developments in the 1990s}

The World Bank took up these issues in the late 1980s in a policy study that resulted in the publication of two seminal works: Vocational and Technical Education and Training: A World Bank Policy Paper (World Bank 1991), and Skills for Productivity: Vocational Education and Training in Developing Countries (Middleton, Ziderman, and Adams 1993), a subsequent compilation of the evidence, hereafter referred to collectively as "the Policy Study."

On methods to help balance supply and demand, the Policy Study advocated the development of training markets and reliance on labor market 
signaling, plus an array of means to enhance the demand responsiveness of training institutions. The Policy Study noted that movements in wages and employment signal changes in the demand for and supply of particular skills and trades in competitive market economies. A careful monitoring of these signals could identify trends in supply and demand for skills (Middleton, Ziderman, and Adams 1993, p. 140).

The use of this method requires investment in LMIS. Key data sources include national household and establishment surveys, social insurance, tracer studies, and cost analyses. Rate-of-return studies form part of labor market signaling. On the supply side, the Policy Study advocated various means to enhance the response to market demands, including strengthening national training authorities, managing by incentives, improving links between training and employment, and increasing institutional autonomy and accountability (Middleton, Ziderman, and Adams 1993, pp. 205-15).

On the roles of government and the private sector, the Policy Study made the useful distinction between government financing and government provision. It asserted that there is no blanket case for government financing and provision of training. Government financing could be justified in cases of externalities (where private investment in training does not take into account broader benefits that may accrue to society from the availability of a skilled labor force), market failures and imperfections (where insufficient incentives exist for employers and individuals to invest in training; for example, because of fear of poaching, compression of wages, or capital market imperfections), and equity (where interventions are needed to ensure the access of disadvantaged populations to skills training). Although government financing of training can be justified in such instances, government provision of skills training could be justified only rarely-usually as a second-best alternative to building up private training capacity (Middleton, Ziderman, and Adams 1993, pp. 115-18).

In terms of cost-effectiveness, the Policy Study found that some forms of training were generally more efficient than others (for example, enterprisebased training). However, all forms could be cost-effective when linked closely to employment demand and focused on available jobs. The exception was diversified secondary education (adding some occupational skills to an otherwise academic curriculum). In most cases, this type of curriculum did not give graduates any advantage in the labor market. It was an expensive form of secondary education because of the need for special facilities, specific equipment, and specific training for teachers. It also proved difficult to implement in most countries (Middleton, Ziderman, and Adams 1993, pp. 50-51).

The Policy Study noted that the analytical basis of lending for TVET had remained comparatively weak. Noteworthy was the lack of attention to the economic rationales for public-sponsored training and encouragement of private training. The Policy Study called for deeper analysis of the economic context in which skills are delivered, including labor market issues. It pointed out that analysis of the economic context of training requires examination of two main questions: "What skills are needed over the medium 
term?" and "What is the impact of economic and social policies on labor market efficiency and employment?" Answering the first question involves several steps, including anticipation of structural shifts in the economy and identification of growth trends; identification of economic policies (for example, protectionist measures) and strategies (for example, targeted sectors) that will influence skills demand; and forecasts of the effects of these patterns on the growth of employment by subsector and industry (World Bank 1991, pp. 65-66).

The Policy Study advocated a two-stage approach to skills development. The first stage involves addressing important non-TVET issues, particularly creating a regulatory framework that encourages investment in physical and human capital; instituting macroeconomic policies that foster sustained output and employment growth; and especially strengthening primary and secondary education-recognizing that basic education provides the foundation of skills and flexibility needed in any work force.

The second stage of the strategy entails the reform of skills development in three areas:

1. Improving the effectiveness and efficiency of public training by developing strong links between training institutions and enterprises, improving institutional responses to market forces, using resources efficiently, building capacity for policy implementation, and diversifying the sources of financing through payroll levies and cost recovery

2. Strengthening private training by creating a favorable policy environment, strengthening employer training, and reducing the regulation of private training

3. Using training as a complementary input in programs designed to improve the incomes of the poor and socially disadvantaged by improving levels of general education, training for jobs in the informal sectors, improving access to wage employment, reducing legislative discrimination against women, and reducing the opportunity costs associated with training (World Bank 1991, pp. 21, 30-63).

\section{International Assistance for Skills Development}

Concerns about the effectiveness of public training and recognition of the importance of bringing basic education to all children produced a shift of international interest in the 1990s away from new investments in public training capacity to a focus on TVET reforms. Subsequent reviews have noted the challenges posed by these reforms but have also highlighted successes.

\section{Trends and Shifts in Emphasis}

In the middle to late 1990s, attention to skills development by donors seemed to wane. Assistance for skills development also diminished within the World Bank. Total Bank lending for TVET fell slightly in absolute terms between the 1980s and 1990s, but it decreased by more than 40 percent in the Africa region, 
Figure 1.1. World Bank Lending for TVET, Total and Africa Region

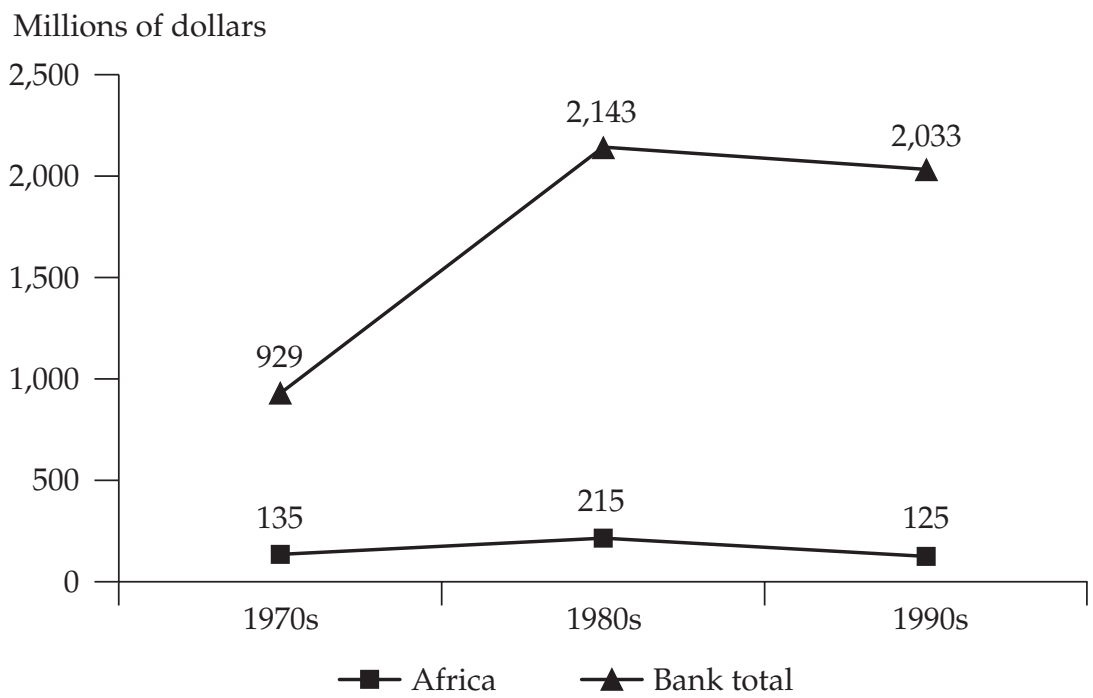

Source: Johanson 2002 (part I, annex 1).

from $\$ 215$ million in the 1980s to $\$ 125$ million in the 1990s (figure 1.1). ${ }^{4}$ As a percentage of total lending for education and training in the Africa region, the decline was relatively more precipitous, from 22 percent of all lending in the 1970s, to 19 percent in the 1980s, and just 5 percent in the 1990s (figure 1.2). The decline was also evident in the proportion of Bank-financed education and training projects that included training investments (figure 1.3).

Reduced attention to skills development by the wider donor community paralleled the decline in Bank assistance. Skills development did not receive much attention in either national or donor agendas for the region over the past decade. The goals for Education for All state that "All young people and adults must be given the opportunity to gain the knowledge and develop the values, attitudes and skills which will enable them to develop their capacities to work," ${ }^{15}$ but the emphasis has been on provision of basic education. The Africa-led New Economic Program for African Development (NEPAD) does not refer to skills development apart from the need to develop ICT specialists. ${ }^{6}$ The absence of skills development from the poverty reduction agenda is also noticeable. Skills development as a means to provide sustainable livelihoods is strikingly absent from many of the initial Poverty Reduction Strategy Programs (PRSPs).

Several factors contributed to this decline. Within the Bank a more rigorous economic justification was required for TVET programs, and the objects of assistance changed from costly heavy equipment and buildings to relatively inexpensive investments in policy and institutional development. 
Figure 1.2. TVET Lending as a Percentage of Total Education Lending

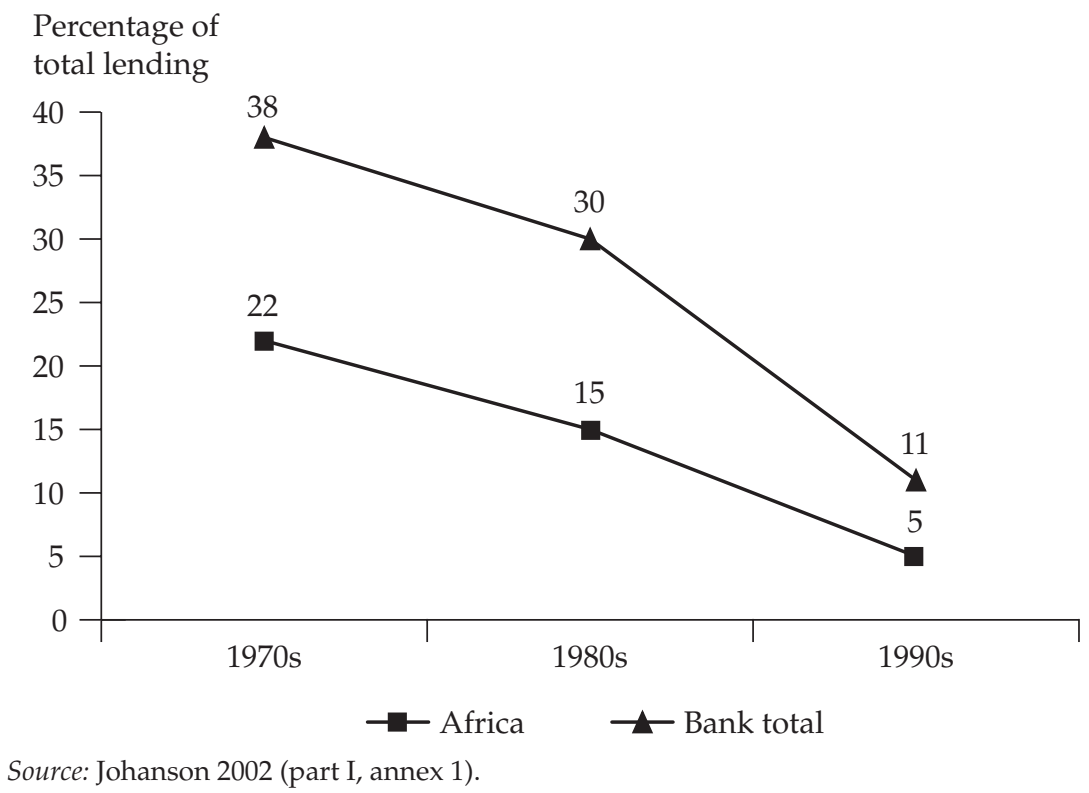

Figure 1.3. World Bank Education and Training Projects with Training Investments

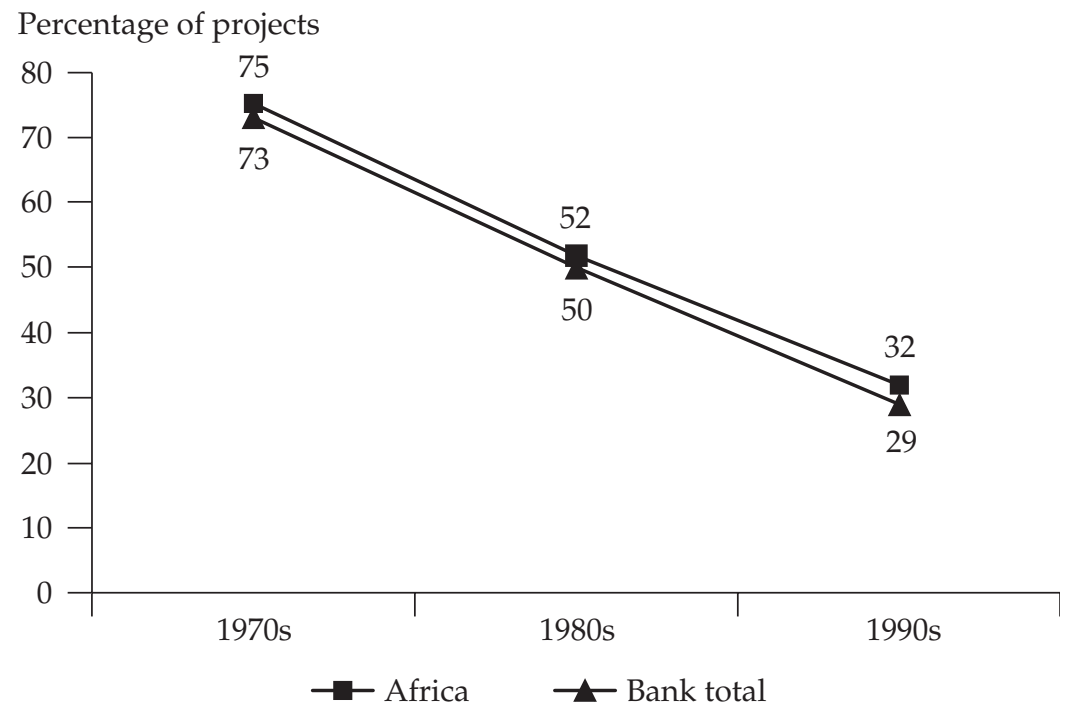

Source: Johanson 2002 (part I, annex 1). 
The Working Group for International Cooperation in Skills Development referred to the Bank's policy as one of the reasons for reduced overall donor interest in skills development in the 1990s. The Bank's 1991 Policy Paper did not actually call for reduced support to public training, but the strong critique of the performance of public training reportedly encouraged other agencies to reduce their involvement in this area (Working Group for International Cooperation in Skills Development 2001, p. 33).

Three additional factors were responsible for the reduced attention to skills development. First was the necessary emphasis on basic education and the movement toward universal primary education. This absorbed most donor attention and assistance in the 1990s. In addition, more recently, the development of the Millennium Development Goals and the focus on poverty led to a further reduction in the priority given to skills development. The absence of any reference to skills development in the Millennium Development Goals has tended to undermine international support for training. This may be explained in part by the strong pre-employment, formal sector orientation of traditional TVET for wage employment (rather than income generation in the informal sector) (Working Group for International Cooperation in Skills Development 2001, p. 33).

Despite the overall decline in attention to skills development, several donors continued to support TVET during the 1990s. Assistance from France was substantial and fairly diversified. In 2000, 23 countries in Sub-Saharan Africa benefited from French assistance for TVET, totaling about \$30 million equivalent, mostly for external technical assistance. Germany assisted 17 countries in the region over the past decade, Danish International Development Agency (DANIDA) assisted 12 countries with about \$120 million, and the Swiss government provided assistance for $\$ 50$ million, mainly in five countries. In addition, the African Development Bank (ADB) identified the provision of middle- and high-level skills as one of its priority areas ${ }^{7}$ and provides substantial assistance in this field. ${ }^{8}$

Assistance programs were guided by new policies on TVET in several countries, including Germany in 1992, Switzerland in 1994, and DANIDA in 1995. ${ }^{9}$ The World Bank policy work in 1991 helped stimulate discussion on many of the issues. The Bank's advocacy of more private sector involvement in training was not readily accepted, but the focus on institutional development and systems reform resonated among several donors.

One of the salient shifts in policies in the 1990s was the priority given to the reform and development of TVET systems by international development agencies DANIDA and Deutsche Gesellschaft für Technische Zusammenarbeit (GTZ). A recent comprehensive evaluation of DANIDA programs documents the shift away from supporting individual vocational training institutions to systems reform and institutional development (DANIDA 2002, pp. 9, 41). Within this context, DANIDA placed increased emphasis on the creation and development of national training authorities and training funds. Another major shift was the priority assigned by international development agencies to training for the informal sector. 
Another clear trend in donor policies was the shift from projects to programs and broader issues. The increased emphasis on system and institutional reforms suggested a broadening of approach. Many donors reduced their emphasis on targeted projects in favor of dialogue on sector policy development and reform. Sectorwide approaches (SWAPs) were the main instrument for increased scope of operations. ${ }^{10}$ The move from project to program and from project to policy was stimulated by the realization that projects could achieve enclaves of excellence within a small part of the training system, but have little impact on improving the system as a whole. As stated by DANIDA, "it was entirely possible to deliver a 'successful' project, protected and insulated by longer or shorter term donor funding from the wider organizational and political environment. But far too many such development initiatives were failing shortly after the implementation phase" (DANIDA 2002, p. 63). The shift to SWAPs had implications for assistance to TVET, which does not fit neatly into a single sector. SWAPs were accompanied by reductions in the number of countries and sectors that agencies were assisting. One consequence of the sectorwide approach was a reduction in the number of countries receiving assistance. DANIDA's program has decreased from 12 countries to about 5 countries (DANIDA 2002, p. 89).

Concentration is another pattern, as indicated by German assistance. Assistance in each country is allowed to concentrate on no more than 3 of 10 allowable areas. Vocational training is a subpart of one of the focal areas of economic reform and development of the market system. One consequence of this concentration may have been to "crowd out" projects for vocational training (DANIDA 2002, p. 89); Working Group for International Cooperation in Skills Development 2001, pp. 14-17). The Swiss Agency for Development Cooperation has also adopted a similar thematic approach to assistance. Employment and income is one of five thematic means to achieve the objective, and skills development is a key instrument in combination with micro and small enterprise promotion (Working Group for International Cooperation in Skills Development 2001, pp. 18-20).

\section{Aid Effectiveness}

A review of World Bank lending in the 1990s against the prescriptions of its 1991 Policy Study found several innovations. Much greater attention and assistance were given to various kinds of in-service training, whereas assistance had previously been skewed toward preservice training. In particular, most new projects featured support for the informal sector. More demandside financing was instituted, particularly through the creation or support of training funds. These innovations were generally rated as successful. Weaknesses were also identified, including weak economic analysis and analysis of constraints on nonpublic providers, failures of most labor market observatories (chapter 2), and inadequate monitoring and evaluation of impacts, especially on costs of interventions (Johanson 2002). 
In terms of bilateral assistance, German aid was successful in the 1990s in creating several experimental projects on informal sector training, but studies also noted the lack of information by which to evaluate the interventions (Nell, Shapiro, and Grunwald 2002). DANIDA's evaluation pointed to the complexity of systems reforms, difficulties of reorienting supply-driven training systems in a context of reduced industry demand for skills, limited impact on poverty reduction, and inadequate attention to gender strategies. It noted the difficult tradeoffs between cost-recovery and equity objectives. Other findings stress the importance of incentives for system reform. "It is only through the nurturing of truly competitive training markets and genuinely hard budgets that these organizations become demand-driven and cost-effective" (DANIDA 2002, p. 53).

\section{Highlights of the Literature}

Research on TVET in the 1990s covered a wide array of topics, ${ }^{11}$ following the issuance of the Policy Study. Attention was given to the effects of structural adjustment and liberalization on training needs, the overall transition between school and work, and the needs of the informal sector. Several studies were published about reforms in South Africa. Regionwide studies included a study sponsored by the U.S. Agency for International Development (USAID) on work force development (Center for Workforce Development 1998) and three compilations by the International Project on Technical and Vocational Education (UNEVOC) on the development of TVET in Africa (UNEVOC 1996), partnerships (UNEVOC 1995), and the informal sector (UNEVOC 1998), respectively. The U.K. Department for International Development (DfID) financed an extensive study on the effects of competition on micro and small enterprises (Afenyadu and others 1999). The Working Group for International Cooperation in Skills Development provided a useful forum for discussion of TVET issues and helped document donor policies during the $1990 \mathrm{~s}^{12}$

Two documents warrant more detailed attention. Vocational Education and Training Reform (Gill, Fluitman, and Dar 2000), based on the experiences of 19 countries worldwide, including 3 in Africa, examined the constraints faced in implementing vocational education and training (VET) policies and analyzed how some countries managed to achieve successful reforms. The joint World Bank-International Labour Organisation (ILO) study found that successful reforms (i) make school-based VET more like general education-that is, they make content more general and the vocational track less dead-end; (ii) combine public financing of pre-employment training with evaluation of program impact in design and ensure competition among providers; and (iii) recognize that it is difficult to provide incentives for enterprise training. Mandatory training targets and levy-rebate schemes, for example, do not increase training significantly, and tax incentives work only when the tax base is broad and subsidies increase public expenditures. 
The study contained four principal messages:

1. Matching training instruments to target groups is as important as picking the best delivery mode.

2. Many governments have been preoccupied with providing vocational training at the expense of providing information about the availability and effectiveness of training programs.

3. A vigorous private response has refuted claims about the reluctance of private providers to enter the field.

4. Political will, not organizational capacity, is the main obstacle to reform (Gill, Fluitman, and Dar 2000, pp. 33-35).

The second document is the Policy Paper on TVET adopted by the InterAmerican Development Bank (IDB 2000). Based on experience in the Latin America and Caribbean region, the strategy paper outlined the IDB's position on training under six themes:

1. Training requires an enabling environment. Recognize that training alone is not an effective means to combat unemployment. To minimize the risk that training will be ineffective, job creation must also occur.

2. Training does not replace good education. A solid basic education is the best preparation for a wide range of jobs and often will shorten the length of training required. Substantial efforts in training are necessary to generate economic development.

3. Good training is also good education. To meet the demands of an increasingly technological labor market, workers need a good mix of practical skills and conceptual understanding. Good training can provide the same skills taught in general education by focusing more on language, mathematics, and science and by integrating skills development and theory. Training of this type requires teachers who have pedagogical skills in both general and skill-specific areas.

4. Training pays. Training increases productivity and hence workers' income. Together with job skills, training imparts the necessary values and attitudes recognized or rewarded in the labor market. Aggregating training data across occupations is risky, since the success or failure of one occupation may mask the true value of another.

5. Mismatch between training and jobs has been the number one problem. To get a good fit between jobs and training, appropriate incentives are needed, and mechanisms to link training and employment must be in place.

6. The beneficiary should pay. Although no empirical evidence is provided, it is asserted that good quality training generates as many external economies as education and, for this reason, training systems should not aim at full cost recovery. Private provision of training is preferable to public provision, unless public providers are subject to the same incentives and accountabilities as private providers. 
The IDB offered the following advice for improving training:

- Enhance the performance of existing providers through appropriate monitoring and evaluation, provide competitive training funds, link employers and trainers and encourage joint decisionmaking, create an oversight agency, and link budgets to outcomes (employment of graduates).

- Offer new modes of apprenticeship to teach the full spectrum of skill levels. These programs could, for example, reproduce the high-quality training of the German "dual model."

- Promote lifelong learning.

- Invest in new delivery forms for traditionally underserved groups; for example, distance training and training for entrepreneurship.

- Upgrade training for the modern economy. Develop good materials and provide good trainers.

- View training as a social policy, not as a means of job creation. Training is essential for improving the productivity and competitiveness of an economy. To the extent that an economy is growing, jobs will be created and training will increase, but training alone does not create jobs.

\section{Modeling Training Decisions}

Over the past decade economists have extended arguments for public interventions in training markets on the grounds of market failures. Much of the early modeling of education and training was influenced by the seminal work of Gary Becker $(1962,1964)$. Becker showed how, under competitive conditions and the absence of constraints impeding trainees' ability to finance the investment through borrowing or acceptance of a training wage, training markets would function efficiently without any need for the public sector to intervene. Becker's policy conclusions have since been challenged by models of training under imperfect competition (Acemoglu and Pischke 1998, 1999; Chang and Wang 1996; Katz and Ziderman 1990). Imperfectly competitive labor markets can create conditions leading to underinvestment in general skills training.

Studies in the 1990s have taken advantage of the growing availability of training information in micro data sets to study the effects on training of individual and firm-related characteristics (Altonji and Spletzer 1991; Bartel and Sicherman 1998; Haltiwanger, Lane, and Spletzer 1999; Tan and Batra 1995; Velenchik 1997).

\section{Role of the Public Sector in Training}

Becker contended that governments did not need to intervene in training markets except to ensure equity and address market failures attributed to credit and information constraints. Where credit constraints were present, the preferred interventions were improvements in loan markets and removal of regu- 
latory barriers to training wages to allow self-financing of training by workers. With these reforms, investments in training and skills development by trainees and firms would be efficient and government interventions unnecessary.

Becker's distinction of general and specific skills was important to this conclusion. General skills were considered useful to all employers, while specific skills were seen as uniquely useful to the worker in his or her current job. Thus, in a competitive labor market where workers are paid their marginal product, workers derive the full benefit of investments in general skills and are willing to pay for these skills. Employers would be willing to pay only for investments in specific skills that are uniquely useful to the firm, because investments in general skills can be lost to other firms through worker turnover.

Acemoglu and Pischke (1999, pp. 126-128) have since shown that labor market imperfections produce inefficiencies in training by compressing wages and reducing worker incentives for investing in training. The payment to workers of a wage less than their marginal product under conditions of wage compression creates the space and incentive for firms to extract in profits some of the worker's increased productivity due to general skills training. This provides a rationale for firms to share in the cost of investment in general skills, in contrast to the predictions of Becker's model. From a policy perspective, the reduced incentive of the worker to invest in general skills may be offset by the increased incentive for the firm to invest in these skills. However, other problems arise with the presence of labor market imperfections that create the conditions for market failure and the rationale for government intervention in training markets.

General skills training is found to increase wages paid by current employers less than wages paid by future employers, producing an externality that in an uncompetitive labor market leads to underinvestment in general skills (Bishop 1987; Loewenstein and Spletzer 1998). Unless employment contracts combine wage setting and training commitments to absorb this externality, the resulting market failure and underinvestment in training will justify public interventions.

Even when such contracts can be devised, the informal manner in which some skills are imparted on the job will make it difficult to monitor training and enforce contracts, leaving the risk of underinvestment. Faced with a market failure, public interventions can take different forms to expand training investments: subsidies through public financing for training; public delivery of training; and regulations-for example, testing and certification - that would enhance the feasibility of monitoring training contracts.

The introduction of imperfect labor markets thus produces a different set of policy conclusions than that reached by Becker. Even when liquidity and information constraints are relaxed, the amount of training in an imperfectly competitive labor market is likely to fall well short of the levels produced in a competitive market. Wage compression and payment to workers that is less than their marginal product can make employers willing to share in the cost of general skills training, but difficulties in monitoring training commitments in the enterprises and the potential variance between wages 
paid in current and in future employment can produce underinvestments in general skills training.

The presence of imperfectly competitive labor markets in many countries within Sub-Saharan Africa, joined by weak capital and information markets, raises the risk of market failure and strengthens the case for public intervention in training markets. The presence of these conditions, however, has to be assessed on a country-by-country basis.

\section{Determinants of Training}

Over the past decade, new information has emerged in micro data sets that enables the study of individual and employer characteristics that influence training decisions; however, the majority of these studies refer to experience in industrial countries. This type of analysis has been largely missing in many developing countries, and in particular, in Sub-Saharan Africa. Tan and Batra provide one of the few empirical studies of training in developing countries. Their study covered Colombia, Indonesia, Malaysia, Mexico, and Taiwan and focused on manufacturing. They found that 50 to 80 percent of small firms and 20 to 70 percent of large firms did not provide formal structured training for employees. Informal on-the-job training by coworkers and supervisors was more common, but even then more than 20 percent of the smaller enterprises and 8 to 13 percent of the larger enterprises did not train. The top three reasons given for the lack of training, especially by micro and small enterprises, were limited resources, imperfect information on the benefits of training, and potential loss of the investment through turnover.

The benefits that provide incentives for training come from increased productivity translated into higher earnings for workers and profits for firms. In a global survey of training, Middleton, Ziderman, and Adams (1993) found considerable variance in these benefits in developing countries, with inservice training generally producing more benefits than preservice training.

Good preservice training can be found, however. In a recent study by Gill (2003, vol. 2, ch. 3, p. 29), using household labor force and tracer surveys in Mexico for the CONALEP (Colegio Nacional de Educación Profesional Técnica) program, significant economic returns on preservice vocational training are attributed to an autonomous national organizational structure, decentralized operations, strong links to industry, industry-experienced instructors, and modular courses. Tan and Batra find in-service training associated with higher firm-level productivity in all five economies they study. In a more detailed examination in three of these economies, training is associated with higher relative pay.

Evidence exists to connect in-service training in Sub-Saharan Africa with the payment of higher wages. Bigsten and others (2000) examine rates of return on physical and human capital in Africa's manufacturing sector in a survey of small and large enterprises in five countries: Cameroon, Ghana, Kenya, Zambia, and Zimbabwe. Although the primary focus is on education, earnings functions are estimated that include measures of experience based on age and 
firm-specific learning measured by tenure of the worker on the current job. The findings confirm the impact on earnings of learning through experience, but with differences across countries. Cameroon, Zambia, and Zimbabwe show similar returns, while Ghana's returns are higher than average and Kenya's lower. The limited evidence available on the impact of training in Sub-Saharan Africa demonstrates the presence of economic incentives for investments in training by individuals and enterprises but suggests that the results may vary.

The impact of technological change on training decisions is ambiguous. One hypothesis holds that by making past education and training obsolete, technological change encourages workers to invest in on-the-job skills training to accommodate each new wave of innovation. An alternative hypothesis contends that general education better enables workers to adjust to and benefit from technological change and that workers will substitute general education for specific skills training. Using longitudinal data from the United States for young men in manufacturing to examine these hypotheses, Bartel and Sicherman (1998) find that technological change increases the likelihood of formal company training, narrows the training gap between educated and less educated workers, and extends training to those previously lacking it. Tan and Batra (1995) show similar findings for their sample, with enterprises that invest in technology and new production methods more likely to offer in-house training.

The innate and acquired abilities of workers are potentially important determinants of training through their impact on the efficiency with which workers can acquire new skills (Mincer 1962, Rosen 1976). However, these abilities can also reduce the incentive to acquire subsequent skills by raising the value of time spent in work. Using data from the U.S. National Longitudinal Survey of the High School Class of 1972, Altonji and Spletzer (1991) demonstrate that those who have more education and higher skills are more likely to engage in training. Curriculum differences seem to have little impact on subsequent training. Postsecondary education has a particularly strong positive relationship with training. A significant part of the linkage reflects differences in aptitude and achievement measured at the end of secondary school. Tan and Batra (1995) refer to the interaction of education with technological change. Employers in their sample who invested in new technologies were more likely to use highly educated workers adept at working with these technologies and to provide them with training.

Characteristics of the enterprise and the employment also influence training decisions. Tan and Batra (1995) show that firms are more likely to train when they are large, employ an educated work force, invest in research and development, possess technology or licenses, have foreign capital participation, use quality control methods, and export to foreign markets. Velenchik (1997) uses a 1993 survey of manufacturing firms in Zimbabwe to investigate the presence of wage premiums associated with working for larger firms. The breakdown of these premiums supports the idea that larger firms use higher wages to increase the quality of their applicant pools, reduce employee turnover, and enhance worker loyalty. Training plays a role in achieving these ends. 
Occupational requirements linked to the technology of the firm also shape demands for training. Altonji and Spletzer (1991) demonstrate that the incidence of training varies directly with the verbal, math, and clerical skills requirements of an occupation but inversely with the manual skill requirements.

The growing body of evidence on training provided by micro data thus confirms the active role of enterprises in training, but shows that it is a role that is selective, favoring certain firms and workers over others. Smaller firms train less. Tan and Batra (1995) note in their sample of five developing countries that small and medium enterprises operate at lower average efficiency levels than their larger counterparts, but that a significant number of these smaller enterprises are actually more productive than many larger firms. This is an important finding since it indicates that smaller firms are not inherently inefficient and that there is a potential for many to become more productive and competitive. The high returns on training observed suggest the value of training in achieving this objective.

A second important policy conclusion emerging from this review is the importance of early schooling as an influence on future access to skills training. Those who acquire an early foundation of education are more likely to continue adding to this foundation through training at later stages of the life cycle.

\section{Questions of Particular Relevance to Sub-Saharan Africa}

Against this backdrop, several basic questions remain of vital interest for skills development in Sub-Saharan Africa:

- What should be the role of training when there is not enough modern sector employment?

- Given the widespread decay in public training systems, what should be the role of the public sector in training?

- Are private training providers more cost-effective than public sector training providers? What is the capacity of private training providers to fill the gap left by declining public investment in training?

- What is the relative importance of training within enterprises and does the state need to intervene to stimulate it?

- In view of shortages of public financing, how can needed skills development be financed?

- What role can financing mechanisms play in improving the effectiveness and efficiency of training?

\section{The Africa Regional Review of Skills Development}

With the passing of a decade since publication of the World Bank's policy paper on TVET, a review of reforms and experience is timely. The review, focused on Sub-Saharan Africa, sets out to capture this experience and the lessons that can be derived from it in response to the questions posed above. 


\section{Objectives and Target Audiences}

This review of skills development in Sub-Saharan Africa was undertaken to help answer the questions above and to fill gaps in the knowledge base on training in the region. Specifically, the review seeks to update knowledge about TVET in the region; explore issues and recent developments; and distill lessons as a guide to future skills development in the region. The aims are to inform clients about best practices, build consensus among donors and clients on these practices, and create Bank staff capacity to assist in TVET. Therefore, the main target audiences are policymakers and leaders concerned with skills development in Sub-Saharan Africa, donors to skills development, and, in particular, Bank staff members.

The review is not intended to be a policy paper offering prescriptions for country policies. Instead, it is a knowledge product that analyzes recent trends and practices and identifies possible lessons and guidelines for future action. It cannot substitute for in-depth analysis of skills development within countries. It provides some guidance for country analyses but cannot replace them.

SCOPE This review considers skills development by youth and adults broadly over the life cycle. A decision was made to focus on urban and rural nonfarm employment and skills development, while recognizing the importance of employment in agriculture. Agricultural training is vitally important, particularly in view of the high proportion of people working in the sector (chapter 2). In fact, agriculture was regarded from the beginning as so vast and so important a subject that it should be dealt with in a separate study. Pre-employment training for agriculture is done mainly through higher education. Training for farmers is done largely through agricultural extension services or by suppliers. Coverage of these means is beyond the scope of this review.

The central issue, then, is how to manage and promote growth in the nonfarm sector. The importance of diversifying into nonfarm skills was also stated in ILO's "Jobs for Africa" Program: "As well as increasing output of traditional crops, rural African economies will have to aim for greater diversity. This will mean not just producing more crops for export, such as vegetables or flowers, but also developing a greater range of nonfarm activities. Many of the poorest workers will need assistance to move in this direction-with greater access to technology, skills and training" (ILO 1999, p. 14).

APPROACH The review seeks to consolidate information about what has-and has not-worked in skills development under various circumstances. It is based on a general literature review, a review of the Bank's operational experience in TVET in the 1990s, and in-depth investigations of specific thematic issues and case studies.

The review has been conducted in three phases. The first phase encompassed a literature review, nine thematic studies, and an initial synthesis of 


\section{Figure 1.4. Studies Included in the Review}

1. Literature review

2. Labor market developments (ILO)

3. Review of Bank TVET lending

4. Financing TVET

5. Public sector training (IIEP)

6, 7. Private sector training2 (IIEP)

8, 9. Enterprise training-2 (ILO)

10,11 . Informal sector training2 (ILO)
12. Distance learning

13. Literacy and livelihood skills (IZZ)

14. Vocationalizing secondary education

15. Entrepreneurship education and training

16. Synthesis

Total: 14 thematic studies, 20 country reviews, 70 case studies

findings. The second phase included five additional thematic studies designed to deepen the analysis and fill gaps in knowledge identified in the first phase, plus a synthesis. Overall, the 14 thematic studies produced 20 country reviews and 70 case studies. (figure 1.4). The distribution of the countries and case studies is shown in table 1.1.

The third phase involved extensive consultations and dissemination of the completed synthesis of findings, first with donors in Edinburgh under the auspices of the Working Group for International Cooperation in Skills Development and subsequently with African policymakers and practitioners in Turin under the aegis of the International Training Center of the ILO. The final synthesis report, produced in early 2003, takes into account the views of clients and partners.

The review has been jointly financed by the World Bank, the Norwegian government, and the DfID. Partner agencies have made important contributions. Several studies have been contributed by the International Training Center of the ILO and the International Institute of Educational Planning of the United Nations Educational, Scientific, and Cultural Organization (UNESCO). In addition, the Institute for International Cooperation of the German Adult Education Association (IIZ/DVV) has collaborated with the Bank on one study. These organizations provided additional financing for their studies.

Training serves economic, social, and political objectives. This review follows the approach taken by the 1991 World Bank study, namely that economic and equity objectives are paramount and must be related to actual prospects for employment and income generation. In other words, the evaluation of training programs must be rooted in real possibilities for wage or self-employment. On the issue of social objectives for training, the Policy Study noted that pre-employment training generally had not been costeffective when used as a supply policy to stimulate industrial growth, to reduce youth unemployment, to serve academically less able students, or to 
Table 1.1. Distribution of Country and Case Studies

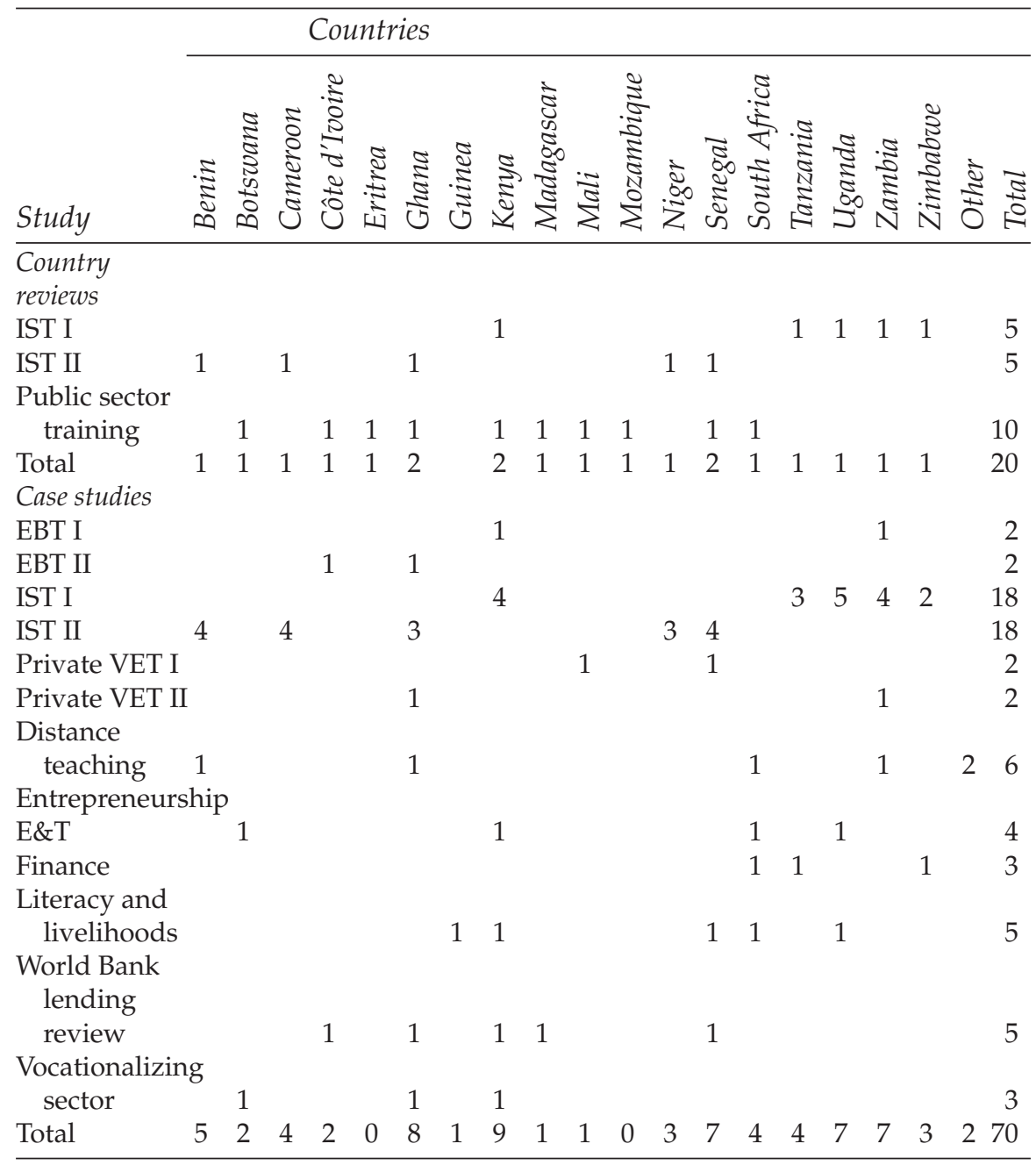

Notes: IST = informal sector training, EBT = enterprise-based training, E\&T = education and training, VET = vocational education and training. Totals include 20 country reviews, of which 7 are francophone, and 70 case studies, of which 24 are francophone. Roman numerals refer to Phase I and Phase II studies.

change youth aspirations (Middleton, Ziderman, and Adams 1993, pp. 38-39, 70). Instead, it recommended that skills development be focused exclusively on wage employment and self-employment. Thus, training is treated throughout this review from an economic perspective, with equity as a parallel concern. Other political and social objectives of training, such as human rights of youth, have their valid uses, but are not a primary focus of this review. 
LIMITATIONS Weak government capacity for monitoring and evaluation of TVET in many African settings remains an important constraint on policy development and reforms. Household data sets for studying the incidence and impact of training are limited. The review has benefited from the availability of enterprise data sets covering enterprise training in manufacturing in eight countries, from the Regional Program on Enterprise Development (RPED). Against this background, the review has made a substantial investment in producing additional data on TVET through the thematic and country case studies.

It is not possible to generalize across a continent of such vastly different country conditions and circumstances as exist in Sub-Saharan Africa. No country typologies are developed in the review, apart from some treatment of differences in anglophone and francophone training systems. Given the data constraints faced and the diversity of country conditions present, the findings of this review are offered with a note of caution. On the positive side, many of the findings appear robust. Extrapolation of these findings, however, should be limited to economies distinguished by low economic growth, high population and labor force expansion, and large informal sectors, excluding countries like Mauritius and South Africa.

ORgANIZATION OF THE REPORT The report synthesizes 14 thematic studies and their related case studies. The structure covers the economic setting for skills development with labor market developments (chapter 2), training provision (chapters 3-6), and training finance (chapter 7). Training provision covers state-sponsored training (chapter 3), nongovernment training institutions (chapter 4), enterprise-based training in modern sector employment (chapter 5), and training for the informal economy and entrepreneurship (chapter 6) (see figure 1.5).

For each provider the emphasis is on issues, recent experiences, innovations, and lessons for future policy and practice. Although the synthesis

\section{Figure 1.5. Training Provision by Location and Ownership}

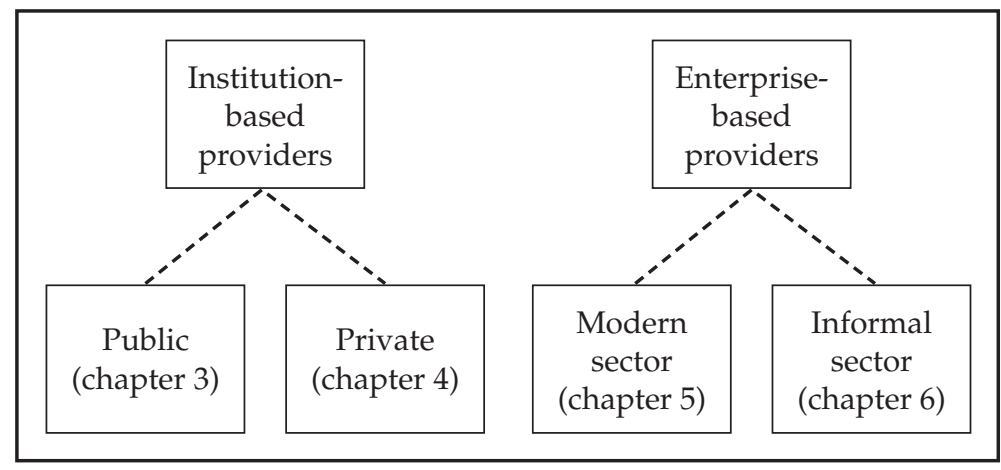


compiles the main findings from the underlying studies, the views expressed are those of the authors of this review and not necessarily those of the authors of the background thematic studies or of the World Bank. All of the thematic studies have been made available to readers on the external World Wide Web pages of the World Bank and its Social Protection Network (http://www.worldbank.org/labormarkets). Most will subsequently be published by the World Bank or by partner organizations in this review.

\section{Notes}

1. TVET is used in this review to refer to formal and informal sources for skills acquisition, excluding informal learning on the job. Skills development is used in referring to the outcome of the learning process without reference to the source of skills acquisition.

2. With the correct choice of technology, the cotton textile industry can grow dramatically in African countries because it is a process-based, labor-intensive activity with limited linkages to other manufacturing sectors. Yet the growth of this industry can be severely constrained by the absence of 50 to 60 key technicians (Biggs, Shah, and Srivastava 1995a, pp. 6, 202).

3. Rate-of-return analysis makes the questionable assumptions that observed wages reflect the marginal productivity of labor and that the content of the additional years of schooling an individual undertakes is responsible for the marginal increase in income associated with these years of schooling (Richards and Amjad 1994, pp. 3-4).

4. All dollar amounts are U.S. dollars.

5. "Education for All: Meeting Our Collective Commitments," Text adopted by the World Education Forum, Dakar, Senegal, April 26-28, 2000. 2001.

6. The New Partnership for Africa's Development, Abuja, Nigeria, October

7. African Development Bank, 1999. "Education Sector Policy Paper." Abidjan: African Development Bank.

8. The ADB's statistical information does not isolate TVET or the training components included in other sector investments such as agriculture and industry.

9. France has not outlined any cooperation strategy for vocational education and training. Its efforts derive mainly from local contacts and are related to broader social objectives rather than economic development targets (Atchoarena and Delluc 2001, pp. 64,169).

10. Featuring close linkages with the macroeconomic framework, the establishment of sectorwide expenditure frameworks, a focus on policy and systems, the harmonization of donor procedures, and the channeling of resources through existing government structures and processes and use of coordinated implementation reviews. See Johanson 2001.

11. See annotated bibliography prepared for this review at http://www. worldbank.org/labormarkets under the link for "Vocational Education and Training," and then for "Special Report on Africa."

12. See http://www.vetnet.ch/wg. 



\section{Labor Market Context and Developments}

Labor markets provide incentives for and guide skills development through movements in wages and employment. Labor market outcomes in Sub-Saharan Africa have been influenced by "environmental" issues ranging from disease and wars to weak institutions and lack of information on the types of skills needed. Rapid labor force growth, combined with modest economic expansion and creation of wage employment, has increased open unemployment. With too few jobs in the modern sector, most entrants to the labor market have no choice but to work in the informal economy. The growth of the informal economy poses new challenges to skills development.

\section{Introduction}

Rapid expansion of population and the labor force continues in Sub-Saharan Africa, placing considerable pressure on labor markets to absorb new entrants and provide productive employment for all. Against this background, economic reforms during the past decade have failed to produce new wage employment, so that many have pursued self-employment in the informal sector. This context for skills development is shaped by other labor market issues, such as open unemployment among youth, gender inequality, child labor, "brain drain," and HIV / AIDS.

This chapter establishes the context for skills development in Sub-Saharan Africa and addresses the following questions:

- What are the characteristics of labor supply and demand and the major trends in African labor markets?

- What are the structural dimensions of the modern and informal sectors of the economy?

- What challenges are posed by the expansion of the informal sector to skills development?

- What barriers exist to the use of labor market analysis for guiding skills development?

This chapter is based on Working, But Not Well: Notes on the Nature and Extent of Employment Problems in Sub-Saharan Africa, by Fred Fluitman, International Training Center of the ILO, 2001. See also Betcherman (2001), Dabalen and others (2000), Haan (2001), and Haan and Serriere (2002). 


\section{Income and Poverty}

Excluding South Africa, the region's average income per capita was just $\$ 315$ in 1997. Real income in terms of purchasing power parity was onethird less than in South Asia, making Africa the poorest region in the world (World Bank 2000, p. 7). GNP per capita in Sub-Saharan Africa decreased by 0.9 percent from 1975 to 1990 , and by 0.4 percent from 1990 to $1998 .{ }^{1}$ Private consumption per capita in the region decreased by 1.2 percent per year over the 1980-1998 period. $^{2}$

Gross national product (GNP) in Sub-Saharan Africa stood at $\$ 321$ billion in 1999, which represents a mere 1.1 percent of global GNP. Out of a total population of around 650 million, some 500 million people are estimated to live on less than \$2 a day, including some 300 million who live below the poverty line of $\$ 1$ a day. Throughout the 1990s, both the number and the proportion of the poor increased in the region as a whole (Fluitman 2001, p. 24). In Nigeria, which accounts for nearly one-fourth of SubSaharan Africa's poor, the number of people living in extreme poverty rose steeply in the 1990s, reaching an estimated 66 percent of the population; owing to massive migration from rural areas, urban poverty has grown faster and now matches rural poverty. ${ }^{3}$

An array of "environmental" issues constrains the functioning of African labor markets. Major health issues predominate, such as the high prevalence of HIV / AIDS and the fact that nearly 2 million people die of malaria in the region each year.

\section{HIV/AIDS}

According to the United Nations AIDS Prevention Agency (UNAIDS), an estimated 3.8 million adults and children in Sub-Saharan Africa became infected with HIV during 2000, bringing the total living with HIV / AIDS to 25.3 million. Over the same period, millions of Africans infected earlier began experiencing ill health, and 2.4 million people at a more advanced stage of infection died of HIV-related illnesses. HIV/AIDS differs from other terminal diseases in that it affects people mainly in their productive years. Most of the deceased were people of prime working age on whom others depended for income and care. In the eight African countries in which at least 15 percent of today's adults are infected, conservative analyses show that AIDS will claim the lives of one-third of today's 15-year-olds.

The size of the labor force in high-prevalence countries will be between 10 and 30 percent smaller by 2020 than it would have been without HIV / AIDS. The number of employees lost to AIDS over the next 10 years could be the equivalent of 40 to 50 percent of the current work force in some South African companies (Atchoarena and Delluc 2001, p. 274). For countries with HIV/AIDS prevalence levels above 20 percent, gross domestic product (GDP) is estimated to be 2.6 percentage points less per year (Forsythe 2002, p. 35). The modeling of the impact of HIV / AIDS in Mozam- 
bique indicates that the economy will be 14-20 percent smaller in 2010 because of reductions in productivity growth, population growth, and physical and human capital accumulation (Arndt 2003).

Successful business operations require a steady supply of adequately trained workers. The spread of HIV/AIDS can prevent businesses and countries from meeting their labor needs, particularly for trained or experienced workers (Forsythe 2002, pp. 31, 35). Unfortunately, empirically wellgrounded studies of the impact of AIDS on rates of productivity growth and labor force turnover are relatively rare and "patchy" (Bloom, Mahal, and River Path Associates 2002, p. 13; Simon and others 2000, p. 2). The literature does suggest the following main points about the skills implications of HIV / AIDS.

AIDS depletes scarce human capital and magnifies the need to replace skills lost across a wide range of occupations (World Bank 2000, p. 42). Some studies have found that HIV infections can be disproportionately concentrated among the more skilled and qualified workers at certain stages in the epidemic (Bloom 2002, p. 6; Simon and others 2000, p. 2; Aventin and Huard 2000 , p. 163). These tend to be the hardest categories to replace (Biggs, Shah, and Srivastava 1995a). Work force turnover does not affect all businesses equally, but hits especially hard in firms with highly skilled work forces (Bloom 2002, p. 4). Reductions in the skills of labor force entrants have potentially serious, but unquantified consequences for business competitiveness (Bloom 2002, p. 10).

HIV / AIDS affects business profitability by increasing production costs and reducing output. (See Aventin and Huard 2000, p. 171, for a classification of direct and indirect costs.) One study divided the economic impact of work force HIV/AIDS into three categories: (i) the direct costs of preemployment training, of in-service and on-the-job training, and of the salaries paid while new employees become productive; (ii) the indirect costs of reduced worker performance due to HIV / AIDS sickness on the job; and (iii) the systemic costs, including the reduction in the average level of skill, performance, institutional memory, and experience of the work force (Simon and others 2000). To this should be added the potential cost increases implicit in the wage inflation that results from skill shortages. The main costs relate to workdays lost from HIV and AIDS absenteeism. However, the costs of recruiting and training new staff can also be substantial (Forsythe 2002, p. 32). A study of firms in Botswana and Kenya early in the epidemic found that recruitment and training accounted for 16 percent of the increased labor costs due to HIV / AIDS (Bloom 2002, p. 45).

This early study may have understated the increase in labor costs. The Africa Competitiveness Report of 1999 showed that business leaders in several countries expected moderate to substantial increases in training costs because of the epidemic (table 2.1).

Apart from direct costs of recruitment and skills training, the loss of skilled workers affects informal on-the-job training and therefore the overall stock of knowledge and skills within firms. Socialization and learning 
Table 2.1. African Firms That Ranked the AIDS Epidemic as Having a Moderate or Major Impact on the Costs of Running Their Businesses (percent)

\begin{tabular}{lcc}
\hline Country & $\begin{array}{c}\text { Reduction in skill level } \\
\text { of the work force }\end{array}$ & Increase in training costs \\
\hline Botswana & 45.8 & 52.5 \\
Burkina Faso & 70.0 & 22.2 \\
Gabon & 50.0 & 25.0 \\
Ghana & 14.3 & 12.9 \\
Kenya & 35.2 & 31.2 \\
Lesotho & 50.0 & 53.3 \\
Malawi & 78.0 & 68.8 \\
Mozambique & 45.5 & 63.6 \\
Namibia & 36.7 & 35.5 \\
South Africa & 28.2 & 34.0 \\
Swaziland & 65.4 & 53.8 \\
Tanzania & 28.6 & 25.6 \\
Uganda & 40.0 & 32.5 \\
Zambia & 66.2 & 56.3 \\
Zimbabwe & 50.8 & 49.6 \\
\hline
\end{tabular}

Source: African Competitiveness Report, as presented in Bloom and others 2000, p. 30.

within a firm play an important role in the maintenance and renewal of routines and skills. HIV / AIDS weakens the ability of firms to reconstitute and renew themselves, an indirect cost that is difficult to quantify. (Aventin and Huard 2000, pp. 183, 185).

A firm in Zambia described the attrition of key staff to AIDS as a "big problem" in terms of the loss of key skills, the reduced return on investment in skills development, and the added challenge of maintaining competitive levels of consistency and quality (Grierson 2002). As one Kenyan manager stated, "If you lose someone you have trained for twenty years, that is a great loss. Condoms and AIDS education cost peanuts" (Bloom 2002, p. 7). The direct impact on family productivity can be even more devastating with the loss of skilled, self-employed breadwinners. The death of a breadwinner cut maize production on a typical small farm in Zimbabwe by more than 60 percent (Fluitman 2001, pp. 30,34). Entrepreneurs typically manage micro and small enterprises on their own with family members having little knowledge of the business. Loss of the owner-manager means the business closes or is taken over by an inexperienced family member, with associated lost productivity (ILO 1999).

The full effect of HIV/AIDS has not yet been felt in high-prevalence countries owing to the long lag between the acquisition of the virus and the onset of AIDS, but it is clear that productivity growth is bound to suffer. 
Among other things, the pandemic will inevitably result in a much younger, less experienced labor force, with significantly less opportunity for mentoring or training on the job and reduced incentives for investment in training due to curtailed life horizons. The supply of skills training (as of other government services) is also likely to be disrupted. AIDS may have an impact on the quality or output of training institutions through instructor mortality. Higher labor force attrition rates will strain already overburdened and inefficient systems of skills training. Finally, HIV/AIDS not only reduces current levels of skills but also potentially depresses future investments in skills development. The mortality of skilled employees reduces company returns on training investments and discourages additional spending on training (Simon and others 2000, p. 4). The burden of dealing with HIV/AIDS is also likely to depress family investments in education and training (DANIDA 2002, p. 88).

\section{Migration}

There are long-standing traditions of labor movement across borders such as between the Sahel and the coast, along the Lagos-Abidjan corridor, and from Southern to South Africa. In addition, large numbers of people in SubSaharan Africa are being forced to flee their homes and countries as a result of war and conflict. The U.N. High Commission for Refugees (UNHCR) estimated that more than 5 million people were affected at the end of 2000, including 3.4 million refugees, 1.1 million internally displaced persons, and 0.5 million returnees (Fluitman 2001, p. 30). Tanzania alone hosts some 700,000 refugees. These numbers are bound to affect the functioning of both source and destination labor markets. Moreover, institutions are weak, and a wide range of structural factors and inequities, including laws, cultural norms, and access to land, credit, productive inputs, information, and health care, prevents African women from participating more productively in their country's labor markets, (Fluitman 2001, p. 1).

\section{"Brain Drain"}

Another aspect of migration also warrants mention: the flow of skilled and educated workers from the poorer to more advanced countries, or "brain drain." Income disparities and a demographic slowdown in industrialized countries fuel most of the migration. Brain drain occurs not only between continents, generally from south to north, but also within the region. South Africa, for example, is able to attract large numbers of the best educated and skilled workers from its neighbors. Some advanced countries actively recruit teachers, nurses, or skilled workers in developing countries. Migration of educated and skilled populations, either intra- or inter-regionally, can drain resources from poorer countries (DANIDA 2002, p. 83). Not only do the poorer countries lose their investments in the education and skills of those who emigrate, but they are also deprived of the emigrants' contributions to economic productivity. To an extent, these costs may be offset by 
repatriation of incomes earned while abroad, but such payments tend to decline over time. In some instances, return migration may offset the early losses and bring new skills back to a country.

\section{Labor Supply}

Even with recent evidence showing a demographic transition to lower fertility rates in a small group of middle-income countries in Sub-Saharan Africa (World Bank 2000, p. 16), the region as a whole still has some of the highest population growth rates in the world. The overall rate was 3 percent in 1990 and has declined to an estimated 2.4 percent per year only since 1999 (Dabalen and others 2000, p. 4). The population in Sub-Saharan Africa is expected to increase by 200 million from 653 million in 2000 to 854 million by 2010 (Fluitman 2001, p. 5).

Rapid population growth foreshadows increases in the size and growth of the labor force. Between 1990 and 1999 the labor force in Sub-Saharan Africa is estimated to have grown by 60 million workers, an average of 2.7 percent per year (Dabalen and others 2000, p. 4). The ILO estimated the total labor force of the region at 275 million in 1997 and 300 million in 2001, and projected it would reach 400 million by 2011. The magnitude of Africa's employment challenge is stark. On average, every year about 10 million additional people will seek work and income in one of Africa's multiple labor markets. Even if the Sub-Saharan labor force increases at a slower pace, for example, 2.2 percent, the region will have to cope with more than 7 million additional job seekers each year (Fluitman 2001, pp. 5-6). Hundreds of thousands of young people enter the labor market every year, mostly from school systems. They include about 500,000 in Kenya, 700,000 in Tanzania, and 200,000 to 300,000 secondary school-leavers in Zimbabwe (Haan 2001, pp. 51, 92, 147).

Labor force participation rates are comparatively high in Sub-Saharan Africa. The rates for women are lower than for men, as shown in table 2.2; however, labor force definitions underestimate the numbers of women working and their contribution to the gross national product. A detailed household survey on time use in Benin indicated that, if domestic chores are taken into account, women work 43 percent more hours per day than men do (see table 2.3).

The quality of the growing labor force largely reflects past investments in human capital, especially in education and training. The region's stock of human capital is exceedingly low by world standards. Progress has been achieved in lifting literacy rates in most African countries, but overall levels are still low, especially for women (see table 2.4).

Enrollment ratios in primary and secondary education are an indicator of the future quality of human capital. Even with improvements in the late 1990s, Africa is the only region where primary enrollment rates in 1995 fell below those in 1980 (World Bank 2000, pp. 105-06) Female enrollments were only about 45 percent of the total at the primary and secondary levels, and just 35 percent at higher education levels (see table 2.5). 
Table 2.2. Labor Force Participation Rates, by Gender, 1980 and 1997 (percent)

\begin{tabular}{|c|c|c|c|c|c|c|c|c|}
\hline \multirow[b]{3}{*}{ Country } & \multicolumn{2}{|c|}{ Labor force } & \multicolumn{6}{|c|}{ Labor force participation rates } \\
\hline & \multirow{2}{*}{$\begin{array}{c}\text { Total } \\
\text { (thousand) } \\
1997\end{array}$} & \multirow{2}{*}{$\begin{array}{l}\text { Annual } \\
\text { growth } \\
\text { 1980-97 }\end{array}$} & \multicolumn{2}{|c|}{ Total } & \multicolumn{2}{|c|}{ Men } & \multicolumn{2}{|c|}{ Women } \\
\hline & & & 1980 & 1997 & 1980 & 1997 & 1980 & 1997 \\
\hline Angola & 5,298 & 2.5 & 49.4 & 45.8 & 53.3 & 49.7 & 45.7 & 41.9 \\
\hline Burkina Faso & 5,541 & 2.3 & 54.6 & 50.0 & 57.7 & 53.5 & 51.6 & 46.5 \\
\hline Cameroon & 5,650 & 2.7 & 41.8 & 40.5 & 53.6 & 50.8 & 30.4 & 30.4 \\
\hline \multicolumn{9}{|l|}{ Congo, } \\
\hline Dem. Rep. of & 20,074 & 3.1 & 44.5 & 41.8 & 50.4 & 47.7 & 38.8 & 36.0 \\
\hline Côte d'Ivoire & 5,675 & 3.3 & 40.0 & 39.7 & 53.1 & 52.2 & 26.4 & 26.7 \\
\hline Ethiopia & 26,053 & 2.8 & 44.9 & 43.3 & 52.4 & 51.0 & 37.5 & 35.6 \\
\hline Ghana & 8,632 & 3.1 & 47.4 & 47.1 & 46.8 & 46.8 & 47.9 & 47.3 \\
\hline Kenya & 14,376 & 3.6 & 47.1 & 50.6 & 50.8 & 54.5 & 43.3 & 46.7 \\
\hline Madagascar & 7,423 & 3.1 & 48.7 & 46.9 & 54.0 & 51.9 & 43.6 & 41.8 \\
\hline Mali & 5,616 & 2.8 & 51.5 & 48.9 & 56.2 & 53.3 & 47.0 & 44.6 \\
\hline Mozambique & 9,484 & 2.1 & 55.3 & 51.9 & 57.3 & 54.3 & 53.3 & 49.7 \\
\hline Nigeria & 46,791 & 2.7 & 41.5 & 39.5 & 53.6 & 50.9 & 29.7 & 28.4 \\
\hline South Africa & 17,035 & 2.6 & 37.5 & 39.3 & 48.9 & 49.4 & 26.2 & 29.4 \\
\hline Sudan & 10,945 & 2.8 & 36.6 & 39.2 & 53.4 & 55.7 & 19.7 & 22.7 \\
\hline Tanzania & 16,170 & 3.2 & 51.2 & 51.3 & 52.2 & 52.6 & 50.2 & 50.1 \\
\hline Uganda & 10,309 & 2.5 & 51.7 & 49.6 & 54.3 & 52.2 & 49.1 & 47.0 \\
\hline Zimbabwe & 5,383 & 3.1 & 44.9 & 46.1 & 50.4 & 51.6 & 39.5 & 40.6 \\
\hline
\end{tabular}

Notes: Countries were selected for having a total labor force of more than 5 million each in 1997. The labor force, or economically active population, is defined as all persons of either gender who furnished the supply of labor for the production of goods and services during a specified time period. The labor force participation rate is defined here as the ratio of the economically active population aged 10 years and older, by the population of all ages.

Source: ILO estimates and projections, included in ILO, World Employment Report 1998-99, as presented in Fluitman 2001, p. 6.

Table 2.3. Benin: Time Use, by Women and Men

\begin{tabular}{lccccc}
\hline & \multicolumn{2}{c}{ Women } & & \multicolumn{2}{c}{ Men } \\
\cline { 2 - 3 } \cline { 6 - 7 } Description of activity & Urban & Rural & & Urban & Rural \\
\hline Marketed economic activities & 13.9 & 10.5 & & 15.3 & 11.9 \\
Nonmarketed economic activities & 2.4 & 10.6 & & 1.1 & 7.8 \\
Domestic activity & 13.5 & 13.6 & & 4.3 & 4.5 \\
Total work & 29.8 & 34.7 & & 20.7 & 24.2 \\
Total work and nonwork & 100.0 & 100.0 & & 100.0 & 100.0 \\
\hline
\end{tabular}

Note: Data are for average time use, by women and men, aged 6 to 65 , in urban and rural areas, 1998, as a percentage of a 24-hour day (1 percentage point equals 15 minutes).

Source: United Nations Development Programme, Rapport sur le développement humain au Benin 1998, PNUD, Cotonou 1998, as presented in Fluitman 2001, p. 15. 
Table 2.4. Adult Literacy Rates, Selected African Countries, 1985 and 1995 (percent)

\begin{tabular}{lcccc}
\hline & 1985 & & 1995 & \\
\cline { 2 - 5 } Country & Total & Total & Men & Women \\
\hline Botswana & 63 & 20 & 70 & 75 \\
Burkina Faso & 13 & 70 & 77 & 11 \\
Cameroon & 55 & 40 & 49 & 62 \\
Côte d'Ivoire & 28 & 36 & 36 & 30 \\
Ethiopia & 27 & 65 & 75 & 25 \\
Ghana & 51 & 77 & 85 & 55 \\
Kenya & 64 & 39 & 55 & 69 \\
Mozambique & 29 & 56 & 66 & 23 \\
Nigeria & 41 & 83 & 84 & 47 \\
South Africa & 79 & 46 & 58 & 35 \\
Sudan & 35 & 68 & 79 & 57 \\
Tanzania & 56 & 61 & 73 & 50 \\
Uganda & 51 & & & \\
\hline
\end{tabular}

Note: Rates are percentages of the population, 15 years of age and older.

Source: Based on Association for the Development of Education in Africa:

http://www.adeanet.org/spessa99, as quoted in Fluitman 2001, p. 9.

Table 2.5. Gross Enrollment Rates in Africa, 1960-79 (percent)

\begin{tabular}{lccccc}
\hline Level & 1960 & 1970 & 1980 & 1990 & 1997 \\
\hline Primary total & 43.2 & 52.5 & 79.5 & 74.8 & 76.8 \\
$\quad$ Primary female & 32.0 & 42.8 & 70.2 & 67.6 & 69.4 \\
Primary male & 54.4 & 62.3 & 88.7 & 81.9 & 84.1 \\
Primary female as a share of total & 37.0 & 41.0 & 44.0 & 45.0 & 45.0 \\
Secondary total & 3.1 & 7.1 & 17.5 & 22.4 & 26.2 \\
Secondary female & 2.0 & 4.6 & 12.8 & 19.2 & 23.3 \\
Secondary male & 4.2 & 9.6 & 22.2 & 25.5 & 29.1 \\
Secondary female as a share of total & 32.0 & 33.0 & 36.0 & 43.0 & 44.0 \\
Tertiary total & 0.2 & 0.8 & 1.7 & 3.0 & 3.9 \\
Tertiary female & 0.1 & 0.3 & 0.7 & 1.9 & 2.8 \\
Tertiary male & 0.4 & 1.3 & 2.7 & 4.1 & 5.1 \\
Tertiary female as a share of total & 20.0 & 20.0 & 22.0 & 32.0 & 35.0 \\
\hline
\end{tabular}

Source: UNESCO, Statistical Yearbook, 1978-97 and 1998, as presented in World Bank 2000, p. 106.

Another measure of human capital is the educational attainment of the population. Levels of primary school completion are exceedingly low in many countries: just 9 percent in Mauritania, 12 percent in Ethiopia, and 22 percent in Madagascar (the sum of the last three columns in table 2.6). 
Table 2.6. Education Levels of Household Heads, Selected African Countries, 1993-97 (percent)

\begin{tabular}{lcccccc}
\hline Country & Year & $\begin{array}{c}\text { No } \\
\text { education }\end{array}$ & $\begin{array}{c}\text { Primary } \\
\text { not } \\
\text { completed }\end{array}$ & $\begin{array}{c}\text { Primary } \\
\text { completed, } \\
\text { no secondary }\end{array}$ & $\begin{array}{c}\text { Secondary } \\
\text { not } \\
\text { completed }\end{array}$ & $\begin{array}{c}\text { Secondary } \\
\text { completed } \\
\text { higher } \\
\text { education }\end{array}$ \\
\hline Côte d'Ivoire & 1995 & 60 & 5 & 14 & 11 & 10 \\
Ethiopia & 1995 & 75 & 14 & 2 & 6 & 4 \\
Ghana & 1997 & 41 & 6 & 3 & 36 & 13 \\
Madagascar & 1993 & 29 & 49 & 4 & 15 & 3 \\
Mauritania & 1995 & 85 & 6 & 2 & 2 & 5 \\
Zambia & 1996 & 18 & 28 & 19 & 20 & 14 \\
\hline
\end{tabular}

Source: Based on data from http:/ / www4.worldbank.org/afr/poverty/measuring/indicators/, as presented in Fluitman 2001, p. 10.

\section{Labor Demand}

The question is where do new entrants to the labor market go? The lucky few find wage employment in the formal sector. Others become openly unemployed. However, the vast majority becomes part of the informal economy through self-employment. These three destinations are examined further below.

Aggregate labor demand bears no relationship to what is a structural oversupply of labor in many countries. In other words, there are by far too few wage jobs for all of the currently un- or under-employed or new entrants to the labor market (Fluitman 2001, p. 13).

No reliable data are available, but figure 2.1 offers a rough estimate of the main segments of Sub-Saharan Africa labor markets (excluding South Africa and Mauritius). Roughly two-thirds of all people employed are employed in agriculture, mostly in nonwage subsistence agriculture. About one-third of the labor force is situated in urban areas, of which about 60 percent are self-employed in the informal sector, 20 percent are in wage employment in the formal sector, and another 20 percent are unemployed.

Employment in the agricultural sector dominates African labor markets. Except for South Africa and Nigeria, agriculture occupies two-thirds to threequarters of the labor force. In contrast, the industrial sector exceeds 10 percent of employment in only a handful of countries (Ghana and South Africa in figure 2.2, plus [not shown] Botswana, Côte d'Ivoire, and Mauritius).

The share varies, but wage employment in the formal sector rarely exceeds 20 percent (Fluitman 2001, p. 18). In Uganda, the formal sector is said to absorb only 10 percent of new labor market entrants (Haan 2001, p. 96). In Zimbabwe, the formal sector absorbs only 10 percent of the 200,000 to 300,000 secondary school-leavers (Haan 2001, p. 147). In 1997, in Côte d'Ivoire, only 5 percent of the labor force was wage-employed in the formal sector, and 43 percent of these workers were employed by the public sector (Fluitman 2001, p. 19). 


\section{Figure 2.1. Sub-Saharan Africa: Estimated Proportions of Formal and Informal Sector Employment}

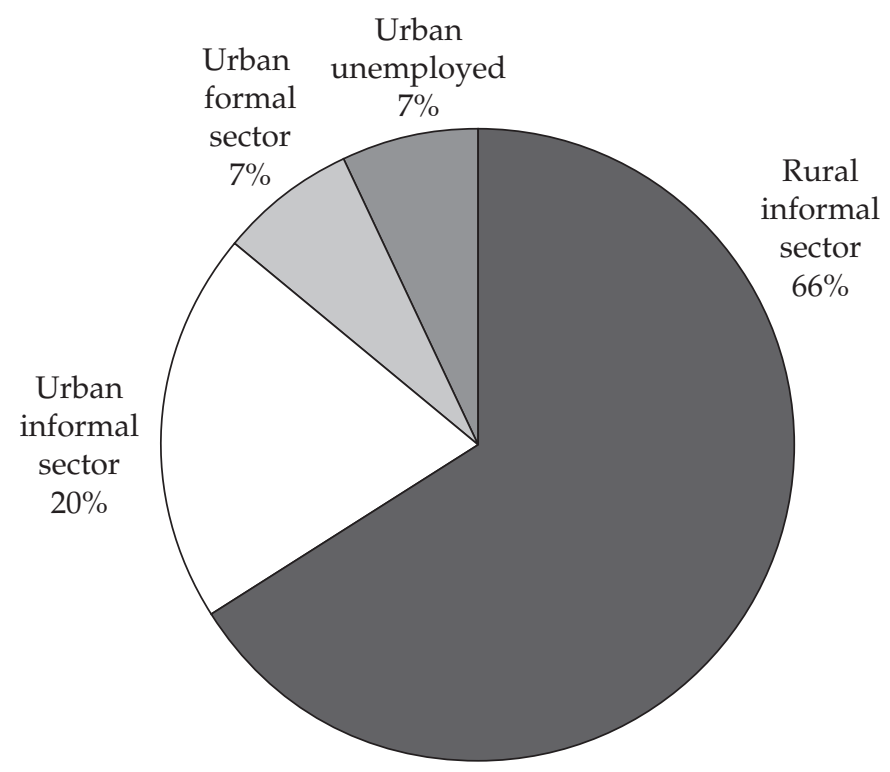

Source: Authors.

The formal economy has been stagnating in most countries in Sub-Saharan Africa. Zimbabwe had a net addition of about 100,000 wage-employed workers during the entire decade of the 1990s, less than the number of annual new entrants to the labor force. Zambia took 20 years to generate 100,000 formal sector jobs. Wage-employment levels in Ghana in the 1990s fell well below those achieved a decade earlier. Similar contractions occurred in Côte d'Ivoire and Tanzania (Dabalen and others 2000, p. 6).

Private sector growth has been modest. Employment creation in the private sector was either miniscule (except for Botswana and Mauritius) or negative in the 1990s. The growth of the public sector, which expanded rapidly in many countries in the 1980s, ${ }^{4}$ slowed or contracted with economic reforms in the 1990s. In Benin the number of civil servants dropped from almost 40,000 in 1990 to fewer than 30,000 in 1999 (see table 2.7; Fluitman 2001, p. 20) In short, overall formal sector growth, from either private or public sources, has been minimal.

The formal sector currently does not generate enough jobs to absorb all labor market entrants. If the formal sector of a given country employed 20 percent of the labor force, then wage employment would have to grow at 12.5 percent per year to absorb the 2.5 percent annual increase in the labor force (Dabalen and others 2000, p. 4). Allowing for growth in productivity, formal sector wage employment would need to grow even faster. This exceeds the realm of feasibility. 
Figure 2.2. Labor Force Structure, by Major Economic Sector, Selected African Countries, 1997

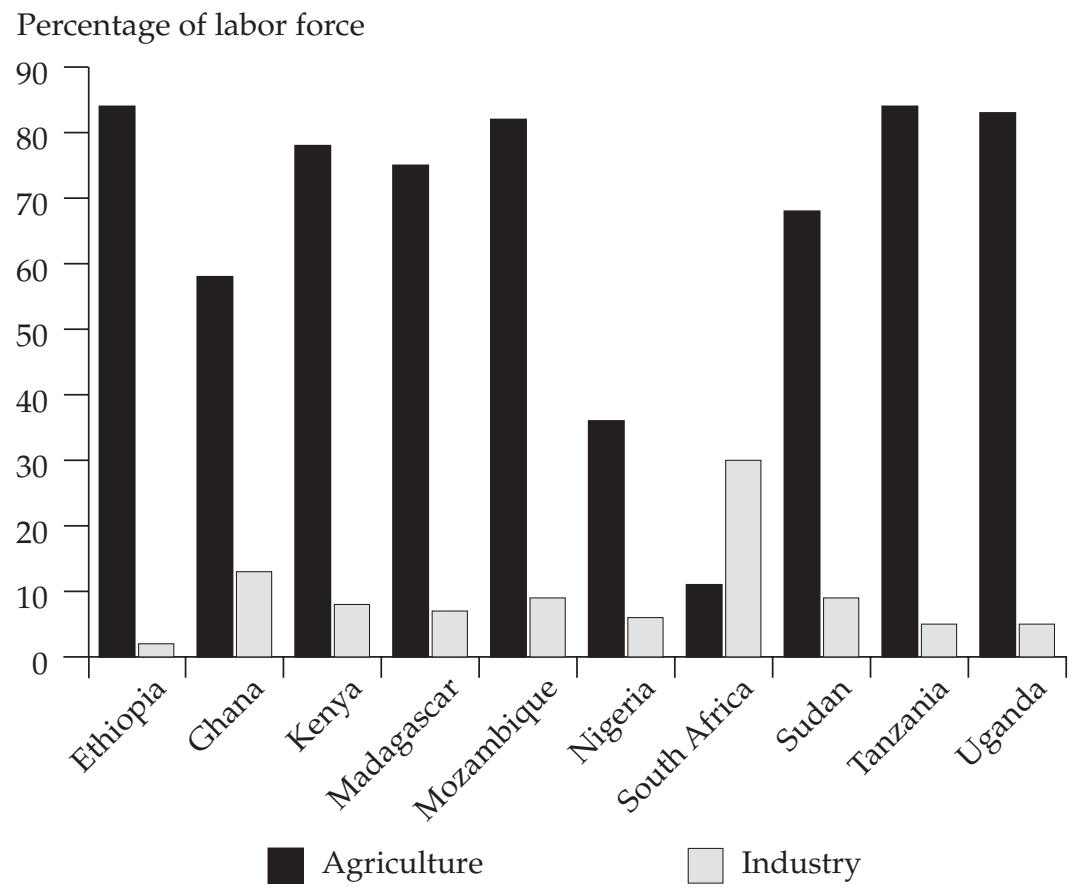

Source: ILO, 1998, World Employment Report 1998-99, table 3, ILO, Geneva, as presented in Fluitman 2001, p. 16.

Table 2.7. Public Sector Wage-Employment, Selected African Countries, 1993-99

\begin{tabular}{ccccccc}
\hline Year & Benin & Côte d'Ivoire & Gabon & Mauritania & Senegal & Togo \\
\hline 1993 & 34,966 & 123,900 & 44,794 & - & - & 34,130 \\
1994 & 34,449 & 120,700 & 45,694 & 18,471 & 66,733 & 34,736 \\
1995 & 32,241 & 118,700 & 47,247 & 19,288 & 67,168 & 34,467 \\
1996 & 32,283 & 116,200 & 47,386 & 20,093 & 67,130 & 33,855 \\
1997 & 32,019 & 117,400 & 49,476 & 20,819 & 65,949 & 32,931 \\
1998 & 30,619 & 110,100 & 53,620 & 22,425 & 66,341 & 29,753 \\
1999 & $28,000^{\text {a }}$ & 113,200 & 52,886 & 22,950 & 66,518 & 32,093 \\
\hline
\end{tabular}

- Not available.

a. From the U.N. Development Programme's Report on Human Development in Benin, 2000, as quoted in Fluitman 2001, p. 20.

Source: http:/ /www.afristat.org 
Increased open unemployment has been one of the consequences of rapid labor force expansion and minimal economic growth. Officially, unemployment tends to be low, at 8.1 percent in Ethiopia, 3.9 percent in Ghana, 8 percent in Cameroon, and 3.2 percent in Madagascar (Fluitman 2001, pp. 22-23). Official rates may be understated because people who are discouraged from actively seeking employment are not included. However, as the formal sector stagnates, workers who are not self-employed are increasingly becoming openly unemployed. South Africa, where 27 percent of the black labor force is unemployed, is a well-known example but no longer a special case. A labor force survey in eight major cities in Nigeria put unemployment at 17 percent. Comparable rates have been observed in Swaziland (Dabalen and others 2000, p. 13).

Open unemployment is particularly severe among young workers. Those between the ages of 15 and 24 are disproportionately represented, making up an estimated 40 percent of all the unemployed. In addition, the unemployed tend to be relatively better educated, including people educated at the secondary level. The openly unemployed tend to be concentrated in urban areas. In Zambia, the rate in urban areas is three times that in rural areas. The duration of unemployment is also increasing, compounding the already high social costs of unemployment by further eroding family savings and resources (Dabalen and others 2000, p. 14).

Unemployment rates were highest for youths, especially those with some (primary or secondary) education and those living in urban areas. In Zambia, Uganda, Malawi, Kenya, and Ghana, unemployment rates for the age group 15-24 in the mid-1990s were at least two times higher than the rates for those 40 years and older. This pattern can also be observed in industrial countries. Unemployment rates among primary school-leavers for the same countries exceeded 40 percent, and rates for secondary graduates ranged from 13 percent to 38 percent. Unemployment rates were twice as high in urban areas as in rural areas of Kenya and over three times as high in Zambia (Dabalen and others 2000, p. 15).

High rates of youth unemployment have led several African governments to attempt active labor market programs to ease the transition of youth, especially educated youth, into employment. Examples include national youth services or brigades. The success rates of such youth employment programs have not been promising. At least at the national level, such programs have not succeeded in reducing rates of unemployment (Fluitman 2001, pp. 28-29).

The failure of the formal sector to generate enough wage employment to absorb all labor market entrants has drawn attention to the need for labor market reforms. As a consequence, structural adjustment programs have given considerable attention in the past decade to the review and reform of labor codes that create costly barriers to labor mobility and impede wage flexibility, especially in francophone countries. Although such reforms may be important, little evidence has emerged to suggest that reduced labor regulation is a spur to employment growth and demand for skills. Attention has 
shifted to getting the macroeconomic policies right, promoting good governance, and supporting the rule of law in order to spur private investment.

\section{The Informal Sector}

The rapid growth of the informal sector is a major consequence of rapid labor force expansion coupled with minimal growth in wage employment. Growth in the informal sector is probably a permanent feature for the foreseeable future. It is not just a transitory phase, as governments have conceived of and treated it. Instead, micro and small enterprises will remain the backbone of many developing economies (Haan 2001, p. 167).

The informal sector is heterogeneous and is viewed as consisting of three segments:

1. Subsistence types of self-employment characterized by part-time (seasonal) operations, traditional technologies, local materials, and local markets, a particularly important source of income for poor rural women.

2. Micro enterprises of up to 10 workers, mostly family members or apprentices using a mix of technologies, serving rural markets, and often operating in rural centers.

3. Small-scale enterprises with 10 to 50 workers, using some modern technologies, semiformalized, and with some growth potential.

Each of these segments has its own set of constraints and requires a particular support strategy (Haan 2001, p. 169).

\section{Size and Structure}

The informal economy is already responsible for most rural nonfarm and urban employment (figure 2.3). According to a 1997 nationwide household survey, 87 percent of people employed in Ghana worked in the informal sector-92 percent in rural areas and 77 percent in urban areas. Official estimates for Cameroon are that 4.2 million people were working in 1996, 15 percent of them in the formal sector and 85 percent in the informal sector. On average, in Benin the informal sector accounts for 78 percent of nonfarm employment and more than 92 percent of all employment (Haan and Serriere 2002, pp. 17-24, 133). Almost equal numbers of women and men were employed, but more women than men worked in the informal sector; formal sector employment is largely a male domain (Fluitman 2001, p. 16). The informal sector seems to be particularly important for people migrating from rural to urban areas (Haan and Serriere 2002, p. 134).

Employment in the informal sector has risen sharply since the early 1970s. The informal sector in Benin grew at 10 percent per year between 1979 and 1992 (Haan and Serriere 2002, p. 133). In Uganda informal sector employment was estimated to be growing 20 percent per year. In Kenya micro and small enterprises accounted for 10 percent of employment in 
Figure 2.3. Informal Sector Employment as a Share of Nonagricultural Employment, Selected African Countries (1990s)

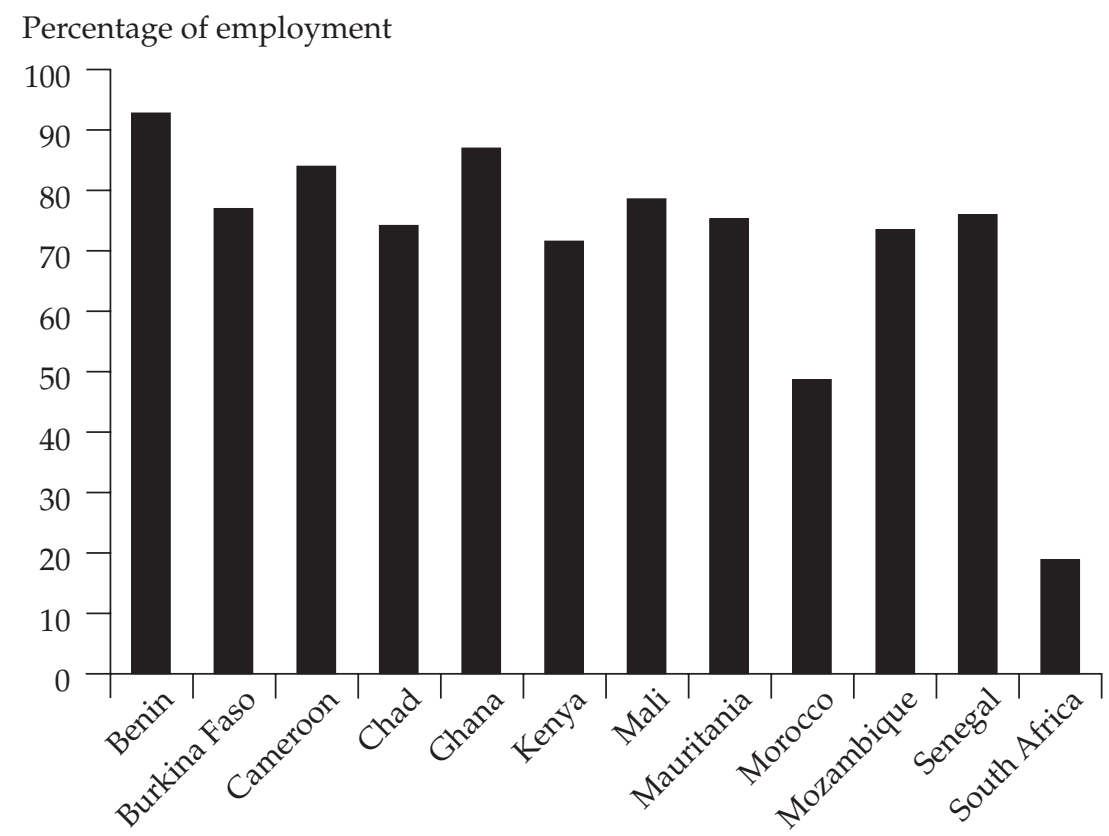

Source: Based on Haan 2001, table 1.

1972 but 54 percent in 1994. At the same time, public sector employment declined from 36 to 21 percent, and modern private sector employment from 54 to 24 percent (Haan 2001, pp. 42, 96).

The informal sector is dominated by small trading activities, which account for 35 to 88 percent of informal sector enterprises. Services, including transport, account for 6 to 26 percent of informal sector enterprises and manufacturing from 6 to 42 percent in countries reviewed (Haan 2001, Haan and Serriere 2002).

In West Africa the best known segment of nonfarm employment is l'artisanat, or traditional craft activities. Commonly l'artisanat is equated with traditional small-scale manufacturing activities, such as blacksmithing, weaving, and wood carving. More modern activities such as welding, metalworking, and furniture making are also included. Small trading and personal services are not considered part of l'artisanat. Thus, the "artisan sector" generally represents the "higher end" of the informal sector (Haan and Serriere 2002, pp. 17, 131). (Figure 2.4 shows the proportions for selected francophone countries.)

The informal sector is geared to final consumption. Small-scale trading is mostly for wholesale goods; services consist of repair and personal services 
Figure 2.4. Structure of the Urban Informal Sector, Selected Francophone Countries, 1980s/1990s

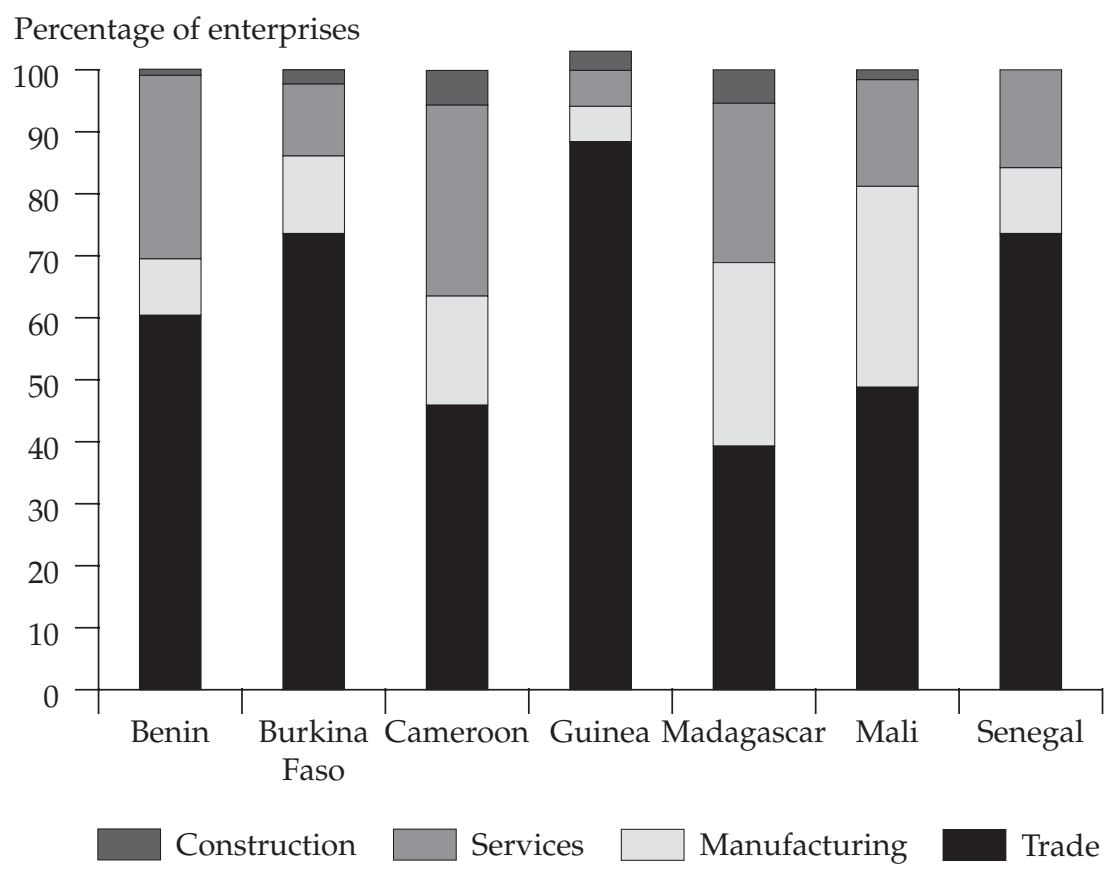

Source: Based on sample surveys in selected urban areas. Based on Haan 2001, table 2.

for consumers. Production of goods for final consumption (garments, leather products, furniture, foodstuffs) is by far the most important activity in manufacturing (Haan and Serriere 2002, pp. 18, 134).

Women constitute an important part of informal sector employees. Given limited opportunities, self-employment in micro businesses has become the most common form of women's labor force participation next to employment on the farm. In many African towns and cities, women represent a large if not the major share of the self-employed in the informal economy, including work in retail trading, tailoring, handicraft production, food processing, and hairdressing (Fluitman 2001, p. 26).

\section{Dynamics and Complexities}

The informal sector is neither static nor hermetically separated from modern wage employment. Many people straddle the line, complementing income from wage jobs with secondary sources of income generated in the informal sector (Afenyadu and others, 1999). Or, they move from one sector to the other. One beneficial consequence of company downsizing due to 
liberalization and economic reforms has been the transfer of skills between the formal and informal sectors as workers change sectors.

"Push" rather than "pull" factors have been responsible for the growth of the informal sector (Haan 2001, p. 168). The informal sector has been considered the employer of last resort for people who could not find wage employment. This implies that individuals with low or no education are the first to enter the informal sector, and studies have confirmed this trend (Dabalen and others 2000, p. 11).

The informal sector is dynamic, with considerable "churning," a complex and uneven process of simultaneous expansion and contraction of different segments of the sector. When the economy is growing, the high end of the informal sector in manufacturing and maintenance services thrives, while at the low end, income-generating activities shrink as the persons employed in those activities move to more rewarding activities. When the economy stagnates, few micro and small enterprises expand, and most lay off workers. Income-generating activities then grow rapidly (Haan 2001, p. 169).

The character of the informal sector also changes as it expands. New activities are included; for instance, informal cybercafés. These activities are started by what some observers call a "new generation" of entrepreneurs in the informal sector. These entrepreneurs are younger and, on average, better educated. Reportedly, they do not view the informal sector as an employer of last resort, but instead have come to appreciate the opportunities offered by self-employment. These new entrepreneurs in the informal sector are more open to upgrading not only their own skills but also those of their workers (Haan and Serriere 2002, pp.17, 135).

The rate of failure among informal sector enterprises is high (13 percent a year, according to African surveys, but this is probably an underestimate [Haan 2001, p. 34]). Half of these businesses close for economic reasons and one-fourth for personal reasons. More than half the closures take place in the first three years of operation. In Kenya, entrepreneurs of 60 percent of micro and small enterprises that ceased operation subsequently opened another business (Haan 2001, p. 34). These patterns are not unusual when compared with those in other regions.

Education is an important building block for new entrepreneurs in the informal sector. Educated informal sector entrepreneurs in West Africa are likely to need less time to enter into self-employment. A typical sequence in becoming an entrepreneur is to acquire a basic education, then develop skills through a variety of means (formal training, informal training, on-thejob training), then obtain wage employment, and finally enter into selfemployment (Haan 2001, p. 23) (see box 2.1).

\section{Problems and Constraints}

In view of the extraordinarily large numbers of persons turning to the informal sector almost everywhere in Sub-Saharan Africa, the informal sector could reach the limits of its absorptive capacity. Already saturation is evident in a 


\section{Box 2.1. Cameroon: Pathways to Entrepreneurship in the Informal Sector}

A recent survey of skills and work in the informal sector of Yaoundé, the capital of Cameroon, illustrates how operators of various micro enterprises have reached their current positions along different pathways, includingusually-periods at school, in training centers, as apprentices, and otherwise as learners on the job. The 682 entrepreneurs in the sample, involved in 1 of 12 selected economic activities other than commerce, had spent an average of 11 years in school. Half of them had obtained a diploma higher than primary school, and 6 percent had a university diploma. Leatherworkers were the least educated, with an average of 8 years of schooling, and 22 percent of them did not complete primary school. Entrepreneurs involved in informal secretarial services and cybercafés were the most educated, with an average of 17 years of schooling and 30 percent who held a university diploma. The better educated entrepreneurs were a few years younger than the less educated, much more likely to have grown up in a family of wage employees, and more likely, in addition to their general or vocational education, to have had a period of vocational training. Indeed, almost one out of two entrepreneurs had, at some stage, been enrolled in some form of pre-employment vocational training. The duration of such training varied by activity but may also have been a function of cost: 72 percent of those trained had paid for it, and 58 percent were trained in a private for-profit institution. In addition to whatever education and training they might have had, two-thirds of the sample entrepreneurs had also been apprentices, usually for two to three years. To complete the picture, half of the respondents had one or more apprentices; another 20 percent had had apprentices in the past. Only in the case of restaurants did apprentices appear to be the exception rather than the rule. Apprentices were almost invariably part of the work force in garages and in dressmakers' workshops. Nine out of 10 such entrepreneurs had apprentices.

Source: Fluitman 2001, p. 13.

limited number of economic sectors, especially trade and personal services. Most of the newly created "jobs" have been at the low end of the informal sector, where the returns on labor are minimal, there is no capital accumulation for reinvestment, and the closure rate is high. Trade, retailing, and personal services are typical examples of such activities (Haan 2001, p. 169). In short, ever larger numbers of people are getting a smaller share of national income.

Even in countries like Zimbabwe and Ghana, where the informal sector is viewed as relatively developed with a high proportion of manufacturing and linkages with medium and large companies, the sector appears to have succumbed to being largely a mere "re-distributor of poverty" through street vending and other retailing activities. Trade ventures now constitute 45 percent of informal sector employment in Zimbabwe and 70 percent in Zambia (Haan 2001, p. 168). In Kenya, the enormous influx of entrants 


\section{Box 2.2. Constraints on Informal Sector Enterprises}

- Lack of capital: Past informal sector surveys invariably found a lack of capital (formulated in whatever way) to be the most serious problem facing micro and small enterprises, but entrepreneurs tend to overrate the beneficial effects of capital and underestimate the risks of taking loans larger than their capacity to repay.

- Poor management and technical skills: Informal entrepreneurs in general are reluctant to prioritize poor skills as a major problem for their business.

- Inadequate technology: This is usually stated as an access issue, but some firms could have access to improved technology available in the market if they had higher literacy and technical skills and stronger business planning and investment skills.

- Disadvantageous market structures: Micro and small enterprises experience this problem as too much competition in low-income markets, low demand for their products and services, lack of access to physical markets where larger and higher-income groups shop, difficulty in procuring inputs, low prices provided by traders, etc.; as a result, informal sector firms suffer from diseconomies of scale. Market structures are primarily issues of access, but forces external to the firm often play a key limiting role.

- Inadequate infrastructure: Low access to services such as work sites, water and electricity, roads and communications, result from inadequate government investments.

- Government policies, regulation, or harassment: Government is one of the most significant external forces that affect the performance of informal sector business.

Source: Haan 2002, sec. 2.5 .

(500,000 a year) is threatening the informal sector's absorption capacity. Many of the markets for micro and small enterprise goods are saturated, and the potential for gainful insertion of additional job seekers in the more traditional micro and small enterprise trades has become limited (Haan 2001, p. 51). The main constraints impinging on the informal sector are summarized in box 2.2.

The opening of the economy for the importation of industrial goods, even at much higher prices than before, means that competition for many micro and small enterprise products has significantly increased. At the same time, purchasing power has declined, especially among the lower and middle classes who are important customers for informal sector goods and services (Haan 2001, p. 11). 


\section{Policies}

The climate for informal sector operators has improved in the past 15 years, but government continues to give little attention to effective policies supporting micro and small enterprises. Countries have formulated elements of informal sector policies, but nowhere does there exist a clear and coherent framework for development of the informal sector. Even in Kenya, where informal sector policies have been on the books since 1986, the encouragement of micro and small enterprises is watered down by a lack of implementation capacity (Haan 2001, p. 172). In Tanzania, no specific policy exists to promote the informal sector, even though it is by far the largest "employer" in the country. In francophone West and Central Africa, early approaches favored the creation of government-inspired organizations such as the Chambres de Métiers to provide for one segment of the informal sector, l'artisanat. However, legal and administrative aspects were emphasized at the expense of grass-roots participation ${ }^{5}$ and the organizations became bureaucratic and inefficient. Entrepreneurs were largely bypassed (Haan and Serriere 2002, p. 135).

\section{Strategies}

To ensure that the informal sector can continue to absorb new entrants, the sector will need to expand-particularly at the high end, in productive activities such as manufacturing and repair services. More than benign neglect is needed for this expansion to happen. The following actions can help strengthen growth of productive employment in the informal sector:

- Remedying the serious infrastructural problems of the informal sector by allocating workshop plots, improving electricity supplies, and constructing feeder roads and transport

- Addressing the effects of macroeconomic policies for trade on the informal sector

- Ensuring education, training, and technology policies suitable for micro and small enterprises, such as simplifying licensing and tax procedures, disseminating relevant information to micro and small enterprises, and supporting microcredit efforts (Haan 2001, p. 172).

\section{Labor Market Information}

Figure 2.5 shows the key role played by labor market analysis and followup at the micro level in the training process. Training ideally starts with analysis of labor market demands and ends with follow-up information about the use of skills in employment, for example, through tracer studies.

Labor market information is also important at the macro level. LMIS collect, collate, process, and analyze the data, and disseminate the results (labor market signals or indicators), to help guide allocations of resources to 


\section{Figure 2.5. Steps in the Training Process}

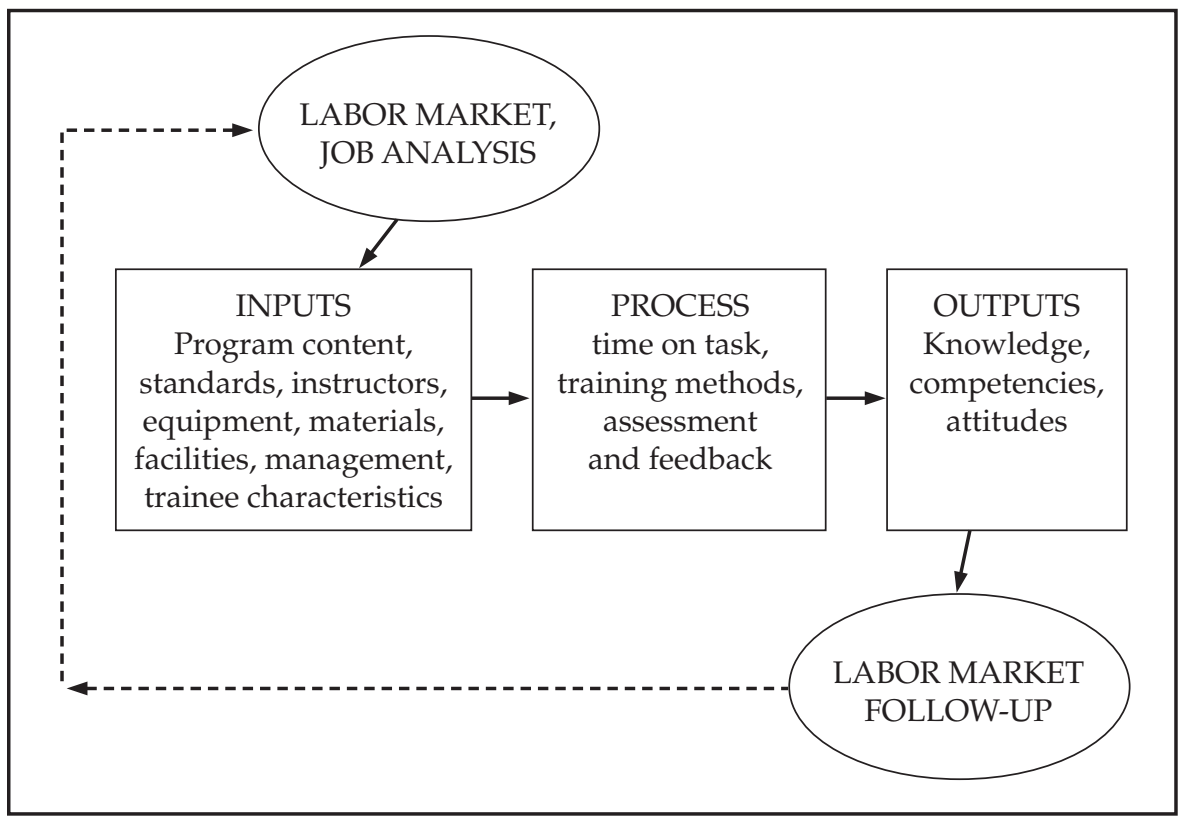

Source: Authors.

the provision of skills. LMIS are not so much intended to generate new surveys as to collect, analyze, and collate information already available from other sources such as establishment and household surveys, tracer studies, and wage surveys (Middleton, Ziderman, and Adams 1993, p. 152).

The Bank's Policy Study recommended increased attention to the development of information about labor markets through feedback from employers and labor market analysis (chapter 1). Labor market "observatories" became instruments of choice in virtually all World Bank projects. In the 1990s, 22 of 24 vocational education and training projects included labor market observatories to guide client choice within training systems.

Results have been disappointing, for the most part. Several examples illustrate the difficulties encountered. An observatory was established in Madagascar, but it failed to build linkages with employers. The observatory established in Djibouti was weak in statistical analysis and did not use the technical assistance provided. A labor market information system in Togo was delayed because of coordination and institutional difficulties. In Côte $\mathrm{d}$ 'Ivoire, the problems were weak top management and attrition of qualified staff until some financial incentives were put in place. In Ghana, a labor market survey was conducted, but the files became infected with a computer virus and the data were not analyzed. Mauritius seems to be an excep- 
tion among completed World Bank projects, with a well-developed and functioning LMIS. Most World Bank-financed projects on labor market information and observatories ran into difficulties in implementation. With the possible exception of Mauritius, no cases of good practice exist.

What accounts for this weak performance? The difficulty of establishing effective labor market observatories is easy to underestimate. They are much harder to establish and operate than is apparent at first glance, for several reasons. First, a labor market observatory can be many things and take different forms. It is important to be explicit about its mission and purpose. Similar clarity is required about its role. Second, the existence of a labor market observatory presupposes that information is available from which labor market trends can be discerned. Often such information is unavailable or limited; or, there is little or no demand for the information, or ability to use it. Third, a labor market observatory relies on networking to get information. Traditional organizations find it difficult to work across organizational boundaries. The labor market observatory typically counts on others to produce and share useful information. This requires cooperation across organizational lines.

To be effective, a labor market observatory must have the capacity to generate high-quality research, which, in turn, requires retaining high-quality researchers either in house or under contract. High quality tends to be expensive. Capable research staff will be attracted by other employment opportunities, as in Côte d'Ivoire. Keeping staff may be difficult within the framework of the civil service. Financial incentives for all parties need to be considered carefully. Finally, a labor market observatory has to be dynamic and kept up to date. This requires active leadership — not always available within civil service organizations. ${ }^{6}$ Most new observatories will probably require patient, sustained support for a decade or more in order to build sufficient capacity.

Standards for success in labor market observatories are high and unlikely to be met in many countries in Sub-Saharan Africa. Success requires networking and cooperative work across organizational boundaries, which is difficult to achieve in public bureaucracies; research expertise, which is often scarce; dynamic leadership with continuous efforts at innovation; and adequate budgetary support for the new functions. Future investments will need to be based on an in-depth evaluation of past problems and failures (Johanson 2002, part I, pp. 17-19).

A labor market observatory may not even be required in all circumstances, such as in highly informal economies. The demand for labor market information is undoubtedly stronger in more complex, industrial economies. This suggests that the context for observatories is especially critical to their success. Accordingly, investing in the establishment of LMIS, at least in the form of observatories, may not be a priority for low-income countries.

On the other hand, this review identified several examples of good practice in Sub-Saharan Africa of linking training supplies with the labor market. 


\section{Box 2.3. Namibia: Using Labor Market Information for Flexible Training Delivery}

In the mid-1990s in Namibia the government established seven Community Skills Development Centers (COSDECs) under locally elected boards of trustees. Their main goal is to impart basic skills to enable youth to generate income through wage employment or self-employment. The COSDECs must be flexible training institutions, varying their basic training courses frequently as income-generating opportunities change in the local economy. After a confused start, during which the centers copied traditional courses of the VTCs, the COSDECS, with European Commission (EC) assistance, began to employ three basic techniques to align themselves with market needs.

First, experts conducted market assessment surveys at each location in 2002. The COSDEC Foundation provided experts from its small support unit to conduct the surveys. Building on rapid rural appraisal techniques, the market assessments covered the occupational interests of youth, government and local authorities, local development plans, and project sites, and canvassed employers and businesses in both the formal and the informal sectors. For example, a visit to a local hardware wholesaler gave ideas about imported products in demand that could be made locally. The assessments also took into account training capacity in the locality. Information from these various sources pointed to potentially fruitful economic activities. The survey in Keetmanshoop, a small town in the south of Namibia that has little industrial activity, produced some 30-40 ideas. The surveys were also used to determine whether training institutions would be viable in new locations. A survey showed insufficient demand to sustain a training center for plumbers and pipefitters, as proposed in Khorixas. The market assessments also made clear that what is viable in one location may not be viable in another. For example, small building construction held promise in Oshakati but not in Omaruru.

Second, the teams conducted more thorough feasibility studies of the potential opportunities identified during the market assessments. Feasibility

continued on $p .47$

See box 2.3. One example is the use of trade associations. The creation of regional employer associations (association regionale interprofessionnelle [ARIFs]) in Madagascar has been highly effective in providing signals to training providers (Atchoarena and Delluc 2001, p. 136). The National Federation of Artisans of Mali has also played a more effective role in interfacing with the informal sector than has the procedure-encumbered modern sector (Atchoarena and Delluc 2001, p. 147). Other promising avenues are local market surveys around specific training institutions. The Opportunities Industrialization Council in Ghana, operated by an NGO, conducts regular surveys of the local micro labor market of businesses operating around its three training centers (Atchoarena and Delluc 2001, p. 190). 


\section{Box 2.3. (continued)}

studies found viable demand in various localities for such products as automobile seat covers, small cleaning services, custom-made women's clothes, casket assembly, and household construction. In contrast, the Foundation abandoned a proposal to start horticulture training in Omaruru when the more detailed feasibility study showed major problems with water supply.

Third, the COSDEC Foundation undertook tracer studies in 2002 at all centers to identify the impact of past training. The tracer studies found a wide range of employment rates, generally from 20 percent to 60 percent, depending on occupation and year of training. At the extreme, only 3 of 100 graduates in automobile mechanics from one center found employment. The findings sensitized center management to market saturation. One center discontinued auto mechanics, and another stopped offering carpentry because of poor employment. In another place, employment rates were high in needlework, but tracer results hinted at impending market saturation. Mobile courses in needlework at a succession of locations replaced the center-based program.

The COSDEC Foundation has now adopted several policies to build flexibility into its services. Training initially lasted 12-15 months, longer than necessary for basic skill acquisition, but now it takes 3-6 months. Centers give one-off courses, for example, in interior and exterior painting, not to be repeated in a locality so as to avoid the risk of market saturation. COSDECs give more attention to outreach training by mobile units. The Foundation "owns" all the training equipment, so that it can be moved from center to center as demands change. COSDECs also now employ instructors on short-term contracts, so that training in surplus trades can be abandoned and new ones readily introduced.

Source: Byram and Pringle 2003.

\section{Notes}

1. UNDP 2000, Human Development Indicators, Table 13.

2. World Bank, World Development Indicators 2000/2001, table 1.

3. See http://www.worldbank.org/poverty/data/trends/regional.htm.

4. In Kenya and South Africa, the civil service nearly doubled between 1980 and 1990, and in Botswana it more than doubled. This dramatic expansion led to so much overstaffing that, in some countries (Botswana, Kenya, and Zambia), the ratio of public to private sector employment was nearly one to one. In Ghana, an extreme case, there were five public sector workers for every private sector worker in the 1980s (Dabalen and others 2000, p. 7).

5. For example, the Chambres de Métiers represent no more than 10 percent of the informal sector in Senegal (Haan and Serriere 2002, p. 135).

6. See Richards and Amjad 1994, pp. 77-78, for staffing of and organizational constraints on LMIS. 



\section{Making Reforms Work in Public Training}

Public training systems in Sub-Saharan Africa often come up short in evaluations of their relevance to economic and social needs, their effectiveness in delivering skills, and their costs and efficiency. TVET, in many instances, provides the wrong skills for employment. Budget cuts have had disastrous consequences on quality. Reorienting this training has been difficult, but there have been some promising innovations such as the establishment of national training authorities, the broadening of the autonomy of training institutions, and the development of competencybased qualifications systems.

\section{Introduction}

There are good examples of state-sponsored training provision throughout Sub-Saharan Africa, but this training has faced sharp criticism in the past in many countries for being of poor quality and for failing to serve market needs. Reforms have been called for. Much of this training has focused on pre-employment skill needs. This chapter reviews the experience of public training provision over the past decade with reference to two questions:

- What is the recent experience of TVET with respect to issues of relevance, quality, and efficiency?

- Where reforms have been introduced, what success have they had in making public training systems more market driven?

\section{Diversity in Ownership, Management, and Structure}

The ownership and the management of public training are often complex and fragmented (figure 3.1). Formal skills training is typically offered in vocational and technical schools within the formal school system under ministries of education, more narrow ministries of VET (as in many francophone countries), or at higher levels by ministries of technical and higher education. In addition, ministries of labor typically support various kinds of informal skills training through vocational training centers. Other ministries have specialized training centers to meet their own needs for skills,

This chapter synthesizes the findings of Atchoarena and Delluc (2001). 
Figure 3.1. The Range of Public Training Provision by Ownership

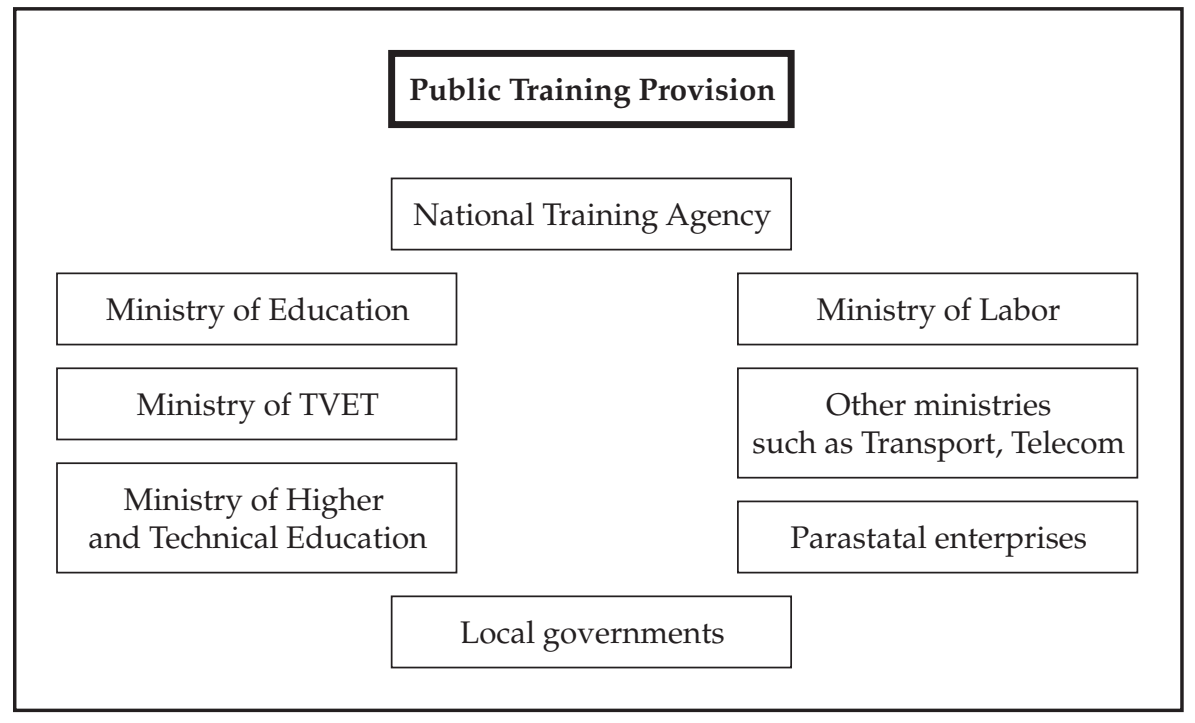

such as those focused on agriculture, industry, public works, energy, and telecommunications. Local governments may sponsor various kinds of vocational training. Some countries have moved to create national training authorities that represent not only the various public providers but employers and labor unions as well.

From time to time TVET has faced instability in management. In Côte d'Ivoire, VET was under a separate Ministry for Technical and Vocational Education (1970), reintegrated into the Ministry of Education (1983), became a separate ministerial department (1996), reintegrated into the Ministry of Education and Scientific Research (1996), and then became part of the Ministry of Youth Employment and Vocational Education (2000). Responsibility for skills development has moved back and forth among ministries in recent years in Mauritius.

Throughout the region considerable diversity exists in the type of training offered. Francophone countries offer three types of technical or vocational streams at the secondary level (two-year Certificat d'Aptitude Professionnelle [CAP], three-year technical baccalaureate, and four-year Brevet Technique [BT]), plus two technical options at the postsecondary level (Brevet de Technicien Supérieur [BTS] and Diplôme Universitaire de Technologie [DUT]). Some anglophone countries (for example, Ghana and Kenya) have opted for vocationalization of general secondary education, with separate technical institutes at the upper secondary levels under the ministries of education, plus informal vocational institutions outside the school system under the ministries of employment and labor. 


\section{An Assessment of State-Sponsored Training}

Public systems of skills development have continued to face crises brought on by difficulties in reacting to a changing economic environment, with consequences for their relevance, quality, equity, and efficiency. These systems face a depressed market for wage employment alongside rapid labor force expansion.

\section{Relevance}

Relevance refers to whether the objectives and outputs of a training system meet a country's economic and social requirements (figure 3.2a). More narrowly, this is referred to as the external efficiency of a training system. Public training systems throughout the region are immersed in a crisis of relevance. Public training tends to be small in relation to general education, imbalanced, and oriented exclusively to wage employment. Central examinations, themselves out of tune with the labor market, tend to reinforce these distortions.

Technical and vocational education (TVE) generally occupies a small, if not marginal, position in the school systems of Sub-Saharan Africa. According to the most recent available statistics, ${ }^{1}$ enrollments in secondary technical and vocational education are relatively small. In only six countries do TVE enrollments total more than 10,000 students. ${ }^{2}$ In terms of the percentage of enrollments in secondary education, countries can be grouped into the categories shown in table 3.1.

The vertical structure of enrollments can also vary. In Senegal, it could be represented by an inverted pyramid, because weight is given to technical higher education and less attention is given to basic training-for example, to the vocational training certificate (CAP). In other settings the opposite structure may apply without a market rationale.

\section{Figure 3.2a. Relevance}

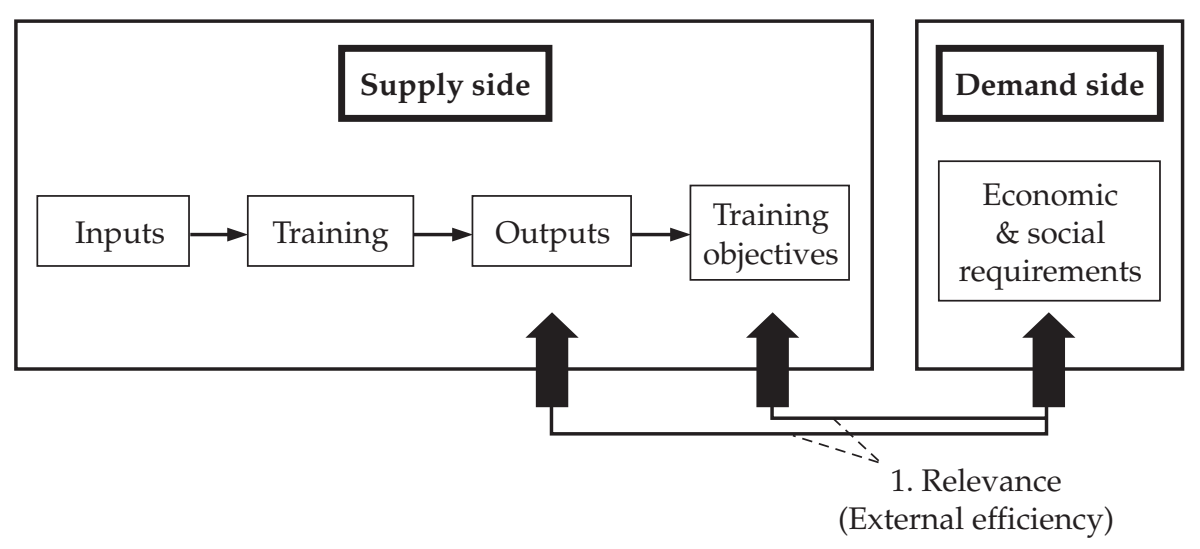


Table 3.1. Secondary Enrollments in Technical-Vocational Subjects

\begin{tabular}{ccc}
\hline \multicolumn{3}{c}{ Percent of total enrollments } \\
\hline$<2$ & $5-9$ & $>10$ \\
\hline Chad & Botswana & Cameroon \\
Eritrea & Burkina Faso & Congo, Dem. Rep. of \\
Ethiopia & Côte d'Ivoire & Gabon \\
Lesotho & Mozambique & Mali \\
Malawi & Togo & \\
Namibia & Uganda & \\
Niger & & \\
Senegal & & \\
South Africa & & \\
\hline
\end{tabular}

Note: The share of TVE has fallen sharply over the past 15 years. In Cameroon, the proportion declined from 27 percent to 17 percent, and in Gabon from 20 percent to 9 percent. In part, the higher relative costs of TVE were responsible for the declines, in a period of tight public finances.

Source: Atchoarena and Delluc 2001, pp. 36-38.

Formal TVET, in many cases, fails to deliver skills for existing jobs. The traditional notion underlying both education and training in Sub-Saharan Africa is that employment refers foremost to wage employment. However, as observed in chapter 2, this type of employment has almost entirely collapsed. Formal TVET has been slow to respond to the changing needs of the labor market. An example of this is the difficulty that Mozambique has had in retooling its training system from the overly specialized and outdated curricula that were designed for a centrally planned economy and employment in large state-owned companies. The government's own critique of TVET points to weak relationships with the world of work; the absence of firms in the management of training, particularly the conceptualization and assessment of courses; and the lack of feedback from the world of work (Republic of Mozambique 2001, 3.3).

In Zambia, public training institutions have perpetuated the occupational training curricula and certification schemes developed and introduced in the 1960s for a very different economy. The system is characterized by centrally developed curricula and rigid, institution-based training with little or no adaptation to local needs (World Bank 2001, p. 94).

TVET in francophone Africa has suffered from obsolescence, insularity, and improper orientation. The French model was excessively school based and detached from the world of work. This pervasive and inward-looking school model has ignored real labor market conditions. These difficulties originate, at least in part, in the common mold constituted by the French models of the 1960s and 1970s. "Today, while they have mostly disappeared in France, this birthmark is still highly visible in French-speaking Africa, and has been the cause of a great deal of rigidity, slowing the capacity of institutions to respond to economic requirements" (Atchoarena and Delluc 2001, p. 165). 
The curriculum followed the French shift in the early 1970s to a model with less emphasis on vocational subjects. The vocational schools ended up "poor cousins" to the academic secondary schools, and students used them to prepare for higher education. Vocational preparation was weakened and sacrificed to make more space for academic subjects. France reversed course and added vocational depth to its home institutions later, but this was not done in francophone African countries, which continued with the earlier models. Thus, access to higher education became the tail that wagged the curriculum dog. This was unfortunate, given the low rate of transfer to higher education. The majority did not proceed to higher education and was inadequately prepared with occupational training.

One of the most obvious deficiencies of the TVE systems in francophone countries is their neglect of the informal sector. Modeled on the school system, they have not taken into account traditional apprenticeship.

Two factors help explain the tendency of TVET institutions to become supply driven: expensive plant and specialized staff. TVET, properly done, requires adequate buildings and often costly equipment. Investment in the necessary facilities and equipment carries with it an inherent tendency toward rigidity. Large and dedicated investments in industrial and construction trades, given limited resources, constrain the introduction of new training courses in response to market changes. Managers of training institutions naturally want to use available facilities and may continue training in the same fields year in and year out, without adequate feedback, beyond the absorptive capacity of the market. In addition, specialized training staffs tend to be hired on long-term or permanent contracts and cannot easily teach new trades.

Centrally determined examinations have reinforced the isolation of formal TVET from labor market requirements in francophone and anglophone countries. Isolation is not the fault of the examinations themselves, but the exams have become outdated and poorly correlated with market demands. Most curricula in Mozambique were conceived 20 years ago and are oriented nearly exclusively to the modern wage sector, where job growth has been stagnant (Republic of Mozambique 2001). Training for central examinations also makes the application of curricula inflexible at the local level. It is difficult to adapt the training content to local labor market needs if those needs are not reflected in the central examination.

Experiences in the World Bank's Ghana project point to the difficulty of reorienting traditional vocational training institutes to short, competencybased training, especially if they are closely linked to long-established examinations and certificate systems (Johanson 2002, part II, p. 12). In Tanzania, until recently, the centrally administered trade testing system has not corresponded to the needs of the world of work (Haan 2001, p. 76). In Uganda, adherence to centralized curricula seriously hampers the flexibility of training providers to adjust their courses to developments in the economy and changes in the labor market (Haan 2001, p. 114). 
TVET in Zambia similarly tends to be certificate-led instead of employment-led (Haan 2001, p. 122). The central control of curriculum development in Kenya has inhibited a close relationship between industry and vocational training institutes (Haan 2001, p. 51). In South Africa, technical colleges are in a "Catch-22" situation. They seek to be responsive to industry but are tied to national curricula that have not evolved with industry. Ironically, most employers pay little attention to a prospective employee's certificates but insist on seeing evidence of competencies and skills.

Tracer studies, where they are available, provide evidence of the ease or difficulty of absorbing TVET graduates into wage employment. Generally, TVET systems lack statistics about the destination of their graduates. Posttraining impact is not often tracked through tracer studies. However, some studies do exist. Although some show relatively good employment rates, others indicate major problems of absorption. Of those attending Vocational Education and Training Authority (VETA) training centers in Tanzania in 1996, reportedly only 14 percent found work upon completing their training (Fluitman 2001, p. 13). ${ }^{3}$ In Mali, a tracer study in two regions in 1996 showed that the employment rate of technical school graduates was just 44 percent three years after graduation. In Madagascar, according to a 1997 survey, only 45 percent of the former TVE students had found a stable job a year after leaving the training system in Antananarivo.

The assessment of TVET's external efficiency depends heavily on the country economic context. Not surprisingly, other studies report better results. A 1990 study of artisan training in Zimbabwe reported very low unemployment (less than 7 percent) among craft apprentice graduates, while another study showed 29 percent unemployment for artisans with school-based training. In Mozambique's rapidly growing economy, a recent survey showed an 83 percent employment rate in the modern sector for graduates of public VET institutions who sought work (about half the graduates continued their studies). Of those employed, about 40 percent were absorbed by the public administration and parastatal organizations. The higher the VET qualifications, the easier it was for graduates to access wage employment (Republic of Mozambique 2003).

In many countries, the civil service has been a major employer of VET graduates. In the mid-1980s, half of all holders of vocational training certificates in Mali were employed by the public sector. An International Institute for Educational Planning (IIEP) tracer study in Eritrea in 1997 showed a 90 percent employment rate among the half of technical school graduates who did not continue their studies. The other half of the graduates proceeded to university with no clear use later for their expensively acquired skills (World Bank 2002, p. 53). Moreover, of those terminating their studies and finding employment, 72 percent found work in the public sector. However, the downsizing of public sector employment through structural adjustment has reduced or eliminated public service as a channel for vocational training graduates in many countries. 


\section{Equity}

Equitable access to skills development, an aspect of social relevance, is a critical problem in much of Sub-Saharan Africa. Gender equity is a particular issue. Young women are seriously underrepresented in technical and vocational education, as in all other subsectors of the education system. Gender inequality of access to TVET reflects a gender-biased division of labor. Girls who enter TVET tend to choose occupational streams that lead to the jobs typically occupied by women such as hairdressing, secretarial work, health care, hotel work, garment manufacture, and home economics. Specialties geared to the industrial sector (mechanics, electrical, and civil engineering) are traditionally reserved for young men. Young women make up less than 15 percent of TVE enrollments in Niger, Ethiopia, Uganda, Eritrea, Malawi, and Namibia-countries that have relatively low secondary enrollments in the first place. In other countries, including Benin, Mauritania, Mozambique, Botswana, Chad, and Guinea, the proportion of women in TVET was between 30 and 35 percent. The generally lower levels of educational attainment and literacy, and the lack of access to skills development restrict women to low-skilled occupations.

Inequity also comes in economic and geographical forms. In Mali, large socioeconomic inequalities exist in access to training. Farmers' children are highly disadvantaged. Most TVET facilities are also concentrated around the capital. These imbalances in the supply of training favor the modern tertiary sector to the detriment of agriculture or the informal sector. Zambia's past emphasis on training for formal sector employment has excluded many individuals from poor socioeconomic and low educational backgrounds (World Bank 2001, p. 10).

\section{Quality}

As defined here, quality is a measure of a system's effectiveness in meeting its teaching objectives: imparting knowledge and skills to students (figure 3.2b). Throughout the Sub-Saharan Africa region, the quality of TVET has suffered as severe decapitalization has occurred in public training systems.

Budget cuts have curtailed investments, so facilities and equipment have become outdated. The decay in public provision of training is evident in the lack of equipment for information technology courses and automotive workshops in Kenya. It is also evident in the lack of maintenance in other workshops such as plumbing, construction, and carpentry. The National Industrial Vocational Training Center (NIVTC), in the heart of the largest industrial area in Eastern Africa, is a shadow of its former self. The machines in many of the workshops date to the 1970s. There has been no replenishment and little refurbishment (Grierson 2002, pp. 8, 20).

Recurrent budget reductions have affected the qualifications, pay, and motivation of teaching staff (Haan 2001, p. 175; World Bank 2001, p. 8). Many governments now restrict their financing to staff salaries, leaving 
Figure 3.2b. Quality (Effectiveness)

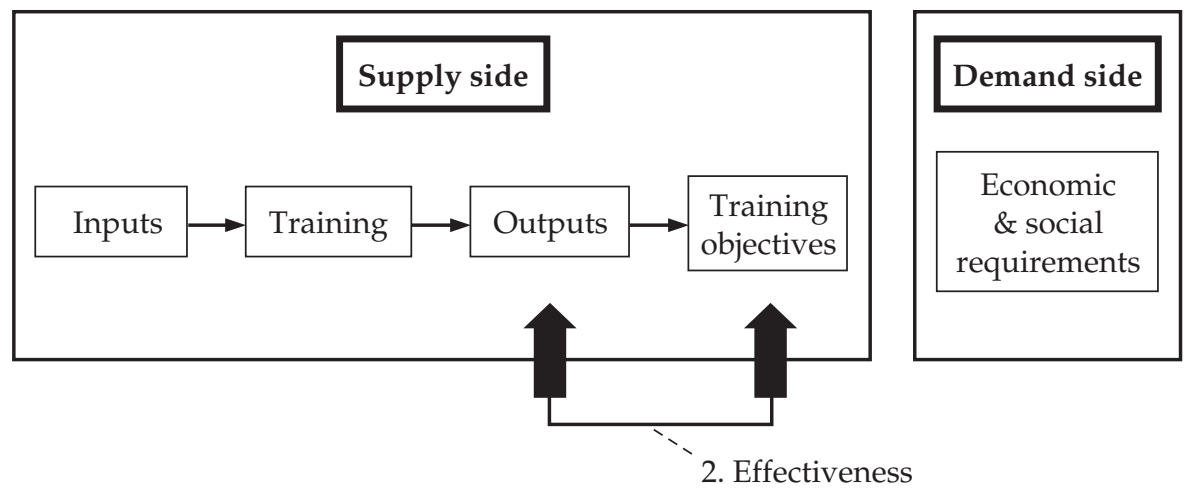

nothing for consumable supplies and maintenance of facilities. This has had disastrous effects on the quality of skills acquired-high-quality skills require workshop equipment, supplies, and practice. Tanzania suffers from a lack of basic equipment, qualified staff, and financial means for effective training delivery (Haan 2001, p. 74). In Uganda, training is mainly theoretical, facilities are largely inadequate, and qualified instructors are lacking (Haan 2001, p. 98). In Mozambique overcrowding is a problem, with 55 trainees per classroom in the first year and adequate workshops and practical facilities in only 20 percent of the public training institutions (Republic of Mozambique 2001, 3.3). Budget reductions make it more difficult to change and upgrade training programs.

The lack of qualified instructors who have experience in enterprises is a chronic failure of most public training systems. In Mozambique most teachers have low qualifications and lack company-based experience in the subjects they teach. In addition, they are subject to poor working conditions, low salaries, and limited chances for upward mobility. Well-qualified instructors in industrial subjects command a premium in the labor market. Civil service pay scales are typically insufficient to attract or retain the best instructors. Existing forms of instructor training also leave much to be desired. Instructor training institutions, where they exist, lack a clear mandate and mission. Instructors need firsthand industrial experience but in most cases have had little or no contact with the workplace or with new technologies. Opportunities for industrial experience and work experience in enterprises are rare, as are opportunities for in-service training (in Madagascar, Centre de Ressources des Personnels des Etablissements d'Enseignement Technique et Professionnel [CERES] is an exception in this regard). Such experience is important to compensate for the overly academic training of teachers and to enable them to meet professional requirements in enterprises. Industrial attachments for teaching staff represent an appropriate response to this problem. 
Figure 3.2c. Internal Efficiency

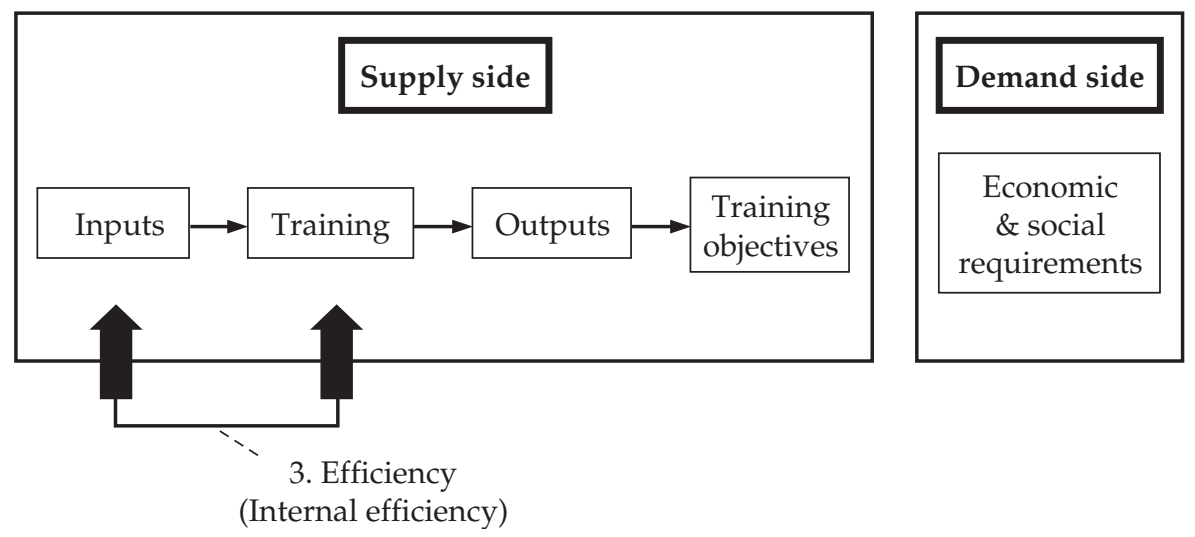

The quality of training can vary sharply within public training systems. Grading exercises in Zambia and Tanzania have shown that some public institutions do not even meet minimum standards. In Zambia no public institution received the top rating of " 1 " in an evaluation of training institutions, and one public institution was even forced to stop training until it raised its standards. Variations in quality reflect in part the different histories of institutions and variations in previous support they received.

\section{Internal Efficiency}

Internal efficiency refers to the relationship of inputs (time and money) and outputs (graduates prepared to fill jobs) (figure 3.2c). The focus on what happens in the training process is described as internal efficiency while the focus on what happens to the outputs of the training process is defined as external efficiency.

The flow of trainees through the training system is an indication of the internal efficiency of the system. In Mozambique, at the basic vocational level, dropouts average 20 percent per year and failures another 30 percent. Only 22 percent of entrants complete the course in the planned three years. This is a measure of internal inefficiencies in the system (Republic of Mozambique 2001, 3.3).

TVET does not absorb a major share of spending on education and training in most countries-from 0.5 percent in Ethiopia to 12.7 percent in Gabon. In Mali, where TVE makes up one-third of secondary enrollments, TVE absorbs 10 percent of total education expenditures with less than 3 percent of the total number of students. TVET is expensive on a per student basis relative to general secondary education. Ratios of TVE spending per student to that of general secondary education range from 0.8 in Togo to 13.8 in Mozambique. At the high end, Gabon spent \$1,820 per TVE student 
in 1992. In Madagascar, vocational training centers cost 60 percent more per student than technical lycées, 4 times more than general lycées, and 18 times more than primary schools.

Smaller class sizes and higher expenditures on equipment and facilities account for the higher unit costs of TVET, but underutilization also contributes. In Madagascar, high unit costs of vocational centers are explained by the relatively few students and the underutilization of facilities. In Senegal, facilities are rarely occupied fully, owing to the intensity of the selection procedures. The mode of training can lead to a high cost structure. Most training tends to be center-based and delivered in long courses with fixed entry points. Ghana and Zambia exemplify this type of training.

Vocational training institutions have maintained their high cost structure in the face of shrinking public budgets for training. As a result, public financing is being gradually reduced to cover only the cost of staff salaries. Many countries are experiencing alarming dropout rates from vocational training, in part for financial reasons (students' inability to pay or to continue paying fees). This, in turn, leads to a downward spiral of utilization of installed training capacity (Haan 2001, p. 87). Center-based modes of training, lengthy course duration, and high dropout rates together raise the costs per graduate. Higher costs compel a search for greater efficiency in expenditures on TVET.

An official document in Kenya, criticizing TVET, could be a summary of the overall analysis of the state of TVET in Sub-Saharan Africa (see box 3.1).

\section{Making Reforms Work}

Can public training systems be reformed? There is no simple answer to this question. The history of vocational training reform is littered with failures, including World Bank projects in the 1990s. At least four World Bank projects (in Madagascar, Togo, Kenya, and Ghana) were intended to reform formal training systems to make them more responsive to the labor market, especially to the informal sector. Each one failed (Johanson 2002). Madagascar failed to take into account parents' incentives to use the Lycées Technique as avenues for access to universities and staff resistance to the Lycées Technique becoming terminal institutions (that is, schools that give the last formal training to students before their entry into the labor market). In Kenya and Ghana, training institutions fought their conversion to support the informal sector tooth and nail. Existing vocational schools may be too expensive, too rigid, and too sophisticated to be deployed in the informal sector. The staff, management, and trainers may fight this shift, as it is perceived as a loss of status.

\section{Innovations in Management}

Reforms and innovations have taken root in some settings, and the experience is worth examining. 


\section{Box 3.1. Kenya: Evaluation of Public TVET}

In an internal analysis, Kenya's Ministry of Labour and Vocational Training concluded that all is not well in the training sector. It summarized the main problems as

- Low success rate of external examinations

- Declining student enrollment in particular traditional courses/trades

- Widespread lack of tuition materials such as textbooks and workshop materials

- Limited opportunities to gain meaningful exposure to work through temporary industrial work attachments

- Growing unemployment among graduates of technical training institutions

- Growing burden of fee payments shouldered by parents

- Poor conditions of equipment and physical facilities

- Growing debt burden in many training institutions

- Low frequency of and poor attendance at VTC board meetings, despite growing expenditure on salaries for the board of governors staff.

It said that various external forces should not be used to excuse the dismal performance, but the complacency and general lack of preparedness in the management of technical and vocational training programs should be recognized.

Source: Haan 2001, p. 67.

POLICY A new policy agenda has emerged in Sub-Saharan Africa, largely influenced by the sharp critique from all quarters of state-sponsored TVET systems in Africa. The new approach to rationalizing the role of the public sector in training (see chapter 1) is built upon the principles of reduced public involvement in provision, partnership in governance, increased reliance on market mechanisms for greater relevance, and efficiency. However, differences exist regarding the precise policy mix and priority given to various objectives. Anglophone countries have adopted more "radical" lines of intervention than their francophone counterparts, including levy systems, attention to the informal sector, entrepreneurship, and new national qualifications frameworks (NQFs). Ministers in francophone countries have also adopted a set of forward-looking principles to guide TVET reforms (the CONFEMEN framework, described in box 3.2).

The CONFEMEN framework offers a comprehensive and challenging agenda for reforming TVET systems. The principles are remarkably well targeted to current weaknesses in skills development. However, little has been done yet to implement these policies. The overhaul of training systems is not under way because of institutional and political inertia. Responsibility for the implementation of TVE reforms has been given to existing supervisory bodies. Success will depend, in large part, on the institutional capacity of these bodies, which is often limited. 


\section{Box 3.2. CONFEMEN Conference on TVET in Bamako, 1998}

The "Conférence des Ministres de l'Education des pays ayant le français en partage" brought those in charge of education and training together with their economic partners for a close look at the topic of integrating young people into working life through vocational and technical training (VTT). The conference focused on the school-to-work transition through closer links to the real socioeconomic situation of the countries of Sub-Saharan Africa, particularly the French-speaking countries. Participants agreed that the overhaul of vocational and technical training should be based on the following guiding principles:

\section{Anchoring vocational and technical training in the new "basic school"}

- A supply of VTT for basic qualification levels (workers, skilled workers, middle management) that focuses less on specialization and more on broad-based skill acquisition

- Access to VTT at all levels of qualification

- New pathways for training.

Strengthening the links between VTT and local, regional, and national socioeconomic conditions

- Involving all VTT stakeholders in both formal and informal sectors

- Promoting contacts and cooperation between the managers of the education system and the working world

- Involving industry in needs analysis, definition of trades, and curriculum development and certification

- Involving the community and local stakeholders in local development projects

- Inducing training institutions to participate actively in these projects by allowing use of their facilities, producing goods, and providing services.

continued

SYSTEM MANAGEMENT Management of TVET is typically shared by various government bodies. TVET is usually the responsibility of a government ministry. Several francophone countries have separate ministries for vocational training (Benin, Côte d'Ivoire, Madagascar, Senegal, and Togo). Ministries of labor are responsible for training outside the school system.

Such diverse management accountabilities make training delivery complex, lead to duplication of efforts (especially when training providers operate with little or no coordination), do not permit mutual recognition of credentials, and generate segmentation of the training supply. The administrative bifurcation does not facilitate the emergence of policies on a joint approach to the relationship between training and employment. The coexistence of various ministries sharing supervision of TVET has undermined the coherence of the system. 


\section{Box 3.2. (continued)}

Increasing and diversifying supply and designing flexible programs centered on skill acquisition

- Better information on the nature of the labor market

- Analysis of formal and informal sector demand for labor.

Diversifying the sources of financing

- Including the contribution of the private sector

- Instituting, for example, a training fund financed by apprenticeship tax payments.

Overhauling the governance of TVET by setting up partnerships geared to the state's redefined role

- Bringing training sites closer to production sites

- Decentralizing authority and the management of training institutions

- Giving more responsibility to local communities

- Giving more autonomy to institutions.

Developing an entrepreneurial spirit that can lead to self-employment

- Introducing entrepreneurial training in VTT programs

- Fostering the emergence of young entrepreneurs

- Helping integrate and maintain entrepreneurs in the working world.

Source: CONFEMEN, cited in Atchoarena and Delluc 2001, pp. 44-46, 118, 122.

More important, the accountability of TVET to one or more government ministries often results in the provision of training that is largely isolated from market forces, subject to centralized curriculum decisions that change only slowly, and circumscribed by limited institutional autonomy. African ministries have long managed TVET without entering into a particular relationship with the economic environment and the world of work (Ziderman 2003, p. 35).

A clear trend exists toward establishing national coordinating or consultative bodies in anglophone countries. This is quite different from the pattern in francophone Sub-Saharan Africa, where ministry-based governance systems remain in place, although new bodies such as training funds and observatories are emerging.

The establishment of national consultative bodies reflects new thinking in public policy, advocating partnership as a key principle for increasing effectiveness and accountability in public management. Partnership promises to achieve a high degree of efficiency in the use of public money by making vocational education and training (VET) more responsive to employment. Partnership may seem to have limited application to the leastdeveloped economies, but it can be applied beyond the limits of the modern economy, as exemplified by the National Federation of Malian Craftsmen. 
This new trend in governance takes the form of coordinating councils, national training boards, and national training authorities (NTAs). Examples include the VETA in Tanzania, the Industrial Vocational Training Board (IVTB) in Mauritius, the National Council for Vocational Education and Training (NACVET) in Ghana, the National Skills Authority (NSA) in South Africa, and the Technical Education and Vocational Education and Training Authority (TEVETA) in Zambia and Malawi. In addition, a National Training Council is proposed for Mozambique, a TVET Board for Eritrea, and a Training Authority for Botswana.

Training boards have met with mixed results. One type of board is the committee or council that operates only in an advisory capacity. In Ghana, attempts to set up a national overseer body for training in 1990 led to the establishment of the NACVET, a largely advisory body within the Ministry of Education that does not have separate legal status. A recent World Bank project completion report found that the NACVET still lacked legal authority over the actors in the field more than a decade after its establishment. In Kenya, the National Industrial Training Council is purely advisory and has little real impact. It has presided over an ongoing deterioration in public provision of training. Following a controversial start, the new NSA in South Africa has been allocated a purely advisory role (Ziderman 2003, p. 76).

Other training organizations (for example, the IVTB in Mauritius and TEVETA in Zambia) have legal authority over resources and policy formulation. The autonomy of these coordinating bodies also helps preserve their pluralism. Structuring the relationship between the training system, employers, and unions constitutes a major feature of NTAs. The specific arrangements reflect a different balance of power among the stakeholders. Most countries are now trying to expand the role of employers. The NTAs may be funded by training levies. NTAs often play a role in the central coordination and planning of the national training system, in developing training policy, and in supervising national skills testing and certification, as well as in providing necessary information services and developing appropriate labor market signals. Independence from close ministerial control and strong representation of employers on managing boards can forge strong industrial links, promote flexibility and responsiveness, and foster private training (Ziderman 2003, p. 68).

The performance of training boards and authorities remains to be assessed. A DANIDA evaluation of its assistance to training authorities in Tanzania and Zambia pointed to the complexities and difficulties involved in establishing NTAs. Enabling legislation was delayed in Zambia and it was difficult to "create a new organizational culture" in Tanzania. DANIDA indicated that the new national training bodies were a considerable improvement over the purely advisory boards that they replaced; however, most did not function as effectively as envisaged. Employer representation was limited in Tanzania and sustainable financing is not assured in Zambia (DANIDA 2002, pp. 10, 41-42). As indicated in the Bank review of its lending, a key issue has been the difficulty of maintaining political commitments 
to reforms under rapidly changing political circumstances, including frequent changes of ministers (Johanson 2002).

Two lessons can be derived in terms of authority and representation:

1. NTAs must be vested with real authority. Too often these bodies lack teeth and are essentially consultative to the relevant minister (Ziderman 2003, p. 79). Such organizations, despite their value, do not radically improve matters unless they can make decisions and control the allocation of resources.

2. Balanced representation is critical to the success of NTAs, especially the weight of employers in governing bodies. In Tanzania, only 2 employers sit on the 11-member VETA Board. In Madagascar, the Conseil National de la Formation Technique Professionnelle (CNFTP) has an employer majority (10 of 12 seats). In Côte d'Ivoire and Zambia, employers represent one-third of the members. In the IVTB in Mauritius, the private sector (employers) has a 50 percent share in governance. Unless employers are given sufficient power in the decisionmaking process, training may not be adjusted to serve the skills needs of the business community. In addition, it is important that employer representatives have close and frequent contact with their membership. Bureaucrats in employer organizations do not ascertain labor trends in industry automatically. The experience of other countries shows that balanced representation is critical to the success of national training strategies (see box 3.3). (See also training funds in chapter 7.)

INSTITUTIONAL MANAGEMENT An emerging consensus favors increased autonomy for training establishments. Devolution of authority means letting the training institutions administer themselves and keep the funds they raise through fees and production, thus forcing them to find their own markets. This breaks the long decisionmaking circuits in centralized systems that militate against dynamic relations with the labor market and beneficiaries at the institution level. Relationships between training centers and enterprises are easier to promote at the local level. This readjustment of local supply and demand can come about only through institutional flexibility and local initiative.

Setting fees is one important element of local institutional autonomy. Local initiative in the imposition of user fees can lead to a more dynamic, even aggressive, approach to exploiting local markets. In this way, institutional fee policy becomes a tool for moving the training system toward open, demand-oriented training (Ziderman 2003, p. 114).

Delegation of responsibilities from central to institutional authorities is being tried in a number of countries. In Ghana, TVET policy focuses on the management and autonomy of training institutions to improve market responsiveness, including the implementation of tracer studies, a monitoring mechanism that at present is essentially absent from the sector. With World Bank assistance in the 1990s, Madagascar and Mauritania implemented projects that helped build institutional autonomy, with some good results 


\section{Box 3.3. Employer-Owned and -Managed Training in Brazil}

Experiences in Brazil, one of the earliest countries to adopt levy-financed training authorities, underscore the importance of ownership and employer participation. The chronic gulf between supply and demand is bridged by giving full control of training to its users. The National Industrial Apprenticeship Service (Serviço Nacional de Aprendizage Industrial [SENAI]) was created in the 1940s and operates under the ownership of the Federation of Industries. SENAI was followed by four other sector-specific services aimed at, respectively, commerce (SENAC), rural areas (SENAR), small enterprises (SEBRAE), and transport (SENAT). All the institutions operate under the same basic structure and legal framework. The industries tax themselves to fund their training programs. A 1 percent levy on the payroll funds the training operations, and the chambers of employers run the institutions with full independence and under private sector statutes. All five institutions have evolved in separate directions. SENAI maintains a network of 500 training institutions and trains 2 million workers a year. SENAR and SEBRAE were first created as government bureaucracies, but this led to inefficiencies, lack of responsiveness and flexibility, and political spoils. They were recreated more recently with ownership, management, and budgets given to the respective employer associations. Because training markets had already been developed in the country, both SENAR and SEBRAE opted to buy training in the market rather than to establish their own training institutions. SENAT, the most recent offshoot of SENAI, with the same rules and legal framework, took an entirely different path for delivery of training. It created an extensive network for training via satellite for more than 1,000 firms throughout the country.

Source: Castro 2000.

(Johanson 2002, part I, p. 19). Substantial autonomy was granted more recently to training institutions in Zambia to improve their capacity to respond to local labor market needs (box 3.4). It is important to note that this decentralization occurred within the context of a government-wide reform shifting more authority from the central to the lower levels of government.

Central authorities typically resist allowing the directors of local training institutions to decide which courses to offer in their official program. Getting the freedom to make these decisions may be an uphill battle. A partial devolution of authority can be more palatable in these cases: allowing training centers the right to buy, sell, pay, and receive in order to offer courses that are not part of the official programs and budgets. The directors of training centers are close to the market and know local demand. To sell courses and short training programs, they must be able to hire temporary labor, give extra pay for extra work, pay bills, purchase materials, and sign contracts for the programs. In many training centers, however, this is not possible.

Autonomy is not a panacea; it can be fraught with problems. The Botswana Brigades provide a cautionary tale. The Brigades are owned by 


\section{Box 3.4. Zambia: Granting Autonomy to Public Training Institutions}

The government of Zambia is changing the role it plays in training-from provider of training to financier, regulator, and coordinator. As part of the reform, the government has transferred the control of 21 public training institutions to autonomous Management Boards. This decentralization was done in parallel with broader central government devolution of authority to local authorities. The new Management Boards are responsible for curriculum decisions, for ensuring the maintenance of training standards prescribed by the Technical Education and Vocational Education and Training Authority (TEVETA), for administering the affairs of the institution including the finances, and for providing such services as needed. Letters of appointment to the boards were issued in early 2000. All staff members of the public training institutions were removed from the government payroll from January 1, 2000, and received their termination benefits from the government during 2000. However, over a 2- to 3-year period, the government agreed to continue to pay the salaries of staff members who opted to continue working under the autonomous Management Boards. After this period ends, previously public training institutions will have to compete for finance on the basis of quality, cost-effectiveness, and responsiveness to demand. The government considered two basic options on how to implement the devolution of authority: gradually, with expansion of autonomy over several years, or quickly, with the stroke of a pen. In the end the government decided to devolve authority quickly in order to avoid the resistance of vested interests.

Source: TEVETA; World Bank 2001, p. 11.

communities and managed through boards of trustees. Mismanagement in the running of the boards' affairs is persistent, mostly due to lax control by the boards. This is taken to reflect one of the limitations of communitybased initiatives. Kenya is another case in point. The debts accumulated by training institutions reflect the scope, but also some of the limits, of institutional financial autonomy.

As the DANIDA review observed, decentralization has proven to be far more complex and protracted than originally envisaged (DANIDA 2002, p. 42). Any movement toward institutional autonomy has to be carefully planned. It should include development of appropriate management capacity, new accounting systems, and training for board members. Limits may have to be placed on autonomy, particularly the freedom to borrow funds and pledge assets.

\section{Innovations in Service Delivery}

Five innovations are reviewed, with the goal of improving training delivery: dual modes of training, training for competencies, competency-based training, expanded training services, and distance teaching. 
DuAl Modes of Training Most African countries have little experience with dual forms of training (alternance), except for Botswana, South Africa, Zimbabwe, and Namibia. Some countries, including Côte d'Ivoire, Kenya, Congo, and Togo, are developing dual training, often with Swiss and German assistance. Dual training has been demonstrated in Germanspeaking countries in Europe to be an effective means of familiarizing trainees early with the conditions of the work environment. However, the implementation of dual training programs is subject to several difficulties. First and foremost, local enterprises must be willing to provide training and consider it a long-term investment in human resource development. This is akin to Becker's (1964) "general skills training," as described in chapter 1. Second, careful organization, in-company practical training, and supervision are also required. These conditions hardly apply in most of SubSaharan Africa. The lack of an industrial fabric in the Sub-Saharan Africa countries is a major obstacle to the development of dual training. Moreover, dual training systems are not cheap and would probably end up costing a higher proportion of per capita GNP than in industrial countries.

In Côte d'Ivoire, German assistance is being provided for dual training. It is too early to tell about outcomes, but local enterprises initially were unprepared for this form of collaboration. Contacts with enterprises have been more productive when they are part of a policy of opening up the training centers; for example, where the centers offer modules of continuing education. In other countries, dual training schemes have been found insufficient to link technical and vocational education delivery with employers and to ensure the relevance of training in a context of depressed labor markets (Ghana, Kenya, Zimbabwe, and probably South Africa).

TRAINING FOR COMPETENCIES Another class of innovations pertains to occupational standards, testing, and certification, based usually on concepts drawn from industrial countries. The setting and measurement of occupational standards simplifies the enforcement of training contracts, as suggested by Acemoglu and Pischke (1999, p. F119). To what extent are these concepts relevant to developing countries, with less complex economies?

Some countries are moving away from formal examinations to a process of continuous assessment of specific competencies gained. The main form in which this trend manifests itself is the development of national qualification frameworks (NQFs). First developed in the United Kingdom, Australia, and New Zealand, the concept and the principles of NQFs are being adopted and implemented in an increasing number of countries, including sub-Saharan countries in West Africa (for example, Ghana), southern Africa (for example, Botswana, Namibia, South Africa) and in the Indian Ocean (Mauritius). NQFs are seen increasingly in anglophone Sub-Saharan Africa as important instruments to reform TVE. The policy convergence applies particularly to the Southern Africa Development Community (SADC), where 
NQFs are viewed as an important element in increasing labor competitiveness and mobility in the subregion.

NQFs promise several advantages. They can stimulate individuals to continue their education and training by establishing specific, clear steps on the ladder to increased qualifications (and incomes). They can lead to cost-effective training by focusing on outcomes regardless of how the skills are obtained-in classrooms or out of school. They can also support efforts to level the conditions under which private and public institutions compete for public funds. NQFs stress the competencies acquired, not the avenues or ownership of the institutions that teach the skills. South Africa is using occupational standards and certification as a means of equalizing opportunities for black Africans (who have received mostly on-the-job training) and white Africans who have benefited from formal training. The stated NQF objective is "to accelerate the redress of past unfair discrimination in education, training and employment opportunities" (Atchoarena and Delluc 2001, p. 255). NQFs can also promote job mobility and therefore increase labor market efficiency.

NQFs reflect a conceptual shift from the classical focus on the input process to a more modern focus on outputs and toward adherence to a market-oriented policy agenda. Because implementation of NQFs is just beginning, there is little empirically based knowledge about results. Neither is implementation complete in the countries in which they originated-the United Kingdom and Australia. The NQF system has been criticized in the United Kingdom as possibly contributing to deskilling because of a narrowly defined concept of competencies, based on the performance of elementary tasks rather than on a wider range of comprehensive skills and knowledge.

The application of NQF models from the United Kingdom and Australia in other development contexts may be problematic because of the different and much weaker educational, economic, and institutional environments. NQFs are based on the assumption that the primary responsibility for training must rest with individuals instead of governments, which may not be relevant for countries with low enrollments. NQFs may not be relevant where the main problem is insufficient access to skills rather than inadequate quality of assessment. Moreover, little is known about the costs of developing or maintaining qualification criteria and assessment and certification procedures or about their impact.

The South African experience has been a complex, bureaucratic, and slow process. The government's Report of the Study Team on the Implementation of the National Qualifications Framework (April 2002) stated, "The architecture of the $\mathrm{NQF}$, embracing policies, regulations, procedures, structures, and languages, is experienced as unduly complex, confusing, time consuming, and unsustainable. Concerns with the architecture were linked to uncertainty over the respective responsibilities of various departments and organizations, and a perception among many stakeholders of a lack of leadership at all levels. ... The proliferation of bodies responsible for standards setting and quality assurance was strongly criticized (in submissions). . . A Absence of strategic 
leadership and coordination . . . is compounded by inadequate funding from state resources. ... The overall perception is that the implementation of the NQF has been unnecessarily slow" (pp. i, ii).

The success of any reform depends on interrelations between design complexity and implementing capacity. The relative slowness in implementing some of the interventions during the South Africa reform may be due to weak institutional implementing capacity relative to the high level of complexity. In short, NQFs may end up imposing more regulations on training providers that could reduce their responsiveness to demand.

The Ghanaian system of NQFs is outlined in box 3.5.

COMPETENCY-BASED TRAINING A more realistic objective may be the establishment of competency-based training systems. Competency-based training shifts the emphasis from what courses a trainee has taken and for how long, to what the trainee can do. Competency-based training is usually modular and, in theory, facilitates flexible entry and exit points and recognizes different routes for skills acquisition (Nell, Shapiro, and Grunwald 2002 , p. 39). It is well suited to use in training contracts. Zambia and Tanzania, among others, have introduced competency-based training. Implementation is complex and must include the development of standards based on job analysis, the preparation of new modular curricula, and the design of assessment methods and new performance tests. The value of competencybased training is that it focuses on the skills needed for performance in a job, and it places pressure on instructors and center management to deliver these skills. It can lead to a reduction in training duration as well as greater flexibility. One of the lessons of implementation from Tanzania is the need to involve employers in the process and to publicize the concepts widely so that they are understood by enterprises, parents, and trainees (VETA 2002).

EXPANDED TRAINING SERVICES Another innovation, particularly in francophone Africa, has been the expansion of different types of training through public institutions, adding continuing education or job-related vocational training as a paid service to formal TVE offerings. Evening classes or second shifts are started for regular students recruited on a feepaying basis in public institutions. Several institutions in Senegal have done this. Practical continuing training can have a positive backwash effect on the regular school curriculum, to the extent that instructors are involved in workplace environments. To expand service offerings, particularly to new and different types, institutions have to adopt new teaching methods and will probably also have to make organizational changes.

Senegal's evening classes respond to social demand and not to market requirements. There is no hard evidence available at this time of their impact on employment. In Mali, the creation of the Units for Training and Support to Enterprises (UFAE) is one of the most advanced examples of the introduction of continuing education. ${ }^{4}$ Sustainability of the UFAEs remains 


\section{Box 3.5. Plans for the Ghanaian National Qualifications Framework}

TVE in Ghana is characterized by a multiplicity of testing and certification systems. Standards vary and equivalencies are difficult to establish. Testing and certification systems emphasize written examinations and practical skills are not adequately assessed. Certificates and diplomas do not ensure competence. Unlike the academic education track, the vocational education track does not have a coherent hierarchy of qualifications that facilitates articulation and access to further education and training. Learners are trapped in vocations that do not offer opportunities for higher qualifications and lifelong learning. A national qualification framework (NQF) is therefore being planned to achieve the following objectives: to bring all post-basic occupation-oriented qualifications into a unified framework; to facilitate access to further education and training for individuals in vocational and technical occupations; to improve product and service quality by ensuring uniform standards of practice in the trades and professions; and to promote and facilitate access to lifelong learning for all, especially operators in the informal sector of the economy.

The qualification framework consists of a single hierarchy of qualifications nationally recognized for employment and further education purposes. Seven levels of qualifications are suggested. There is no fixed entry point; the entry point will depend on prior learning.

Mechanisms establishing the framework include legislation to establish a single NQF for TVET and deregulation of assessment and certification (within the national framework). A Ghana National Qualification Authority would be responsible for quality assurance through accreditation, registration, and moderation of training providers. The authority will form specific Industry Training Quality Assurance Boards to perform quality assurance functions. Industrial Advisory Training Boards, in collaboration with the Ghana National Qualification Authority, will determine the levels applicable to the trade, industry, or profession. The skills that industry groups and employers want and the performance standards they expect will be the foundation of the qualification framework. Accordingly, trade and industry boards will be formed to determine competencies and performance standards.

Training delivery, assessment, and certification will be deregulated within the national qualification framework. There will be no fixed national schedules apart from estimated hours for coverage of specific training modules. Training providers will be free to develop their own training schedules. The Ghana National Qualification Authority is responsible for ensuring that individuals who are awarded certificates in fact have the certified skills and knowledge.

Source: Atchoarena and Delluc 2001, pp. 252-54.

to be demonstrated, because fees do not cover their cost, and they have not yet contributed, in practice, to the improvement of initial training. Continuing education is attractive to struggling formal training institutions that are searching for new sources of revenue. The trend is expected to continue. Evaluations need to follow. 
DisTANCE TEACHING Information and communication technologies (ICTs) hold a vast potential for skills development. For example, videos are used to conduct technical training courses in several Latin American countries (as in Peru). Many other applications are possible; for example, training counseling over the Internet, posttraining business counseling by e-mail, and dissemination of technological and market information (Haan 2001, p. 183).

These examples raise the hope that Sub-Saharan Africa can leapfrog several stages in the development process to spread high-quality training widely at low cost. A paper prepared for this review, however, concluded that there is not much scope for the immediate use of ICT in vocational education and training on a large scale (Stevens 2001). Constraints imposed by lack of infrastructure, instructional content, and delivery systems are simply too great.

The availability of ICT may improve, however, if some currently planned, large-scale programs are implemented (the Regional Africa Satellite Communication Organization [RASCOM], the Worldspace Corporation, and the Africa Learning Channel). These will facilitate programming, mainly in health and general education, but also may permit some applications in TVET. The most likely new application of ICT would be in formal technical education, where existing correspondence programs form a base (for example, the Technology Enhanced Learning Initiative of Southern Africa [TELISA] of Technikon SA in South Africa). Training video discs, which are not excessively costly to produce and can be borrowed from more advanced countries, also offer some potential where electricity is reliable, video-disc players are affordable, and training sites are secure (Stevens 2001).

\section{Priorities and Policy Issues}

The role of the government in TVET, the importance of basic education, and the addition of occupational training to general education (referred to in chapter 1 in the modeling of training decisions) are all being discussed in Sub-Saharan Africa today.

\section{The Role of the Public Sector in Training}

Given the right incentives, state-sponsored training can compete effectively with other sources of skills development, but should it try to do so? Finding the right role for the public sector in training remains an important issue. The state has a vested interest in making sure skills bottlenecks are removed for economic development and that all citizens have access to skills training, just as they do for basic education. These goals can be achieved by statesponsored delivery of skills training and its financing or by a mixture of government and nongovernment provision and financing. No industrial economy today relies on the first of these options, simply because the state cannot afford the costs. 
The challenge is to find the right balance of government and nongovernmental provision and financing. Some rather clear roles for government emerge where ensuring equity of access to training is concerned and where markets fail to provide the right signals to guide training decisions. Encouraging cost recovery for training can improve the efficiency with which training resources are used but reduce access to training for those without a capacity to pay. (See chapter 7 .) The state has a clear role to promote equity in access and can use its financing in a targeted fashion to achieve this goal in state-sponsored and nongovernment sources of skills training.

Where markets fail to send the right signals to guide training decisions, governments can also justify financing interventions. The presence of social benefits to training that are not captured in increased earnings for the trainee or higher profits for the enterprise will lead to lower levels of private investment in skills development than needed from a social perspective. Targeting public financing to those who would invest in these skills can improve the performance of the market. The use of public financing in subsidies can also overcome other market imperfections, such as the lack of market information about the benefits and location of training, the absence of efficient capital markets for investment, or policies that promote wage compression for social equity and reduce the net benefits of training to individuals. Financing in these cases is really a second-best option to removing the imperfections directly.

There are many things the nongovernment sector does not or cannot do. ${ }^{5}$ These include developing policies and standards, preparing teaching materials, training instructors, and running standardized examinations of graduates. Here, the state's role is clear and positive.

State-sponsored provision of training can also be used to address equity and market failures, but it is not a necessary condition in an environment where nongovernment capacity for skills development exists. As chapter 4 will show, however, nongovernment capacity in training is uneven in its geographical and occupational coverage. Determining the role for the public sector in the provision of training therefore requires carefully assessing in each country - what the nongovernment sector is willing to do and whether, with appropriate incentives, it can be encouraged to fill training gaps. In environments of conflict marked by high risks to investment, such as those found in many African countries, financial incentives may not be enough to encourage the building of nongovernment capacity for skills development.

What kinds of skills might the public sector finance or public providers deliver? Every society has some activities that cannot be done without highly productive labor, industries and services that are strategic to development or to expansion of exports. Some areas have chronic maintenance problems that engender horrendous losses. Equipment breaks down; machines need repair. In these areas, it is critical to teach others the skills that current providers have not mastered. There are externalities connected with these skills that lead to high social costs if the skills are not developed. Those critical areas can be identified and public resources concentrated on them. 
As reflected in the assessment of public provision of training, no government today can afford to provide and finance all the skills needed by a modern economy. Faced with the importance of supporting basic education for all, choices must be made. Finding a balance in government and nongovernment provision and financing of skills is essential from a policy perspective. The highest priority for government is in getting the policies right to facilitate skills development that encourages each of the partners to pursue its comparative advantage in a market context. The balance in the partnership may vary from country to country given the economic context and will need to be informed by analysis of this context.

\section{The Importance of Basic Education}

African employers, like their counterparts the world over, want to recruit trainable workers. Whether a prospective employee already has vocational skills does not matter much to them. The few specialized skills needed in most entry-level jobs can be learned after employment. What employers want most are the basic academic skills taught in general education at the primary and secondary levels - the ability to communicate, calculate, follow directions, solve problems, learn on the job, and work in teams. This is why basic education is so important to the development of occupational skills. Many larger African employers prefer to recruit workers who have little previous training for shop floor jobs and put them through on-the-job training programs (see chapter 5). The pool of unskilled labor is so abundant that employers can easily choose applicants they can train.

Today's workers everywhere are assuming responsibility for decisions made on the job and for learning and using new skills. Desirable skills include a strong grounding in language and mathematics, but employers also look for the ability to solve semistructured problems in which hypotheses must be formed and tested; to work in groups; to communicate effectively, both orally and in writing; and, for higher end jobs, to use personal computers to carry out simple tasks like word processing (Murnane and Levy 1996). This list highlights changes in the nature of work and the importance of knowledge and skills in today's workplace. Basic education and the foundation for learning that it provides are essential to the alleviation of poverty.

Basic education is important not only because it represents what employers look for in recruiting, but also because it provides the essential foundation for acquisition of new occupational skills over the life cycle as technologies change. (See reference to Altonji and Spletzer [1991, p. 66] in chapter 1.) Efficient skills formation requires a solid educational base. Learning occupational skills is not a one-off exercise. Early investment in basic education and vocational skills helps launch the individual into the world of work. Basic education enables persons to become learners throughout their lives, to specialize and update themselves as economic opportunities and technology change. That is why investment in basic education is the most cost-effective use of public resources (Betcherman 2001). 
In Sub-Saharan Africa, many primary and secondary schools do a poor job of teaching the basic skills and provide too much useless information not related to the local context.

\section{Vocationalizing General Education}

Many parents and educational leaders in Sub-Saharan Africa are concerned because young people complete primary and secondary education without learning any occupational skills. The assumption is that occupational skills will ease the transition into work when they leave school. Consequently, some want to change the curriculum of general education by adding vocational skills useful in agriculture, business studies, or construction, for instance. Vocationalizing general education means adding some practical courses (for example, 5-9 hours per week) to an academic curriculum; it is not the same as providing VET in separate institutions or streams in parallel with academic education.

Such arguments have a long history of debate in education policy for Africa. The main reasoning behind such a policy is something like this: School-leavers need skills in the labor market to be productive and earn incomes. The general school curriculum does not provide sufficient occupational skills, and many graduates are unemployed. Therefore, the school curriculum should be changed to add vocational preparation so that graduates can function better in the labor market. Other rationales linked to using practical skills as a pedagogical tool have also played a part, especially among educators, but "economic relevance" has been at the core of the argument among policymakers.

Research has documented problems with the "economic relevance" case (Lauglo and Narman 1987; Middleton, Ziderman, and Adams 1993, pp. 50-51, 186-90; Psacharopoulous and Loxley 1985). An update of the literature on vocationalization with three case studies (Ghana, Kenya, and Botswana) was commissioned as part of this review (Lauglo and others 2002). The study found that not much empirical research has been done on the topic since the 1980s. It produced the following findings:

- Vocational subjects are desirable on general education grounds, as part of a well-rounded education intended for everyone, if they can be afforded and provided without detracting from efforts to improve quality in core subjects in the secondary school curriculum. The skills learned may also have private uses. But research has not borne out the labor market justifications for such subjects. So far, no study has shown that vocationalization that affects a minor proportion of the student's total curriculum-five class periods a week, or as much as one-third of the time in the instructional schedule-gives an advantage in finding work (let alone self-employment) within the first few years after leaving school, particularly under severely depressed labor market conditions for youth. Exposure to vocational subjects may enhance interest in the types of work for which these subjects 
are broadly preparatory; however, tracer studies have failed to show a positive impact on actual access to work after students leave school. Nor have they found any strong effect on access to relevant further technical training.

- Vocationalization is costly. Most vocationalization variants are more costly per student class period than mainstream general education subjects, primarily because of smaller classes and greater expense on facilities, equipment, and consumables. Unless a course can be taught to a full class of students (few can), operating costs will be more than twice that of nonlaboratory academic subjects.

- Enrollment in some types of vocational courses is often strongly gender biased. The skills concerned are culturally identified with one gender only; for example, domestic science and secretarial skills with girls, industrial arts skills with boys.

- Vocationalization is hard to implement well. It requires specially trained instructors, preferably with actual work experience in the types of skills being taught. Teachers who have those qualifications are hard to recruit and retain. Vocationalization requires administratively complicated coordination of inputs. Finally, time spent on vocational skills training can detract from the teaching of basic academic skills, which are badly in need of improvement-also for labor market purposes.

For vocational skills development, it is better to look to training centers that are specialized for such purposes, set up to respond to the labor market, and have stronger institutional links to that market than secondary schools will have. Minor portions of a predominantly academic secondary school education will not suffice. It can also be argued that a more practical approach to the learning of existing subjects, stressing problem solving rather than reproduction of factual information, can improve the "economic relevance" of education, just as it improves quality more generally.

There are two cases in which vocationalization may be considered. The first is in the use of computers, which is applicable across a variety of occupations and which has potential for use across subjects within education itself. This is costly, however, and financial constraints limit the pace at which computers can be introduced. The second is low-cost programs that are not gender specific, such as agriculture and business studies. Both are useful for broad occupational segments. However, in introducing any practical subjects it is important to implement them systematically (as in Botswana) rather than precipitously (as in Kenya), to analyze and weigh cost implications before going to scale, and to evaluate learning outcomes and impact.

The teaching of entrepreneurship as an integral part of formal education and training is a variant on vocationalization. The purpose is to teach the knowledge and skills that will enable a graduate to plan, start, and run a business. A collateral purpose is to combat the negative image of self- 
employment. A review of the literature on integrated entrepreneurship education (IEE) and three case studies (Botswana, Kenya, and Uganda) were commissioned as part of this review (Farstad 2002).

The case studies found that entrepreneurship education and training has been a regular part of the curriculum at secondary and postsecondary levels in the three countries. The courses are mostly taught by teachers who have backgrounds in business management or entrepreneurship development. In Kenya, the curriculum is being delivered with the support of small business centers at all postsecondary public institutions. The study encountered an all-too-familiar lack of reliable data on the costs and impact of IEE. Moreover, entrepreneurs usually have a few years of work experience before they start their own businesses, so the impact of any school-based program must necessarily be diffuse.

The review also found three pedagogic tools that look promising if they are closely and competently supervised, namely (i) work placement with an entrepreneur as part of the school program; (ii) establishment of student enterprises; and (iii) compulsory development of a business plan (planning a specified production, assessing the market, and writing a cost and financing plan). Careful planning and implementation are clearly required, as has been done in Botswana. Curriculum materials already exist, internationally and in the three countries, that could be used elsewhere.

\section{Notes}

1. Statistics on TVET must be interpreted with caution. The complexity of the systems, combined with different governing authorities and a lack of capacity for data collection, can produce widespread undercounting. This applies especially to enrollments in private institutions (Atchoarena and Delluc 2001, p. 36). No comprehensive statistics are found on skills training outside the school system.

2. In Cameroon, Democratic Republic of Congo, Côte d'Ivoire, Mali, Mozambique, and Uganda.

3. The DANIDA evaluation in Tanzania found that the percentage of graduates from DANIDA-assisted institutions in training-related employment dropped from 52 percent for graduates in 1995-97 to 17 percent for graduates in 2000 (DANIDA 2002, p. 57).

4. UFAEs are modeled after the Groupements d'Etablissements (GRETAs) in France, which hire regular TVE teachers to teach continuing education part-time.

5. Argentina tried to replace its derelict public technical schools with thousands of small training companies, hired competitively. The model largely worked, but these small, private companies did not have good training materials, well-trained trainers, or formal quality standards. As time went by, the same mediocrity kept reproducing itself for lack of better models that could be copied. 



\section{Opening Markets for Nongovernment Training Institutions}

Nongovernment training provision by for-profit and nonprofit institutions is a significant and growing part of technical and vocational education in Sub-Saharan Africa. Providers are a diverse group, with different ownership and objectives. They include religious-based providers and other nongovernmental organizations, and many of them give considerable attention to social objectives such as training of the poor. Unit costs of nongovernment providers are generally lower than those of public providers, partly because of the different skill mix offered but also because of the more intensive use of resources. Variance in quality is an issue in nongovernment provision. Regulation can be an important tool for encouraging expansion of nongovernment training provision as a partner to the public sector. A case can be made for public subsidies.

\section{Introduction}

Providers of training outside the public sector are a significant and growing part of technical and vocational education in Sub-Saharan Africa. ${ }^{1}$ These providers include for-profit and nonprofit institutions as well as enterprises. The focus of this chapter is on institutionally delivered training outside the public sector; chapters 5 and 6 treat enterprise-based training in the formal and informal economies, respectively. Nongovernment training institutions constitute a diverse group of providers, as illustrated in figure 4.1.

These distinctions are not airtight. Many nongovernment institutions got their start with funding from public sources or external aid agencies. Individually owned proprietary institutions generally pursue profits in the delivery of training services. Nonprofit institutions can act like for-profit institutions in aggressively seeking to expand. NGOs often draw on public resources within and outside a country.

The composition and behavior of nongovernment providers of training is thus complex. The diversity and lack of good statistical data make

\footnotetext{
This chapter reports on the findings of two studies by the IIEP. The first, a study by Atchoarena and Esquieu (2002), includes a literature review and two in-depth case studies on Mali and Senegal. The second, by Igor Kitaev, with contributions from others (2002), reports on additional cases in anglophone Africa (Ghana and Zambia).
} 
Figure 4.1. Diversity in Nongovernment Institution-Based Training

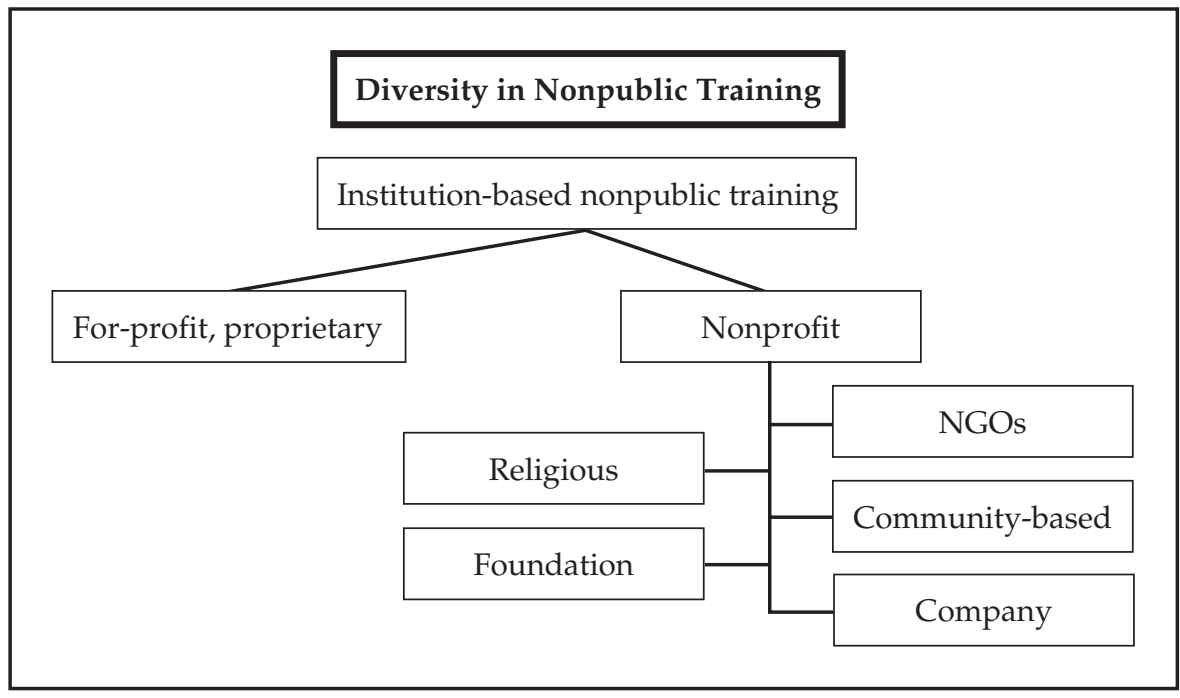

generalizations about nongovernment training institutions especially hazardous. Improving this state of knowledge has to be one of the priorities for the public sector in developing policies for skills development. This review tries to answer the following questions:

- What are the scope and characteristics of nongovernment training institutions?

- What are the strengths and weaknesses of this training?

- How cost-effective and demand-responsive are nongovernment providers?

- To what extent does regulation of these providers inhibit entry and initiative?

Public support for nongovernment training rests on the following assumptions. First, nongovernment training saves the government money by reducing the need to provide and finance training from the public budget. The growth of nongovernment training institutions, where trainees pay full costs, opens a pathway for expanding the national training system without making heavy commitments of public funds. Indeed, expanding nongovernment training can enable the diversion of public spending to basic education without reducing a country's overall supply of TVET (Ziderman 2003, p. 118).

Second, nongovernment training providers can be more innovative because they are subject to fewer bureaucratic restrictions than public institutions (particularly in centralized systems). Third, in competition with the public sector, the presence of nongovernment training can help raise quality system-wide. Like their public sector counterparts, nongovernment training 
providers face a rising number of job seekers, but with limited options for wage employment. Skills for the informal economy are an important market to be served.

\section{Scope and Characteristics of Nongovernment Training}

Nongovernment providers of training tend to take on the characteristics of the informal sector, in that they are difficult to define, identify, and regulate. In some countries, many nongovernment providers are not registered and some operate illegally. The IIEP study characterized Senegal's nongovernment sector as an "iceberg, in that the submerged part is not well known but represents a considerable volume" (Atchoarena and Esquieu 2002, pp. 25, 134).

Nongovernment sources of training often eclipse public sources. The IIEP review concluded that "there is enough corroborating evidence today to affirm that the nongovernment TVE sector occupies a significant and growing position in Sub-Saharan Africa"2 (Atchoarena and Esquieu 2002, p. 133). In some countries, the majority of trainees are enrolled in nongovernment institutions. This includes Mali, where nongovernment training makes up two-thirds of all TVET, Tanzania with 90 percent (figure 4.2), and Zambia with 82 percent (figure 4.3). Bennell found that private training was a "mass phenomenon" in Zimbabwe and estimated that at least 180,000

\section{Figure 4.2. Tanzania: Vocational Training Places by Ownership}

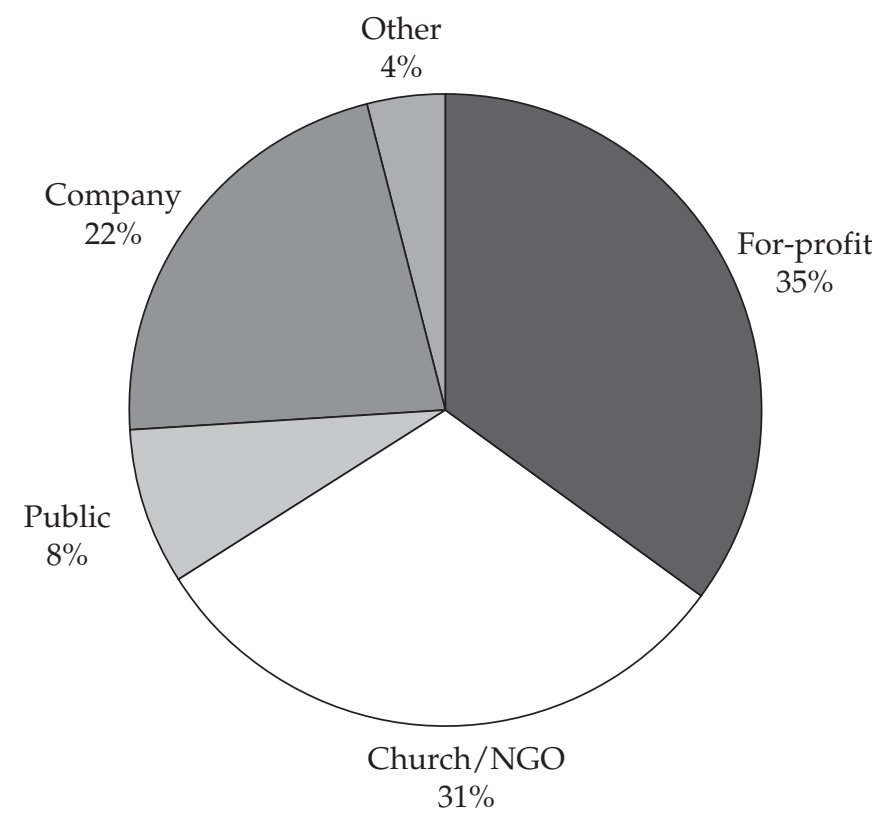

Source: Haan 2001, p. 76. 
Figure 4.3. Zambia: Training Institutions by Ownership

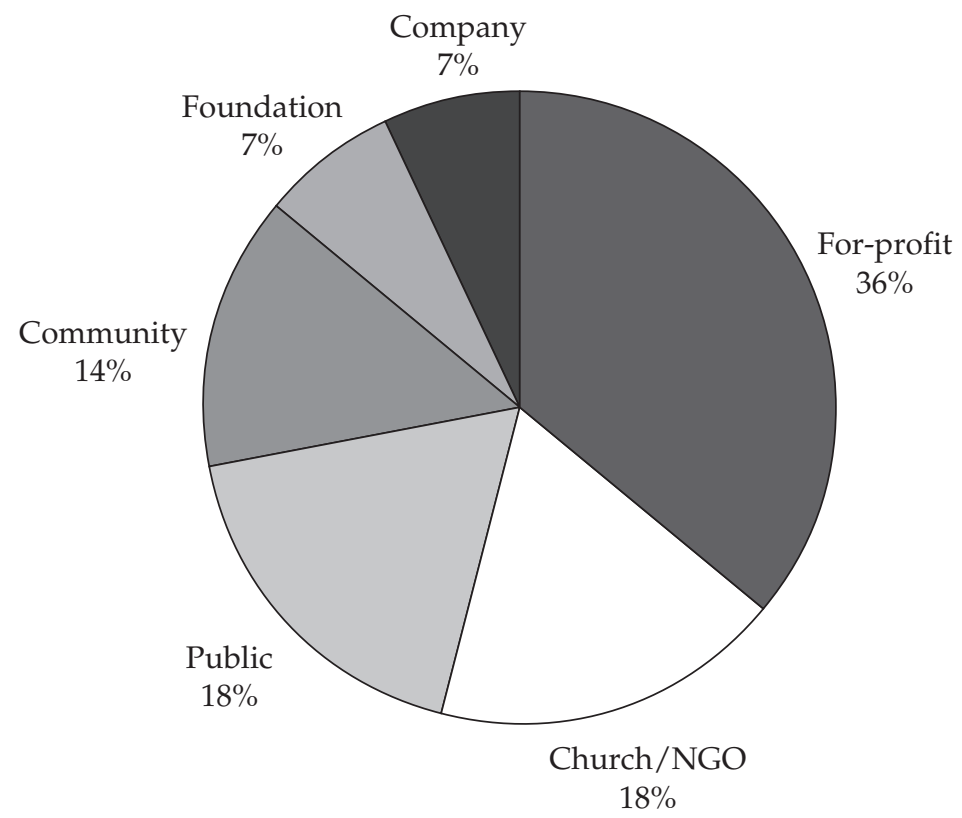

Source: Kitaev with others 2002, figure 2.

persons, or 5 percent of the economically active population, received training from private sector training institutions (Bennell 1993, pp. 37-8).

In Ghana, 20 public technical institutes enroll about 15,000 trainees compared with more than 370 nongovernment institutions enrolling an estimated 100,000 trainees. In Yaoundé (Cameroon) a survey of 682 informal sector operators found that almost half had received some kind of preemployment vocational training. Two-thirds of those got their training in nongovernment institutions (58 percent nongovernment for-profit and 9 percent NGOs, as compared with 24 percent in government institutions) (Haan and Serriere 2002, p. 122).

Moreover, the importance of nongovernment training seems to be growing. In Côte d'Ivoire, for example, the number of nongovernment institutions increased from 45 to 77 between 1984/85 and 1987/88 and from 15,000 to 17,000 students, while public provision declined from 89 to 69 institutions and from 16,400 students to 10,600 students. In Madagascar, the growth of nongovernment training has been more dramatic. Between 1990 and 1996, enrollment in nongovernment vocational institutions increased by 70 percent as public enrollment decreased. At the end of the period, 255 nongovernment training institutions enrolled 75 percent of all trainees.

At the technical level, expansion was also substantial, increasing from 7,550 students in 1990 to 32,000 students in 1999 in 730 registered non- 
government technical institutions. In Senegal, nongovernment training providers enroll almost half of all vocational training students. Between 1995 and 2000, nongovernment enrollments increased by 84 percent. In Mali, the number of nongovernment training providers rose from 11 in 1993 to 71 in 2000. Enrollments exploded at the end of the 1990s, increasing by 86 percent in just two years, between 1997 and 1999. Today, nongovernment training providers account for two-thirds of total enrollments in TVET.

The prevailing assumption going into the review was that most nongovernment training providers concentrate on "light" vocational skills such as business, commercial, and service skills, because of the high capital costs involved in providing more industrial-type skills. This assumption by and large was confirmed. Haan found that most of the recent nongovernment training providers in Uganda, mostly church based, focus on office qualifications and various business skills that require only limited investment (Haan 2001, p. 99). In Mali and Zambia, however, about 20 percent of students in nongovernment training were enrolled in courses that require capital investment. Perhaps because of the tendency toward commercial courses, nongovernment training providers in some countries tend to enroll more women than men. In Ghana, women make up 76 percent of total enrollments in nongovernment training institutions, and in Tanzania and Zimbabwe women make up 60 percent of the total nongovernment training enrollment. The survey of 28 nongovernment technical-vocational schools in Senegal found young women in the majority, with 55 percent of total enrollments. Moreover, NGOs and denominational schools typically have philanthropic purposes and enroll a significant number of low-income students. In contrast, for-profit training providers tend to target higher income groups because fees are virtually their only source of income.

Geographical concentration is another characteristic of nongovernment providers, especially for-profit institutions (church-based providers are often found in rural areas.) The IIEP surveys in Ghana and Zambia both found most of the institutions to be concentrated in a few regions. In Ghana, the institutions were most prevalent in the south of the country, probably due to the concentration of industrial and commercial activities in those areas. In Zambia, the nongovernment providers tended to concentrate in Lusaka and the Copperbelt region.

In terms of student entry, nongovernment training institutions often are at a disadvantage compared with public institutions. Nongovernment trainers tend to get students who were unable to gain places in public institutions. Public institutions may be preferred because of lower fees and better reputations in the mind of parents.

Associations of nongovernment training providers have been formed and are active in a few countries (for example, Uganda, Tanzania, and Zambia). They are usually small (the one in Uganda has only 20 members), but represent an important group to focus attention on issues that concern them and advocate fair treatment from government. 
An unfortunate characteristic of nongovernment training organizations is their often complex and uneasy relationships with the government. In some countries a socialist past shapes the present generation of civil servants for whom state control over TVET is the norm. For-profit TVET is often viewed with disdain and suspicion. Nonprofit training is regarded as insignificant. In turn, operators of nongovernment institutions often do not trust the government bureaucracy as they get little or no support from it. This kind of mutual distrust runs counter to the cooperation required if overall skills development is to progress in a partnership.

\section{Financing and Costs}

Tuition is the major source of income for for-profit training providers. Even denominational and nongovernment institutions typically charge fees. However, many contend these fees have been raised to the maximum and cannot increase further. According to Haan (2001, p. 87), some of the consequences of high fees have been dropout and underutilization of training capacity and exclusion of students from poor families. In some countries (Côte d'Ivoire, Mali), nongovernment institutions receive substantial government subsidies and tax incentives. However, heavy state subsidies can squelch innovation. State financial support for nongovernment TVET amounts to about 1 billion CFA francs in Mali. This policy is not without perverse effects. "State intervention that is overly conspicuous or constraining can come to resemble an outright welfare system which is far removed from the image of a (nongovernment) training market" (Atchoarena and Esquieu 2002, p. 137). Denominational providers often receive substantial donations from abroad. NGOs and denominational providers also generate substantial income through product sales (see chapter 7).

Financial issues dominate discussion of constraints among owners of nongovernment training providers (see table 4.1). The Mali and Senegal cases highlighted the problem of financing the initial investment to start up nongovernment training institutions. The difficulty in gaining access to land also constituted a sizable obstacle, especially in urban areas. In Zambia a survey of nongovernment institutions identified lack of seed capital, poor access to credit, and generally poor economic conditions (causing inability of many trainees to pay fees) as the most serious constraints for establishing and operating a training center.

The IIEP reviews concluded that the unit costs of nongovernment training are generally lower than in comparable public institutions. However, the evidence is thin (figure 4.4).

Differences in the skill composition of training that favor less capitalintensive courses, probably account for much of the difference in unit costs. However, this does not explain all the variance. Nongovernment providers usually employ more part-time teachers, pay them less per hour (table 4.2), use larger class sizes, and economize through intensive use of facilities. An 
Table 4.1. Obstacles to Nongovernment Technical-Vocational Training and Solutions

\begin{tabular}{ll}
\hline Obstacles & Suggested proposals \\
\hline Difficulty financing initial investment & $\begin{array}{l}\text { Land grants } \\
\text { Soft loans } \\
\text { Establishment of fund to support } \\
\text { nongovernment training initiatives }\end{array}$ \\
\hline Student defaults on loans & $\begin{array}{l}\text { Grant of fellowships by the state and } \\
\text { local governments }\end{array}$ \\
\hline $\begin{array}{l}\text { Overhead (taxes, VAT on equipment, } \\
\text { amortization of capital investments) }\end{array}$ & $\begin{array}{l}\text { Tax reductions } \\
\text { VAT exemption for pedagogical } \\
\text { equipment }\end{array}$ \\
\hline Lack of market transparency & $\begin{array}{l}\text { Recognition of nongovernment } \\
\text { institutions by government to promote } \\
\text { quality standards and to enable them } \\
\text { to benefit from public subsidies }\end{array}$ \\
\hline
\end{tabular}

High cost and bad quality of utilities needed for production (for example, electricity, telecommunications)

VAT, value added tax

Note: Based on interviews with headmasters in Mali and Senegal.

Source: Atchoarena and Esquieu 2002, p. 141.

example is the Mansfielt Institute of Technology (a for-profit provider) in Zambia. As a private business, the institute tries to make maximum use of its facilities and training equipment. Training courses are shorter and more intensive than in the public or NGO sector (Haan 2001, p. 132). In addition, the IIEP review found that for-profit institutions tended to use rented premises in Zambia to cut down on expenses.

The nongovernment sector benefits by using resources from the public sector. "To a large extent, nongovernment providers benefit from the investment and experience accumulated by the public sector through the use of curricula, training materials and, not least, instructors from the public sector. . . A significant proportion of nongovernment sector training instructors are public sector teachers moonlighting for additional income" (Atchoarena and Esquieu 2002, pp. 11, 135).

Many nongovernment training institutions are in a precarious financial situation. The review in two anglophone countries concluded that "the financial situation of most institutions seems fragile" (Kitaev with others 2002 , p. 64). This is because they depend mainly on fees and tuition payments are frequently overdue. In many schools the long delay in payment of 
Figure 4.4. Costs per Trainee, Nonpublic and Public TVE Institutions in CFA francs

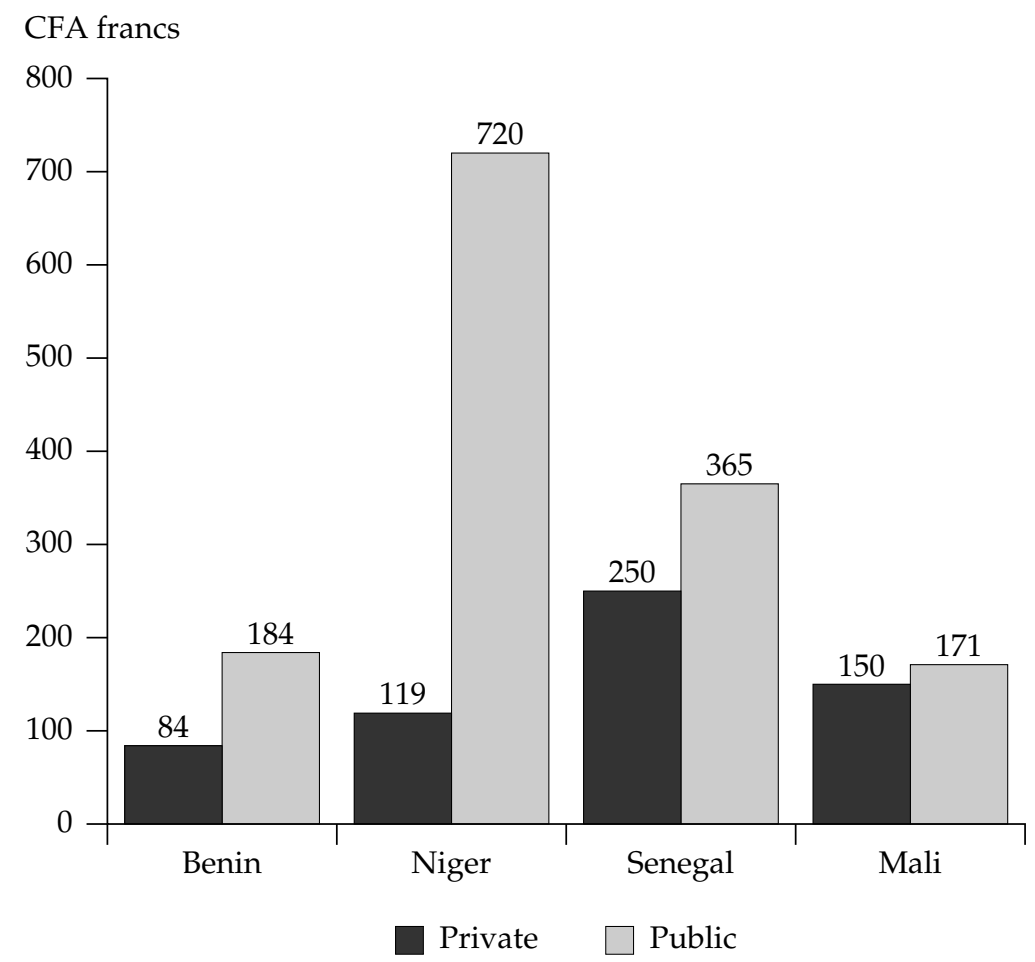

Source: Atchoarena and Esquieu 2002, pp. 11, 12, 45, 47.

Table 4.2. Annual Salaries of Public and Nongovernment TVE Instructors in CFA francs, Mali and Senegal

\begin{tabular}{|c|c|c|c|c|}
\hline \multirow[b]{2}{*}{ Country } & \multicolumn{2}{|r|}{ Minimum } & \multicolumn{2}{|c|}{ Maximum } \\
\hline & Public & Nongovernment & Public & Nongovernment \\
\hline$\overline{\text { Mali }}$ & 916,000 & 480,000 & $2,158,000$ & $1,920,000$ \\
\hline Senegal & $1,646,000$ & 510,000 & $3,125,000$ & $2,445,000$ \\
\hline
\end{tabular}

Source: Atchoarena and Esquieu 2002, pp. 97, 126. 
salaries demoralizes instructors so that effective performance cannot be guaranteed.

The movement for public institutions to charge higher fees may indirectly help nongovernment training providers. So far, for-profit training providers have faced major financial constraints in expanding their services. Now that charging more realistic fees is becoming commonplace, nongovernment training providers have more opportunities to enter this market (Haan 2001, p. 177). The competitive advantage enjoyed by public institutions based on fees has been reduced and may eventually disappear as the institutions become mainly self-financing.

\section{Effectiveness}

The effectiveness of public and nongovernment training institutions can be compared in three respects: placement rates in the labor market, responsiveness to the labor market, and quality of learning. On the first, the IIEP reviews found no data on employment rates by which to compare the performance of the different types of provision. "At the microeconomic level, even the schools that do take an interest in the future of their students rarely collect information on their integration into the job market. In this respect, nongovernment schools do not always differ from public schools and training centers" (Atchoarena and Esquieu 2002, p. 136; see also Kitaev with others 2002, p. 57).

Nongovernment and public institutions were found to be different in terms of demand-responsiveness. Both the Senegal and Mali cases indicate that the nongovernment sector can show more flexibility, adaptability, and imagination in satisfying the needs of the job market. In both countries, "the nongovernment sector has invested in new market niches that are considered to have growth potential (information technology, tourism), but are neglected by a state education sector that in many respects is ossified and turned inward toward programs and courses that in some cases are completely obsolete" (Atchoarena and Esquieu 2002, pp. 135-36).

In Uganda, the Mengo Institute of Technology, a nongovernment training provider, illustrates the search for new markets. Management of the institution recently developed new training courses in welding, radio repair, motor rewinding, catering, and business skills, which are in high demand. Since no official curricula existed, the staff developed them (Haan 2001, p.105). Similarly in Zimbabwe, when demand for existing technical training courses fell, the largest of the nongovernment training providers immediately diversified into new trades such as refrigeration, welding, and automotive electronics (Haan 2001, p. 162).

The study by Atchoarena and Esquieu found no difference between the public and nongovernment sectors in terms of actual links with employers and businesses. Little evidence was seen of internships or in-firm training combined with school-based education. "Nothing indicates that the autonomy, initiative, and profit motive that accompany nongovernment status 
Figure 4.5. Mali: Examination Results, Nonpublic and National Totals, by Type of Diploma (1999-2000)

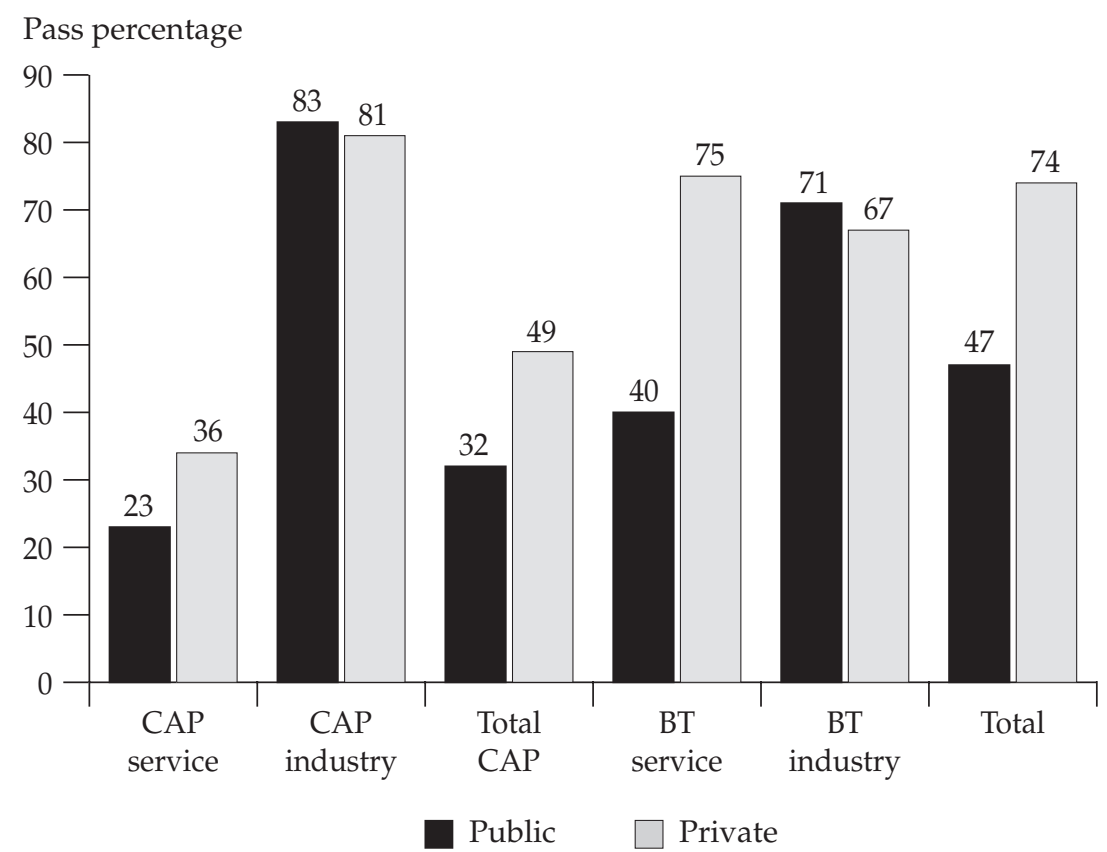

Note: BT, Brevet Technique (nondegree technical education); CAP, Certificat d'Aptitude Professionnelle (Vocational Training Certificate).

Source: Calculated from tables 17 and 18, Atchoarena and Esquieu 2002, p. 128. Data for providers come from the IIEP survey and do not cover all candidates from private institutions.

are enough to bring nongovernment training centers any closer to the job market than their public counterparts" (Atchoarena and Esquieu 2002, p. 135). Part of the reason for indifference to employers may be the obsession of both public and nongovernment providers with teaching official curricula and preparing students for state-administered final examinations. In Uganda, most nongovernment training providers follow official standardized training curricula, since their main goal is to prepare trainees for government-run trade tests for an official certificate (Haan 2001, p. 101).

Performance on final examinations can be considered a proxy for effectiveness, but the information available or generated by surveys was too fragmentary to produce firm conclusions. Figure 4.5 compares the examination results for nongovernment institutions in Mali in 1999-2000 with public school results.

The success rate of nongovernment school candidates in Mali seems to surpass results for public institutions for both the CAP and BT (figure 4.5). Within that total, however, the public institutions do marginally better in industrial fields and the nongovernment institutions do better in service subjects. 
Figure 4.6. Senegal: Success Rates for State Diplomas, 2000

Successful graduates as

$\%$ of successful candidates

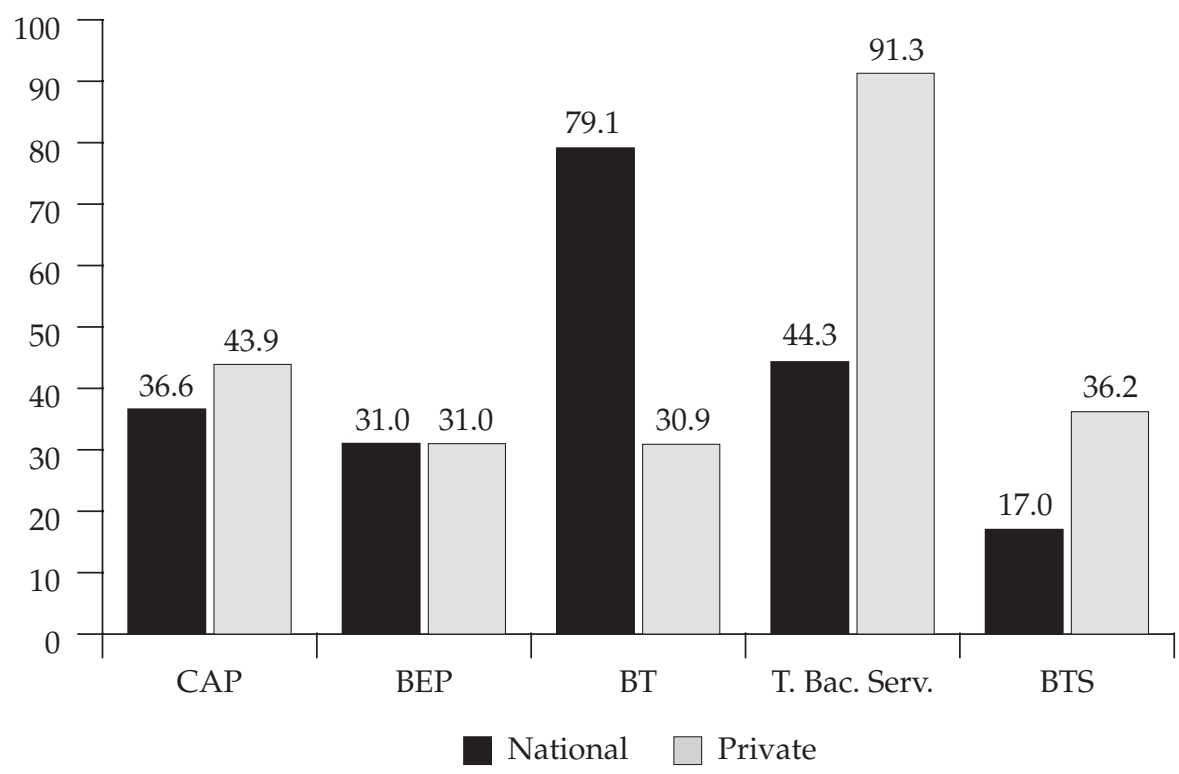

Notes: BT, Brevet Technique (nondegree technical education); BEP, Brevet d'Études Professionnelles; BTS, Brevet de Technicien Supérieur (nondegree postsecondary technical education); CAP, Certificat d'Aptitude Professionnelle (Vocational Training Certificate). T. Bac. Serv., Technical Baccalaureate (Service Sector). National includes both public and nongovernment.

Source: Atchoarena and Esquieu 2002, table 11. Data for providers come from the IIEP survey and do not cover all candidates from private institutions.

In Senegal, a comparison of the sample of 28 nongovernment training institutions yielded the comparisons with national results (public and nongovernment) presented in figure 4.6. The overall success rates for nongovernment institutions did not appear particularly good, but they equalled or bettered those reported for all schools in most categories. Specifically, the nongovernment sample surpassed the national results in three of four examinations (except for the BT examination) and matched those for the BEP.

The results presented in figures 4.5 and 4.6 suggest that students from nongovernment institutions may perform better than those from public institutions on examinations. However, the sample is too small for firm conclusions. Data for Zambia are not available to compare the performance of public institutions with nongovernment organizations, but the latter seem to be doing well in preparing trainees for both local and foreign examinations (figure 4.7). 
Figure 4.7. Zambia: Examination Passes in Nonpublic Institutions by Type of Examination, 1998-2001

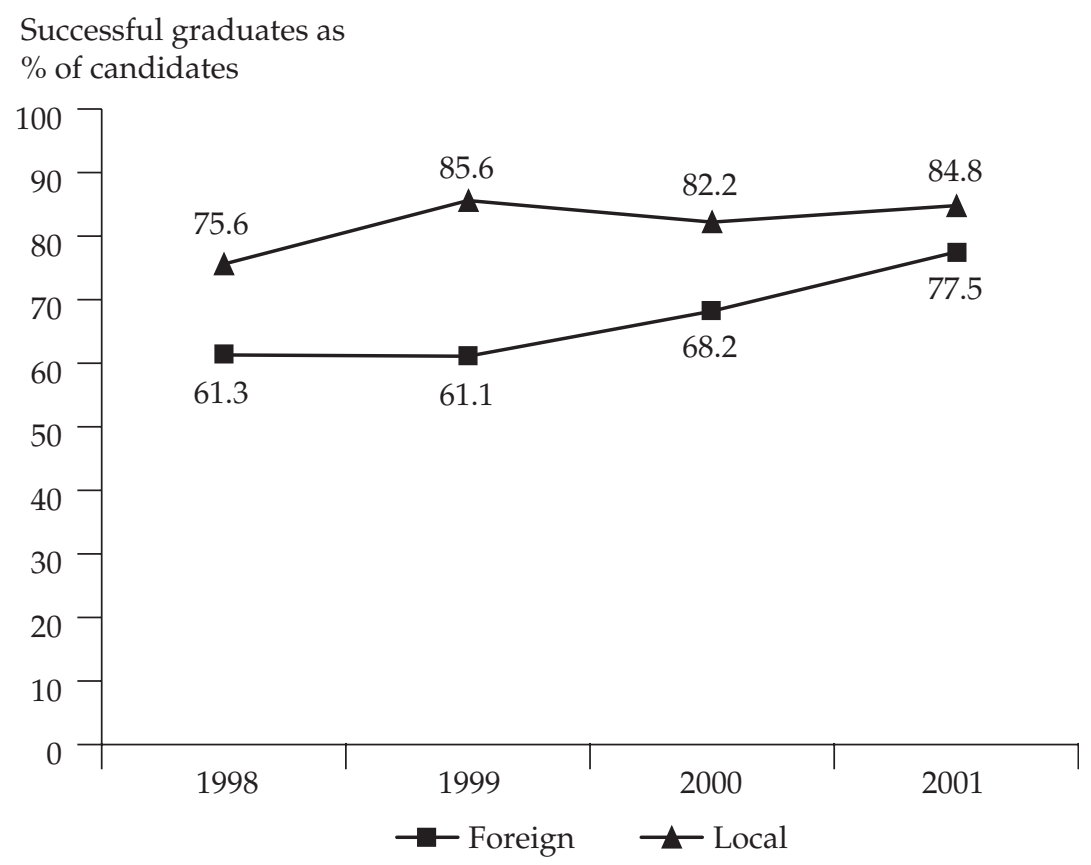

Source: Calculated from Kitaev with others 2002, table 3.4.

In the nongovernment sector, quality varies greatly from one institution to another. The IIEP study concluded that it is "likely that variations in standards are much wider within the nongovernment sector than for public institutions which are all subject to the same rules" (Atchoarena and Esquieu 2002, p. 11). In fact, variance in quality seems to be a major issue among nongovernment training providers, particularly among the lower third. Data from Ghana illustrate this point. Only half the institutions in the IIEP survey adhered to government policy directives on the number of teaching hours per week (theory and practical). Among the institutions, the number of hours in first-year theory in dressmaking ranged from 3 to 25 hours per week and in practical subjects from 2 to 20 hours. A similar pattern was found for carpentry and joinery, with ranges from 3 to 24 hours in theory and 6 to 36 hours per week in practical instruction. In addition, many institutions operate with below-standard equipment and facilities, and often with less qualified staff than the public sector does.

TEVETA in Zambia, having divorced itself from direct management of public training institutions, has been able to evaluate objectively the standards of all training providers in the country, public and private. Each year 
Figure 4.8. Zambia: Training Institutions by Type Ranked by Level of Standards, 2001

Percentage of VTIs

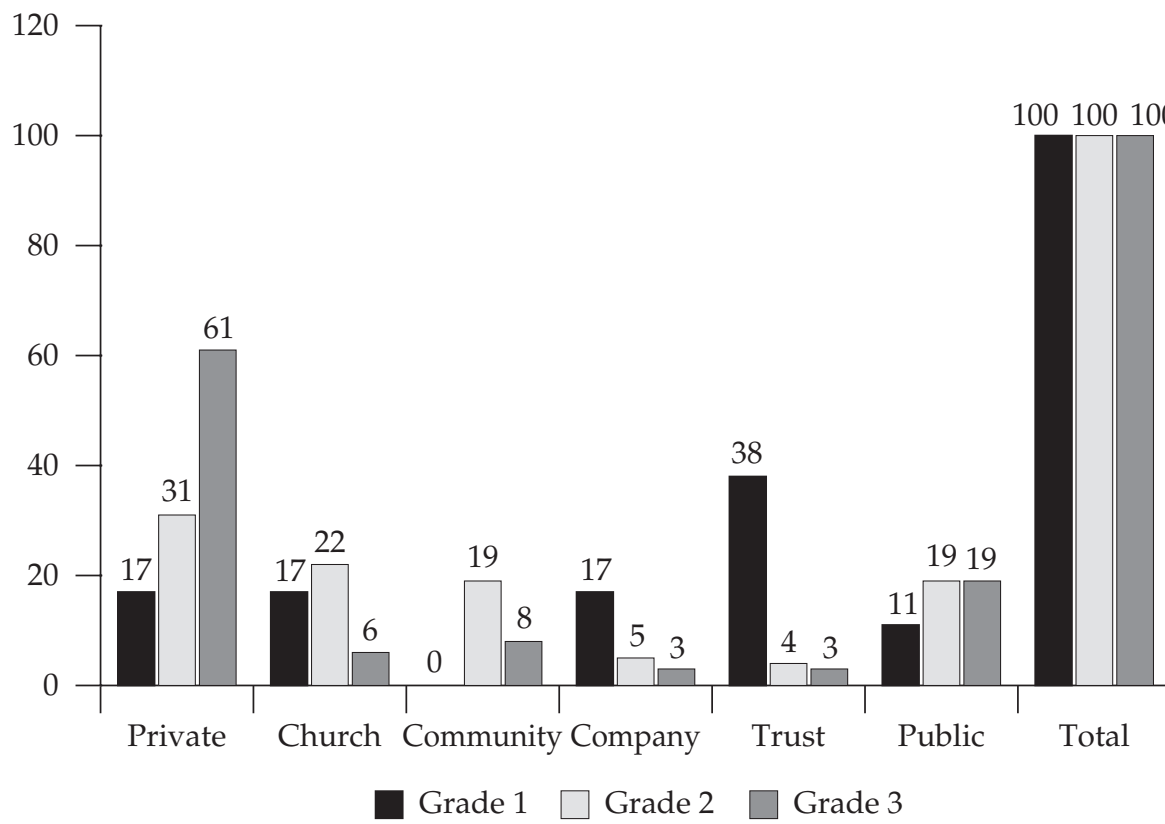

VTIs, Vocational training institutes

Note: Grade 1 institutions were deemed by TEVETA to have met standards fully; Grade 2 institutions met minimum qualifications; Grade 3 institutions failed to meet the minimum qualifications.

Source: Kitaev with others 2002.

it evaluates all 250 training centers on the basis of open and transparent criteria. Evaluators are subcontracted for this purpose and paid for each evaluation completed, and therefore have an incentive to identify "clandestine" training providers. The evaluators must use the published evaluation instrument and discuss the findings with the school. Figure 4.8 shows the variation in standards attained by the various categories of nongovernment and government providers. For-profit providers show the greatest variation, with over 60 percent ranked in the lowest category. Interestingly, government institutions made up 19 percent of the lowest category.

The IIEP study considered, but rejected, the notion that strong student and parental demand, and willingness to pay, necessarily indicated better quality or relevance of nongovernment education. Demand for places by parents and trainees cannot be equated necessarily with demand for skills by employers. Instead, strong social demand in Senegal indicated a surplus demand for places that the public sector could not satisfy. 


\section{Box 4.1. Forms of Regulation}

\section{Administrative controls}

Schools must be accredited by the government.

Schools must comply with health and safety standards.

Schools must comply with construction standards.

The number of pupils is limited to the school's admission capacity.

Schools must have not-for-profit status.

Schools must submit financial balance sheets.

A minimum level of investment is stipulated.

\section{Regulation of scholastic affairs}

Schools must adhere to public sector programs.

The government sets the numbers of hours of instruction and school holidays.

The government sets the attainment level required for admittance.

The government specifies the teaching language.

\section{Certification: Regulations concerning teachers and pupils}

The government sets teachers' wages and qualifications.

The government sets procedures and criteria for hiring and firing teachers.

Statements must be submitted to the government explaining the allocation of resources between teachers' compensation and other inputs.

The government controls tuition charges.

The government sets procedures and criteria for selecting students.

Source: James 1991, as cited in Atchoarena and Esquieu 2002, p. 53.

\section{Regulation of Nongovernment Training Providers}

Governments typically use various regulatory tools to encourage, monitor, and control nongovernment training providers (box 4.1).

Regulations can control (i) the opening of a new training institution (registration), (ii) the operation of the institution (certification and accreditation), (iii) the types and levels of fees charged (upper and sometimes lower limits), (iv) teachers (qualifications and salaries), (v) curricula (number and types of courses), (vi) distribution of profits, and (vii) the credentials conferred on graduates. Registration and accreditation perform useful functions in applying minimum quality (input) standards and are therefore seen by many as essential government functions when performed in a rational and transparent manner.

Support provided by governments to nongovernment training providers includes (i) direct subsidies (tuition grants), (ii) indirect subsidies (fellowships or bursaries to students), and (iii) tax exemptions. Without concessions, taxes can account for 7 to 10 percent of nongovernment school costs in Mali and Senegal. 


\section{Table 4.3. Regulatory Frameworks for Nongovernment Technical-Vocational Training, Mali and Senegal}

\begin{tabular}{|c|c|c|}
\hline & Mali & Senegal \\
\hline $\begin{array}{l}\text { Legal framework } \\
\text { Conditions for setting } \\
\text { up a nongovernment } \\
\text { institution }\end{array}$ & $\begin{array}{l}\text { Law of } 25 \text { July } 1994 \\
\text { Prerequisite authorization }\end{array}$ & $\begin{array}{l}\text { Law of } 23 \text { November } 1994 \\
\text { Prerequisite declaration }\end{array}$ \\
\hline Fees & Free to decide & Free to decide \\
\hline Subsidies & $\begin{array}{l}\text { Granted to institutions } \\
\text { that enroll students } \\
\text { assigned by the } \\
\text { Education Ministry }\end{array}$ & $\begin{array}{l}\text { Low amount, granted to } \\
\text { very few institutions }\end{array}$ \\
\hline Fellowships & $\begin{array}{l}\text { Yes, granted by the state } \\
\text { to a few students }\end{array}$ & $\begin{array}{l}\text { Few, granted by local } \\
\text { governments }\end{array}$ \\
\hline $\begin{array}{l}\text { Access to land or } \\
\text { buildings }\end{array}$ & No & No \\
\hline Tax exemptions & No & $\begin{array}{l}\text { Value added tax exemption } \\
\text { (depending on legal } \\
\text { structure) }\end{array}$ \\
\hline Recruitment of teachers & Free to decide & $\begin{array}{l}\text { Free choice, subject to } \\
\text { qualification requirements }\end{array}$ \\
\hline Teachers' salaries & Free to decide & $\begin{array}{l}\text { Free (guidelines provided } \\
\text { by the Ministry) }\end{array}$ \\
\hline Curricula & $\begin{array}{l}\text { State curricula, } \\
\text { development of specific } \\
\text { curricula for new subjects }\end{array}$ & $\begin{array}{l}\text { State curricula, } \\
\text { development of } \\
\text { "homemade" training }\end{array}$ \\
\hline Certificates/diplomas & $\begin{array}{l}\text { State-recognized or } \\
\text { specific }\end{array}$ & $\begin{array}{l}\text { State-recognized or } \\
\text { specific }\end{array}$ \\
\hline
\end{tabular}

Source: Atchoarena and Esquieu 2002, p. 141.

Ceilings imposed on tuition fees, although intended to protect trainees from exploitative activities, may limit nongovernment training institutions' ability to enter new training markets, especially those that require high investment and recurrent costs. Fee controls may produce the undesirable effect of low-cost, low-quality training (Ziderman 2003, p. 116).

The evidence from Senegal and Mali did not point to excess state regulation as a major impediment to the nongovernment sector's expansion (table 4.3). The IIEP study noted a general tendency to relaxation of state regulations. "In many cases, the legislative and regulatory structure established by 
the state over the course of a country's history was both over-elaborate and inefficient. More recently, the trend has been toward deregulation or greater flexibility of the rules applied to the nongovernment sector" (Atchoarena and Esquieu 2002, p. 134). Of the 20 respondents in the Zambia study 12 were established in the 1990s, 10 of the 12 were for-profit institutions. The review concluded that most institutions were probably established as a result of the liberalization policy introduced by the government in 1992 . Senegal moved from a system requiring prior authorization to one in which mere declaration sufficed. This seems to have encouraged growth of nongovernment provision.

In many countries, governments are concerned about the irresponsibility of some promoters and the uncertain quality of the training provided, particularly among unregistered institutions. Abusive practices fuel a legitimate demand for protection of users, but too often unfounded assumptions persist that for-profit training providers will be exploitative. Representatives of the nongovernment sector are often the first to demand tightening of standards and to call on government to weed out schools of poor quality.

De facto enforcement of standards can be a major governmental shortcoming. In Ghana registration is about the only stage at which the government gets involved; very little follow-up supervision is provided. Zambia is not enforcing minimum instructor qualifications. In Mali the state has given official recognition to only 11 nongovernment training schools and in Senegal to only 8 (none in the past seven years). This amounts to creating genuine barriers to entry.

In addition, there appears to be a failure of information about nongovernment training. This is one of the rationales offered in chapter 1 for public interventions in training markets. Earlier, reference was made to the appallingly weak statistical base on nongovernment schools and enrollments. Without reliable information, consumers are unable to make wise and informed choices. Relevant information on both the quality and the stability of nongovernment training institutions is clearly lacking. Providing updated information on the relevance of courses to labor market demands and job opportunities is also important.

\section{Issues}

Competition and subsidies are among the unsolved issues in TVET.

\section{Regulatory Environment}

The regulatory environment should facilitate the growth and development of nongovernment provision, while providing appropriate protection to consumers. Regulation and enforcement should be sparing, but sufficiently robust to counter excesses and to encourage nongovernment training institutions to operate honestly and efficiently. Truth in advertising is one essential 


\section{Box 4.2. Zambia: Playing Field Slanted Against Nongovernment Providers}

Nongovernment for-profit providers account for two-thirds of the institutions and total enrollment in Zambia. However, they face problems such as limited access to capital and the inadequacy of the competitively determined fees to finance the necessary equipment and instructional materials. They also face increasing competition against for-profit centers in public institutions, where they have to compete against fee-paying training offered by staff associations in public training institutions, which use the income to augment teachers' salaries. These training associations use the facilities, materials, and equipment of the public training institution at a minimal cost, allowing them to charge much less than their nongovernment competitors. According to preliminary estimates, academic staff associations enroll about 4,000 students, as compared with 6,000 government-subsidized students.

Source: World Bank 2001, pp. 9, 60.

requirement. However, nongovernment training institutions are unlikely to flourish in an overly strict regulatory environment. The key questions, then, are what is essential to control and what capacity does the public sector have to regulate.

\section{Level Playing Field}

Sometimes the nongovernment sector must compete against fee-paying courses offered in public institutions. Because these institutions use public facilities, their marginal costs are low, and they can charge lower fees than nongovernment institutions. Zambia is a case in point (box 4.2). In addition, certain promoters of the nongovernment sector condemn what they call "unfair competition" from the state sector in Senegal. In general, the government should charge fees that reflect fully the cost of all resources used in the provision of training.

\section{Subsidies}

A critical policy question is whether state subsidies are justified for nongovernment institutions, and, if so, under what conditions. Subsidies to nongovernment providers are justified to the extent that they facilitate equitable access to disadvantaged groups (equity) in employable occupations (relevance), and achieve quality results (performance).

To the degree that subsidies encourage cost-effective expansion where investment is inhibited by market failures and imperfections, subsidies can 
improve efficiency. The case of market failures is taken up in chapter 1. However, excessive state subsidies can undercut one of the benefits of nongovernment training: innovation. In the Mali case, nongovernment institutions are so heavily subsidized that management has little incentive to seek new markets or better ways of training.

\section{Notes}

1. Appendix A compares the findings of the case studies with initial hypotheses (expectations), in terms of the reasons for support of private training provision. Appendixes B and C summarize the findings of the Mali and Senegal case studies, respectively.

2. Because of poor statistical reporting, it is more common to find data about the number of nongovernment training providers than the number of trainees enrolled or graduates produced. For example, in Botswana, the number of nongovernment training providers increased from 70 in 1994 to 121 in 2001, but data were unavailable on enrollments and dropout. 


\section{5}

\section{Recognizing Formal Sector Enterprises as Trainers}

Trade liberalization has increased competition throughout much of Sub-Saharan Africa. Companies have turned to reducing costs by shedding labor, outsourcing activities, and adopting new technologies. Knowledge and skills have become increasingly important. Against this background, formal apprenticeship programs are declining in the modern sector. Labor is so abundant that companies can easily hire workers with sufficient education and aptitude who will need relatively short periods of on-the-job training. Formal and informal training of workers of varying educational background, age categories, and occupation streams is widespread in Sub-Saharan Africa. Firms in Sub-Saharan Africa appear willing to invest in all forms of skills training, but are selective in terms of which firms train and who they train. The case for public subsidy of enterprise training is stronger in smaller enterprises.

\section{Introduction}

Formal sector employers in Sub-Saharan Africa provide substantial amounts of training on the job (enterprise-based training). The rationale for this training is set forth in chapter 1 under modeling training decisions. This training encompasses all forms of employer-sponsored training, including formal and informal on-the-job training and formal and informal off-the-job training sponsored by the employer. Patterns of this training, however, are inadequately understood. Key questions include the following:

- What is the scope of enterprise-based training in the formal sector, and what are the trends in its provision?

- What skills do employers recruit, and how much pre-employment training is needed?

- Who receives training in the enterprise, how much training do they receive, and for what skills?

- Do enterprises train enough? If not, how can their training be increased?

Andrew Dabalen contributed to the writing of this chapter. 
This chapter draws findings from three studies. ${ }^{1}$ The studies fill an important gap in describing training decisions in Sub-Saharan Africa. The Biggs, Shah, and Srivastava and the Dabalen, Nielsen, and Rosholm studies (hereafter referred to as the BSS study and the DNR study) are based on enterprise-level data collected under the Regional Program on Enterprise Development (RPED). The RPED surveyed nearly 600 enterprises with selected follow-up interviews in 108 firms across four manufacturing industries (textiles and garments, wood working, metal working, and food processing) in five countries (Côte d'Ivoire, Ghana, Kenya, Zambia, and Zimbabwe) in 1992-96. Firms were chosen randomly and included a full spectrum of enterprises, ranging in size from 5 to more than 1,000 employees and including local, private, and state-owned enterprises.

The Grierson study was carried out under the auspices of the International Labour Organisation/International Training Center (ILO/ITC). It examines training practices in 13 large or important modern sector enterprises in two countries: Kenya and Zambia. The individual case studies examine intercompany work force composition and patterns of change, enterprise-based training practices and plans, the effect of and response to HIV / AIDS, and methods of financing training. The findings in this chapter, therefore, relate mostly to anglophone countries.

\section{Background}

Trade liberalization entails the removal of import protection to open markets and increases competition. Productivity is a critical factor determining the survival and profitability of companies faced with growing competition. Increased competition has had two distinct effects in Sub-Saharan Africa. First, companies have shed labor in an effort to become more efficient. The ILO/ITC survey found downsizing and outsourcing reduced the number of core employees by as much as two-thirds in the Kenya case. Second, the technological capacity of companies-the skills and knowledge needed to set up and operate industrial enterprises efficiently-has become increasingly important. In many cases, training has gone global with multinational firms sending their African employees to Europe or Asia for training.

The BSS study found that African manufacturers were similar in structure to their counterparts in other regions. They exhibited the same relationship between factor intensities and partial factor productivities as is found in Asian countries. The study also found considerable variation in the technical efficiency of companies across the three countries surveyed. Companies in Zimbabwe were generally more efficient than those in Ghana or Kenya. Intersectoral variations were not significant. In terms of size, medium-size enterprises were the most efficient. African companies on average had lower levels of total factor productivity (the growth of output or value added resulting from the growth of the factors of production, such 
as capital and labor) than had counterparts in other regions of the world (Biggs, Shah, and Srivastava 1995a, pp. 2, 61).

\section{Importance of Enterprise-Based Training}

Governments and businesses in Sub-Saharan Africa have invested significant resources in improving the skills of their work force through training in the enterprise. Chapter 1 described several explanations. First, training workers improves the productivity of enterprises and promotes economic growth and poverty reduction. Second, training in the enterprise is seen to be market responsive, and it allows for continuous learning and adaptation to new technologies. The high unemployment rate observed among graduates of formal general education institutions is attributed to the poor linkage between the supply of skills and market demand. Third, on-the-job training in the enterprise is viewed as a means to expand access to skills training, with the advantage that it can be delivered in less time. Such training can be a vehicle for achieving social goals and equalizing opportunities. Finally, because firms may be able to extract benefits from general skills training when labor markets are imperfect, firms will invest in both general and firm-specific skills (Acemoglu and Pischke 1999).

\section{Pattern and Determinants of Enterprise-Based Training}

Four factors are expected to account for variation across companies and sectors in the amount and types of training:

1. Company size is positively correlated with amounts of training given to workers (smaller companies train a smaller proportion of the work force than larger employers).

2. Employers are more likely to train workers in skilled occupations where the capital per worker is high, along with the cost of mistakes.

3. The amount and quality of the workers' prior education encourage training by increasing the ability of the worker to acquire new skills.

4. The amount a company invests in new technologies correlates directly with amounts invested in training, as does the extent to which the company serves export markets, where providing quality and meeting product standards are important to consumers.

One might expect that the obstacles to in-firm training would be higher in Africa than in other regions: the prevalence of small enterprises and the high population of uneducated and unskilled workers would reduce incentives for enterprise-based training. If this context were accurate, the level of training required could be higher than in other regions but prove too costly for African companies. In fact, the pattern and determinants of enterprise training across companies, sectors, and types of workers turn out to be 
much the same in Africa as in other regions. ${ }^{2}$ Moreover, African companies appear willing to expend substantial resources on training their workers.

\section{Overall Training Incidence within Enterprises}

Enterprise training is widespread and substantial in Africa. Virtually every company puts shop-floor employees through some kind of training. Most companies engage in ongoing or continuous training. The DNR study found that the extent of both formal and informal training is significant. Formal training means organized training that takes the trainee off the job site and is delivered mainly in classrooms. This training is often general in nature, not specific to the firm. Informal training means training that is in the workplace and is not delivered as part of a formal training program.

Figures 5.1 and 5.2 show the extent of formal and informal training in African enterprises, with informal training accounting for the major share of training offered by enterprises in the sample. This finding matches that of Tan and Batra (1995) in a sample of five non-African developing countries.

Figure 5.1. Incidence of Formal Training by Industry: Kenya, Zambia, and Zimbabwe, 1995

Percentage of firms

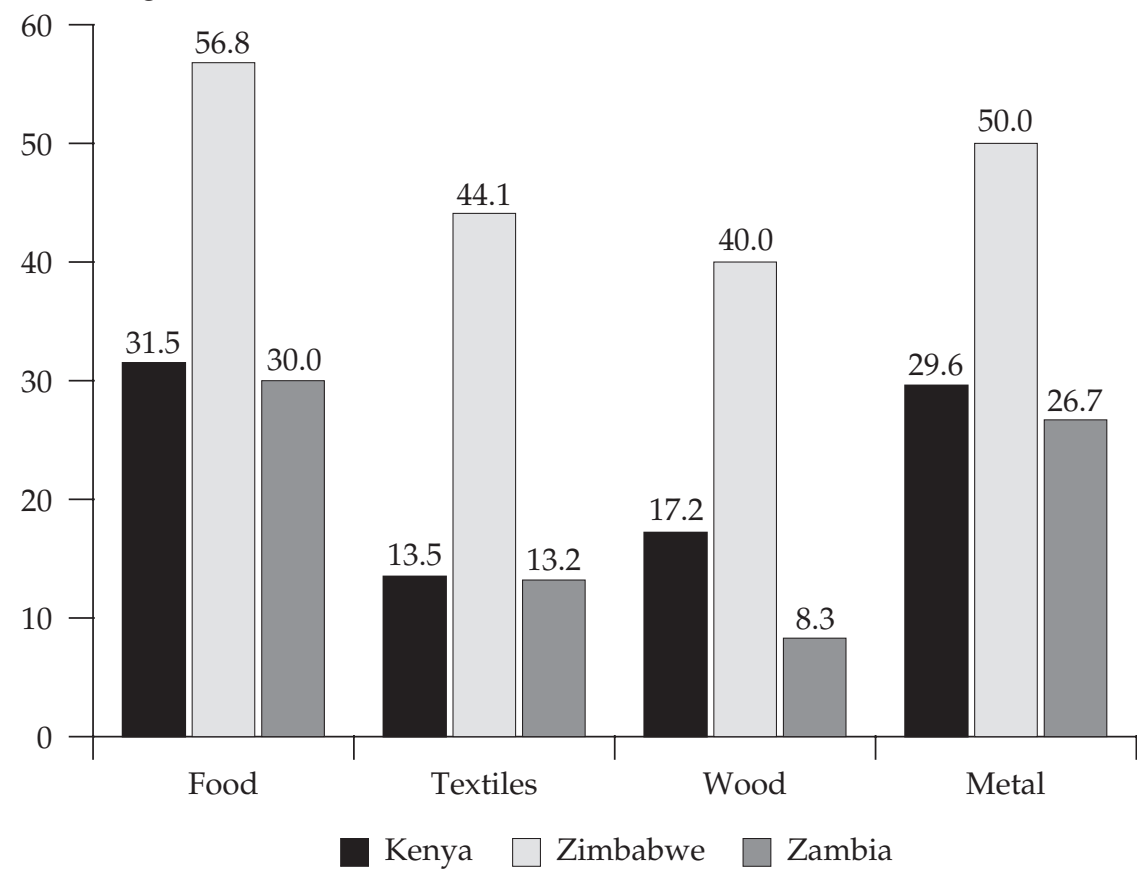

Source: Dabalen, Nielsen, and Rosholm 2002, table 4. 
Figure 5.2. Incidence of Informal Training by Industry: Kenya, Zambia, and Zimbabwe, 1995

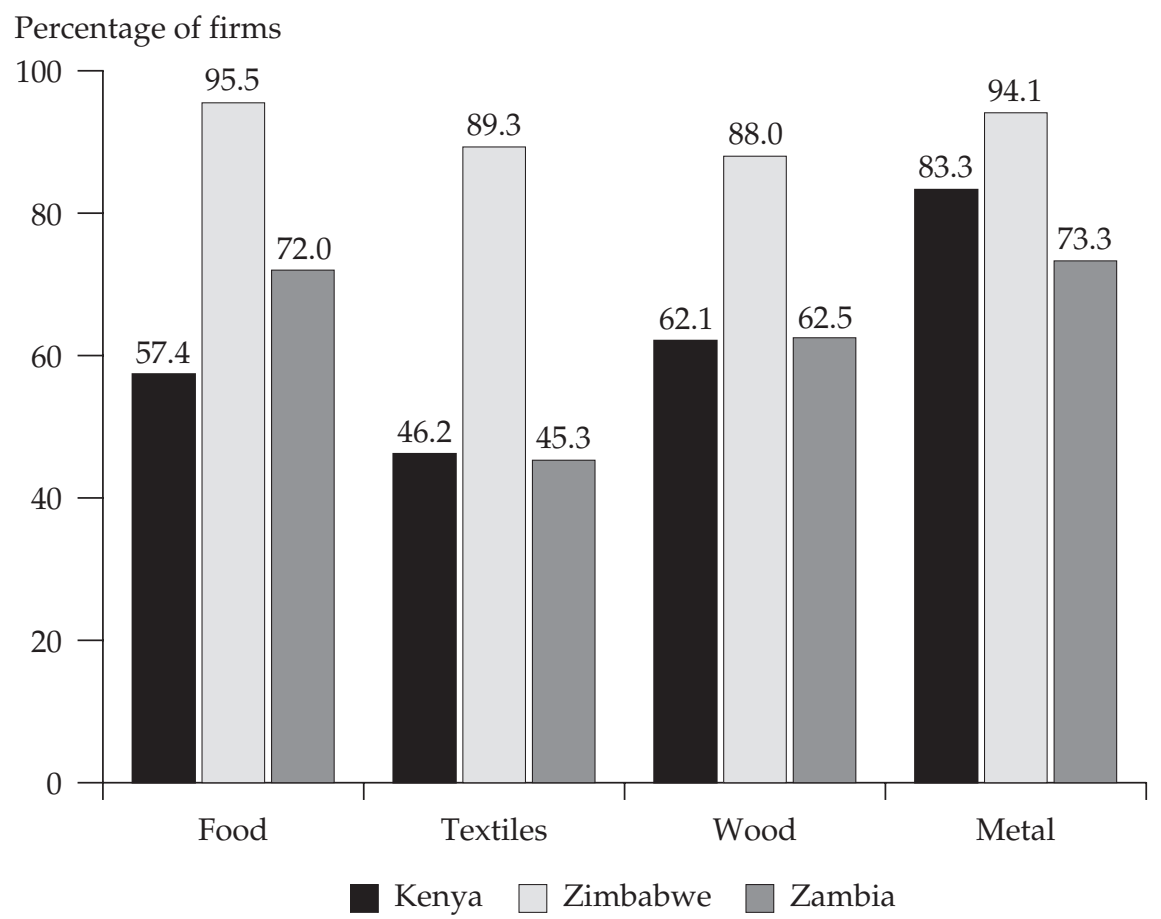

Source: Dabalen, Nielsen, and Rosholm 2002.

Training varies by sector for both formal and informal training, reflecting a mix of factors, but it is generally substantial in the firms surveyed.

More than 60 percent of firms in Kenya, Zambia, and Zimbabwe provided informal training. In Zimbabwe, this figure rose to 90 percent of firms. Informal training is typically targeted at new employees. In Zambia, a new employee received about 4 times as much informal training as the average worker, while for Kenya, a new employee receives 10 times as much. Equally significant is the finding that one out of five firms in Kenya and Zambia and nearly one out of two in Zimbabwe provide formal training. Formal training is more likely to be provided outside the firm than in house (Dabalen, Nielsen, and Rosholm 2002). It is also an indicator of firms' willingness to offer general skills training.

\section{International Comparisons}

The surveyed African firms compared favorably with several middleincome and semi-industrial countries in Asia and Latin America (Biggs, 
Shah, and Srivastava 1995a, p. 90; Tan and Batra 1995, pp. 5-7; see also figure 5.3). The surveyed African manufacturing firms fell within the range of international experience. Both formal and informal training are comparable with such training in the selected East Asian and Latin American countries. The incidence of informal training in the African firms even exceeds the comparators.

The pattern and determinants of enterprise training turn out to be much the same in Africa as in other parts of the world in terms of firm size, ownership, and categories of workers trained. Provision of formal and informal training is undertaken by enterprises of different sizes, from different sectors, and of diverse ownership.

\section{Figure 5.3. International Comparison of Incidence of Informal} and Formal Training: Selected Countries

Percentage of firms training

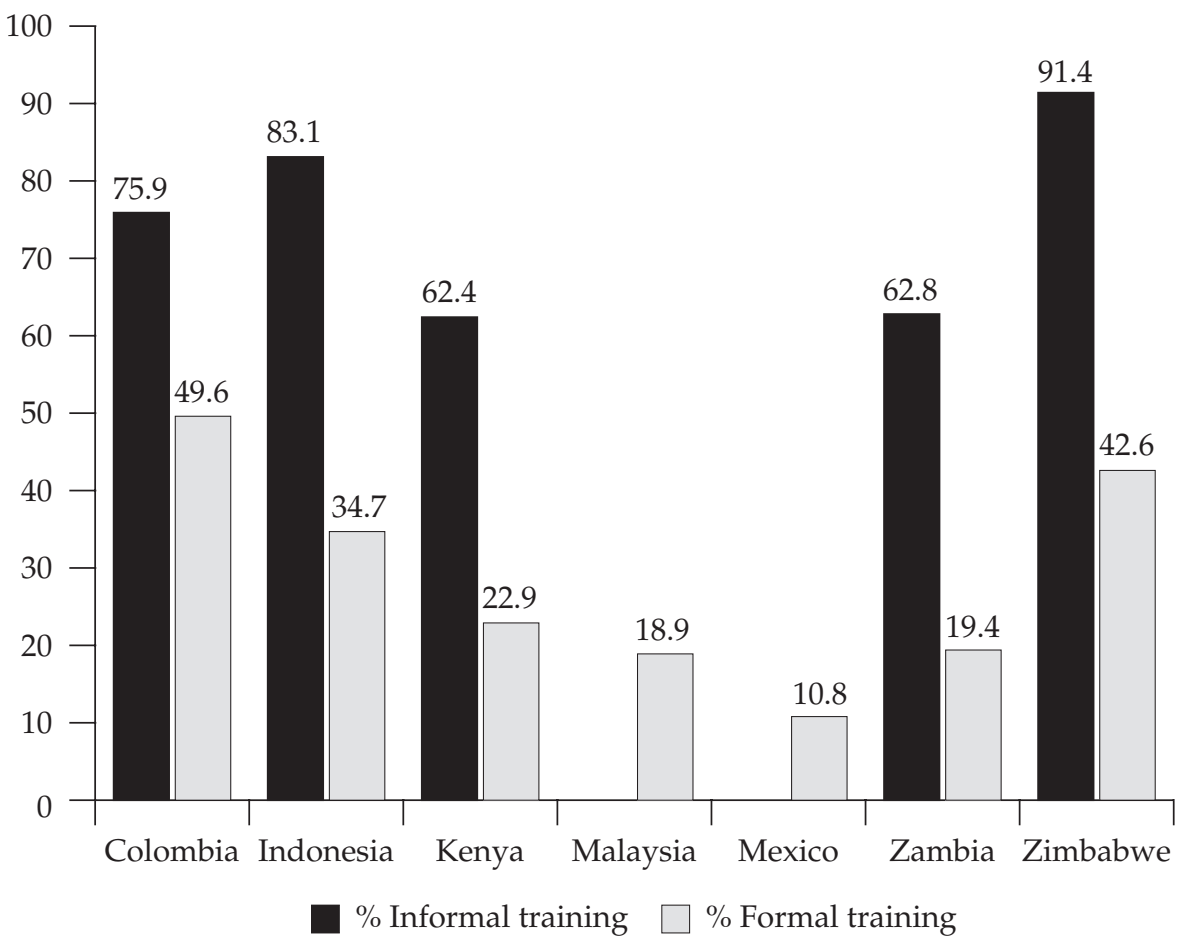

Note: 1992 for Colombia, Indonesia, and Mexico; 1994 for Malaysia; 1995 for African countries.

Sources: Biggs, Shah, and Srivastava 1995a, table 4.14, for non-African countries; Dabalen, Nielsen, and Rosholm 2002, table 2, for African countries. 


\section{Firm Size}

Large firms, measured by employment, show more willingness to train than do small employers (figures 5.4 and 5.5). Larger firms do more informal training and formal training than do the smaller firms. The pattern is most pronounced in formal training, where small firms do not provide much formal training to their workers.

In all countries, larger companies with higher skill ratios for workers are more likely to train than are smaller companies with unskilled workers. Because of economies of scale, larger companies can afford to engage in more training, particularly formal training. Workers in larger companies are also known to be more productive (Idson and Oi 1999). Zimbabwe, with a more elaborate vocational training system, has higher average enterprise training. Companies and workers there usually take advantage of the existing training infrastructure (Biggs, Shah, and Srivastava 1995a, pp. 208-9).

Figure 5.4. African Enterprises Providing Informal Training by Firm Size, 1995

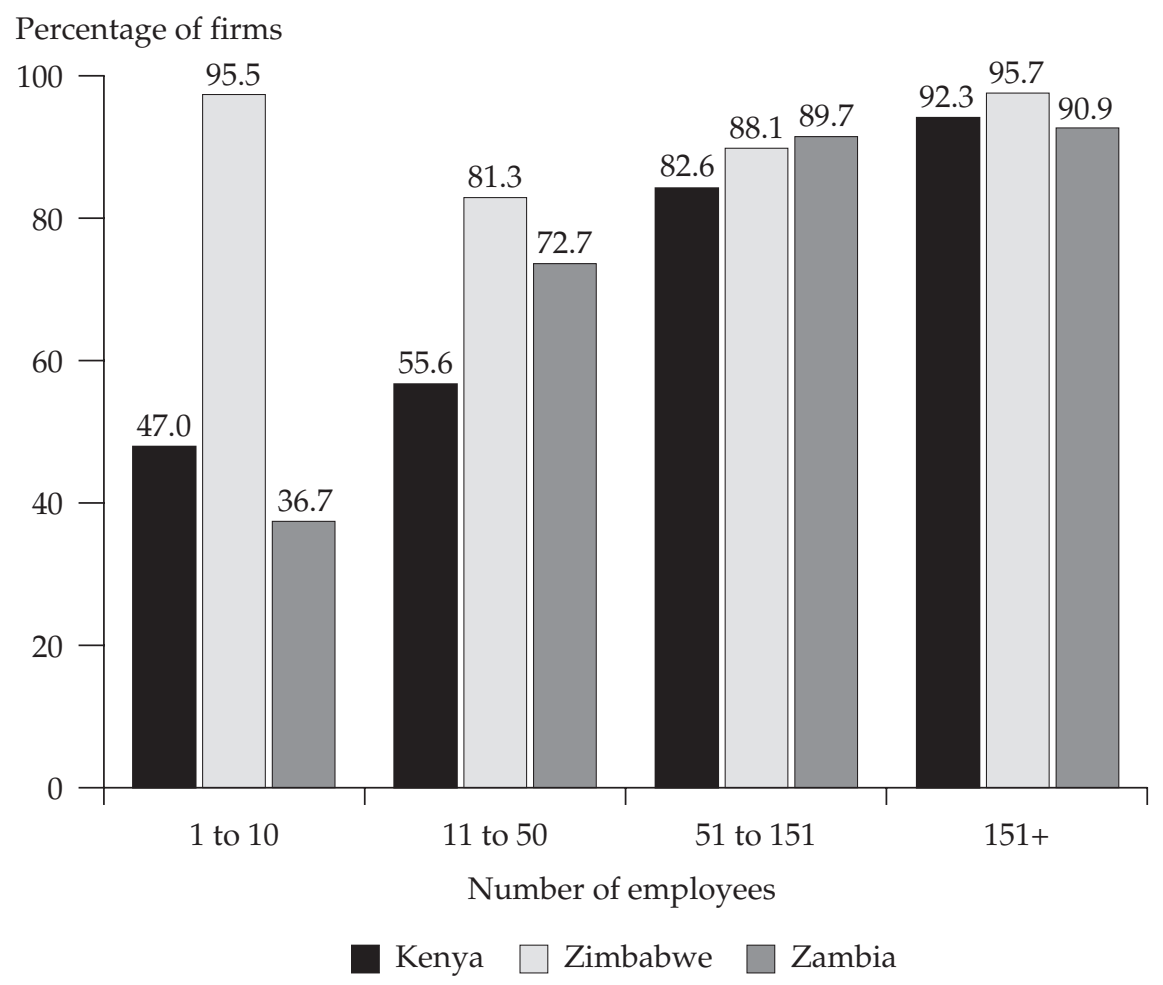

Source: Dabalen, Nielsen, and Rosholm 2002, table 4. 
Figure 5.5. African Enterprises Providing Formal Training by Firm Size, 1995

Percentage of firms

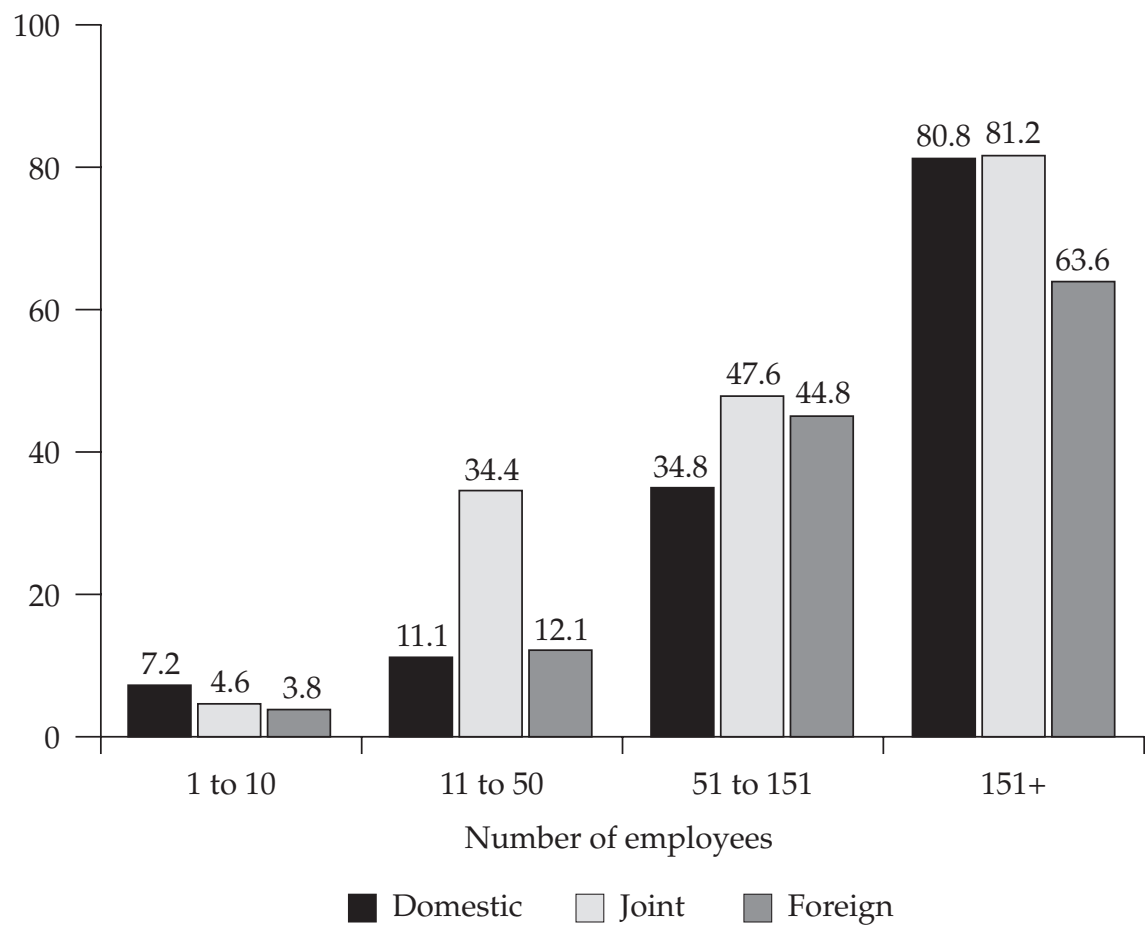

Source: Dabalen, Nielsen, and Rosholm 2002, table 4.

\section{Firm Ownership}

Foreign-owned enterprises proved to be active trainers. This finding reflects one of the advantages of foreign direct investment with the transfer of technology and investment in the skills of the work force. Foreign ownership is particularly striking in formal training (figures 5.6 and 5.7).

\section{Export-Oriented Firms}

Exporters are also more likely to train than nonexporters (figure 5.8). A probable explanation is that exporting firms face stiffer competition in the international market which stimulates interest in enhanced productivity through staff training.

\section{Training by Occupation}

White-collar and skilled occupations tend to receive more training than do the less skilled occupations. Correlated with this finding, educated workers 
Figure 5.6. Percentage of African Firms Providing Formal Training by Ownership, 1995

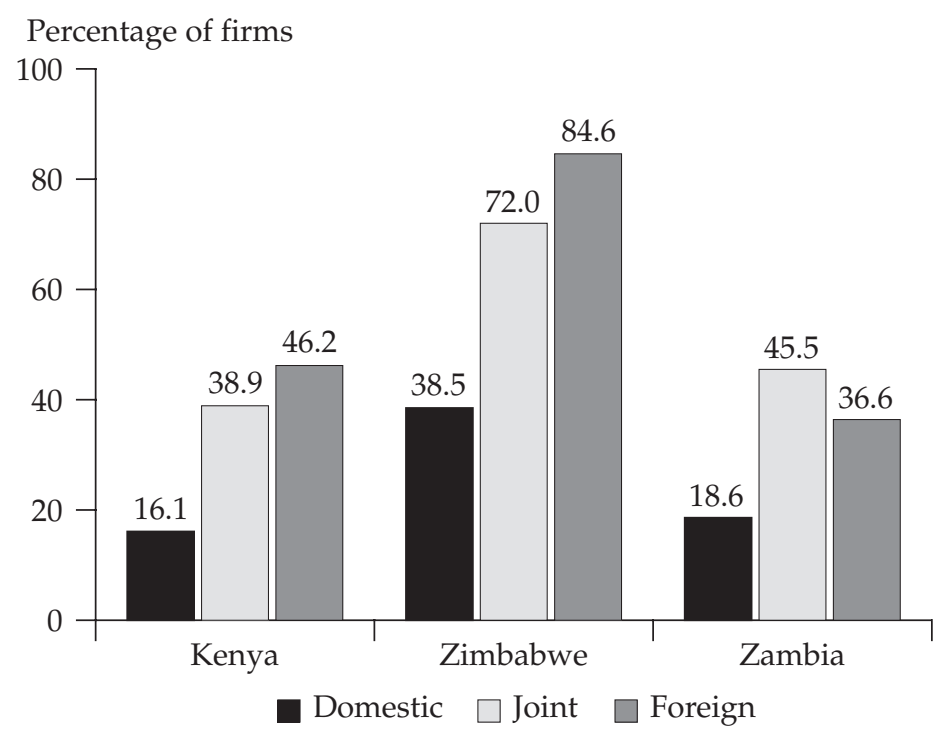

Source: Dabalen, Nielsen, and Rosholm 2002, table 4.

Figure 5.7. Percentage of African Firms Providing Informal Training by Ownership, 1995

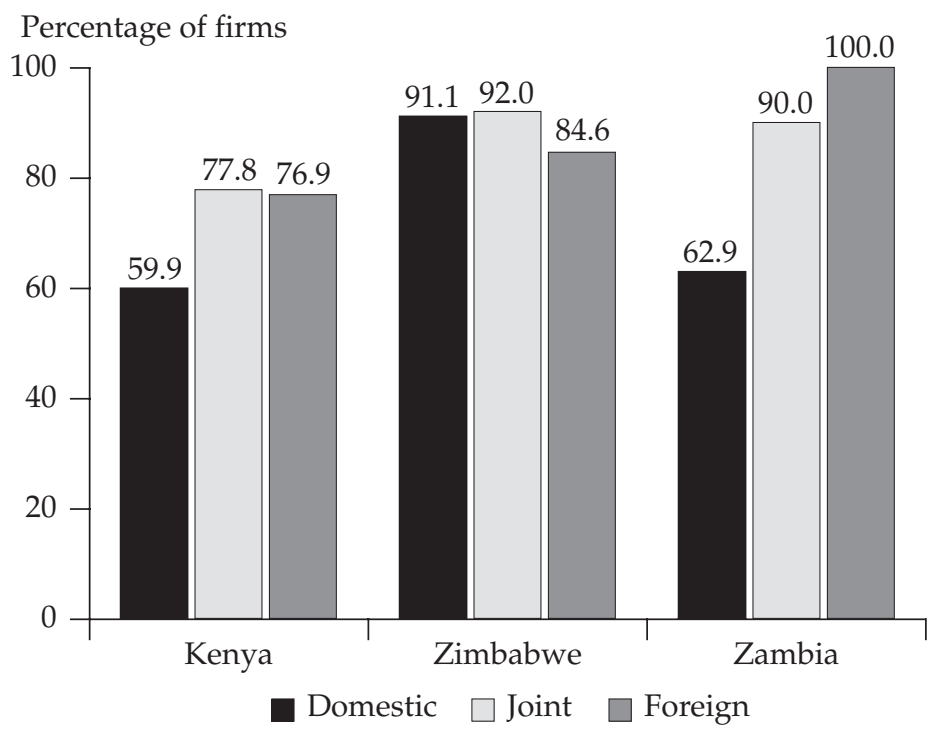

Source: Dabalen, Nielsen, and Rosholm 2002, table 4. 
Figure 5.8. Informal and External Training by Exporting and Nonexporting Firms

Percentage of full sample

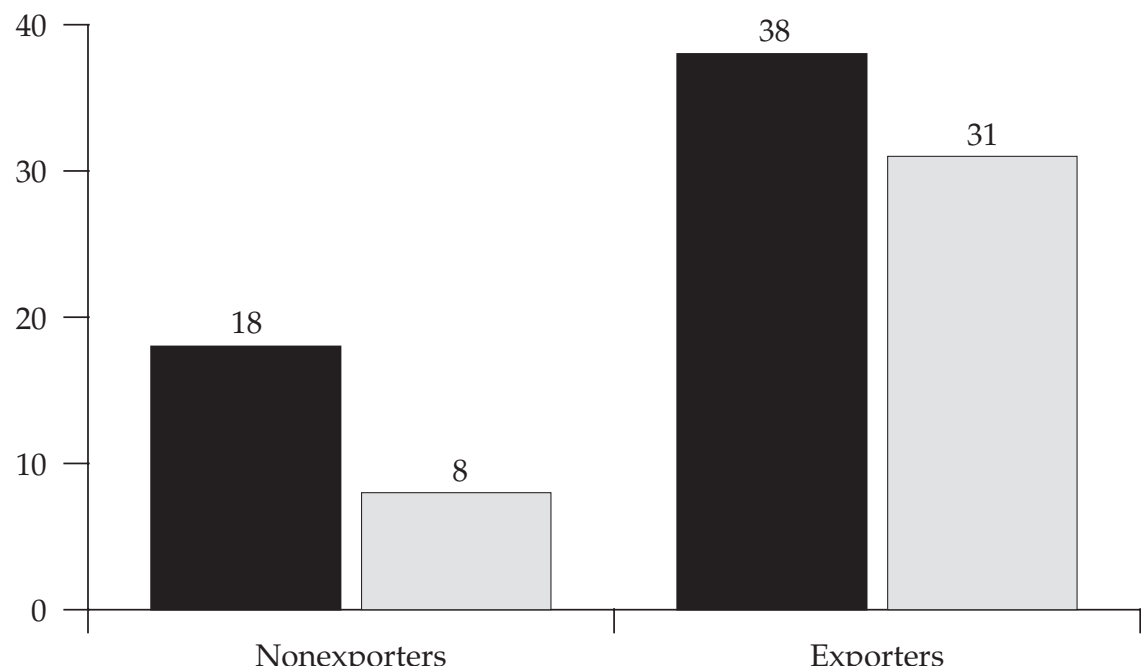

$\square$ Internal $\square$ External

Source: Biggs, Shah, and Srivastava 1995a, table 4.20.

receive more training than do less educated workers. This tendency is particularly evident in Côte d'Ivoire, Ghana, and Zimbabwe. The more detailed questions asked of Kenyan and Zambian workers show that workers with higher levels of education are more likely to participate in formal training, while less educated workers are more likely to receive training through informal means such as instruction by supervisors and learning by doing. These findings match those of Altonji and Spletzer (1991) for a sample of U.S. workers.

\section{Benefits of Enterprise-Based Training}

The benefits of enterprise-based training for firms and workers are substantial, as measured by the RPED data. All learning mechanisms used by enterprises have an unambiguously positive effect on the productivity of the enterprise. ${ }^{3}$ Among these mechanisms, on-the-job training of workers inside and outside the enterprise had the largest relative effect on value added by companies. Training had a high effect even in relatively low-skill companies and very small companies. Worker training was more important for firm 
Table 5.1. Determinants of Enterprise Efficiency (percentage increase in value added)

\begin{tabular}{lcc}
\hline Factor (learning mechanisms) & All firms & Micro and small enterprises \\
\hline $\begin{array}{l}\text { Increases workers trained by 1 } \\
\quad \text { percentage point }\end{array}$ & 60 & 99 \\
$\begin{array}{l}\text { Has foreign ownership (information } \\
\text { links by foreign direct investment) }\end{array}$ & 27 & n.a. \\
Has technical assistance and licensing & 30 & n.a. \\
$\quad$ agreements & 40 & 37 \\
Has access to working capital financing & & \\
\hline
\end{tabular}

n.a. Not applicable.

Note: Total sample was 588 firms, of which 164 were in Ghana, 224 were in Kenya, and 200 were in Zimbabwe.

Source: Biggs, Shah, and Srivastava 1995a, tables 3.10 and 3.12.

productivity and growth than even access to working capital. If the percentage of total workers being trained by firms increased by 1 percentage point from its sample average of 9 percent, value added would increase by 60 percent for the sample as a whole and 99 percent for small enterprises (Biggs, Shah, and Srivastava 1995a, p. 54; see also table 5.1).

Workers also benefit from training through obtaining wage premiums. Training was estimated to increase wages by 15 to 21 percent (that is, the wages of workers who received training were 15 to 21 percent higher than the wages of those with similar characteristics but without training). Statistically significant estimates in the DNR study show that the returns to training in African manufacturing in the form of individual wage increases ranged from 19 to 37 percent in Ghana, 15 to 21 percent in Kenya, 16 to 81 percent in Zambia, and 20 to 70 percent in Zimbabwe (Dabalen, Nielsen, and Rosholm 2002, p. 27).

The findings of this chapter, which are based on surveys of manufacturing enterprises in Kenya, Zambia, and Zimbabwe, are consistent with patterns of enterprise training in other developing and industrial countries as summarized in chapter 1 . Using investment in formal training outside the enterprise as an indicator of general skills training, researchers have found that enterprises show a willingness to invest in general skills training alongside firm-specific skills training (see figure 5.9). Both enterprises and workers benefit from training. Firms investing in training for workers tend to be larger in size, foreign owned, and more likely to export. Workers selected for training by enterprises tend to hold white-collar and skilled occupations and are more likely to have higher levels of education. Training in enterprises, while significant, thus tends to be selective. 
Figure 5.9. Workers Receiving Training by Type and Job Category: Kenya and Zimbabwe, 1995

Percentage of workers

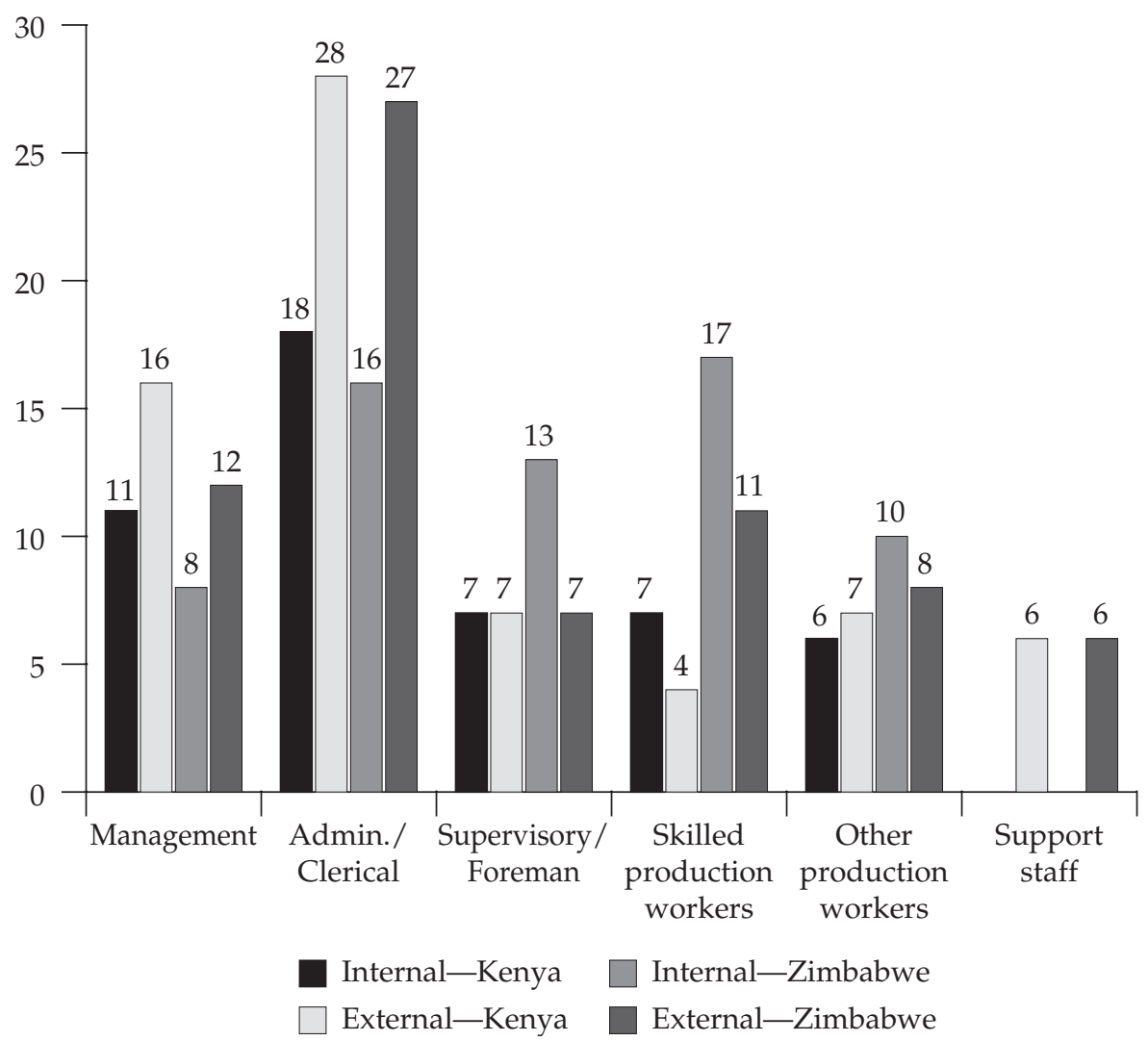

Source: Biggs, Shah, and Srivastava 1995a, tables 4.17 and 4.18.

\section{Recruitment Practices}

Case study interviews in Zimbabwe found that many enterprise managers preferred to hire workers with little previous training or job experience for shop-floor jobs and to put them through a company on-the-job training program. The unskilled labor supply reportedly was so abundant that it was easy to choose workers with sufficient education and aptitude who would require relatively short on-the-job training (Biggs, Shah, and Srivastava 1995a, p. 138). The Kenya and Zambia studies found that young people are being recruited increasingly with entry-level skills acquired-at no expense to the firm - in a variety of training centers and institutes.

Short-term upgrading and skill improvement courses then attune these workers to their new context, which means that the various training institu- 
tions play an important role in providing institution-based training. Companies justify abandoning their long-term in-house training investments because of a ready supply in the market (Grierson 2002, pp. 11, 21). Surveyed enterprises had little expectation of hiring employees who were already skilled. The specific skills are imparted by and within enterprises. For example, one firm in Zambia periodically employs graduates of technical schools and colleges but does not consider them skilled at the point of entry. In all cases, companies seek workers with a good basic foundation and the willingness and ability to learn on the job (Grierson 2002, p. 32). Most enterprises are also raising entry-level qualifications because of the high level of "trainability" required by new management practices and technologies.

\section{Types of Training}

New investments, new technologies, and competitive pressures change the incidence and intensity of employee training after downsizing. There are fewer employees to train, but the sophistication of training often increases. The expanded emphasis on training for the restructured work force is reflected in a more structured and systematic approach to training and a focus on efficiency, quality, and flexibility. In Zambia, for example, emphasis has shifted away from a short-term ad hoc approach to training to a longerterm, more strategic perspective. Training is increasingly competencybased, consistent with the demands of individual enterprises (Grierson 2002, p. 53).

\section{Initial Training}

As stated, virtually all companies put shop-floor employees through some kind of initial training. The duration, rigor, and formality depended largely on the nature of the tasks to be learned and the size of the enterprise. While all firms offered formal training, most of the enterprises in the RPED sample that conducted formal training were multinationals and larger domestic companies. Smaller enterprises engaged in less structured, on-the-job training. Most new shop-floor workers in medium-size and large companies were designated trainees and received a training wage lower than the wage for more experienced employees. In Kenya and Zimbabwe, training was concentrated on senior and key staff members, although almost all staff members received some form of training.

\section{Formal Apprenticeship Training}

Apprenticeship training can be more efficient than institution-based training, as was found in Zimbabwe in the early 1990s (Bennell 1993). However, formal apprenticeship programs are relatively small in modern sector enterprises in Sub-Saharan Africa and appear to be declining in importance. For 
example, only about 6,000 workers are enrolled in formal apprenticeships in Côte d'Ivoire. Apprenticeships take only 0.9 percent of school-leavers in South Africa and 1.5 percent in Botswana. In Zimbabwe, there were only 1,140 apprentices in 1998 (Atchoarena and Delluc 2001, pp. 128, 205, 225). Moreover, the results of apprenticeships have sometimes been disappointing. A different review in Zimbabwe found that 60 percent of the apprentices were unemployed after the apprenticeship period. Absence of follow-up after completion of training and a general lack of business orientation in the apprenticeships contributed to this outcome (Haan 2001, p. 153).

The surveys found that apprenticeship training has virtually disappeared from larger manufacturing companies in, for example, Zimbabwe. ${ }^{4}$ In Kenya, companies were found to be reluctant to maintain long-term apprenticeship trainees, in part because of the outdated training centers to which they would be sent, but especially because of the costs of training and lack of employment opportunities within the enterprise on completion (Grierson 2002 , p. 20). Also, the sheer supply of graduates on the labor market with some technical qualifications has enabled large, formal industry to retreat from the formal apprenticeship system (Grierson 2002, p. 11). Apprenticeships are most prevalent in informal, small companies, particularly in Ghana, where school-leavers pay companies to learn from master craftspersons or technicians (see chapter 6). However, the structure of the apprenticeship system, as constituted in West Africa, is not well suited for training better educated workers for skills needed in modern manufacturing, and thus larger enterprises do not generally use the apprenticeship system.

The problem with formal apprenticeship is partly explained by the length of time and commitment required-usually 2 to 4 years. South Africa is introducing an innovation in the form of "learnerships," which reduce the length of training. Learnerships are "workplace learning programs supported by structured institutional learning which result in a qualification" (South African Department of Labor, as quoted in Afenyadu and others 1999, p. 52). They cover not just employed people but also people who have yet to seek employment and the unemployed, and they are intended to span all sizes of enterprises and all degrees of formality, including micro and small enterprises. Learnerships seek to eliminate the dichotomy between formal and informal when providing training (Afenyadu and others 1999, pp. 52-53). From a provider perspective, the learnership system offers a new source of funds. As an incentive to take on more learners, employers will receive grants to apply toward the costs of training. This innovation is expected to expand the market for providers (Atchoarena and Delluc 2001, p. 239).

\section{Upgrading Training}

Another form of enterprise-based training is upgrading training of a more continuous nature. Companies invest in continuous training of their experienced employees to maintain and improve skills or to impart new skills. 
This upgrading may take place in-house or outside. Training within the enterprises was the most common form of skills training because of the limited array of external training options. External training was more prevalent than in-house training in Zimbabwe. This finding reflects the existence of a local training infrastructure that can be accessed. In particular, Zimbabwe's more extensive array of training centers provided more alternatives than did institutions in Kenya and Ghana. Both large and small companies engaged in external training, but large companies did more (Biggs, Shah, and Srivastava 1995a, pp. 80-83).

Enterprises with strong company group linkages or the resources to access external support have the advantage in training employees. Many enterprises in the Grierson (2002) survey acted as agents or representatives of multinational corporations and thus had access to training support from parent companies. In such cases, training policies, practices, materials, and trainers are often provided — and sometimes required - by the parent enterprise. Such relationships appear to be growing, as in Zambia, and can be seen as a normal and positive aspect of globalization and foreign direct investment (Grierson 2002).

The ILO/ITC survey in Kenya identified a decline in off-the-job sponsorships, both to local polytechnics and to overseas institutions. Instead, there appeared to be support for access to distance-learning programs for the highest level of technical qualifications. Distance-learning programs can ensure international standards and can cost substantially less, particularly in terms of work time lost while attending the programs. One food-processing company replaced full-time external training with internal training, supplemented by training videos (Grierson 2002, p. 16).

Generally low educational levels of the industrial labor force increase the amount and cost of training needed by workers and also reduce the effectiveness of that training. The costs and methods of training are affected by the pool of talent on the shop floor. In industrial countries with high levels of education, such as Germany and Japan, workers can follow detailed and complex written instructions in job specifications and procedures manuals. Most of the training materials are, therefore, designed for self-teaching. However, in Africa, very little of this type of learning takes place because of low literacy levels. In both Kenya and Zimbabwe, half the companies surveyed used no technical documentation or procedures manuals, and another 30 percent used very little documentation. In Ghana, the use of documentation and procedures manuals is even lower. High illiteracy and innumeracy raise the cost of a company's investment in training and productivity improvement (Biggs, Shah, and Srivastava 1995a, pp. 92-93).

Underinvestment in training in Africa can take two forms. First, African firms are generally spending less and providing workers with lower-quality training than competitors in other developing countries. Second, even with the same level of spending or training quality, lower human capital at entry 
means that the training in African firms cannot achieve the skill proficiencies of competitor countries (Biggs, Shah, and Srivastava 1995a, p. 93).

\section{Public-Private Partnerships}

The surveys detected a distinct disengagement by enterprises from public sector training provision and oversight. In Zambia, private and public training were seen as increasingly "worlds apart" (Grierson 2002, p. 57). Despite growing training needs, there is little effective interaction between public sector training institutions and formal sector enterprises. The use of formal training institutions is largely limited to hiring school-leavers and graduates as needed. In part, this limitation is because of the severe decapitalization in public training and its failure to modernize and to reform (Grierson 2002, p. 7).

The BSS survey also pointed to a problem of lack of cooperation between the government and private training providers. Governments are involved in training the work force, collecting training taxes, and qualifying and certifying skills. These services are not generally valued by the industrial community (Biggs, Shah, and Srivastava 1995, p. 108). Much of the public-industrial interaction has been adversarial, including industries pushed to absorb unwanted graduates from vocational institutions while at the same time being excluded from a role in the organization and curriculum of training and in the allocation of training taxes (Kenya and Zimbabwe). Some private training providers have picked up the slack in meeting external training needs of companies, particularly Zimbabwe's large correspondence schools and growing network of private colleges and training centers. But the government and the private schools have often been in conflict. The government sometimes characterizes the private schools as of poor quality but seems more concerned with control and regulation than with improving its own contribution to human capital development (Biggs, Shah, and Srivastava 1995a, p. 108).

One area for public-private partnerships could be in supporting open training by enterprises. Some enterprises, notably in Southeast Asia, open their training programs to outsiders, such as suppliers and employees of smaller firms. This openness not only benefits the wider community, but also allows the company to employ those who perform the best.

\section{Collective Support Services}

Scarcity of technical personnel can be countered by collective support services. Access to technical courses outside the firm is the most popular, broad-based support in other countries such as Indonesia (Biggs, Shah, and Srivastava 1995a, p. 212). Similarly, among the African companies surveyed, employee training was at the top of everyone's wish list (Biggs, Shah, and Srivastava 1995a, pp. 93, 104). However, business associations were found 
to deliver virtually no technical services to members (Biggs, Shah, and Srivastava 1995, pp. 105-7). This vacuum was confirmed by the ILO/ITC case studies. Little interenterprise cooperation existed in training in Kenya and Zambia, and no evidence was found that trade or sectoral associations offered useful training support, provision, or assessment.

\section{Coping with HIV/AIDS}

HIV / AIDS is a recognized problem with a significant negative impact on companies (chapter 2). Many companies have now begun to screen applicants, offer awareness training and counseling, and provide limited forms of financial support. Some companies externalize their work forces through day contracts or subcontracting of services. However, these practices are less appropriate for skilled workers. It is not possible to select a worker at random to do a skilled job. Employers use an array of means to compensate for skills lost to HIV / AIDS. Some multinationals in South Africa reportedly hire three workers for each skilled position "to ensure that replacements are on hand when trained workers die." (The Economist 2001, as cited in Bloom and others 2002, p. 7). More typically, enterprises increasingly rely on training functionally flexible workers ("multi-skilling") for two or more different, usually related, occupations. Functionally flexible workers are capable of carrying out several types of work involved in manufacturing (Aventin and Huard 2000, 173). Multi-skilling and team-working help alleviate the effects of HIV / AIDS by increasing and dispersing manual skills within and among teams, instead of concentrating them on individuals. In Zambia, the main reason for adopting these practices was not to compensate for AIDS but to increase efficiency and quality and to ensure enough skilled workers to support three-shift production (Grierson 2002, p. 44). Multi-skilling naturally involves increasing company investments in training and has implications for the type of skills that should be offered by training institutions.

\section{Notes}

1. See Biggs, Shah, and Srivastava 1995a; Dabalen, Nielsen, and Rosholm 2002; Grierson 2002. The DNR study is based on a series of background papers prepared by the authors for this review.

2. It is important to recognize the strengths and limitations of the RPED surveys. They were conducted in firms of varying size and ownership but included mainly anglophone countries (four of five) and all firms were in the manufacturing sector. The data pertain to the period from 6 to 10 years ago.

3. Such mechanisms include training workers inside and outside the firm; conducting internal research and development; hiring expatriates; obtaining external access to foreign buyers and suppliers; interacting with other companies; and transferring technology from abroad through technical assistance contracts or licensing arrangements, foreign ownership, and exports (Biggs, Shah, and Srivastava 1995a, pp. 52, 207). 
4. In the late 1950s, a formal apprenticeship system was introduced in Zimbabwe, but only for Europeans. It operated in seven fields. At independence, this system was opened to all Zimbabweans. Between 1,000 and 2,000 apprentices were registered annually by companies in the 1960s and 1970s, but at the time of the RPED survey, the number had declined substantially to the point where it was difficult to find an apprentice on the job in manufacturing. Most of the apprentices receiving training were working in parastatal organizations such as railways (Biggs, Shah, and Srivastava 1995a, p. 138). 


\section{Building Skills for the Informal Economy}

Enterprises in the formal sector are active trainers, but in the informal sector among smaller enterprises-many operating at the subsistence level with unpaid family workers-skills development is more problematic. Filling this gap is important for poverty alleviation. Traditional apprenticeship is the most important source of training for workers in the informal sector. This training is closely matched to market needs, cost-effective, and self-financing, but it tends to perpetuate existing technologies. Improving awareness of and access to skills development in the informal sector remains a challenge for public intervention. A list of ideas for doing this is offered along with ideas for developing a training strategy for the informal sector.

\section{Introduction}

The stagnation of wage employment in the formal sector, highlighted in chapter 2, has forced large numbers of workers to pursue employment in the informal sector through self-employment. In most African countries, 30 percent of total employment is engaged off farms in the informal sector, two-thirds in urban areas and one-third in rural areas. Workers in the informal agricultural sector account for about half of total employment. The informal sector is the safety valve for these economies and an increasingly important instrument for poverty alleviation, in view of the low productivity and earnings in many micro and small enterprises.

Training by itself, however, is not sufficient to achieve this objective; other interventions are often crucial—for example credit, stable work environments, and access to markets and technology. Skills development is nevertheless an essential instrument in enabling an enterprise to generate income. Training is one element in a package of inputs for supporting the informal sector (Nell, Shapiro, and Grunwald 2002, pp. 14, 66). This chapter looks at skills development in the informal economy and addresses the following questions:

- What are the strengths and weaknesses of traditional apprenticeship training?

- What lessons can be drawn from recent efforts to support skills development in the informal economy?

- What are the elements of a training strategy for the informal economy?

This chapter summarizes two works commissioned for this review by the ILO/ITC (Haan 2001 and Haan and Serriere 2002). 
The importance of skills training for the informal sector is rooted in the need to enhance the productivity of informal sector activities and improve the quality of its products and services, in order to raise the incomes of those employed in the sector. Technical skills are crucial to diversifying product ranges and avoiding saturation of conventional informal sector markets. They are also important for improving occupational safety and health.

\section{Demand for Skills}

Few informal sector operators see the need for, or value of, skills development for themselves or their workers. Instead, as identified by informal sector operators in Tanzania, their main problems are limited access to capital, inadequate demand for their goods and services, lack of appropriate equipment, and difficulties in finding work sites. Lack of qualified workers was at the bottom of the list. Problems with the regulatory framework also constrained informal sector operations; for example, business registration and licensing, bribes, inability to comply with the health act, and the requirement to open an income tax account (Haan 2001, p. 72).

Lack of awareness of skills shortcomings and of opportunities to apply newly acquired skills stunt the demand (and the willingness to pay) for training (Ziderman 2003, p. 155). Despite low skill levels, fewer than half of the informal sector operators surveyed in Uganda indicated that they needed training. In Kenya, small producers did not deem training very important. Half said there was no need to train their workers. In Senegal, just over one-third of the informal entrepreneurs surveyed among leather workers indicated any skills problems, as compared with three-quarters who were experiencing marketing problems. However, there are exceptions. In Uganda, demand for training was high among the 45,000 clients of microfinance institutions (Haan 2001, p. 51, 102).

If the informal sector is to continue to absorb more people and supply a modest but reasonable return on their labor, it is crucial to increase the skills of informal sector operators. Improved technical and business skills are of prime importance for enhancing the productivity of informal sector activities as well as the quality of the goods and services produced. These improved skills will strengthen the informal sector's ability to compete in the present situation of economic liberalization and globalization. Technical skills, together with other types of support (for example, access to credit, technology, markets, and information), are imperative. Consistent with information market failures and the perceived lack of need for skills, the majority of informal sector operators have no formal training. In Tanzania, only 2 percent of informal sector operators have acquired any skills through the formal training system. In Uganda, the comparable figure is 6 percent, and only 1.4 percent of Ghana's working population has received any formal skills training. Operations in the informal sector face difficulties in identifying their training needs because of limited knowledge of recent technological developments in their trade. 
What distinguishes skill requirements in the informal sector from formal wage employment is the breadth of tasks that need to be performed. Selfemployed workers in the informal sector usually need to complete specific jobs by themselves, from beginning to end (Nell, Shapiro, and Grunwald 2002, p. 22). They must perform a full range of business functions, from initial marketing surveys through cost and quality control, financing, and marketing. The main skill requirements fall into four categories, as shown in table 6.1. A major focus of training should be to enhance the creativity of the producers in finding solutions to their own problems, not just to provide standard programs (Nell, Shapiro, and Grunwald 2002, p. 22).

\section{Training Supply}

In relation to these training requirements, existing public training capacity is inadequate (see chapter 3). Training provided in Kenya reaches less than 7 percent of labor market entrants each year, not counting the backlog of those already in the labor force. The existing training capacity is devoted almost exclusively to pre-employment training for the wage economy. Training is rarely given to the vast majority of the population already working in the informal sector and in need of skills upgrading. Vocational training centers offer a limited range of conventional trades and pay little or no attention to business skills. Choices are especially limited for girls and women (for example, tailoring and catering). To some extent NGOs have stepped in to fill the gap left by government. Their training is generally more relevant (more practical, linked with literacy and some business skills), but the courses tend to be lengthy, limited in range of trades, and lacking posttraining assistance.

Training for work in the informal sector is fundamentally different from that for work in the formal sector. It is characterized primarily by a close link with production, a distinct target group, full self-financing, and an unconventional delivery for immediate results. The dominant form is traditional apprenticeship training.

\section{Traditional Apprenticeship Training}

Traditional apprenticeship training is responsible for more skills development than the offerings of all other training providers combined. It is less well developed in eastern and southern Africa than in West Africa. Still, in all countries traditional apprenticeship training is probably the most important source of technical and business skills for workers in the informal sector. In Ghana, 80 to 90 percent of all basic skills training comes from traditional or informal apprenticeship, compared with 5 to 10 percent from public training institutions and 10 to 15 percent from nongovernment for-profit and nonprofit training providers (Atchoarena and Delluc 2001, p. 225). Almost all the training programs taken at formal vocational training institutes (VTIs) in Ghana can also be mastered through traditional apprenticeship. 
Table 6.1. Training Needs in the Informal Sector

\begin{tabular}{|c|c|}
\hline Skill area & Informal sector operators and master craftspersons \\
\hline Technical skills & $\begin{array}{l}\text { - General upgrading of technical skills used in trade } \\
\text { - Improved knowledge of materials utilized in trade } \\
\text { - Practical ways to cut down on waste of materials } \\
\text { - Basic reading of designs and drawings } \\
\text { - Repair of own equipment } \\
\text { - Additional skills required for new product designs } \\
\text { - More advanced equipment, improved technologies } \\
\text { - Basic knowledge of industrial production techniques } \\
\text { in the trade }\end{array}$ \\
\hline Management practices & $\begin{array}{l}\text { - Costing and pricing and related aspects of financial } \\
\text { - Vdministration } \\
\text { - } \text { rudimentary market research } \\
\text { - Customer relations, including setting up a customer } \\
\text { - Data base } \\
\text { - } \text { manision of labor in the workshop and personnel } \\
\text { - Input stock planning } \\
\text { - Quality control } \\
\text { - Time management } \\
\text { - Legal and fiscal regulations }\end{array}$ \\
\hline Literacy and numeracy & $\begin{array}{l}\text { Low educational attainments limit trainability and } \\
\text { consequent skills achievements. Studies on the } \\
\text { training needs of operators in the informal sector } \\
\text { reveal a felt need for functional language, either } \\
\text { English or French. }\end{array}$ \\
\hline Other & $\begin{array}{l}\text { - Knowledge of recent technological developments in } \\
\text { the trades } \\
\text { - Teaching skills: improvement in the teaching skills of } \\
\text { master craftspersons, to increase the effectiveness of } \\
\text { the training. Apart from the naturally gifted, masters } \\
\text { typically know little about effective training methods } \\
\text { for (young) adults. } \\
\text { - Cooperative work: why and how to work together, be } \\
\text { it informally or as a trade association. This would } \\
\text { include the role of groups in micro and small } \\
\text { enterprise development, structures and processes of } \\
\text { an association, group dynamics, etc. }\end{array}$ \\
\hline
\end{tabular}

Source: Haan and Serriere 2002, pp. 135, 145. 
The number of apprentices in the informal sector is substantial, particularly in West Africa, and is expanding. In Benin the number of traditional apprentices increased by more than 10 percent per year, from 36,000 in 1979 to 145,000 in 1992. In Cameroon, in contrast with a total public training capacity of about 14,000 trainees, traditional apprenticeship is said to enroll a total of 200,000. In West Africa, it is not uncommon to find more apprentices than regular wage employees in informal sector firms. This is also true in Senegal, where the share of apprentices has grown from 40 percent of the total work force in the informal sector in 1980 to an astounding 70 percent in 1995 (Haan and Serrier 2002, pp. 50, 57, 133).

Traditional apprenticeships are not just about training. They serve broader social objectives of socialization and economic objectives of reproduction and expansion of the informal economy.

The ubiquity of apprenticeship in the informal sector, especially in West Africa, derives from a variety of social and economic factors. First, low enrollment rates and poor internal efficiency force children out of school at a young age. Many either drop out of primary school or are "locked out" by lack of places in secondary education. Second, families with many children often can afford to send only a few to schools; boys are typically placed in workshops if they are not in school. Third, low value-added products and irregular revenues discourage informal sector entrepreneurs from employing full-time workers and force them to rely on cheap labor such as apprentices.

Traditional apprenticeship training can be the least expensive way to get skills training. It can cost only a few dollars per month, although at that price the usefulness of such training may be commensurately low. A more realistic level of apprenticeship fees would be about $\$ 10$ to $\$ 15$ per month, which is in line with recent training charges assessed by the public sector and NGO VTIs. Private for-profit training is considerably more expensive, with training fees running at about $\$ 50$ to $\$ 60$ per month.

No single approach applies, but the following description captures the main parameters of traditional apprenticeships. A written or oral agreement is concluded between a "master" and parents or guardians for an apprentice to acquire a set of relevant, practical skills. Sometimes the master receives a training fee. In other situations, the apprentice has to "earn" the training in exchange for work or reduced wages. Training consists primarily of observing and imitating the master. The apprenticeship is usually for a fixed period ( 3 to 4 years) instead of competency based, and it is product specific. Theoretical aspects and basic technical practices (for example, precise measuring) are largely ignored. The dropout rate is estimated at 25 percent. Few apprentices start their own business immediately upon completing apprenticeships. Apprentices today often have had more formal schooling than their master. It is also common for people who took formal vocational training to pass through apprenticeship before setting up shop for themselves.

Views about traditional apprenticeship vary among the principal actors. Working conditions can be harsh (box 6.1). 


\section{Box 6.1. Senegal: Views on the Position of an Apprentice}

View of Apprentice

Apprentices express dedication to their trade and are anxious to get out of being a "galley slave": "They ask me to do too many things-it is as if to learn a trade I have to be exploited."

\section{View of Master Craftspersons}

Most master craftspersons feel that apprenticeship training is the last resort for youth on whom parents have turned their backs. This notion is reinforced by the impression that many apprentices are on the brink of delinquency when they enter into training. The master craftspersons consequently feel like good citizens and are fully in charge.

\section{View of the Family}

For the parents, apprenticeship training is the last recourse: they are keen to pass on, without further cost, their responsibilities with regard to education and training of their children.

Source: Haan and Serriere 2002, p. 58.

Traditional apprenticeship training confers substantial advantages over conventional training methods and is a major provider of skills in SubSaharan Africa, but it also has some disadvantages (table 6.2). The characterizations below are general and not every one applies to every type of apprenticeship (of which there are many).

The main strengths of traditional apprenticeship are its practical orientation, self-regulation, and self-financing. Apprenticeship also caters to individuals who lack the educational requirements for formal training, serves important target groups (rural populations and urban poor), and is generally cost-effective. Its disadvantages must be weighed against these strengths. Traditional apprenticeship is gender biased, screens out applicants from very poor households, perpetuates traditional technologies, and lacks standards and quality assurance. In many countries and business environments, apprenticeship has served the informal sector well but is proving too narrowly focused to cope with the increasing challenges of technical change, skills enhancement, and wider markets (Ziderman 2003, p. 154). Efforts are needed to stimulate improvements in traditional apprenticeship training.

Although widespread, apprenticeship training is relatively unsophisticated. The practice is fragile and can be easily distorted. Any attempt to intervene directly in the practice of training apprentices could easily do more harm than good and create another supply-driven, dependency-induced training program. Many of the advantages of traditional apprenticeship stem 


\section{Table 6.2. Advantages and Disadvantages of Traditional Apprenticeship as a Means of Skills Development}

\begin{tabular}{ll}
\hline Advantages & Disadvantages \\
\hline Organization and structure & \\
\hline $\begin{array}{l}\text { Self-regulating } \\
\text { No tradition of government support, } \\
\text { control, or supervision }\end{array}$ & No clear organizational structure \\
& Lack of supervision can allow exploitation of \\
& $\begin{array}{l}\text { cheap labor } \\
\text { Sometimes long duration (up to } 8 \text { years) }\end{array}$ \\
&
\end{tabular}

\section{Coverage and equity}

Major source of skills development among all training sources in most Sub-Saharan Africa countries

More mature, motivated trainees than in formal pre-employment training

Important source of technical skills for those who lack the education required to qualify for formal training, especially those who are illiterate or semiliterate

Easy access for boys from early age to age 18-20

Relevant for the unemployed in general

Apprenticeship is a mechanism to integrate idle and sometimes delinquent youth into the world of work

Serves mainly rural populations and urban poor

Useful for skill upgrading
Possible screening out of poor applicants by up-front payment of apprentice fee

More common in male-dominated trades and therefore, less access for women and girls Expansion of coverage is limited

Entry of very young children (possibly onefourth of apprentices in Senegal are younger than 15)

Cost and financing

Self-financing; no need for subsidies; no cost to state or community; costs borne by apprentices and their families

No need for special training centers and separate training tools or equipment

Costs are markedly lower than formalized training Parents can pay over time (monthly) 


Advantages Disadvantages

\section{Training content and teaching methods}

Closely tied to employment (rooted in the world of work); youth get acquainted with real work conditions

Work-based, therefore practical; what is taught depends on what is produced

Technical skills, business skills, customer service, and work

attitudes often integrated

Learning by doing

Well adapted to conditions in the real world of work

No predetermined training program with curricula and training materials

Static, not dynamic; introduction of new product designs and production technologies excluded; traditional technologies perpetuated

Not exposed to modern training approaches; masters perhaps lacking in teaching skills

Learning generally passive and not experimental Lack of attention to theoretical aspects

Important skills often deferred to end of training by masters to prevent early departure of apprentices

Some masters do not teach full set of skills for fear of competition from graduated apprentices

Often poor training and working conditions

Often high apprentice-to-master ratio

Little attention to occupational safety and health issues

Low educational levels of apprentices often limit results

Lack of clear standards and monitoring; disparate quality; outcomes dependent on workshop owner's abilities and interest

No common competency-assessment procedures; seldom linked with posttraining skills testing No accepted certification

Skills obtained often incomplete; related aspects sometimes not taught (for example, resource use, customer orientation)

Effects and outputs

Allows for building up informal sector business network (for example, contacts with suppliers and clients) Often results in employment in the same workshop
Graduated apprentices starting a business in competition with master craftspersons for same customers

No training follow-up support (for example, credit, business advice)

Sources: Authors' compilation based on Haan (2001), Haan and Serriere (2002), and Atchoarena and Delluc (2001, p. 225). 
from its informal and flexible nature. Attempts to formalize it through bureaucratic regulations on type, duration, and conditions of training may decrease its appeal.

Apart from traditional apprenticeships, training markets for the informal sector have largely failed to develop because of constraints on the demand and supply sides. Effective demand for external training in the informal sector is stunted for several reasons. As already mentioned, informal sector entrepreneurs often lack an awareness of shortcomings in their skills and those of their employees. They also lack information about how to exploit new skills to their economic advantage.

Master craftspersons who have upgraded their skills often are not able to increase their prices to reflect their improved products. Consumers may not be able to afford higher quality at a higher price. These circumstances discourage demand for training by artisans. The lack of training supply means that potential trainees have little scope to learn about training opportunities. The incentive for new training suppliers is weak, given the lack of demonstrated demand and the risks involved in pioneering new training. Formal training institutions have done a poor job of adapting to the informal sector's particular skills needs (Ziderman 2003, p. 155). In this setting, governments, training authorities, or donors can play a central role in facilitating the development of training markets.

\section{Initiatives to Support Training Markets}

Most of the attention to training for the informal sector has been donor driven. Over the past decade, extensive attention has been given to informal sector training by donors including GTZ, the World Bank, the DfID, DANIDA, and the Swiss Development Corporation. A typology of donorassisted programs includes both supply-side interventions (most common) and a few attempts at generating demand for training. Supply-side projects are of two types: pre-employment training for entering self-employment (Tanzania and Madagascar); and in-service training to raise the productivity and incomes of individuals already working in the informal sector (Benin, Côte d'Ivoire, Kenya, Zimbabwe). The World Bank voucher scheme in Kenya illustrates a demand-side intervention that tapped the available financing for employees through informal sector associations to generate a supply response in the form of courses offered by master craftspersons. Nine project cases are presented in the appendices. ${ }^{1}$ The following lessons can be extracted from these projects and others reviewed by Haan (2001) and Haan and Serriere (2002).

Overall, the review reached a positive conclusion: Informal sector enterprises can be upgraded through targeted skills development. The application of new skills stimulated growth, innovation, and productivity improvements in informal sector enterprises. Training interventions proved a useful entry point for upgrading the technology of small and medium 
enterprises (Kenya Strengthening Informal Training and Enterprise [SITE], Cameroon Programme d'Appui au Milieu Artisanal de Maroua [APME]).

Projects need to start with an assessment of market niches and growth prospects, and avoid saturated markets (Tanzania Integrated Training for Enterpreneurship Promotion [INTEP], Ghana Opportunities Industrialization Council [OIC]). Programs tended to overconcentrate on particular trades. Market studies can help avoid this problem. A market-oriented approach, in which new local products are identified or created through promotional activities, was also found to be effective (Cameroon APME).

Demand for training among master craftspersons cannot be assumed. It has to be cultivated. The SITE project in Kenya found that master craftspersons were not immediately interested in receiving skills training and needed to be "hooked." The Bureau d'Appui aux Artisans (BAA) project in Benin found the need to inform master craftspersons extensively about the benefits of complementary training for themselves and their apprentices. The training must be seen to generate tangible business improvements so as to interest the masters.

Selection of master craftspersons for upgrading is a key factor in success. The Informal Sector Training and Resources Network (ISTARN) project in Zimbabwe found that it had to pay more attention to the suitability of the masters. They did not always understand their mentoring role and training function.

Working through informal sector associations (ISAs) can be instrumental to success (see box 6.2). The Kenya SITE project found that collaboration with ISAs is of prime importance. ISAs were the main implementers in the BAA project in Benin. The training committee of the ISA helped prepare training modules, select trainees, and control attendance and final evaluation of the training. ISAs also played a major role in the Ghana Rural Enterprise Project in selecting participants, developing curricula, monitoring progress, and arranging follow-up support.

However, the use of informal sector associations is no guarantee of success. In the Ghana Vocational Skills Project (VSP), ISAs were not helpful with distributing "intake vouchers" to members. Incentives were missing. Small, grass-roots ISAs, although weaker, tend to be easier to work with than large, national, more bureaucratic ISAs. For example, the Chambres des Metiers (trade chambers) in Senegal were set up in the early 1980s to act as intermediaries on behalf of the sector. They were expected to support the artisan sector by providing, among other things, skills training. Instead, they emphasized legal and administrative organization and became rather bureaucratic and ineffective, representing at most 10 percent of the enterprises.

ISAs themselves can be instrumental in addressing common problems of skill shortages. Groupement Interprofessionnel des Artisans (GIPA), a group of more than 100 small enterprise owners in Cameroon, exemplifies collective action to overcome a lack of adequately skilled workers for small workshops. It organizes supplementary training and has introduced a common examination for workshop trainees among the membership. In 


\section{Box 6.2. The Role of Informal Sector Associations}

West and Central Africa offer interesting examples of the role that informal sector associations (ISAs) can play in apprenticeship training. In Ghana, associations of dressmakers, carpenters, and others are actively involved in the supervision of skills training. The member master craftspersons monitor the training providers and award their own certificates upon completion of training. GIPA, as part of its activities to get more skilled workers for key trades in Cameroon, is planning to organize technical theory workshops to be conducted by educated artisans.

In various countries, especially in donor projects, ISAs are used to identify the training needs of their members and prepare the training curricula. Especially in Benin, ISAs are fully engaged as partners in project implementation. They assist in the selection of the training participants, provide some of the locations for the training, and take care of the monitoring of the training programs. Sometimes they are responsible for the payment of the contribution of the masters towards the training (for example, 30 percent of the training costs).

Experiences in Senegal and Benin point to the contribution that ISAs can make to raising awareness, especially among master craftspersons, about the need to upgrade their own skills as well as the benefits of letting their apprentices follow complementary training. Finally, there are some interesting examples of ISAs taking responsibility for following up on the training. In Yaoundé GIPA has gained valuable experience in organizing skills testing. Other ISAs ask their more experienced members to guide younger artisans and to assist them in marketing, and they make (group) loans available to apprenticeship graduates.

Source: Haan and Serriere 2002, p. 151.

addition, it awards certificates and is in the process of establishing standards for content and length of apprenticeship training. Fédération National de Professionnels de l'Habillement (FEDNAPH), an organization in Senegal with some 10,000 members among small- and medium-sized garment enterprises, shows that trade associations can effectively provide skills for the informal sector under the following conditions: (i) clearly understood self-interest among the members to participate, (ii) leadership, and (iii) relevant financial and technical assistance. The program demonstrates that enterprises in a particular sector-when faced with a shortage of skilled workers-can band together to set up a training facility to solve their common problems.

Similarly, collaboration among small training providers is a promising means to raise quality. About 15 NGO training centers in Douala (Cameroon) have organized themselves into a network to try to improve the quality and outcomes of their training. An association of apprentices and compagnons (apprentice graduates) was established in Senegal to raise 
awareness on problems related to apprenticeship training (for example, organization and conditions of apprenticeship training and lack of start-up capital).

A participatory approach needs to be used in planning the training. Positive results were obtained through this method in Tanzania and Kenya. On the negative side, the Cameroon APME project followed a paternalistic approach in which the artisans were more subjects than partners. The training needs were not indicated by the micro-producers themselves, but by the trainers, who were said not to listen well to the artisans.

It is difficult to reorient VTIs to training for the informal sector. This was found earlier in an examination of attempts by training institutions to reorient themselves to training for entrepreneurship and self-employment (see chapter 3). Most alleged reorientations were VTIs converting into some form of enterprise start-up, abandoning vocational training entirely. Others simply added on enterprise components without much success. Thus, few successful reorientations can be identified-and certainly no replicable models (Grierson and McKenzie 1996).

National training agencies supported by DANIDA in Sub-Saharan Africa were criticized for their almost exclusive orientation to pre-employment training in the rapidly disappearing wage sector. "There was no clear vision supported by well-defined objectives ... in relation to poverty alleviation and how, in particular, micro-enterprises could be more effectively served" (DANIDA 2002, p. 43).

This review found the same difficulties in reorientation of formal training providers to the clientele and requirements of the informal sector. Linkages with VTIs proved disappointing in the Kenya SITE project. They did not become sustainable providers of training to micro and small enterprises. The use of instructors from technical training colleges in the ISTARN project in Zimbabwe who were accustomed to teaching trainees with much higher levels of previous education, also proved ineffective. It resulted in instruction over the heads of the target group. Moreover, training in formal VTIs could mean the use of inappropriate equipment. As found in the Senegal Association pour une Dynamique de Progrès Economique et Social (APDES) project, training for master craftspersons should not take place in technical colleges; the equipment can be too modern and the skills not those used in the typical marketplace. Moreover, attempts by VTIs to revitalize themselves may be primarily responses to ministerial dictates that involve little or no responsiveness to the informal sector (Hoppers 1994).

As presently structured, formal government VTIs appear to have little to offer for promoting employment in the informal sector. If used, they need to be reoriented and revamped to participate in providing complementary training to master craftspersons and apprentices.

Project experience shows that independent trainers can be groomed as providers of training services to the informal sector. It is possible to stimulate a supply response from independent trainers (as in Uganda and 
Kenya). The main lesson from the Uganda project is that master craftspersons trained as advisers to small and medium enterprises have grasped the idea that those businesses can improve their operations and that they, the trainers, can help them do it. Unexpectedly, skilled craftspersons emerged as the leading providers of training under the voucher program in Kenya. Entrepreneurs preferred to learn from craftspersons rather than from formal institutions.

Low levels of basic education handicap training, both of master craftspersons and of apprentices. Literacy training addresses a real local demand and is an important precondition for effective business development (Cameroon APME). International experience from the combined teaching of adult literacy and livelihood skills is relevant here (Oxenham and others 2002). The main findings from this experience are shown in box 6.3. Combining literacy with livelihood skills training can be considered when developing strategies for supporting the informal economy.

In content, it is best to mix technical with business skills (record keeping, pricing, marketing, and customer relations). However, interest in business skills often has to be stimulated. Few artisans have a genuine interest in bookkeeping. If they start bookkeeping, they tend merely to go through the motions while maintaining their own informal system; bookkeeping only becomes interesting once a firm reaches a certain level of sales (Cameroon APME).

Shorter courses do not necessarily affect the quality of training adversely. On the contrary, the evaluation of two projects in Ghana (VSP and OIC) concluded that job-oriented competency is achieved more quickly in shorter courses (6 and 12 weeks) that focus on practical skills rather than lengthy theoretical classroom instruction.

Training has to be delivered in a flexible manner, taking into account the opportunity cost of the time and labor of the participants. All examples show that training should be part-time and should take place in the (late) afternoons or weekends, in order to allow the masters and apprentices to carry out their regular work to the extent possible. Part of the success by master craftspersons in providing training in the Kenya Jua Kali in formal sector project was their adaptation of training schedules to entrepreneurs' need for short, practical training.

Make the training groups homogenous. Do not mix master craftspersons with apprentices in the same classes or compagnons (graduated apprentices who continue to work with the master) with apprentices (Senegal APDES).

One of the shortcomings of traditional apprenticeship is the absence of end-of-training assessment of the skills acquired. The National Vocational Training Institute in Ghana has introduced competency-based skills tests that allow illiterate trainees, including traditional apprentices, to submit their skills to practical, nonwritten evaluation. The proficiency tests differ from regular trade tests and do not include written examinations. The knowledge of tools and equipment is assessed during an interview. Proficiency tests 


\section{Box 6.3. Main Findings from Study on Literacy for Livelihood Skills}

- The success of combined teaching of literacy and livelihood skills has been demonstrated in a number of promising cases.

- Hardly any cost analysis has been done on these combined programs, but they most likely have higher unit costs than programs that teach only literacy. Compared with annual unit costs in formal schools, recurrent unit costs in adult education can be expected to be low because there is nearly always much less teaching input. Investment in special facilities for adult education will rarely be needed.

- A basic grasp of literacy and numeracy is a valuable foundation for learning vocational skills and for succeeding as a micro entrepreneur. An adult education course is one means of providing such a foundation of basic general skills (in addition to basic education in schools). For the average learner, 360 hours of tuition in reading, writing, and calculating seem to be a safe minimum needed to achieve lasting literacy skills.

- The most effective approach to teaching combinations of literacy and livelihood skills is to add literacy and numeracy teaching to projects that have been set up mainly to teach vocational skills for livelihood-rather than projects that would add vocational skills training as an extension of projects set up, managed, and staffed mainly to teach adult literacy.

- Vocational skills for livelihood will normally require inputs from teachers recruited for that purpose. Literacy instructors cannot be expected to provide that input. Therefore, livelihood training with literacy requires two cadres of instructors: livelihood skill specialists and literacy instructors.

- Responsiveness to demand is a prerequisite for success-the content (and the style of teaching) should seek to respond to what the learners want.

- In mounting such programs, collaboration with established groups of learners (for example, women's associations, farmers associations, religious congregations) seems more promising than individual recruitment of learners.

- Access to micro credit helps learners turn new skills into improved livelihoods. Collaboration with established savings and credit schemes is a way to do that. Setting up savings and credit schemes in conjunction with developing combined literacy and livelihood training can also succeedprovided that staff members are sufficiently well trained to help groups start their own savings, followed by help in using the savings to generate credit and then by expansion from the reflows.

Source: Oxenham and others 2002.

accounted for 45 percent of the annual total of 30,000 tests in 2000. Tanzania is also introducing competency-based testing under VETA, which will enable those in the informal sector to be tested on specific modules. GIPA in Yaoundé (Cameroon) is another interesting case. It has organized respected outsiders 
from the public and private sectors to conduct joint trade tests for the apprentices of its member workshops.

Institutional sustainability refers to the integration of new interventions into ongoing organizational structures so the activities can be carried on routinely after assistance has ceased. An evaluation of German-assisted projects in South Africa observed a lack of attention to institutional replication, such as through preparation of guides and manuals, and a lack of integration of training efforts into the normal government department process of training delivery (Nell, Shapiro, and Grunwald 2002, pp. 20, 23).

Financial sustainability turned out to be decidedly low in Tanzania INTEP, as well as Zimbabwe ISTARN and Benin BAA. Fee income rarely exceeded one-fifth of the total costs, so thought has to be given to improving sustainability. Cameroon APME did better in this respect by supplementing fees with the rental of workshops and sale of products to achieve a cost sharing of 62 percent in technical training.

Link training with credit assistance and follow-up support. The impact of apprenticeship training is greatly reduced by the inability of graduates to access start-up capital or business advice on day-to-day problems. Followup support is essential but lacking in almost all cases. BAA in Benin lacked links with posttraining assistance (for example, credit). As found in Senegal APDES, linkages between training and other support activities needs to be designed carefully in advance. In Ghana, the OIC-G has an interesting approach to posttraining follow-up (see box 6.4).

Evaluate the costs and impact of training interventions for the informal sector. This may appear obvious, but it is by no means routine. Most training projects for the informal sector collect information about inputs and immediate outputs (for example, numbers of persons trained), but fail to include

\section{Box 6.4. Training Follow-Up in Ghana}

OIC-G found that many of its training graduates did not manage to set up their own businesses after completing the training. They simply could not mobilize sufficient resources. The Centre therefore employed job developers, who draw up job plans for each trainee and start job searches even before they have finished their training. The Centre continues the counseling sessions for the trainees after they have left the Centre. They help graduates cope with the transfer into the real world of work. It also gives the Centre an opportunity to assess the results of its training offerings and get feedback from both trainees and employers. OIC-G established procedures for field workers to monitor the performance of trainees on attachment as well as the progress of self-employment and micro enterprises set up by its graduates.

Source: Haan and Serriere 2002, p. 38. 
evaluations of the impact of training on income. Some more recent projects supported by the World Bank fared better on impact evaluation, particularly in Côte d'Ivoire ${ }^{2}$ and Ghana. These were decided improvements over earlier efforts. However, even these massive efforts failed to evaluate adequately the costs of training interventions in the informal sector (Johanson 2002, p. 25; Nell, Shapiro, and Grunwald 2002, pp. 19, 21, 42). The least likely question to be asked appears to be, "At what cost were the results obtained?"

Finally, employment and training funds are becoming widespread in West and Central Africa (National Office of Vocational Training [ONFP], which started in 1986 in Senegal; National Employment Fund [FNE], which started in 1990 in Cameroon; National Office of Vocational Training [ONAFOP], which started in 1998 in Niger; and Fund for Development of Continuing Education, Training and Apprenticeship [FODEFCA], which started in 2001 in Benin). They offer opportunities to finance training for and by the informal sector and build capacity in the TVET sector. Employment and training funds are characterized by (i) linkages to greater sources of financing, such as payroll levies; (ii) tripartite governance (employers, workers, government); (iii) training of workers in both the formal and informal sectors; (iv) use of both formal and informal training providers; and (v) use of competition for funds to get the best results. Issues with training funds include their (i) relatively small coverage of training in relation to needs, (ii) uncertain and perhaps excessive unit costs, (iii) unclear criteria for selection of trainees, and (iv) possible lack of impact on broader TVET reform and capacity building. (See chapter 7 for more information on training funds.)

\section{Policies}

Many governments in Sub-Saharan Africa have put policies in place that emphasize training for the informal sector. The Poverty Reduction Strategy in Ghana stresses skills and entrepreneurial development of youth. The program calls for developing and expanding traditional apprenticeship training, promoting entrepreneurship among youth, and technology upgrading for master craftspersons. Policy documents in Senegal give increased priority to the provision of vocational training for small producers and the selfemployed. In Senegal and Benin, major steps are being taken to redefine institutional mandates. Formation continue (skills upgrading) and formation par l'alternance (complementary training for apprentices) have become popularized. In Benin, government technical schools have started to open their doors for training of masters and apprentices outside regular hours.

\section{Training Strategies for the Informal Sector}

One of the first questions to address for training strategies in the informal sector is, "What role should the public sector play?" Box 6.5 provides one answer. 


\section{Box 6.5. Role of Government in Informal Sector Training}

The ILO/ITC study did not find any indication that the public sector has a comparative advantage in providing basic skills training. On the contrary, experiences in Benin with complementary training for master craftspersons and apprentices show that public training centers and especially lycées need to upgrade their training equipment, enhance instructor skills, and adopt more modern teaching methods (for example, adult teaching). The experiences in Ghana with the Vocational Skills Project (see Johanson 2002, part II) indicate that private training institutions pick up innovative training approaches much more quickly, and that they need less support to carry out training on their own.

Instead of providing training, the state can focus on creating an enabling environment for training to take place. This requires (i) providing a clear policy framework (for example, regulations and incentives); (ii) improving the quality of existing skills training, especially in nongovernment training institutions, indirectly by supporting curriculum development, training of trainers, and (competency-based) skills testing; (iii) stimulating investments, for instance through tax incentives or financial support, to increase the capacity and the quality of skills training (for example in facilities, equipment, instructor training, and preparation of training handouts); and (iv) reviewing and revising existing apprenticeship acts which are not only outdated but tend to contain regulations that severely hamper enterprise-based training.

Governments tend to believe that training quality and results can be achieved through compulsory registration of nongovernment training providers. There is no evidence to support this belief. The dissemination of relevant information (for example, type of training provided, fees, and particularly the dropout and completion rates of different providers) can be more effective. The objective need not be the conversion of unregistered nonpublic training providers into a formalized "parallel training system" by stipulating standards for training facilities, equipment, programs, testing, etc. This makes it less attractive for masters to provide training and for low-income apprentices to attend.

Source: Haan and Serriere 2002, p. 142.

Recognition of the informal economy (see chapter 2) has important implications for training. Simple self-employment and income-generating activities require a different set of technical and business skills than are needed to run a larger enterprise that is part of the formal sector. Interventions need to be differentiated or they will not be cost-effective. Depending on their strategies and target group, training providers can (i) direct their training at the high end of the informal sector, for instance, by providing courses for wage employment in small manufacturing workshops; (ii) focus on self-employment in micro-enterprises, preparing trainees to start their 
own business; or (iii) contribute to the promotion of income-generating activities. Each is discussed in sequence below.

\section{Small Workshop Employment}

The option of preparing trainees for subsequent wage employment in small manufacturing workshops requires the least reorientation for training providers. Such training can be made more effective-for instance, by ensuring that the courses indeed respond to the demand for skills that local small enterprises want. Other changes are needed in the delivery of training. Such a focus appears to be especially relevant for urban areas. In view of the churning and turnover in the informal sector and the high failure rate of small and medium enterprises (see chapter 2), one strategy for success is to focus training on the survivors-individuals who have been in business for a few years and are therefore less likely to fail than someone just starting out.

\section{Self-Employment}

Training for self-employment in micro enterprises requires major changes for most training providers, particularly with regard to the following areas:

- Labor market linkages. New trades selected for training need to be based on an analysis of the local labor market and will probably be different for each geographic area. Trainers need to be selected for their special competencies and with attention to cost-sharing.

- Training content. Practical business skills need to be taught, and training for examinations and official certificates de-emphasized. Short modular courses can be introduced. Technical training will need to be broadened beyond the standard trades for which it is now offered (for example, tailoring, carpentry) to avoid market saturation for the products of these trades.

- Training delivery. Training has to be short, modest, and competencybased. Entry requirements should be flexible and training hours and venues convenient for trainees. The focus is on outreach training (that is, taking training programs out to the target audiences) instead of on fixed center-based training.

- Training materials. Poorly educated trainees should be able to follow the materials, most of which still need to be developed.

- Certification. Certification should be based on demonstrable competency.

- Training follow-up. Early attention should be given to complementary services needed to succeed as a self-employed person (for example, credit, marketing, business counseling).

- Income-generating activities. The promotion of income-generating activities is particularly relevant for rural areas, and many NGOs are already engaged in such efforts, by providing micro-credit. Technical 
skills may not be in demand, but income-generating activities cannot be promoted effectively without addressing a "technical" side to transfer practical knowledge about, production techniques, raw materials, tools and equipment, and product design. This does not necessarily amount to a real skills training course, but it requires activities that can be called para-training such as

-Pre-credit technical orientation. Prospective borrowers should be advised of promising economic activities, relevant technologies, the kinds of tools and equipment to buy, and other practicalities.

-Demonstrations. Short demonstrations of applications can be given to introduce nontraditional production techniques and product designs. -Skills transfer. Short training sessions can be offered on skills transfer and the technical aspects of income-generating activities.

-Business counseling. Frequent visits can be paid to borrowers who have started up a new business to help them deal with common administrative and technical problems.

\section{Toward a Strategy to Improve Traditional Apprenticeship Training}

Improving traditional apprenticeship is vital in view of the numbers involved and the potential to raise productivity and incomes in selfemployment. To make traditional apprenticeship more effective, an integrated strategy needs to involve the following elements:

- Improve the image of apprenticeship training. Despite its traditional role, apprenticeship lacks standing. It is often seen as the training provider of the last resort by parents and policymakers, as well as the apprentices themselves. General information campaigns about the role of traditional apprenticeship training in skills development are needed, as well as awareness-raising activities during primary and secondary education.

- Start with market surveys. This is relatively obvious in theory and relatively rare in practice. Determine from the beginning what trades and skills have market potential, what types of skills are in demand, and what complementary support is needed.

- Assist the poor in financing their apprenticeship training. It is commonly assumed that traditional apprenticeship is open to everyone, or at least to all young men. This is not so. Very poor households typically cannot afford to pay the costs of apprenticeship, particularly for trades that require a high fee or tools and equipment. The Rural Enterprise Project in Ghana addressed this issue through a fund that financed three-fourths of the costs to enter apprenticeship.

- Improve basic education. In West Africa a general view prevails that basic literacy, including functional French, is of prime importance for better results in apprenticeship training. An important condition to 
improve the quality of apprenticeship outcomes is to raise the basic educational levels of apprentices early in their training. Literacy training can be integrated with apprenticeship, but often new curricula need to be developed for this purpose.

- Upgrade the skills of master craftspersons. The most appropriate training intervention may be to upgrade the skills of master craftspersons, assuming better skills will make them more productive and have a trickle-down effect on apprenticeships. This skills upgrading should focus first on pedagogy. Apart from the naturally gifted, most masters lack knowledge of how to train young adults. Since most master craftspersons view themselves foremost as technical specialists, they can be quite interested in upgrading their technical skills. Managerial competency is another matter. Master craftspersons may not appreciate the need to improve their managerial practices and may need to be induced. For both technical and managerial skills a strong argument can be made that the training should focus on helping them find solutions to their own problems.

- Improve the limited purchasing power by consumers for better quality products. This problem may be addressed by (i) focusing the training on increasing productivity and reducing costs (for example, wastage of materials, as in APME Cameroon), and (ii) training enterprises to move up-market where consumers can afford better quality.

- Enhance traditional apprenticeship training. Doing this needs more than improved delivery of training. It also requires the infusion of new skills and technical knowledge into the informal sector. One way to infuse such knowledge and skills would be to link apprenticeship with specialized training providers. However, this will not happen by itself. Facilitators are needed to create such linkages. The role of the facilitator is to convince master craftspersons of the advantages of training for them and their apprentices; to identify suitable training providers; to organize or animate ISAs to become involved; and to help finance the first rounds of training. The role of facilitator will gradually disappear as the parties enter into direct relationships.

- Introduce supplementary training for apprentices. Besides better literacy and numeracy, apprentices need (i) theoretical training to enable them to grasp the basics of the trade, such as measuring, calculating, and reading of drawings and (ii) expanded technical training, for example, on equipment unavailable in their particular workshops. The provision of such supplementary training through alternance (for example, Benin BAA) is promising.

- Evaluate and certify the skills obtained. One of the major shortcomings of traditional apprenticeship training is the lack of quality assurance, through either monitoring the process or applying objective end-oftraining assessments. Efforts by informal sector associations (Cameroon GIPA) can fill this need. 
- Arrange for posttraining support. The lack of marketing skills and other business acumen among recent apprenticeship graduates poses a serious risk to their success in self-employment and entrepreneurship. Lack of access to credit for business start-up and initial operation makes it difficult to use the skills acquired. The need for follow-up services does not mean that training providers should include such services in their menu. On the contrary, in conformity with the preferred approach to business development services, specialized intermediaries can be responsible for credit, management, and technological advice to informal sector enterprises.

\section{Issues}

Three issues need to be addressed to improve skills training for the informal sector: reorientation of the training institutes, scaling up successful programs, and financial sustainability.

\section{Reorientation of VTIs}

It is unclear whether existing public sector training centers can make the sweeping changes needed to serve the demands of the informal sector. Most would have to make major changes in identifying market trends, translating them into training programs, and finding appropriate delivery modalities to reach new target groups. It may be preferable to use master craftspersons for the training. Moreover, reorientation of existing training centers requires major investments to upgrade facilities and equipment; to attract, develop, and retain new staff; and to develop new curricula and materials. Quality improvements require resources in excess of current public subsidies. Increased training fees are not likely to prove feasible in view of the poor benefits of past training and constraints on family incomes.

\section{Scaling Up}

Most of the successful examples of training for the informal sector, and for literacy and livelihood skills, consists of small projects. Sponsors provided intensive inputs to develop programs responsive to local demand. These precedents, therefore, provide no recipe for quick expansion to mass provision. Rather, working in partnerships with communities and NGOs and ensuring adaptation to local demand requires slower growth and long-term commitment. One unanswered question concerns the extent to which traditional apprenticeship can help transfer basic technical skills to the burgeoning number of people entering the informal sector. Expansion of coverage is inherently limited by the number of master craftspersons willing to provide training. On the other hand, the Kenya Jua Kali project, done on a relatively large scale, is a good example of scaling up (see appendix G). 


\section{Financial Sustainability}

Full cost recovery has proven elusive in informal sector training. There is a legitimate role for targeted government subsidies for pre-entry courses that facilitate access by disadvantaged groups to self-employment. Cost recovery can be only minimal, or perhaps deferred. The case is less clear for inservice training because it carries few of the external benefits, and the informal sector operators benefit immediately. This suggests a policy of using subsidies for preservice courses but attempting to recover as much of the in-service training costs as possible, with increased cost-sharing gradually replacing subsidies (Ziderman 2003, p. 161).

\section{Role of External Agencies}

Observers have noticed the tendency of international partners to focus on small microprojects. Interventions in projects can be useful mainly in learning what does not work and in demonstrating models that can succeed on a wider scale. It is also important to work at the meso (institutional) and macro (system) levels to help ensure that conditions are present to enable successful training (Nell, Shapiro, and Grunwald 2002, p. 44). One important role for donors collectively is to help place or keep the informal sector on the government's agenda.

\section{Notes}

1. Benin BAA, Cameroon APME, Cameroon GIPA, Kenya Jua Kali, Kenya SITE, Senegal FEDNAPH, Tanzania INTEP, Uganda, and Zimbabwe ISTARN, described in appendixes D through $\mathrm{L}$, respectively.

2. The impact analysis found positive economic outcomes, particularly for training of women and for training in agricultural skills (Verner and Verner 2002). 


\section{7}

\section{Promoting Reforms with Training Finance}

Dependence on public financing of TVET has diminished over the past decade and financing for this purpose has become more diversified, with financing from employers, trainees, and their families. The enterprise training leoy, a common source of financing for training elsewhere, has been less successful in Sub-Saharan Africa because of the small size of the industrial base. Almost everywhere, fees are being introduced or raised as public financing declines under budgetary pressures. In addition, many training institutions are looking toward income-generating activities, through the sale of products and services, as well as tuition.

Institutions and mechanisms that distribute available financing within the training system can have a powerful influence on the effectiveness and efficiency of resource utilization. One such mechanism, training funds, has been established in 30 countries across the region. Newer training funds draw upon many sources of financing, including the government budget, self-generated income, and donors. As funding sources have broadened, so too have training purposes. Competition for funding has stimulated efficiency and has sometimes resulted in lower costs.

Moves toward more objective budgeting criteria-specifically, composite formula funding based on inputs, outputs, and outcomes—seem well within the grasp of governments in many countries. Training vouchers can stimulate demanddriven training but require substantial administrative capacity and controls. Levygrant schemes can be successful but also demand considerable capacity to administer, and care has to be taken to avert the tendency toward reduced effectiveness over time. The shift of attention to performance and financing outcomes holds considerable promise for the reform of training systems.

\section{Introduction}

No government today can finance all the skills development needed in a modern market economy. The cost is too great. Diversification of financing is essential. Diversification combined with new instruments for linking financing to institutional accountability for performance can be powerful tools for reform and can ensure that training is directed to market needs. These instruments provide incentives for market-responsive training and

This chapter is based on Financing Vocational Training to Meet Policy Objectives: Sub-Saharan Africa by Adrian Ziderman (2003). 
create a level playing field for government and nongovernment provision of training.

This chapter is divided into two parts. The first part discusses the mobilization of funds to finance TVET. The second part presents mechanisms that distribute funds within training systems.

\section{Resource Mobilization}

TVET is expensive-more expensive than general education. Across-theboard reductions in public financing have cut into TVET in Sub-Saharan Africa. This experience over the past decade raises the following questions:

- How have TVET institutions managed in a climate of reduced public financing for skills development?

- Payroll taxes have been introduced to diversify TVET financing in many countries, but how well have they worked?

- What has been the experience with other measures used to diversify the financing of skills development?

\section{Background}

Confronted by budgetary pressures, many governments continue to find it difficult to provide adequate, stable financing for public training institutions and skills development in general. Pressures on public budgets have forced a search for alternative sources of funding. When funds from traditional state resources are insufficient to cover requirements, two avenues are open: (i) improve the efficiency with which existing resources are used, (that is, pursue more cost-effective training solutions), and (ii) mobilize new sources of funds outside government. The latter has been part of a trend over the past decade in efforts to diversify financing for TVET.

\section{Sources}

There are five options for mobilizing additional training resources: payroll levies on employers; tuition and other fees paid by trainees and their families; production and sale of goods and services by training institutions; community support and donations; and, indirectly, expansion of nongovernment training provision. These options for diversification can be used simultaneously.

Financing of TVET is usually based on the principle that those who benefit are those who should pay. Those benefiting from skills development through increased productivity (employers) and higher incomes (individuals) have an interest and an incentive to help shoulder the costs of training. Application of this principle, however, is impeded where poverty and ability to pay are issues and where capital markets are not fully developed for borrowing against future income streams. 


\section{Training Levies}

The training levy has become a popular tool for augmenting training finance. Earmarking levies on enterprise payrolls is the most widely adopted funding mechanism for training, both in public training institutions (usually under the aegis of a national training fund or authority) and in enterprises. These levies are central to training finance policies in many countries (Tanzania, Zimbabwe, Mauritius, South Africa). Other countries are examining the benefits and feasibility of introducing payroll levies to finance training (Botswana, Lesotho, Zambia).

TWO TYPES OF LEVY Discussion of the levy-exemption scheme is reserved for later in this chapter, since it is essentially a transfer mechanism. Alternatively, the use of a levy to generate revenue produces proceeds that typically are used to finance public training or contract for training procured competitively from government and nongovernment providers. Latin American levies on wages finance public training organizations that are governed by public administrators, workers, and employers. These levies are an important source for diversifying the financing of TVET and have become more popular in Sub-Saharan Africa. (See table 7.1.)

UNIFORM APPROACH The scope for levying payroll taxes is well established by international experience. Almost all countries that have introduced payroll levies have adopted an approach that sets a standard national levy rate in the range of 1 to 2 percent of company payroll, mostly at the lower end of the range.

Sectoral Levies Some countries (for example, Mauritius, Kenya, and South Africa) have introduced sector-level training taxes, usually (but not

Table 7.1. Revenue-Generating Payroll Taxes in Sub-Saharan Africa

\begin{tabular}{lcc}
\hline Country & $\begin{array}{c}\text { Training tax as } \\
\text { percentage of payroll }\end{array}$ & Used for training? \\
\hline Gambia & n.a. & No \\
Mali & 0.5 & Yes \\
Mauritius & 1 & Yes \\
Senegal & 3 & Very little \\
Tanzania & 2 & Yes \\
Zaire & 1 & Yes \\
Zambia (planned) & $2 \mathrm{a}$ & n.a. \\
\hline
\end{tabular}

n.a. not applicable.

a Suggested.

Source: Ziderman 2003, table 6.1, p. 95. 
always) based on payrolls. Sales or turnover can also be used as the basis. The sector levy permits tailoring of the levy format to the characteristics and needs of the sector in question. The narrow focus of sector levies, however, obviates an integrated, national approach to financing and planning skills development and makes it difficult to shift funds from mature to emerging sectors that have different skills needs. South Africa collects a uniform 1 percent levy on enterprise payrolls and distributes 80 percent of that levy to various sectoral boards (SETAs) for use in sector-specific training programs.

ADVANTAGES AND DisADVANTAGES The strengths and weaknesses of payroll taxes need to be weighed against their possible dangers and limitations.

Among their advantages, payroll levies

- Diversify the revenue base for financing training, by mobilizing additional revenues

- Can provide a stable and protected source of funding for national training provision, which is particularly important in the context of unstable national budgets

- Can be viewed as "benefit taxation," if earmarked for training

- Can serve as a vehicle for cross-subsidization of training, especially from the formal to the informal sector, when collected from formal sector employers.

Limitations of payroll levies include the following:

- Given their particular training needs, many companies, particularly small ones, will not benefit from the scheme. This exclusion breeds resentment and opposition and compromises the status of training levies as "benefit taxation."

- Earmarked taxation does not conform to the principles of sound public finance and weakens attempts to unify national tax systems.

- Under fiscal pressure, government may combine training levy proceeds with general public tax revenues. Levy proceeds may be diverted to nontraining uses. This diversion seems to have occurred frequently in Sub-Saharan Africa (for example, in Côte d'Ivoire, Gabon, the Gambia, and Togo).

- Payroll levies may constitute an oversheltered source of funding, leading to unspent surpluses, inefficiencies, and top-heavy bureaucracies. Two examples of this can be seen in Zimbabwe and Mauritius. The Zimbabwe Manpower Development Fund generated a surplus of 28 percent, which was invested in property. Property assets tripled even though property ownership was not in the mandate of the fund.

- Payroll levies raise the cost of labor to the employer, possibly discouraging employment.

- Employers may shift the incidence of the levy onto workers in the form of lowered wages. In this case, workers would bear the burden of the tax. 


\section{Issues}

Issues affecting the use of payroll taxes include cross-subsidization, applications of the funds, and choices in design and implementation.

CROss-SubsidizATION Payroll levies can be used to finance training outside the enterprises being taxed. This is called cross-subsidization. Twenty percent of the South African levy is earmarked for use in training outside sectors that pay the levy. In Côte d'Ivoire, the Vocational Training Development Fund allocated between 18 and 20 percent of its budget (financed through a 1.2 percent payroll tax on formal sector enterprises) for training that benefits the informal economy (Johanson 2001, pp. 2, 3, 8). This crosssubsidization financed training in areas where informal enterprises could not raise their own funds. It contradicts the principle of beneficiary financing and succeeded only because formal sector enterprises cooperated. Such cooperation can appear where enterprises are seeking to improve the capacity of suppliers of intermediate goods and services.

Application of the Levy Proceeds In some countries, the levy proceeds finance exclusively or mainly the training centers run by the financing authority. Tanzania uses levy proceeds to finance its own centers, with 4,000 graduates a year, while other providers-with 60,000 graduates-receive little or no financing. In part this is because the levy proceeds are limited, but it also indicates the preferential treatment given to institutions run by the Tanzanian VETA (Atchoarena and Delluc 2001, p. 269). Similarly, in Mauritius, as a priority, the levy finances the centers owned and operated by the IVTB. This policy is in the process of being changed.

DESIGN AND IMPLEMENTATION Different considerations affect the design and implementation of payroll levies:

- Levy rate. Levy rates should be subject by law to periodic review to avoid the accumulation of surpluses, as has happened in Zimbabwe and Mauritius.

- National or sectoral levy rates. A standard, national payroll levy is preferred to a sector levy for its greater ability to permit funds to be allocated where training needs are greatest.

- Sectoral coverage. Levy coverage should be as wide as possible across economic sectors and should include public enterprises.

- Company size. Very small companies can be exempted from levy payment, on both efficiency and equity grounds (they tend not to capture the benefits).

- Levy collection. Levy collection is best placed in the hands of effective agents; self-collection by a funding organization should be avoided. In Tanzania, collection by the social security administration did not work properly. Collection was recently transferred to the national 
revenue collection agency, and revenues subsequently increased dramatically.

- Security of levy proceeds. Special attention needs to be given to guarding levy revenues from raiding by the government (especially where tax authorities act as the collection agent), by placing the proceeds in special, closed accounts. This has worked successfully in Côte d'Ivoire despite persistent efforts to divert the proceeds to other purposes.

- Employer buy-in. Employers need to be involved in the formulation and execution of payroll levy policy. The introduction of a levy is usually controversial and so is bound to face difficulties without employer support, as was the case in Tanzania (Atchoarena and Delluc 2001, p. 18).

- Premature introduction. Payroll levies may be inappropriate where levy income-generating capacity is weak-because of either the limited size of the formal sector or the administrative and organizational difficulties of levy collection. In Zambia, for example, a levy was adopted but never implemented.

Overall, the record of success of training levies in Sub-Saharan Africa is lower than in other regions. Côte d'Ivoire is considered a success, but there are few other unambiguous examples. The expectation that levy income complements other government financing and provides additional financing for training has not always been realized in practice. In Tanzania, levy income completely displaced government spending on formal skills development. In other countries (the Gambia, Togo), earmarked training taxes were absorbed into general government revenues instead of being used to finance public training. In some cases, funds have proven excessive, leading to an inefficient use of resources (Zimbabwe and Mauritius, for a time.) Finally, the scope for establishing enterprise levies is limited by the small size of the modern sector in many countries of the region.

\section{Raising Revenues at the Level of the Training Institution}

Financial pressures over the past decade have forced almost all countries to promote income-generating activities at the institutional level (Atchoarena and Delluc 2001, p. 1). Income generation generally takes two forms-fee income and sale of goods and services-but it may also include donations and contributions from the local community. Madagascar is characterized by relatively low dependence on state subsidies (47 percent and 66 percent at lycées and vocational education centers, respectively). Fee income accounts for 12 percent of income at lycées and 14 percent at vocational education centers. Vocational education centers receive 21 percent of their revenues from the sale of products and services (Atchoarena and Delluc 2001, pp. 93-94). Most institutions depend on multiple sources of revenue for their operations, as in Tanzania (table 7.2). 
Table 7.2. Tanzania: Sources of Incomes and Training Costs, Selected Church-Owned Training Centers

\begin{tabular}{lcccccc}
\hline & $\begin{array}{c}\text { Training } \\
\text { costs/year }\end{array}$ & $\begin{array}{c}\text { Training } \\
\text { fees/year }\end{array}$ & & \multicolumn{4}{c}{$\begin{array}{c}\text { Sources of income } \\
\text { (percentage of total) }\end{array}$} \\
\cline { 5 - 7 } Institution & (TSh 000) & (TSh 000) & Fees & Production & Donations & Other \\
\hline Kasasha Village TC & n.a. & n.a. & 60 & 28 & 10 & 2 \\
Kalwande VTC & 734 & 70 & 7 & 62 & - & $31^{\text {a }}$ \\
Hai VTC & 375 & 150 & 42 & n.a. & n.a. & n.a. \\
Kilimanjaro YTTC & 270 & 154 & 61 & -39 & n.a. \\
Don Bosco VTC & n.a. & 65 & n.a. & - & n.a. & - \\
Mafinga Lutheran VTC & 450 & 100 & 20 & n.a. & 3 & $32^{\text {a }}$ \\
Tushikamane VTC & 330 & 50 & 15 & 50 & 16 & $10^{\text {b }}$ \\
Kisa Homecraft Center & 240 & 100 & 42 & 32 & &
\end{tabular}

n.a. not available.

a. Business activities unrelated to training undertaken for income generation.

b. Income and distributions from the diocese.

Notes: TC, training college; VTC, vocational training center; YTTC, youth technical training center.

Source: Haan 2001, p. 88.

Donations, particularly from abroad, can be important sources of revenue to tide training institutions over rough economic periods. Nongovernment institutions naturally are reluctant to disclose such sources of support.

\section{Cost-Sharing through Fees}

Fees for training have been introduced or raised in many countries as public financing declines. ${ }^{1}$ Countries including Malawi, Madagascar, Mauritius, Nigeria, Tanzania, Zambia, and Zimbabwe have introduced fees for training courses. ${ }^{2}$ The rationale for charging fees is beneficiary financing: Trainees can be expected to bear at least a part of the cost of training when skills acquisition is seen as an investment in human capital, with the promise of higher labor market earnings and a greater probability of sustained employment.

SHARE ReCovered Fees are often set at a symbolic level only. For example, fee income accruing to the IVTB in Mauritius accounts for only between 1 and 2 percent of revenue. In some cases, however, fees are more substantial but still far from sufficient for full cost recovery. In public training centers in Tanzania, fees represent about 15 percent of recurrent costs; in Madagascar, 27 percent. Cost sharing has also begun in formal apprenticeship training in Kenya. One auto mechanics company has gradually introduced a policy of charging apprentices for training. By 1993, all apprentices were paying KShs 80,000 (about $\$ 1,200$ ), but this rate was still nowhere close 
to the company's total investment per apprentice in training (Grierson 2002, p. 18).

APPRENTICESHIP FEES Collection of fees from traditional apprenticeship training in the informal economy is the norm in many countries. In Yaoundé (Cameroon) 70 percent of the informal sector entrepreneurs indicated they paid for their skills training (Haan and Serriere 2002, p. 115). In Ghana, one study of traditional apprenticeship found divergent practices of cost-recovery. About 60 percent of the enterprises charged apprentices (averaging $\$ 70$ for up to three years of training) and 40 percent of the firms did not. The latter tended to be larger enterprises that expected compensation in the form of work for reduced wages. The apprenticeship fee is usually paid up front at the start of training; however, in some cases a down payment is made and some 20 percent to 40 percent of the fees are paid at the end of training. The deferment of payment gives the apprentices some security that they will in fact receive the training to which they are entitled. When the employer prefinances the skills training and expects to recover these costs through lower wages, the apprentices have incentives to leave the firm before repaying. This "incentive" can be countered by paying substantially higher wages in the postapprenticeship period as an inducement for graduates to stay (Haan and Serriere 2002, p. 34).

TUITION FeES Compared with practices related to training levies, practices related to tuition are much less uniform. The feasibility of setting fees in relation to unit costs of training is a function of diverse factors that vary from location to location with countries. They include the type and costs of the training, the price elasticity of trainee demand for different training courses, political constraints, and policies pertaining to equity of access.

\section{Issues in Charging Fees}

Deciding whether to charge for training involves more than an analysis of the break-even points: At what price will fees scare off students? What will happen to students who cannot afford to pay? This is a Catch-22, a perverse cycle. The scope for charging additional fees may be limited, and attention to the capacity of trainees to pay is important. Some critics contend that training fees have about reached their maximum. However, in the absence of fee increases, institutions may not be able to invest in inputs to raise the quality of training; quality will deteriorate, and fewer trainees will enroll, further reducing fee income. Tanzania cut its contributions to the Folk Development Colleges in 1994, limiting them to cover only salary costs. The colleges introduced fees, but their revenue from fees was inadequate to purchase new tools and equipment. College management is unable to invest in and improve training quality, without which their underutilization will increase further, thereby further lowering fee income. 
Centrally Or Locally Established A central issue in fee policy is whether to impose standard, nationwide compulsory fees or to allow individual training institutions to set and vary their fees. In Tanzania, fees for public training institutions are set centrally. Institutional autonomy in fee setting seems the best approach, but it may not be feasible in otherwise centralized training systems. Standard, compulsory fee-setting may be an inflexible tool, unlikely to reflect local market realities, but it is generally acceptable as a second-best measure. Because of the various factors involved, no prescriptions can be written for tuition fees.

EQUITY IMPLICATIONS The positive financial benefits from cost-recovery need to be weighed against the potentially adverse effects on equity. Here the tradeoff is clear. Higher, realistic fees may exclude from training those who cannot afford to pay, while comfortably low fees may not contribute enough for the provider to recover costs. Negative impacts on access to training opportunities for the poor, minorities, rural populations, and other disadvantaged groups are likely to ensue. The level of fees can also have an impact on dropout rates. The case of two Zambian community-based trade schools is illustrative (box 7.1). Since training fees were increased, the very underprivileged can no longer afford training (Haan 2001, p. 176).

Governments can offset the adverse impact of fees on equity by using some of the savings realized from fee income to provide targeted scholarships to low income groups. ${ }^{3}$ Theoretically, at least, increased fees could lead to increased equity of access because with the savings the government can afford to finance the enrollment of more low-income students. The weakness of this argument is the limited ability of most trainees in SubSaharan Africa to afford increased fees.

The equity implications of charging fees underscore the widely recognized need to introduce subsidies targeted to at-risk groups, in the form of scholarships and fee discounts. However, targeting the most needy individuals within these groups is not easy, particularly in Sub-Saharan Africa.

USE OF FEES Local institutional initiative in generating income from fees will be stunted if this income does not contribute to institutional budgets. In Zambia, vocational training institutes were unable to retain fee income (World Bank 2001). In Namibia, the public Vocational Training Centers are similarly unable to keep any income generated by the institutions. Such income must be transferred to the Treasury. In Kenya, the management of the Department of Industrial Training is considering advertising courses and charging fees to any member of the public who wishes to enroll. However, current legislation does not allow the department to retain the fee income for refurbishing and essential maintenance (Grierson 2002, p. 20).

A public institution can also earn fee income from expanding fee-paying enrollments where demand exists. In Tanzania, the VETA's institutions are not allowed to increase fees for individual trainees, but they can increase fee income by expanding enrollments, including adding a second session. In 


\section{Box 7.1. Zambia: A Tale of Two Community-Based Trade Schools and Their Fee Policies}

The Chilenje and Dzithandizeni Trade Schools in Lusaka are interesting examples of nongovernment community-based training centers. Founded in the late 1970s, both received small but crucial contributions in the form of technical equipment and financial assistance from international donors until a few years ago. Both trade schools are essentially self-sustainable in terms of operating costs. Initially, they provided training free of charge but gradually introduced elements of cost-sharing. First they asked students to pay for their own training materials and later raised the fees from a token commitment to a level of substantial cost-recovery. Chilenje Trade School has gone farther in this direction than Dzithandizeni. Chilenju charges ZK 20,000 (\$7) per month for its courses ( $\$ 126$ for the 18 -month course). Dzithandizeni is asking only ZK 125,000 (\$40) for its 18-month training period, against an estimated actual training cost of ZK 1.3 million (\$433) for one trainee over 18 months. This means that the training fees paid cover more than 25 percent of the total costs at Chilenje and less than 10 percent of the total costs at Dzithandizeni. Dzithandizeni Trade School makes some additional money by letting informal sector operators use the center's equipment (for ZK 1,000 per hour). The school's graduates get a 50 percent reduction in the equipment fee.

All this means that training is still funded by the trade schools' production units. Both have offered training-cum-production from the beginning and have been successful with it, partly through the appealing designs that volunteers brought in from Europe. With the opening of the Zambian economy, a number of new and more modern furniture shops have opened up in Lusaka and competition has increased markedly.

In Dzithandizeni, the dropout rate is low (5 percent, mainly for nonfinancial reasons) although a few years ago when it was decided that the (tailoring) students had to buy their own materials, a number of the students left. The markedly higher training fees in Chilenje have led to substantially higher dropout rates (up to 50 percent). The trainees are said to reason that after they have obtained sufficient basic skills to use the equipment after a few months, there is no further need to spend ZK 20,000 per month to continue their training.

Source: Haan 2001, pp. 127-31.

Mali, the establishment of Units for Training and Support to Enterprises permitted the training centers to generate additional income through continuing education (Atchoarena and Delluc 2001, p. 102). An appropriate share of the proceeds from extra (evening) classes is expected to accrue to the training institution, for reinvestment in facilities and equipment. Senegal also provides an interesting example (box 7.2).

In the context of high social demand, there is no guarantee that the courses correspond to market needs. Parents or trainees may be willing to pay the fees to obtain credentials regardless of the market relevance of the 


\section{Box 7.2. Senegal: Introduction of Extra Courses on a Fee-Paying Basis}

A 1991 decree allowed Senegal's TVE establishments to generate new resources, and they seized the opportunity. An IIEP survey in Dakar showed that these resources can amount to seven times the school's current operating budget (minus teacher salaries). Enrollment expansion also permitted a more intensive use of costly pedagogical equipment and extended vocational training to people without qualifications. The training school first attempted to make and sell school furniture, but the training market rapidly appeared to be more lucrative.

Parallel recruitment takes place for students who do not pass the entrance examination. They can now attend for a fee. Introduction of fees for these students has had some negative consequences. The schools have overloaded classes to increase income, compromising training quality. Regular teaching programs have suffered in competition with fee-paying classes. Teachers race for extra teaching hours and neglect their regular teaching duties. Conflicts have arisen between teachers and management about use of the funds, leading to strikes by teachers. The conclusion drawn from this experience is that uncontrolled growth of fee-paying courses can undermine quality.

Source: Atchoarena and Delluc 2001, pp. 111, 148, 150-51.

training. Moreover, fee-paying training courses at public institutions may compete with nongovernment training. Certain promoters of the private sector condemn what they call "unfair competition" from the state in Senegal (Atchoarena and Delluc 2001, p. 148). In general, the state sector should refrain from "crowding out" competent private providers. However, competition between public and private providers can be healthy and can lead to a more demand-oriented system of higher quality (or lower prices), provided both providers are competing on an equal footing.

\section{Sale of Goods and Services}

Income generated from the sale of products and services can constitute a useful form of additional institutional revenue. The revenue is derived as a by-product of the training process itself. Exposure to local markets may also lead to more relevant, market-oriented training.

The proportion of recurrent expenses that can be covered by production sales varies and in some cases can be substantial. (See Ziderman 2003, table 6.2.) In Zambia, the income of the community-based trade schools is still funded largely by production units. After finishing their training, graduates work two to three years in the school's production unit or at a company. The school benefits from the production and the graduates can save to buy the tools they will need to start their own business (Haan 2001, p. 127). Income 
from production in Swaziland makes up 80 percent of total revenue in some training institutions. The potential for income generation from production depends on numerous local factors, including the nature of the product, local demand, and potential market competition.

Training institutions may also generate income from the sale of services, including renting out underused facilities and providing consulting services to local enterprises (box 7.3).

Schools have to maintain a healthy balance between their main mission of instruction and their sideline of producing and selling goods. As more weight is given to instruction, the income potential from production declines. Alternatively, quality of training can suffer if more emphasis is placed on production than on instruction. Trainees can be exploited by unscrupulous staff for their free labor. On the whole, if in proper balance with instructional objectives, income from production can constitute a small but significant share of total revenues at the institutional level (Ziderman 2003, p. 117), perhaps $10-15$ percent on average.

\section{Community Contributions}

In keeping with rich cultural traditions, local communities often support vocational training institutions. Members of the local community supply the training institutions with land and premises, built from donated materials and with donated labor. Only rarely, however, can the community support the operating costs of such institutions. The extent of community contributions to VET is difficult if not impossible to determine. However, in Zambia, community-owned training centers constitute 14 percent of the registered institutions under TEVETA (Kitaev with others 2002, p. 46).

\section{Strengths and Weaknesses of Alternative Means for Resource Mobilization}

Table 7.3 summarizes the major advantages and risks of the main options for mobilizing resources.

\section{Box 7.3. Togo: Income Mobilization by Renting Institutional Premises}

During a recession in Togo, the regional centers for TVET received very little operating budget from the state. They found extra income by renting out equipment not available locally, such as high-speed saws and machines to check the structure of a car's bodywork and to balance wheels. Proceeds of these rentals made up for the budget cuts. Management of these resources is also interesting: it is done through a cooperative, recognized by decree.

Source: Atchoarena and Delluc 2001, p. 151. 
Table 7.3. Mechanisms for Funding Diversification: Advantages and Risks

\begin{tabular}{|c|c|c|c|}
\hline $\begin{array}{l}\text { Mechanism (leading } \\
\text { policy variant) }\end{array}$ & $\begin{array}{l}\text { Income } \\
\text { accrues to }\end{array}$ & Advantages & Risks \\
\hline $\begin{array}{l}\text { Fund augmentation } \\
\text { (training levies) }\end{array}$ & $\begin{array}{l}\text { Public sector/ } \\
\text { training funds }\end{array}$ & $\begin{array}{l}\text { Diversifies revenue } \\
\text { base for financing } \\
\text { training, by mobilizing } \\
\text { additional revenues } \\
\text { - Can provide stable and } \\
\text { protected source of } \\
\text { funding for national } \\
\text { training }\end{array}$ & $\begin{array}{l}\text { - Small companies } \\
\text { tend not to benefit } \\
\text { - Earmarked taxes } \\
\text { weaken budgetary } \\
\text { unity } \\
\text { - Government may } \\
\text { confiscate levy for } \\
\text { other purposes } \\
\text { - Source of income } \\
\text { may be oversheltered } \\
\text { - Raises cost of labor, } \\
\text { possibly discouraging } \\
\text { employment }\end{array}$ \\
\hline $\begin{array}{l}\text { Cost-sharing } \\
\text { (tuition fees) }\end{array}$ & $\begin{array}{l}\text { Training } \\
\text { providers }\end{array}$ & $\begin{array}{l}\text { - Training becomes } \\
\text { more cost-effective } \\
\text { as training providers } \\
\text { vie to attract trainees } \\
\text { - Training becomes more } \\
\text { demand oriented }\end{array}$ & $\begin{array}{l}\text { - Imposes hardship on } \\
\text { disadvantaged } \\
\text { students, depending } \\
\text { on scope of scholar- } \\
\text { ship policy } \\
\text { - Income may not } \\
\text { remain with provider }\end{array}$ \\
\hline $\begin{array}{l}\text { Income generation } \\
\text { (income from } \\
\text { production) }\end{array}$ & $\begin{array}{l}\text { Training } \\
\text { providers }\end{array}$ & $\begin{array}{l}\text { - May lead to training } \\
\text { outcomes more closely } \\
\text { geared to market needs }\end{array}$ & $\begin{array}{l}\text { - Neglect of training } \\
\text { function may lower } \\
\text { quality and supply of } \\
\text { training } \\
\text { - Resources may be } \\
\text { diverted from } \\
\text { training into } \\
\text { production } \\
\text { - Income may not } \\
\text { remain with provider }\end{array}$ \\
\hline $\begin{array}{l}\text { Private training } \\
\text { provision (reduced } \\
\text { public investment) }\end{array}$ & $\begin{array}{l}\text { No income; } \\
\text { budgetary } \\
\text { savings to } \\
\text { public sector }\end{array}$ & $\begin{array}{l}\text { Expansion of national } \\
\text { training system can be } \\
\text { achieved without } \\
\text { commitment of public } \\
\text { funds }\end{array}$ & $\begin{array}{l}\text { - Concentration of } \\
\text { private providers on } \\
\text { low-cost, high- } \\
\text { demand courses may } \\
\text { leave public sector } \\
\text { providers with more } \\
\text { costly, technical } \\
\text { courses and limited } \\
\text { possibilities for cross- } \\
\text { subsidization }\end{array}$ \\
\hline
\end{tabular}

Source: Ziderman 2003, pp. 126-27. 


\section{Allocation Mechanisms}

Over the past decade, new mechanisms for the allocation of training resources have introduced greater institutional accountability for achieving results and helped provide a level playing field for government and nongovernment provision of training. These mechanisms do not increase the level of funding for skills development; they distribute the funds available within the training system. The mechanisms through which government transfers financing to training institutions can affect institutional behavior and the way funding is used. Shortcomings in the transfer mechanisms may promote low internal efficiency of training institutions and perpetuate supply-driven training provision.

Trends identified in the allocation of financing for training include movements

- From direct state allocations to vocational training institutes to the widespread use of intermediaries in the form of training funds

- From a public monopoly by vocational training institutes over training budgets to competition for funds among state and private providers

- From budgeting based on historical precedent (ad hoc) to allocations based on norms and outputs, and indirect allocations through student vouchers.

Each trend is described in more detail below, followed by incentive schemes for enterprise training.

\section{Training Funds}

Training funds pool resources for targeted assistance to training programs, institutions, and trainees. Training funds are fairly common, having been established in some 30 countries in Sub-Saharan Africa. (See appendix M for a list of the funds, sources of financing, and objectives.) They are a powerful mechanism to unify various sources of funding for training and to allocate funds in line with national policies and priorities. Separate training funds were developed initially, to protect levy proceeds from government encroachment. The funding organization serves as a buffer between government and the training system.

Managers of training funds can evaluate the needs and priorities of the labor market as a whole, largely unfettered by political influence and more closely aligned with stakeholder interests.

In older, established training funds, training levies were the predominant and usually the only source of financing. Newer funds draw from a variety of sources, including the regular government budget, self-generated income, and donors. Some training funds derive no revenue from training levies; either levies have not been instituted or, where in place, levy proceeds are not passed on to the fund (table 7.4).

Early training funds financed with payroll levies were largely single purpose-to finance state-sponsored provision of pre-employment training (revenue generating schemes) or enhance the amount and quality of 
Table 7.4. Income Sources of National Training Funds, Selected Sub-Saharan African Countries

\begin{tabular}{|c|c|c|c|c|c|}
\hline \multirow[b]{3}{*}{ Country } & \multirow{3}{*}{$\begin{array}{c}\text { Year } \\
\text { established }\end{array}$} & \multicolumn{4}{|c|}{ Major source of training funds } \\
\hline & & \multirow{2}{*}{$\begin{array}{c}\text { Government } \\
\text { budget }\end{array}$} & \multicolumn{2}{|c|}{ Training levy } & \multirow{2}{*}{$\begin{array}{l}\text { Donor } \\
\text { support }\end{array}$} \\
\hline & & & Payroll levy & Other levy & \\
\hline Côte d'Ivoire & 1977, 1992 & Yes & $\begin{array}{l}\text { Uniform: } \\
\text { administered } \\
\text { centrally }\end{array}$ & n.a. & Yes \\
\hline Kenya & 1971 & No & n.a. & $\begin{array}{c}\text { Sector-based: } \\
\text { administered } \\
\text { sectorally }\end{array}$ & No \\
\hline $\begin{array}{l}\text { Madagascar } \\
\text { Malawi }\end{array}$ & 1992 & Yes & Planned & n.a. & Yes \\
\hline (being replaced) & 1972 & No & n.a. & $\begin{array}{c}\text { Uniform: } \\
\text { administered } \\
\text { centrally }\end{array}$ & No \\
\hline South Africa & 1999 & Yes & $\begin{array}{c}\text { Uniform: } \\
\text { administered } \\
\text { sectorally }\end{array}$ & n.a. & Planned \\
\hline Tanzania & 1994 & Ceased & $\begin{array}{l}\text { Uniform: } \\
\text { administered } \\
\text { centrally }\end{array}$ & n.a. & Yes \\
\hline Togo & 1988 & Yes & $\begin{array}{l}\text { Uniform: } \\
\text { not used for } \\
\text { training }\end{array}$ & n.a. & Yes \\
\hline Zimbabwe & 1984 & No & $\begin{array}{l}\text { Uniform: } \\
\text { administered } \\
\text { centrally }\end{array}$ & n.a. & No \\
\hline
\end{tabular}

n.a. not applicable.

Source: Ziderman 2003, table 5.1, p. 65.

enterprise training investment (levy-grant schemes). Considerable consonance existed between those that financed the levy and the beneficiaries. With the broadening of training funds both in terms of sources of revenue and the allocation of disbursements, this link has weakened. Training funds are increasingly regarded as a general funding pool, distributed across various recipient destinations according to established priorities and policies.

There are four main destination categories for fund disbursement (funding windows):

1. Core funding to training institutions for pre-employment skills development, aimed largely at formal sector employment.

2. Training incentives to enterprises in the formal sector where initial training (including apprenticeship training) or continuing training is deemed insufficient. 
3. Training courses for the unemployed and other disadvantaged groups.

4. Meeting the training needs of micro enterprises and the informal sector where conventional private markets fail to respond.

The first call in terms of disbursement priorities is likely to be core financing of pre-employment courses and innovative methods of financing training for micro enterprises and the informal sector. Pressures on public budgets may result in the neglect of disadvantaged groups.

\section{Issues}

The World Bank financed the establishment and operation of nine training funds in the Sub-Saharan Africa region in the 1990s. Experiences were generally positive, including experiences with those funds established in Madagascar, Côte d'Ivoire, Mauritius, Cape Verde, and Mauritania (Johanson 2002, pp. 14-15). Two funds even began to cross-subsidize training in the informal sector. The several successes among these funds over the past decade should not, however, obscure the difficulties in making them work properly. The administrative requirements are complex. Establishment of a training fund is a demanding task that requires painstaking preparation.

Agreements are needed at the highest levels about the rationale, purpose, and benefits of the fund. Moreover, the evidence for the efficiency of training funds is not yet clear cut; not much information is available about the unit costs of training financed by funds. Funds' impact on the expansion of training is clear, but the coverage is still only miniscule in relation to the numbers of people who need skills. Evaluation remains important to judging the full impact of funds on TVET reforms (Haan and Serriere 2002, p. 143). Additional issues concerning governance, conflict of interest, and sustainability are discussed below.

GOVERNANCE Training funds often serve three roles: provider, financier, and overseer. Good governance is imperative to avoid conflicts of interest. The effectiveness of a training fund depends first and foremost on its governance and control. Employers need to have substantial control over the use of the levies as a means to bring demand and supply closer. However, employer representation varies greatly within the funds established. The highly effective National Council for Technical and Vocational Training in Madagascar is governed by a board on which 10 of the 12 members represent employers. The equally successful Vocational Training Development Fund in Côte d'Ivoire has only one-third employer representation. The governing body of the IVTB in Mauritius has 50 percent representation from the private sector. However, the VETA in Tanzania was established with weak employer representation, only 2 of the 11 members. (See chapter 3.)

The presence of employers on a board does not necessarily mean fair representation of the broad constituency of employers. They may represent larger employers at the expense of smaller employers. They may represent 
employers' organizations rather than individual employers. Ideally, the governance structure of training funds is truly representative, free of self-serving domination by government or private groups, and autonomous in making policy, controlling budgets, and carrying out decisions. Even with appropriate employer representation, government officials can subvert the process. In some cases-Cameroon, for example-the problem is not in getting agreement for employer participation in training boards but in implementing such participation in the face of government opposition. In Mali, 40 percent of the Training Fund board represents the private sector, including the chair. In practice, however, the government insists that its views prevail. This has discouraged private sector participation (Johanson 2001, part 1, p. 12).

CONFLICT OF INTEREST Some training funds serve as provider, financier, and overseer of national training systems. This is the Latin American model. In Sub-Saharan Africa, Tanzania's VETA serves all three functions, as does the IVTB in Mauritius. ${ }^{4}$ The three functions are often incompatible and involve conflicts of interest. This applies particularly to the financing of the training centers owned by the training authority. The training authority centers receive the bulk of the disbursements and have a protected status, while other, far more numerous, centers receive little or nothing (Atchoarena and Delluc 2001, p. 269).

SUSTAINABILITY National training funds (particularly when financed by company training levies) provide sustained and stable funding for TVET. This is an important reason for setting up a national fund. However, not every national fund succeeds in stabilizing funding for training. Many funds are underresourced because their tax base-companies in the modern sector-is limited, collections are often poor (as, for example, in Tanzania), or because the funds are diverted at the point of transfer (as in Togo and the Gambia, where levy proceeds remain in the treasury and are used for general budgetary expenditures). Medium- and long-term sustainability of training funds is problematic, especially where training funds have been launched by donors and are mainly funded externally. This problem is endemic where public budgets are likely to be severely constrained over the medium term and where training levies cannot yet be introduced. Overly generous external support for national training funds, without planned, complementary development of domestic funding, will ultimately result in moribund training authorities with empty coffers. Successful outcomes are unlikely unless six key conditions are satisfied, as shown in table 7.5.

\section{Competition for Funds}

Training contracts have been used throughout the world to improve institutional performance. Contracts between the funding body and the training institution specify the intended results. This method, which is focused on 
Table 7.5. Key Conditions for Training Fund Success

\begin{tabular}{ll}
\hline Key condition & Justification \\
\hline Security of income & $\begin{array}{l}\text { Ensure adequate, sustainable, and stable volume } \\
\text { of training fund incomes }\end{array}$ \\
\hline Autonomy and control & $\begin{array}{l}\text { Secure decisionmaking autonomy of } \\
\text { management board and its control over budget } \\
\text { allocations }\end{array}$ \\
\hline Stakeholder ownership & $\begin{array}{l}\text { Foster ownership through substantial board } \\
\text { representation of major stakeholders, } \\
\text { particularly employer groups, where training } \\
\text { levies are in place }\end{array}$ \\
\hline $\begin{array}{l}\text { Activities (and disbursements) } \\
\text { for national training needs only }\end{array}$ & $\begin{array}{l}\text { Ensure targeting of training fund policies and } \\
\text { disbursements according to defined national } \\
\text { training needs and avoidance of extraneous } \\
\text { activities }\end{array}$ \\
\hline $\begin{array}{l}\text { Avoidance of training } \\
\text { provider role }\end{array}$ & $\begin{array}{l}\text { Limit subsidies and preferential treatment to } \\
\text { training centers if run (and financed) by a } \\
\text { training fund lest they distort training markets } \\
\text { and inhibit movement toward an open, } \\
\text { competitive training system }\end{array}$ \\
\hline Decisionmaking transparency & $\begin{array}{l}\text { Keep decisionmaking open and make sure the } \\
\text { basis for fund allocation is known and } \\
\text { understood }\end{array}$ \\
\hline
\end{tabular}

Source: Ziderman 2003, table 5.3, p. 81.

results, has advantages over traditional budgeting, which is focused on inputs, but the practice can lead to irregularities. Contracts may not provide sufficient pressures to operate efficiently and at low costs.

A system of competitive bidding can avoid these shortcomings and provide equal treatment for private and public institutions (establishing a level playing field). The Inter-American Development Bank advocates a competitive approach in its policy work, having found that it worked well in two youth employment programs in Argentina (Projecto Joven) and Chile (Chile Joven). The World Bank has also had good results in its financing of training funds that allocate resources through bidding.

In its review of project support, the Bank found that competition had stimulated the beginnings of a training market in Ghana and that nongovernment providers were responsive to the process and won most of the funds. Insisting that public and private training providers play by the same rules is one way to help integrate them. In the Côte d'Ivoire project supporting the Vocational Training Development Fund, competition led to cost 
reductions for the same courses among competing institutions and led to the emergence and development of a training market (which now has 363 authorized training providers) (Johanson 2002, part 2, p. 7). In Mali, the use of competition by the Fund for Vocational Training and Apprenticeship contributed to the emergence of a training market (Atchoarena and Delluc 2001, p. 146).

In South Africa, proposals for the disbursement of public funding for targeted training programs envisage the removal of protection from public training providers and the introduction of performance-related funding criteria. A new system of competitive tendering for long-term training contracts will be adopted. These measures end the privileged position of such public sector providers as the Regional Training Centers, in relation to existing and emerging private sector institutions (Ziderman 2003, p. 134). As the DANIDA review concluded, "It is only through the nurturing of truly competitive training markets and genuinely hard budgets that these organizations (national training agencies) become demand-driven and cost effective" (DANIDA 2002, p. 53).

\section{Direct Allocation Mechanisms}

The mechanism through which government transfers funds to training institutions is likely to have an important effect on the way in which this funding is used and on institutional behavior more generally. Inherent shortcomings in the transfer mechanisms used may promote inefficiencies in training institutions and supply-driven training provision (Ziderman 2003, p. 129).

Traditional Budget Practices Traditional budgeting for statesponsored training institutions has been based largely on past expenditures and incremental needs for the new year. Such ad hoc systems of allocation, rooted in the status quo, cannot stimulate internal efficiency or adjustments to the market. Major defects of ad hoc funding are the lack of incentives for institutional efficiency and the failure to encourage training providers to adapt to labor market needs. Training provision remains static and supply driven (box 7.4).

A potentially important reform is the gradual dismantling of the arbitrary, institutional, core funding arrangements in place in almost all of SubSaharan Africa, and their gradual replacement by objective funding formulas related to inputs, outputs, and outcomes.

INPUT-BASED FINANCING Budgets can be based on more objective criteria relating to the internal operations of the training institutions. Institutions can be financed according to the estimated costs of required inputs. One form of input funding is by formula or norms, such as trainees enrolled or number of classes. The formula typically multiplies enrollments by a measure of unit costs. The advantage of this method, which links funding to training costs, is greater accountability (compared with ad hoc funding). The cost factors used can also be weighted to achieve broader policy goals, 


\section{Box 7.4. Zambia: Traditional Budgeting}

The 23 trades training institutes in Zambia are funded by the Ministry of Science, Technology, and Vocational Training through largely ad hoc funding methods. Institutes present annual budget requests to the ministry. Initial institutional allocations are based on the previous year's budgetary allocation (with an allowance for inflation) but subsequently adjusted downward to reflect the lower total budgetary allocation approved by the Ministry of Finance. Salary allocations for permanent staff continue to absorb almost all of the budget for recurrent expenditures, leaving little for materials, supplies, and maintenance. An independent (restricted circulation) review of training finance in Zambia concluded that this funding approach has encouraged complacency among training providers, because funding is secured regardless of performance, and little attention is accorded to training quality or relevance.

Source: Ziderman 2003, p. 130.

for example, incentives for disadvantaged youth or enrollment in strategic skills. Weaknesses of input financing include (i) the lack of incentives for efficiency (indeed, funding formulas based on average costs may actually promote expansion of the institution) or quality assurance, and (ii) the lack of incentives to close the gap between training and employment needs (Ziderman 2003, p. 131).

OutPut-BASED Funding Output-based funding seeks to reward performance and pay for results achieved. It rewards institutions that meet predetermined targets of training delivery and penalizes institutions that fall short. Outputs may be defined in absolute terms, such as number of course completions or pass rates on examinations, and in relative terms, such as years to completion. The keys are to define simple, transparent, and easily measurable performance criteria, and to have the ability to collect reliable information on the criteria. The benefit of output-based funding is increased efficiency or quality, but the method does not lead automatically to greater relevance (the matching of training supplies with labor market demands). Further, the issue of sanctions and possible removal of funding of institutions requires attention to second-chance and remedial measures.

COMPOSITE FORMUla FUNDING Another form of performance-based budgeting stresses outcomes, that is, the success of the training provider in meeting labor market needs; for example, job placement within a reasonable time. Outcome-based funding can be subject to distortions by the training provider, such as "creaming" — screening out less promising candidates so as to maximize outputs. It can also lead to funding instability, particularly in times of weak economic activity. Output-based funding is unlikely to be 
successful if used as the sole criterion. An approach that balances these risks involves the use of a composite formula for financing. This includes several elements, such as institutional inputs (total enrollment by field), outputs, desired labor market outcomes (job placement), and enrollment of special groups (Ziderman 2003, p. 133).

Experimentation with normative financing has been rare in the region. Barriers to change in budget procedures stem from institutional resistance, opposition of vested interests, and the slow response of training institutions. A shift has been discussed in South Africa from classical input-based budgeting to an outcome-related model of funding for technical colleges and further education institutions (box 7.5).

Normative financing is probably within the capacity of most governments in Sub-Saharan Africa, as it requires no additional financing. The benefits are likely to be substantial in terms of increased efficiency and relevance to market trends.

\section{Indirect Financing: Vouchers}

An indirect method for financing TVET places funding directly in the hands of beneficiaries, in the form of vouchers, to buy training services in an open market. Financing trainees through vouchers (rather than through cash payments to institutions) may help develop the demand side of training markets. Vouchers can make the demand for training more effective by stimulating competition among service providers bidding for the vouchers,

\section{Box 7.5. South Africa: Normative Financing Experiment with Technical Colleges}

In South Africa, to counter present inefficiencies, a lump-sum budget allocation is being considered. The allocation would have two components: the larger part designated for priority programs and the smaller part for lower priority programs. The formula will then be translated into a cost per fulltime-equivalent student enrolled.

The second portion of the funding will be calculated on outputs. For example, colleges that improve their pass and placement rates will get additional funding. The formula will also include an index to promote equity and compensate individuals for certain disadvantages (for example, socioeconomic background, disability).

To improve quality of outcomes, the funding strategy will offer incentives to reward institutions that move toward cost-effectiveness. Institutional capacity to respond to the needs of the labor market will also be a criterion for funding.

Source: Atchoarena and Delluc 2001, p. 274. 
leading to better quality or lower cost. Training institutions could become more responsive to student demands (as a proxy for market demand).

Training vouchers are rarely used in Sub-Saharan Africa, and general student-based funding remains a long way off. Vouchers can play a more immediate role in specific training contexts. Several countries are already using vouchers in largely experimental programs as a mechanism for funding training for the informal sector, with the intent to build up demand-driven training markets for informal sector training over the long term. The best-known example is Kenya's voucher program supporting micro and small enterprises, but there are others, including the Mauritius scheme and the flawed intake voucher scheme in Ghana. In Kenya, the use of vouchers appears to have stimulated a supply response from an unexpected source: master craftspersons (appendix G). Vouchers were used in Mauritius for a different purpose, to correct the tendency of small companies to undertrain (box 7.6).

In Ghana the use of vouchers failed. Vouchers for training were supposed to be allocated through trade associations to train apprentices in Ghana, but the idea was abandoned as unworkable during implementation. The failure can be traced to the following factors: lack of meaningful choice by voucher

\section{Box 7.6. Mauritius: Vouchers for Small Enterprise Training}

The voucher scheme in Mauritius is unusual in providing a framework within the levy-grant scheme whereby small and micro enterprises, all subject to the payroll levy, can receive training benefits. Undertraining has been endemic in small companies in Mauritius, the result of both their inadequate training culture and their difficulties in organizing training-which the existing training incentives under the levy-grant scheme did little to overcome. Incorporated into the levy-grant arrangements in 1996, the voucher scheme allows for the provision of vouchers to small companies, to be used to pay (in part or in full) for training from approved providers that meet small companies' needs. Vouchers are redeemed for payment from the Industrial and Vocational Training Board (IVTB). The system attempts to increase intercompany equity of treatment under the levy-grant scheme, lighten the administrative burden that may weigh heavily on small companies in filing reimbursement claims, and ease their cash flow problems. However, the voucher scheme did not work. After four years the government canceled it. Administrative costs had been high and use of the vouchers by small enterprises was insufficient to justify the continuation of the program. A postmortem analysis suggested that the program had been established on a faulty assumption. It had assumed that small businesses did not engage in training because of financial constraints. The vouchers eased that financial constraint. In fact, the tightest constraint turned out to be time- the inability of small employers to release key workers for the training.

Source: Ziderman 2003, p. 157; IVTB communication. 
holders among training institutions (in fact, little if any choice was available); undue complexity of the scheme for administration of the vouchers; and lack of marketing incentives-the trade associations received no compensation for marketing and processing the vouchers. In the end, the training institutions took over the selection of trainees and the allocation of training places.

Three general observations are made on vouchers:

1. Vouchers have proven an effective instrument for simulating demand-driven training in Kenya. The Kenya case points to the value of putting purchasing power in the hands of employers and entrepreneurs. However, financial management and cash flow systems have to be carefully designed, as seen in both Kenya and Ghana. The need for adequate financial control has to be balanced against the need for efficiency in payment of providers. That balance has not yet been struck in the Kenya project.

2. Some financial incentive must be offered to compensate for the administrative tasks of marketing and distribution of vouchers.

3. The experience in Ghana with vouchers is also instructive. Vouchers allow students to choose their training providers, which fosters competition among the providers, resulting in either lower costs or higher quality. Experience in the Ghana project shows that a region has to have a sufficient number of training providers in order for a voucher system to provide real choices and competition.

Finally, replication of the Kenya voucher successes elsewhere cannot be presumed. It requires the existence of a culture of informal apprenticeships and associations for micro businesses (Johanson 2001, part 1, p. 17).

\section{Enterprise-Based Training}

In openly competitive economies, companies tend to undertrain, particularly for transferable skills. Two reasons are the risk that other companies will poach their trained workers and the possibility that wage distortions may not induce workers to acquire skills themselves. (Chapter 1 reviews these issues in the modeling of training discussions.) As a consequence, undertraining stunts productivity growth, competitiveness, and industrial development (Ziderman 2003, p. 42).

Programs are sometimes needed to give companies incentives to provide training for their workers. Three kinds of financial incentives are provided to companies to enhance the quantity and quality of company training: direct subsidies, company tax credits, and levy-grant mechanisms. Each has been tried in Sub-Saharan Africa.

DIRECT SubSIDIES Formal apprenticeships exist as a means to provide training for wage employment in the formal sector. A particular case can be made for subsidized apprenticeship wages for equity reasons, giving parity 
of treatment to apprentices with their peers in vocational schools or in highly subsidized formal education (box 7.7).

Apprentice wage subsidies can be a useful tool, positively influencing the quantity of initial training provided by companies; however, for this to be the case, some preconditions must be present:

- The design should not permit employers to exploit the availability of wage subsidies to gain access to cheap labor.

- The elasticity of supply of apprenticeship spaces must be greater than one; otherwise, the desired supply response of an increased apprenticeship intake will not materialize.

- Apprenticeship training must provide genuine training and skills development for the worker, imposing costs on the company that are offset (in part or full) by the wage subsidy (Ziderman 2003, p. 148).

INDIRECT SUbSIDIES WITH TAX CONCESSIONS In most countries, corporate training expenses are tax deductible, as are expenditures on capital assets. A further tax concession beyond the usual deduction of training expenses can be offered. South Africa, Botswana, and Mauritius have all tried tax concessions to stimulate enterprise training - all without much success (Ziderman 2003 p. 148). Tax credits did not work in Brazil, either. A prerequisite for the introduction of the scheme is a well-developed and broad-based system of corporate taxation, not usually present in countries in Sub-Saharan Africa. Companies that have low profits and perhaps poor training capacity do not benefit and are not encouraged to train. Tax concessions benefit only stronger, profitable companies. With tax concessions, unlike with levy-grant schemes (explained below), the government bears the cost in the form of lost tax revenues. In this sense, they are "subsidies in disguise," akin to direct training subsidies by the government (Ziderman 2003 p. 148).

\section{Box 7.7. Malawi: Apprenticeship Allowances}

Malawi's levy-financed Industrial Training Fund, which focused mainly on supporting the apprenticeship scheme, is being replaced by a more broadly based scheme covering additional levels of training provision and a wider range of skills. Some three-quarters of levy income was expended on reimbursing apprenticeship wages. Apprentice allowances were provided during the four-year apprenticeship period-both during the initial year of full-time institutional training (paid by the government) and, subsequently, during the three years of indentured training (paid by the company and reimbursed by the fund). From the second year on, apprentices received a fixed monthly allowance, including the annual three-month period of block release at training institutions.

Source: Ziderman 2003, p. 148. 
PAYROLL TAX SCHEMES National payroll tax schemes are usually classified into two distinct groups, reflecting very different underlying objectives: revenue-generation schemes (under which levy proceeds are used to finance training by public sector institutions) and levy-grant schemes (under which levies are used to encourage training investment by companies themselves). Levy-grant schemes attempt to create incentives for enterprises to invest in the skills of the work force, whether by training on the job (setting up or extending and improving existing company training) or by sending workers to train externally. (See chapter 5.) Table 7.6 shows some countries with levy-grant schemes.

LEVY-GRANT SCHEMES Levy-grant schemes come in three forms: cost reimbursement, cost redistribution, and levy exemption.

- Cost reimbursement. The training fund offers grants to companies for costs incurred for designated forms of training (both on and off the job). A ceiling for expenditure reimbursement (for companies that train to acceptable standards) is usually set at up to a given percentage of the levy paid. This is the variant generally adopted in SubSaharan Africa. This type of scheme has been used in Nigeria.

- Cost redistribution. Designed to deal with the ill effects on training supply of the poaching of skilled workers by companies that do not train, cost redistribution redirects the training levy away from companies that do not train toward the companies that do. Enterprises that train may receive grants far in excess of the levies paid, giving them strong incentives to train. There are few examples of cost-redistribution schemes in the region. Mauritius has applied this model (Ziderman 2003, p. 93.).

Table 7.6. National Levy-Grant Schemes in Selected Sub-Saharan African Countries

\begin{tabular}{llc}
\hline Country & Training tax & Used for training? \\
\hline Benin & 2 percent of payroll & No \\
Côte d'Ivoire & 1.2 percent of payroll & Yes \\
Kenya & Sectoral taxes (not based on payrolls) & Yes \\
Malawi & Based on number of skilled workers & Yes \\
& (to be replaced by payroll levy) & \\
Nigeria & 1.25 percent of payroll & Yes \\
South Africa & 1 percent of payroll & Yes \\
Togo & 1 percent of payroll & No \\
Zimbabwe & 1 percent of payroll & Yes \\
\hline
\end{tabular}

Source: Ziderman 2003, table 6.1, p. 95. 
- Leoy exemption. Usually used as part of broader cost-reimbursement schemes, levy exemption allows companies that adequately meet their training needs to withdraw from the levy-grant system or to reduce their levy assessments. A major advantage of this scheme is that it frees companies from the bureaucratic fatigues of levy payment and subsequent grant claim. Although much discussed, this mechanism is more common in industrial economies than in developing countries. Côte d'Ivoire is one country where it has been applied.

Levy-grant schemes basically take two approaches, external and systems (these are not mutually exclusive).

- External approach. The Zimbabwe scheme typifies the external approach. Here, a detailed list is made of approved forms of training and courses that are eligible for rebates. Then, companies are invited to apply for cost reimbursement for these forms of (mainly external) training. The latest listing by the Zimbabwe Manpower Development Fund was drawn up in 1993 and is generally regarded as outdated. This approach offers rebates to companies for certain forms of training and encourages enterprises to train more in designated eligible areas, but it is unlikely to have more than a limited, short-term impact on skills development. The external approach favors standard forms of training instead of supporting forms of training varying across companies.

- Systems approach. Some elements of the systems approach are used in Côte d'Ivoire, in Nigeria, and in a new arrangement being developed in South Africa. In Côte d'Ivoire, reimbursement is contingent on the preparation of a company training plan and its approval by the Fund. In the Nigerian case, grant payment is conditional on the company adopting a systematic approach to training based on given criteria. Thus, companies are encouraged to think through a training program, systematically as they prepare it, defining it in terms of their real skills needs, instead of applying for rebates ad hoc, on a short-term basis. This broader, more progressive approach is developed within the framework of new funding arrangements being put in place in South Africa.

STRENGTHS AND WEAKNESSES OF FINANCING FOR ENTERPRISE-BASED TRAINING SCHEMES The three mechanisms for encouraging enterprise-based training share a number of weaknesses. One policy measure may alleviate one weakness but exacerbate another. The redesign of training-eligibility criteria to avoid training distortions may lead to higher inspection and monitoring costs, as will improved inspection methods to counter repackaging. Lessening the administrative requirements on companies can lead to an increase in company uptake of subsidies at the expense of data for inspection and monitoring. A careful balance of policy measures is necessary (table 7.7).

The three mechanisms to encourage enterprise-based training are not equally effective, as shown in table 7.8. 
Table 7.7. Weaknesses Common to Levy-Grant Schemes

\begin{tabular}{|c|c|c|}
\hline Weakness & Explanation & Policy directions \\
\hline Windfalls & $\begin{array}{l}\text { Eligible training might have been } \\
\text { provided by enterprise in absence of } \\
\text { incentive scheme }\end{array}$ & $\begin{array}{l}\text { Revoke subsidy, if windfalls } \\
\text { are widespread }\end{array}$ \\
\hline $\begin{array}{l}\text { Training } \\
\text { distortions }\end{array}$ & $\begin{array}{l}\text { Biases training toward more formal } \\
\text { and externally provided training, away } \\
\text { from informal training on the job }\end{array}$ & $\begin{array}{l}\text { Redesign training eligibility } \\
\text { criteria to avoid distortions }\end{array}$ \\
\hline $\begin{array}{l}\text { Repackaging } \\
\text { effect }\end{array}$ & $\begin{array}{l}\text { "The adaptation and documentation of } \\
\text { existing training provision to comply } \\
\text { with eligibility requirements"a }\end{array}$ & Improve inspection methods \\
\hline $\begin{array}{l}\text { High costs of } \\
\text { inspection }\end{array}$ & $\begin{array}{l}\text { High central costs of inspection and } \\
\text { monitoring, to counter abuse by } \\
\text { enterprises }\end{array}$ & $\begin{array}{l}\text { Raise sanctions and monitor } \\
\text { a sample of enterprises }\end{array}$ \\
\hline $\begin{array}{l}\text { Administrative } \\
\text { costs on the } \\
\text { company }\end{array}$ & $\begin{array}{l}\text { Considerable cost to enterprise of } \\
\text { establishing eligibility and compliance } \\
\text { (including paperwork and } \\
\text { record-keeping) }\end{array}$ & $\begin{array}{l}\text { Avoid cumbersome } \\
\text { administrative procedures } \\
\text { and onerous eligibility } \\
\text { criteria }\end{array}$ \\
\hline
\end{tabular}

a. Dougherty and Tan 1991.

Source: Ziderman 2003, table 9.1, p. 152.

Table 7.8. Strengths and Weaknesses of Enterprise Training Schemes

\begin{tabular}{|c|c|c|}
\hline Mechanism & Main advantages & Main weaknesses \\
\hline $\begin{array}{l}\text { General training } \\
\text { subsidies (grants) }\end{array}$ & None & $\begin{array}{l}\text { Cost burden falls on public } \\
\text { budgets (increased expenditures) }\end{array}$ \\
\hline $\begin{array}{l}\text { Levy-grant } \\
\text { systems }\end{array}$ & $\begin{array}{l}\text { Costs do not fall on public } \\
\text { budgets-they are met by } \\
\text { enterprises (or, with incidence } \\
\text { shifting, by workers) } \\
\text { Can facilitate a more systematic, } \\
\text { structured approach to } \\
\text { enterprise training }\end{array}$ & $\begin{array}{l}\text { Requires sufficient organizational } \\
\text { capacity to administer; hence, may } \\
\text { not be appropriate in countries } \\
\text { with weak administrative capacity } \\
\text { Tendency toward reduced } \\
\text { effectiveness over time }\end{array}$ \\
\hline $\begin{array}{l}\text { Company tax } \\
\text { concessions }\end{array}$ & None & $\begin{array}{l}\text { Requires well-developed, } \\
\text { broad-based system of corporate } \\
\text { taxation } \\
\text { Cost burden falls largely on public } \\
\text { budgets (reduced revenues) } \\
\text { Responsiveness of companies } \\
\text { often low because few companies } \\
\text { earn sufficient profits to benefit } \\
\text { from tax exemptions }\end{array}$ \\
\hline
\end{tabular}

Source: Ziderman 2003, table 9.2, p.152. 


\section{Notes}

1. The Botswana Brigades seem to be an exception to this trend. In the past the Brigade's training costs were covered from income generated from sales of products and services. Now, the institutions look to government and donor agencies for their daily survival (Atchoarena and Delluc 2001, pp. 234-35). This recent development makes the Brigades closer to public institutions.

2. The wide acceptance of cost recovery notwithstanding, some donor-funded projects continue to offer training free of charge (for example, Centre de Formation Professionnelle d'Abomey, a training project in Benin funded by Hanss Seidel Foundation) or even pay training stipends or sitting allowances (for example, VSP in Ghana), mostly for reasons of equity (Haan and Serriere 2002, p. 140).

3. This cross-subsidy by those who can afford to pay of those who cannot is equivalent to replacing public financing with fee revenues and using public financing to promote access.

4. The IVTB in Mauritius recently decided to divest itself of direct management responsibilities for its training institutions. 


\section{Moving Forward with Reforms}

Five major conclusions emerge in this review: (i) the reform of skills development in the informal sector is essential to poverty alleviation; (ii) the record of TVET reforms over the past decade has been promising; (iii) public training continues to face challenges in reform; (iv) nongovernment training institutions and enterprises account for most of the regional capacity for skills development; (v) management and finance provide powerful instruments for promoting reforms. Moving forward requires governments to recognize that they cannot do all things and that they need to be more strategic. Governments are encouraged to foster partnerships with other providers, promote social equity and fill critical skills gaps, and perform market functions that governments are uniquely equipped to perform. Getting the policies right to encourage efficient training markets is an important first step. The implications of this for international assistance to skills development are outlined, along with a research agenda.

\section{The Assessment}

A decade after publication of the 1991 World Bank Policy Paper on TVET, the subject and its impact on productive employment and opportunities for income generation continue to spark debate about the responsibility of governments for its provision and financing. This review has taken stock of experience over the past decade with TVET reforms to provide further guidance to policymakers, development partners, and World Bank staff on the outcomes and lessons for reform.

The experience applies to nonfarm employment in Sub-Saharan Africa and principally to countries characterized by high labor force growth and stagnant formal economies, but many of the conclusions will resonate in other regions. The review and guidance it offers are important to achievement of the Millennium Development Goals for poverty reduction and Education For All by more clearly defining government's comparative advantage in skills development and providing guidance for raising productivity and incomes in the informal sector where many of the poor work.

Attention has been focused in this review on issues in skills development, but it should not be forgotten that the demand for labor and skills is derived from sound macroeconomic policies that promote investment and 
job creation. Training alone does not create jobs. The stagnation of wage employment in Sub-Saharan Africa, revealed in chapter 2, along with the region's dependence on the informal economy for job creation, emphasizes the priority for getting the macroeconomic conditions right. Government's role in all countries starts here. Debate continues about the role governments are to play in skills development. This review has highlighted the importance of understanding market failures and equity issues in defining this role.

The review extends the analysis that underpinned the 1991 Policy Paper and explores the outcome of reforms in Sub-Saharan Africa. The analysis draws on a rich body of new data developed in thematic and case studies prepared for this review along with formal surveys of skills development in enterprises. It documents the shift of external support for TVET to policy reforms for systems management and finance and extracts lessons from this experience for shaping future reforms.

\section{Attention to Informal Economies is Important}

The growth of wage employment has continued to stagnate over the past decade in Sub-Saharan Africa in all but a few countries. Real wages have fallen and the expected expansion of wage employment has failed to materialize. Employment in public enterprises and the civil service has been reduced while private investment has been slow to emerge and generate new wage employment. Against this backdrop, rapid population growth has continued to expand the labor force and the pressure for jobs.

Labor markets have adjusted in response. The informal sector has absorbed most of those unable to find wage employment. Open unemployment has become more visible, particularly among youths, in urban areas. Crowding-in problems are evident in the informal sector as many new workers enter traditional employment in trade, retailing, and personal services, saturating these markets and reducing individual market shares, and thus reducing personal income. Opportunities exist in small manufacturing and high-end services. Skills development is part of a package of services needed to support micro and small enterprises.

Labor markets in Sub-Saharan Africa support skills development but are affected by issues ranging from disease and wars to weak institutions guiding skill choices. The impact of HIV/AIDS on skills development is devastating. While slowing the pace of labor force growth, the disease is deskilling the work force, driving up the cost of employment, lowering productivity, removing mentors as a source of skills transfer, and shortening the expected life cycle and benefit stream for investments in skills. Timely labor market information for policy development and guidance for trainers and trainees is generally absent.

The reality is that most people will have to eke out livings in the informal sector. However, the majority of people do not receive organized skills 
development at present, and existing formal training programs are directed almost exclusively at wage employment. As a means of poverty alleviation, new training providers (and markets) must be developed to serve this priority group. Reforming existing training programs to serve the informal sector has proven difficult. Nongovernment organizations have demonstrated an ability to deliver training for those in micro and small enterprises. Training funds have stimulated the supply response, including from master craftsmen. Enlarging the scale of these options and making them financially sustainable continues to be a challenge.

The informal economy remains a safety net absorbing many of those who are unable to find employment in the formal sector. New entrants to the sector, however, are changing the character of informal economies, bringing more education with them, looking at self-employment as a preferred option rather than as a transition to wage employment, and engaging in high-end activities with more skill content. Still, the majority of those in the informal economy are operating in enterprises with fewer than 10 workers, mainly unpaid family workers. Raising productivity and incomes in this sector is essential to reducing poverty.

Skills are only part of the package of support needed for micro and small enterprises of the informal sector. Strategies may differ for subsistence-level micro enterprises with fewer than 10 employees, where traditional apprenticeships dominate, and small enterprises with up to 50 employees, where the potential for growth and employment generation is greater. (See chapter 2.) For both, the package of support will require attention to secure work environments, enforcement of contracts, and access to financing and technology, along with skills development. Gender issues are important in this framework.

\section{Reforms in Skills Development Are Promising}

Governments are engaged in the provision and financing of skills development worldwide, including in Sub-Saharan Africa. The challenge is how to make them more responsive to markets and efficient in the use of resources. The past decade has produced promising reforms. The movement toward partnerships in governance-engaging government, employers, and workers in new national coordinating bodies and training authorities-offers hope for better integration of fragmented markets. Diversification of financing has expanded the resources available for skills development, giving increased attention to accountability and incentives for performance, and has encouraged the more efficient use of resources.

Tanzania, Zambia, and South Africa are carrying out comprehensive TVET reforms. Political leadership of the process is essential to its success, as is the engagement of all stakeholders for building consensus around the reforms. Without this consensus and ownership, the reforms are unlikely to take hold. Building reforms on a foundation of sector knowledge is essential. 
Because circumstances differ by country, regional studies like this review are useful but are not a substitute for country-based analyses of the issues surrounding skills development. As experience in Zambia and South Africa illustrates, reforms require patience in building consensus and in implementation. Donors and others supporting these reforms should be prepared to commit to a 10- to 15-year time horizon for policy and institutional development.

\section{Public Training Continues to Face Challenges}

Many of the critiques made of state-sponsored TVET in the 1991 Policy Paper are still relevant today, more than a decade later. Public training, with its focus on wage employment, remains out of touch with market needs in many countries. Reductions in recurrent financing have had serious consequences for quality of instruction. The cost-effectiveness of the training offered continues to be an issue. Still, state-sponsored TVET, albeit more strategically focused, remains important to future skills development. This review points to differences in the markets served by various kinds of training institutions and enterprises. State-sponsored training institutions are shown more willing to invest in capital-intensive skills training, cover wider geographical areas, provide instructor training, and address strategic skill needs to support national economic development strategies.

Public training institutions have been subject to budget constraints over the past decade and are likely to continue facing these constraints. The strategic use of scarce public financing for skills development is therefore essential. Building a policy framework that encourages public and private training institutions to pursue on equal footing their comparative advantages is an essential step toward meeting market needs for skills development. Shifts to performance-based financing can encourage the more efficient use of public financing.

\section{Enterprises and Nongovernment Providers Are Active Trainers}

The case made for public provision of training often rests on the absence of other providers. This review documents for Sub-Saharan Africa the roles played by enterprises and nongovernment training institutions. The evidence confirms the active role of enterprises in the formal sector as trainers, drawing on capacity in the firm and capacity contracted from outside. Traditional apprenticeship is a pervasive source of skills development in smaller firms of the informal economy. Informal sector apprenticeships are rooted in the world of work, serve poorer segments of the population, and are self-financing, self-regulating, and generally cost-effective.

The analysis shows, however, the selective nature of skills development within enterprises. Large, formal sector enterprises are more likely to train, as are those enterprises that produce for export and use higher levels of technology. Those trained tend to have higher levels of education and be 
employed in higher-skilled occupations. Such a pattern contributes to the widening of income distributions, leaving the unskilled and poor behind. Smaller enterprises are less active as trainers. Traditional apprenticeships in the informal sector tend to perpetuate existing technology in skills development, lack standards and quality assurance, and lack access to knowledge of new sources of productive growth.

Nongovernment trainers, for-profit and nonprofit, are a significant and growing part of TVET. Building this capacity brings new private investment into training, broadens access, and reduces pressure on public spending for skills development. Nongovernment trainers are noted for their lower costs, close linkages with the labor market, and attention to female enrollments. This source of training provision, however, is not without problems. Variance in quality is the single most important issue to be faced. The for-profit sector focuses on information technology, business skills, and other skill clusters that require low capital investment. Many depend on the public sector for part-time instructors. Much of this training is located in urban centers not available to those living in rural communities. Fees tend to exclude marginalized groups.

Nonprofit providers, including religious institutions, serve valuable social objectives in reaching vulnerable and disadvantaged groups and often provide high quality training for pre-employment. The sustainability of such training ventures, however, often rests with the commitment of the providing organization.

Taken as a whole, enterprises and nongovernment providers of skills development far exceed the capacity of state-sponsored training institutions in most of Sub-Saharan Africa. Each type of provider has strengths and weaknesses, and therefore comparative advantages and disadvantages (see table 8.1). All providers are essential to meet the full complement of skills required. Partnerships are essential.

\section{Management and Finance Provide Powerful Instruments for Reform}

Both management and finance can help training institutions achieve greater relevance, access, quality, and efficiency in skills development. The creation of national training authorities to govern training systems brings stakeholders together in developing policy and in making decisions on resource allocation to improve market performance. Providing managers of training institutes with increased autonomy (to set fees, select staff, determine curricula, and choose training materials and pedagogy) and then holding these managers accountable for the results creates incentives for good performance.

How training is financed also shapes the behavior of training providers and determines what training is offered, how it is organized, and who receives it. Traditional public financing for TVET contains few incentives for improving performance. Public financing tends to be based on the inputs provided (facilities, equipment, training materials, and instructors) without 
Table 8.1. Strengths and Weaknesses by Type of Training Provider

\begin{tabular}{|c|c|c|}
\hline Type & Strengths & Weaknesses \\
\hline $\begin{array}{l}\text { Government- } \\
\text { owned training } \\
\text { institutions }\end{array}$ & $\begin{array}{l}\text { - Often wide geographical } \\
\text { coverage } \\
\text { - Willingness to invest in } \\
\text { capital-intensive skills } \\
\text { - Often addresses strategic } \\
\text { skills needs for national } \\
\text { strategies }\end{array}$ & $\begin{array}{l}\text { - Often insulated and } \\
\text { unresponsive to market } \\
\text { forces, repeating course } \\
\text { offerings regardless of } \\
\text { employment demand } \\
\text { - Tendency to obsolescence } \\
\text { - Lack of cost-consciousness } \\
\text { resulting in inefficiencies } \\
\text { - Quality suffers when } \\
\text { public budget are cut }\end{array}$ \\
\hline $\begin{array}{l}\text { Non-government } \\
\text { providers }\end{array}$ & $\begin{array}{l}\text { - Major source of skills } \\
\text { training in many countries } \\
\text { - Saves public expenditure } \\
\text { that would have to be } \\
\text { provided otherwise } \\
\text { - Nonprofit providers often } \\
\text { serve vulnerable and } \\
\text { disadvantaged groups } \\
\text { - High proportion of female } \\
\text { enrollments } \\
\text { - For-profit institutions } \\
\text { usually cost-conscious } \\
\text { and attentive to market } \\
\text { developments and } \\
\text { graduate placements }\end{array}$ & $\begin{array}{l}\text { - Wide variation in quality } \\
\text { - Tends to focus on skills } \\
\text { with low investment } \\
\text { requirements } \\
\text { - Training often concentrated } \\
\text { in urban areas } \\
\text { - Fees tend to exclude } \\
\text { marginalized groups }\end{array}$ \\
\hline $\begin{array}{l}\text { Enterprise- } \\
\text { formal sector }\end{array}$ & $\begin{array}{l}\text { - Self-financing and self- } \\
\text { regulating } \\
\text { - Based on actual } \\
\text { occupational tasks } \\
\text { performed in employment } \\
\text { - Matched closely with } \\
\text { existing production } \\
\text { technology }\end{array}$ & $\begin{array}{l}\text { Training is selective-most } \\
\text { notably in larger firms, for } \\
\text { higher skilled occupations } \\
\text { and better educated } \\
\text { workers } \\
\text { - Small enterprises are less } \\
\text { likely to train }\end{array}$ \\
\hline $\begin{array}{l}\text { Traditional } \\
\text { apprenticeship } \\
\text { (see also table 6.2) }\end{array}$ & $\begin{array}{l}\text { Pervasive source of skills } \\
\text { for informal economy } \\
\text { - Based on actual } \\
\text { occupational tasks } \\
\text { performed in employment } \\
\text { - Serves poorer segments } \\
\text { of the population } \\
\text { - Self-financing and self- } \\
\text { regulating } \\
\text { - Generally cost effective }\end{array}$ & $\begin{array}{l}\text { - Perpetuates existing } \\
\text { technologies } \\
\text { - Training delivery is often } \\
\text { poor } \\
\text { - Lack of standards and } \\
\text { quality assurance } \\
\text { - Skills obtained often } \\
\text { incomplete }\end{array}$ \\
\hline
\end{tabular}


accountability for the outcomes of the training in terms of the numbers trained, the competencies achieved, and the relevance of the training to market needs.

Diversification of financing with cost sharing has changed incentives for performance among skill providers by giving consumers more interest in the quality and relevance of the training offered. Further diversification in combination with public financing will expand access, encourage new sources of supply for training, and reduce pressures on public budgets. Training funds have acted as intermediaries for trainees in contracting for training outcomes. Training vouchers have directly empowered beneficiaries and recent movements toward developing funding formulas that combine the contracting of inputs with outcomes are shifting incentives for performance by training providers.

The modalities of financing TVET are perhaps the most important instrument for promoting sector reforms. Shifting public financing to performance-based criteria improves the efficiency of training provision, whether from state-sponsored, nongovernment, or enterprise sources. Performance-based financing needs no bureaucracy to match demand and supply. It requires establishing incentives for performance by all providers and developing much better information and monitoring systems.

The limited availability of public financing has contributed to the performance problems of TVET over the past decade. This situation is unlikely to change in the future. It calls for a more strategic use of public resources, along with encouragement of diversification of financing and provision by other stakeholders. The public sector cannot afford to finance and deliver all the skills that are needed and will have to focus on developing training markets and filling gaps left by these markets. These gaps will vary, but generally include reaching underserved regions, providing access to disadvantaged groups, and ensuring the supply of strategic skills for new industries. Public provision can work where financing incentives are performance based.

\section{Government's Role}

The chapters in this review contain ideas for improving the performance of skills development based on experiences in Sub-Saharan Africa in the 1990s. The priority is to get the policy framework right. Doing so requires defining government's role in the provision and financing of skills development and establishing and building the capacity of institutions to support efficient training markets.

\section{Introduce an Effective Policy Framework}

Getting the policies right for skills development is the number one priority for governments. These policies need to address through legislation the roles and responsibilities of all stakeholders (training providers, government, 
enterprises, workers, trainees, and supporting institutions). The policies adopted should address the following elements:

- How to govern the training system, defining how stakeholders will interact, what their rights will be, and what their respective roles are in training markets

- What licensing and regulation are needed to strike a balance between establishing appropriate consumer protections and removing costly barriers to entry and expansion for nongovernment training providers

- What process will be used to set standards and conduct examinations, in order to provide a level playing field among providers in terms of quality and cost of training provided

- How to finance the training system to provide incentives for good performance by all stakeholders

- How to monitor and evaluate suppliers for promoting accountability and quality.

Broad stakeholder participation in the process is essential to developing effective policies to which all parties can be committed. Financing and standards are important features of the policy framework. Although financing establishes the performance incentives, standards are one of the instruments for measuring this performance. Training to standard or level of competency shifts attention from the provider of the training, public or private, to the results.

\section{Define Government's Role in Provision and Financing}

The development of the policy framework requires establishment of the roles to be played by stakeholders, including government. The determination of this role for government needs to be built on economic analysis of market demand and supply. It should be country-specific. The analysis should assess the presence of market failures. This economic analysis has in many cases been missing over the past decade.

UNDERSTANDING THE ECONOMY AND LABOR MARKETS The economic context affecting the demand and supply for skills training is important as a guide to the creation of good policies for TVET (Middleton, Ziderman, and Adams 1993, pp. 255-256). The context will vary from country to country and will shape the incentives for investment in and provision of skills training. The list below outlines the elements of the analysis needed:

- What is the structure of market demand for skills and the economic forces driving it? Is employment moving toward a service-based economy in finance, as an example, or is it focused on agriculture-led development? This information is important to suppliers of training and to beneficiaries. 
- Who are the suppliers of training, by type of ownership, and how cost-effective are they? Mapping the supply side of training markets and evaluating performance in terms of ownership of the institution are important to assessing public training provision and the potential for expansion of nongovernment training.

- What are the barriers, if any, to the training response? Highlighting and removing barriers to entry, such as high licensing fees, can help open markets for nongovernment provision and reduce the need for public provision.

- What is the capacity and willingness to pay for training? Identifying capacity to pay is necessary in order to target public financing for equity purposes, while measurement of willingness to pay is needed to determine appropriate fees for training, in order to reduce the demand for public spending.

- Are labor markets sending the right wage and employment signals to guide skills development? Do labor markets indicate that policies are distorting incentives for skills development? For example, does wage setting compress wages to achieve social equity and discourage willingness to pay for training? Do minimum wages make employment creation costly and inhibit self-financing skills development? Are market failures present? (See chapter 1.)

- Is public finance for skills development used strategically? Does a public expenditure review indicate that resources for skills development are being used strategically to promote social equity, redress problems where markets fail to work well, and build institutions that promote the working of efficient training markets?

\section{Develop Institutional Capacity for Improving the Performance of Training Markets}

Along with the policy framework, governments need to give priority to the building of institutions to support the efficient operation of training markets. These institutions in their different forms bear responsibility for the regulation of training, setting of standards and examinations, training of instructors, development and dissemination of market information, and monitoring and evaluation of outcomes.

Government's role is to protect the public interest in training markets and promote their efficient operation, but this can often be achieved without building public institutions simply by drawing on the interests of stakeholders. For example, associations of providers may voluntarily set standards for differentiating quality in the market. Similarly, setting occupational standards for training is usually best done by employers in collaboration with trainers rather than will public bodies.

Building institutions that promote national policy interests is important and this applies especially to governance of training systems. National 
Training Authorities have emerged to support policy development and guide resource allocation among government and nongovernment stakeholders. The interests of government, employers, and workers can be combined within this institution to focus on regulation, standards setting and examinations, resource allocation, and monitoring and evaluation of results.

The single largest gap to be filled is that of market information for monitoring and evaluation and policy development. This review was unable to draw on timely surveys of labor force activity and skills development routinely produced elsewhere in industrialized countries by central statistics agencies. Regular indicators of relevance, cost, efficiency, and social equity were not available. These data had to be developed ad hoc as part of thematic and case studies. Building this capacity in the relevant institutions and the culture of learning is an important role for government in SubSaharan Africa.

Government already trains and supplies instructors for many nongovernment institutions. Further building this capacity for preservice and in-service training can encourage the expansion of nongovernment provision and raise the quality of government and nongovernment skills development, as can research and support for new learning technologies, for example, distance learning. In some country settings, this capacity can be further developed through public subsidy of nongovernment institutes for the training of trainers.

Taken together, the central message for governments is to become more strategic instead of attempting to do all things. Taking into consideration the roles identified above, governments are expected to concentrate on the following four priorities:

- Foster partnerships with nongovernment providers and facilitate the growth and development of these providers.

- Promote social equity in training markets.

- Fill training gaps where nongovernment suppliers fail to respond, for example, reaching the informal sector, promoting strategic skills.

- Carry out functions not done ordinarily by nongovernment bodies, for example, policy development, standards setting and examinations, regulation, instructor training, information and evaluation.

\section{Role of International Partners}

For the past decade, the World Bank and other development partners have supported policy reforms of TVET in Sub-Saharan Africa. This review notes the progress made and underscores the long-term commitment required for success. Looking ahead, TVET reforms should be supported as part of a broader sectorwide approach to the reform of education and training systems. Issues of relevance, access, efficiency, equity, and financing for human capital development need to be addressed in a framework where all options are on the table and tradeoffs are visible. 
The review stresses the importance of skills development to the informal sector and poverty alleviation. Several development partners, including the World Bank, have piloted activities over the past decade with this objective. Opportunities exist to scale up ventures that have shown promise and export them as appropriate to other country settings. Continuing to test innovations for reaching micro and small enterprises not well served by current training markets can lead to raising productivity and incomes for those employed in this sector. Searching for sustainable financing for skills development in the informal economies remains important.

International support for skills development should join the movement from financing inputs to financing outcomes and performance in training institutions, government and nongovernment. This has more promise for improving the efficiency with which resources are being used in TVET than any other policy action. At the same time, international assistance for skills development needs to be used as strategically as does public financing. Support for sectorwide approaches to education and training provide a framework for bringing basic education into the dialogue with skills development.

In summary, particular areas for external assistance may be the following:

- Development and evaluation of experimental approaches to provide training services (as part of packages of assistance) to the informal sector; and - the greatest challenge- scaling up successful approaches on a sustainable basis

- Development of public-private partnerships with a view to supporting development of nongovernment programs

- Development of demand-responsive national training systems involving all stakeholders, recognizing that such development requires expertise in change management and may take decades to accomplish fully

- Decentralization of public skills development

- Development of information systems that evaluate the scope, performance, outputs, and impact of public and nongovernment skills provision

- Development and implementation of formula funding and normative financing systems for the public sector

- Development of associations-of nongovernment providers and trade and sector associations-both to advocate their interests and deliver training relevant to their members.

\section{A Research Agenda}

Gaps in our knowledge of skills development in Sub-Saharan Africa have been identified throughout this review. One of the most important gaps is that of skills development for agricultural production. A major study of issues, recent practices, and innovations is needed as a basis for advice on 
how to improve agricultural production and productivity through training. As with informal sector training, interventions doubtless will need to be seen in terms of a package of inputs.

The full implications of HIV/AIDS for skills development remain to be assessed, both on the supply side in terms of the impact on instructors and maintenance of training capacity and on the demand side in terms of the impact on the incentives for investment by enterprises and households. Little has been found in this review, other than scattered anecdotal evidence about the implications of HIV/AIDS for skills replacement. The consequences for labor force growth and loss of skilled workers and the coping strategies of enterprises are among the issues for further examination.

The stagnation of wage employment in Sub-Saharan Africa remains a puzzle for further study. Declining real wages have not been followed by a recovery of wage employment, as observed in other regions marked by structural adjustment. The available evidence fails to point to labor market rigidities and suggests that other sources are impeding investment and job creation. Understanding these sources and their underlying causes is essential to the recovery of African economies and to poverty reduction in the region. Training, by itself, will not create jobs and will achieve its objectives only where the conditions are right for economic growth.

Several innovations have appeared over the past decade with potential importance for skills development; the continuing impact of these innovations has not been fully assessed in this review. One innovation is the movement toward integrated competency-based qualifications systems, such as NQFs. It is fashionable to transport experience from industrial to developing countries, but whether this model for setting and assessing skill requirements will work in low-income contexts remains to be determined. Similarly, the experience of national coordinating bodies and NTAs needs to be followed closely for guidance in their design.

Finally, this review does not replace the need for country analyses of skills development along the lines proposed above for determining the role of governments in the provision and financing of skills development. As DANIDA indicated in its evaluation of TVET assistance, "There is no standard type of VET support program which is equally relevant to all countries. The priorities, approaches, and modalities will vary from country to country. . . . Decisions on the type of VET support to be provided to various countries should be based on in-depth country-specific analysis of needs and opportunities, including gender-sensitive analysis of the demand for skilled labor in the various countries and regions within countries" (DANIDA 2002, p. 70). 


\section{Guide to Appendixes}

\section{Private VET}

Appendix A-Shows how the findings of the study of private VET in Mali and Senegal (Atchoarena and Esquieu 2002) relate to typical arguments for and against private training provision.

Appendix B-Summarizes the main findings from the larger study of private VET in Mali (Atchoarena and Esquieu 2002).

Appendix C-Summarizes the main findings from the larger study of private VET in Senegal (Atchoarena and Esquieu 2002).

\section{Informal Sector Training}

Appendixes D through $\mathrm{L}$ are summaries selected from a broader set of case studies on informal sector training that appear in Haan 2001 and Haan and Serriere 2002. They draw key lessons from support for informal sector through training. Appendixes D through L appear in alphabetical order by country; however, the cases are grouped below according to the three main approaches adopted:

\section{Support to Traditional Apprenticeship Systems (masters and apprentices)}

Appendix D-Illustrates a successful effort to improve traditional apprenticeship training in Benin by sensitizing and training master craftspersons.

Appendix $\mathrm{H}$-Relates experiences in a small project to improve traditional apprenticeship training in Kenya. Lessons include the need to focus on business improvement for the entrepreneurs, the need to make training content and delivery flexible, and the difficulties in getting appropriate training for vocational training institutes.

Appendix L-Summarizes a project to provide efficient training in Zimbabwe both to master craftspersons and to pre-apprentices in the informal sector. Care was taken to keep the training short, economize on costs, and not disrupt the traditional apprenticeship system.

\section{Direct Training Support to Informal Sector Enterprises}

Appendix E-Depicts a comprehensive approach by an NGO to raising the incomes of micro and small enterprises in Cameroon, which starts with technical skills training and follows a market-driven approach.

Appendix G-Summarizes experiences in implementation of a controversial large-scale voucher program in Kenya intended to upgrade the skills 
of workers in informal sector manufacturing. One unexpected outcome was the establishment of a training supply response by skilled master craftspersons and the emergence of a training market.

Appendix J-Emphasizes the importance of combining technical skills with business skills and literacy training in supporting informal sector enterprises in Tanzania, and the likely continuing need for training subsidies because of the low incomes of participants.

Appendix K-Relates the approach used in Uganda to develop a cadre of training advisers to provide technical assistance to enterprises on a costrecovery basis. In addition to in-plant advice on production management, the advisers conduct training needs assessments and set up skills upgrading courses.

\section{Training Organized by Enterprise Associations}

Appendix F-Explains the efforts by an association of informal sector enterprises in Cameroon to solve the shared problem of insufficiently skilled workers. Innovations include the regulation of traditional apprenticeship training and the establishment of exams on training outcomes.

Appendix I-Explains what a trade association did in Senegal to address a common problem of a lack of skilled workers among the association's member enterprises.

\section{Finance}

Appendix M-Lists 21 training funds in Sub-Saharan Africa according to country, organization, funding sources, and objectives. 


\section{Appendix A}

\section{Mali and Senegal: Rationale for Private Provision of Technical-Vocational Education}

\begin{tabular}{|c|c|}
\hline Expectations & Findings \\
\hline Lower cost & $\begin{array}{l}\text { + In both countries, unit costs are much lower in private } \\
\text { institutions. }\end{array}$ \\
\hline $\begin{array}{l}\text { Greater responsiveness } \\
\text { and innovation }\end{array}$ & $\begin{array}{l}\text { + In both countries, private providers are present in new } \\
\text { fields of training ignored by public institutions (for } \\
\text { example, computer science, tourism). }\end{array}$ \\
\hline Increased diversity & $\begin{array}{l}\text { + In a context of limited public delivery, the push to find } \\
\text { a profitable market niche has led private promoters to } \\
\text { diversify offers and expand choices for consumers. The } \\
\text { introduction of some competition has helped inject } \\
\text { elements of change into public institutions regarding } \\
\text { not only training but also curricula and pedagogy. }\end{array}$ \\
\hline Increased quality & $\begin{array}{l}=\text { In the absence of reliable indicators to assess and } \\
\text { compare quality, this dimension could not be } \\
\text { documented. However, both countries have some high- } \\
\text { quality private institutions. }\end{array}$ \\
\hline $\begin{array}{l}\text { Better linkages with } \\
\text { employers }\end{array}$ & $\begin{array}{l}=\text { In both countries and in both the private and the } \\
\text { public sectors, linkages with enterprises are weak (little } \\
\text { or no forms of dual training, little or no involvement in } \\
\text { providing training or other services to businesses). }\end{array}$ \\
\hline $\begin{array}{l}\text { Increased effectiveness } \\
\text { and relevance }\end{array}$ & $\begin{array}{l}\text { = In the absence of labor market data on employment } \\
\text { and income of graduates (from both public and private } \\
\text { institutions), effectiveness cannot be measured and } \\
\text { compared. }\end{array}$ \\
\hline $\begin{array}{l}\text { Concentration on } \\
\text { commercial subjects } \\
\text { and simple trades }\end{array}$ & $\begin{array}{l}\text { + The more expensive programs usually remain mainly } \\
\text { in the hands of public institutions, but private providers } \\
\text { in both countries are present in a wide variety of trades, } \\
\text { including industrial ones. }\end{array}$ \\
\hline $\begin{array}{l}\text { Selectivity of training } \\
\text { providers }\end{array}$ & $\begin{array}{l}\text { + Private providers must earn their income, but they are } \\
\text { not limited to the most profitable market segments. }\end{array}$ \\
\hline
\end{tabular}


Appendix A (continued)

\begin{tabular}{|c|c|}
\hline Expectations & Findings \\
\hline Inequity & $\begin{array}{l}\text { + In Senegal, where private institutions receive little or } \\
\text { no public subsidy, many private institutions enroll } \\
\text { students from low-income families. There is no evidence } \\
\text { that the parental income level of students is higher than } \\
\text { in public institutions. However, a segment of the private } \\
\text { sector clearly targets mainly high-income groups, } \\
\text { particularly at postsecondary level. }\end{array}$ \\
\hline $\begin{array}{l}\text { Variations in quality } \\
\text { and effectiveness }\end{array}$ & $\begin{array}{l}\text {-Visits to institutions and interviews conducted in both } \\
\text { countries indicated wide variations, probably wider } \\
\text { than among public institutions. }\end{array}$ \\
\hline
\end{tabular}

+ Positive finding

$=$ Neutral finding

- Negative finding

Source: Atchoarena and Esquieu 2002, p. 13. 


\section{Appendix B}

\section{Mali: Private Technical-Vocational Training-Main Findings}

The Malian private technical and vocational education (TVE) training sector grew vigorously in the 1990s. The number of schools rose from 11 in 1993 to 71 in 2000. The private sector today handles two-thirds of TVE enrollments, 22,739 students in the 1999-2000 academic year. Between 1997-98 and 1999-2000, private school enrollments grew by 86 percent.

In Mali, state financial support to the private sector is significant and increasing. The growing number of students enrolled by the ministry in private TVE schools has meant a striking increase in state aid, which was in excess of FCFA 1 billion in 2000 ( $\$ 1$ = FCFA 600). This amount represents more than a third of schools' overall revenue. However, this aid varies considerably from school to school. Some institutions receive no public money; others rely entirely on government subsidies. The fees set by private schools are often equivalent to or higher than what the state pays. Monthly payments vary, on average, between FCFA 8,000 and FCFA 10,000. To this is sometimes added a low enrollment fee of about FCFA 5,000.

Based on the survey results, the average cost of a private TVE student is about FCFA 150,000. This amount appeared close to the unit cost of FCFA 157,000 calculated in a review of public expenditure for the TVE sector as a whole. In reality, the cost per student is probably much higher in the public sector alone.

The available data on exam success in the private sector show a prominent fall-off in results during recent years, probably linked to the growing number of student strikes, which have also affected private schools. The success of private school candidates, however, seems to continue to surpass national exam results, which ranged, depending on the field of training, from only 38 percent to 50 percent in 2000 .

A comparison of public-private technical-vocational schools reinforces the idea of comparative advantages: public schools seem to perform better in the industrial field, and private schools seem to do better in services.

The state-led nature of private sector growth in Mali makes the sector very vulnerable and suggests that a new form of regulation should be considered. In the present system, private providers' make investments based 
on anticipated fees paid by the state. Such dependence on state intervention, while assuring them of a guaranteed income, inhibits their ability to adapt the training supply to labor market needs. Focusing state assistance toward schools that perform well and toward disadvantaged students is probably part of the answer.

Source: Atchoarena and Esquieu 2002, p. 12. 


\section{Appendix C}

\section{Senegal: Private TVE-Main Findings}

The precise size of technical and vocational education (TVE) in Senegal's private sector is difficult to gauge. According to official statistics, the private sector enrolls almost half of all vocational training students. Although underestimated, this share far exceeds the average importance of private schools in the overall education system. Survey results show that private TVE is expanding, and the schools surveyed are receiving a growing number of students. Between 1995 and 2000, enrollments increased by 84 percent.

In Senegal, private schools finance their own operations. Nearly 90 percent of their revenue comes from fees. Registration fees for day courses range from FCFA 13,000 to FCFA 22,500 (\$1 = FCFA 600). Monthly tuition ranges from FCFA 7,000 to FCFA 30,000.

The survey results confirm the extreme diversity of private schools, where private entrepreneurs cohabit with private denominational and associative organizations to fulfill a public service mission. This diversity of status and vocation is also reflected in the financial position of many schools. Overall, according to the survey, the private sector manages to break even but does not generate enough profits to ensure survival or expansion.

Based on all of the schools surveyed, the estimated average cost per student is close to FCFA 250,000 (FCFA 1.5 billion for a little more than 6,000 students). This amount is fairly modest compared with the cost of general secondary education (ranging from FCFA 196,000 to FCFA 265,000, including external aid). This unit cost figure is much lower than the official cost figures for the public sector: FCFA 362,000 for technical secondary education and FCFA 370,000 for vocational secondary education.

On the basis of the sample taken, the results of the state exams for students in the private sector are not good-below 50 percent in most areas. However, available data suggest that these results are better than those reported for public schools.

In this context, improving technical-vocational training, both public and private, will require a revision of the state's role, especially further development of its regulatory function. Reform could take three complementary paths:

1. Introduction of new methods of private sector financing, providing access to both existing payroll tax-related resources and scholarships for disadvantaged students. 
2. Establishment of a partnership system, involving private sector representatives, for the definition, recognition, and upgrading of diplomas.

3. Review, in consultation with private sector representatives, of the legal and administrative framework that supervises the operations of private organizations and strengthening of the education ministry's institutional capacity to implement rules and regulations.

Source: Atchoarena and Esquieu 2002, p. 13. 


\section{Appendix D}

\section{Benin: BAA-Improving Traditional Apprenticeship Training}

\section{Objectives}

The Bureau d'Appui aux Artisans (BAA) is improving the quality and results of the apprenticeship training system in Benin through complementary training for traditional apprentices, a kind of "dual system." The Swiss Agency for Development and Cooperation (SDC) is providing external support. BAA's ultimate objective is to break the cycle of "incomplete" skills development of traditional apprentices who later become masters who are not adequately equipped to train their apprentices.

\section{Organization and Implementation}

The BAA works mainly through ISAs, such as Association Professionnelle des Artisans du Bois de Cotonou and l'Union Professionnelle des Artisans Tourneurs, Fraiseurs et Forgerons de Porto-Novo. It links the master craftspersons who are members of these ISAs, as well as their apprentices, with local training centers, either a public sector training provider (for example, a Lycéé Technique) or an NGO (for example, Mgr. Steinmetz VTC). BAA is the catalyst, financier, and technical adviser; the ISAs are the main implementers.

The ISAs organize and supervise the training through a Comité de Formation. The committee's tasks include

- Collaborating in the preparation of new training modules,

- Setting the criteria and carry out the selection of the trainees,

- Negotiating the fee for the instructors,

- Organizing the training together with the staff of the training center,

- Monitoring the attendance of the apprentices,

- Checking on the tools made available to the trainees,

- Co-organizing the trade test at the end of the training, and

- Participating in the evaluation of the training.

The members of the committee are also assigned the task of monitoring the progress of several apprentices through regular workshop visits. To prepare them for these tasks, the committee members made several exchange 
visits to the Centre Régional d'Enseignement Technique et de Formation Professionnelle in Lomé (Togo).

The training is directed first at apprentices of master craftspersons who are members of the ISA. The masters can propose two of their apprentices for the training. The apprentices need to have minimum basic education, be in their second year of training, and have at least two more years remaining. The masters must guarantee that the selected apprentices will be in a position to follow the training regularly, and the apprentices must sign their agreement to this guarantee.

The main topics for such training are (i) theoretical knowledge indispensable for the trades, (ii) improved knowledge of marketing, (iii) perfection of technical knowledge and expansion to include modern production techniques, and (iv) improved professional attitudes. The training in woodworking consists of two cycles and five modules: (i) general knowledge of wood and other materials, (ii) use of manual tools, (iii) wood assembly, (iv) interior and exterior carpentry, and (v) use of mechanized equipment. After the course, the apprentices receive copies of all relevant training materials, so they do not have to take notes during the training. The trainers are contracted from technical colleges and training centers. They receive training and follow-up guidance from staff members of the Lomé training center.

At the end of the training, the committee organizes a trade test. Apprentices who pass receive a certificate of attendance signed by the training institution and the association. After they finish the apprenticeship training they get another certificate from their master.

Master craftspersons are also eligible for training, especially skills upgrading, through groups of 20-30 masters formed by the participating ISAs. Their main motivation to participate is to ensure that they are not surpassed by their apprentices once the apprentices have finished their training.

Most of the training takes place in the workshop of one of the participating master craftspersons at spare hours (afternoons and weekends) and lasts almost two years.

\section{Costs}

On the basis of partial information on the training results, the dropout rate can be estimated at $10-35$ percent and the completion rate at $60-75$ percent. The costs of the training are calculated as approximately $\$ 1.30$ per trainee per session (excluding depreciation of equipment).

The training costs are still largely borne by SDC and BAA, although the subsidy has decreased from 90 percent to $65-80$ percent. The contribution from the master craftsperson has increased from 10 percent to 17 percent while the ISA and parents association (for apprentice training) are contributing the rest. 


\section{Results and Impact}

No data on impact were available. Master craftspersons benefited from the complementary training as it enhanced their technical, pedagogical, and management skills and they became gradually convinced of the need to strengthen their apprenticeship training. The master craftspersons admitted afterwards that the training had changed their approach and methods for apprenticeship training. Apprentices who have received complementary training have become more precise, responsible, serious, confident, and attracted to work well done.

\section{Lessons}

On the basis of limited information, some preliminary lessons can be noted:

- Master craftspersons are not familiar with the notion of complementary training, for themselves or for their apprentices, and they need to be carefully shown the benefits of such training.

- Master craftspersons who allow their apprentices to follow additional training tend to have the most dynamic workshops and to have a real need for skilled workers.

- Apprentices who have followed the training acquired more authority and assumed new responsibilities in the workshop and took more pride in their status.

- Involving existing NGO and public sector training providers in complementary training for master craftspersons and apprentices makes it necessary to improve equipment, enhance the technical skills of the instructors, and adapt teaching methodologies. 


\section{Appendix E}

\section{Cameroon: APME-Micro Enterprise Support and Promotion Program (Programme d'Appui au Milieu Artisanal de Maroua)}

\section{Project Concept}

The project seeks to increase the incomes of micro and small enterprises through increased product diversification and quality. Four trades are supported: leatherworking, metalworking, woodworking, and auto mechanics. To avoid market saturation, APME started motorcycle repair in 2001. Its training interventions are directed at both the masters and the apprentices. The project activities combine action-research with awareness raising and animation. The actual activities can be grouped into training and marketing interventions:

- Skills training: literacy training, management training, and technical skills upgrading and introduction of new technological knowledge (for example, design skills);

- Business advice: advice based on a workshop diagnosis, for instance on improving the layout of the workshop and the organization of the work;

- Financial support: in the form of a loan scheme and a credit and savings union, together with training and follow-up assistance;

- Marketing assistance: in the form of market studies, development of prototypes, informal sector promotion, and improved access to information;

- Opportunities for meetings: exchange visits between artisans, research for collective problems and solutions, and meetings for representatives of the sector;

- Information: through a documentation center with information on administrative and legal aspects; production techniques, equipment, and suppliers; and product designs. 
Technical skills training is the main entry point of the project. It refers to short-term, modular, and personalized training, mostly conducted in the workshops and tested after each module. The trainers move on motorcycles. The training is demand led and tailor made for the participating artisanswhich requires flexibility by the trainers. To improve the marketing prospects, the technical training focuses on (i) improving the quality of the products, and (ii) lowering the costs (for example, of materials). At the end of the training the graduates receive technical materials. Other training concerns management training (orders and cash books) and marketing skills. After the training, there are several follow-up activities for the benefit of the graduates. APME's training interventions are as much as possible linked to its support interventions in marketing. Promotion activities, for instance, are related to the introduction of new products through the development of prototypes.

\section{Costs, Financing, and Implementation}

The project is making a serious effort to introduce genuine cost-sharing for the services it provides. According to its own calculations the level of costrecovery is already high: 62 percent in the case of technical training (presumably of operational costs) - by making available the equipment in the workshops and selling training materials-and 47 percent for marketing assistance. Cost-recovery of literacy training is only 9 percent.

After initial support from Agence Française de Développement (AFD) and the European Union, the project is currently funded by the United Nations Development Programme or UNDP (60 percent). The staff of the project consists of one project manager (expatriate), two trainers-animators, and four trainers. The budget for the period August 1998-July 2001 totaled $\$ 1.7$ million: some $\$ 105,000$ for preparation and studies, $\$ 423,000$ for interventions, $\$ 411,000$ for vehicles and transport costs, and $\$ 692,000$ staff costs.

\section{Results}

During the first phase (1997-99) some 150 informal sector artisans were supported by the project, distributed across four trades. In 2000 APME ran 58 short courses. In December 2001, APME was providing training and followup visits to 83 workshops and a total of 260 artisans: 121 masters, 51 workers, and 88 apprentices.

APME's interventions in marketing resulted in the creation of a brand name by the Maroua micro and small enterprises. The KALKAL brand name is especially applied to leather products: out of 232 articles offered for labeling, 87 percent were accepted after screening. In the first phase of the project, efforts to diversify the production of the informal producers resulted in 65 new items for leather workers, 18 for metalworkers, and 7 for woodworkers. 
Various marketing interventions were undertaken, ranging from participating in local and national trade fairs, to setting up a permanent exposition in Maroua, developing catalogues, and creating new products-all of which resulted in significant extra income in 2000: FCFA 3.8 million in woodworking, FCFA 5.9 million in leather, and FCFA 13.5 million in metalworking.

\section{Lessons}

Some observers characterize APME as a "classic NGO project" with strong NGO leadership to intervene on behalf of artisans, who play a less prominent role themselves. Here are some initial lessons:

- The project has adopted a well-conceived integrated approach in which training is used as an entry point to improve the market position and opportunities for independent sector firms: it was found that it takes some 110 hours of training (9 hours of weekly sessions for 12 months) for a micro artisan to significantly enhance the quality of his or her products.

- Individualized training, while very much appreciated by the clients, is very time-consuming and difficult to plan; the trainers still adhere to standard training programs, defeating the purpose of the individualized training approach.

- The project has engaged in important networking with a good selection of other organizations active in micro and small enterprise development.

- Literacy training addresses a real local demand and is an important precondition for effective business development: the training lasts 2.5 years and takes place in sessions of 19-22 hours held 6 days per week.

- Few of the artisans are genuinely interested in bookkeeping and if they indeed start the books suggested, they tend to merely go through the motions while maintaining their own informal system; bookkeeping only becomes interesting once the firms reach a certain level of sales.

- The market-driven approach in which opportunities for local products are identified or created (through promotion activities) as the basis of the interventions is found to be very effective.

A recent UNDP evaluation characterized the project as taking a "paternalistic" approach, in that the artisans are more subject than partner. It was skeptical about the impact of the training efforts, because the training needs are not indicated by the micro producers themselves. Rather they are identified by the trainers, who are said not to listen very well to the artisans, or are simply inferred from the orders obtained. The use of acquired orders as the bait for training courses has important disadvantages. The items produced serve a particular market (mostly expatriates), causing a certain dependence 
on the part of the artisans. In the case of leather, the number of artisans who benefit from the KALKAL brand name is rather small (especially when compared with the total number of leather workers in Maroua).

The evaluation recommends an approach that relies more on the creativity of the trainers, taking the felt training needs as the point of departure of the training efforts and trying to transfer to the artisans the capacity to find solutions for their problems. Still, the evaluation supports the importance of the commercial strategy and the positive impact on incomes of the project clients.

Source: Haan and Serriere 2002, pp. 121-24. 


\section{Appendix F}

\section{Cameroon: GIPA-One Association's Approach to Improving Traditional Apprenticeship Training}

The Groupement Interprofessionnel des Artisans (GIPA) provides a genuine small enterprise solution for the problem of a lack of appropriate technical skills training. GIPA is an association of more than 100 informal sector enterprises in different economic sectors (for example, woodworking, leather products, textiles, and metalworking). A membership card costs FCFA 4,000 (\$5) and the annual contribution is FCFA 6,000 (\$8) per year; "most" of the members are said to have paid up. GIPA was created to undertake the following activities: (i) to group informal sector enterprises on a sectoral basis, (ii) to provide information and documentation to local artisans, (iii) to stimulate pre-employment training and skills upgrading, (iv) to seek a 'normalization' of apprenticeship training, (v) to participate in trade fairs, and (vi) to create a quality label.

The president of the association is the owner of a small, relatively modern, garment workshop. One of his main problems is a lack of skilled workersalthough the workshop has some 30 electrical overlook sewing machines, the present work force consists of one wage worker and seven apprentices (no apprenticeship fee is paid, only some pocket money given to apprentices). To contribute toward the training of garment workers, he is now setting up a training center for some 30 trainees. At present the association is undertaking the following activities: (i) regulation of apprenticeship training, (ii) provision of supplementary training, and (iii) production of the GIPA newsletter.

GIPA has taken the first steps to regulate the training of apprentices conducted in the workshops of its members. It has introduced a joint examination, for which it organizes an Examination Committee of five members: one from the Ministère du Développement Industrial et Commerce (MINDIC), two expatriates working in informal sector development, and two local master craftspersons. The graduates are presented with a joint GIPA/MINDIC certificate. One of the three graduation ceremonies so far took place in the local Hilton Hotel, paid for in part by the FCFA 30,000 (\$40) 
examination fee. In the future, GIPA hopes to further standardize the apprenticeship training, including its content and duration.

In 2001 GIPA organized short (one afternoon) training seminars in wood drying and marketing/customer relations. They were conducted by an experienced master craftsperson and an expatriate owner of an art gallery. Some 12-15 artisans participated; the training was free. In the future GIPA intends to conduct courses to provide the apprentices with more theoretical background on their trade. They will be given by educated informal sector entrepreneurs and teachers from technical schools.

The GIPA newsletter is produced by its secretary-general, who holds the only paid job in the organization. The GIPA representatives feel that the newsletter (which assumes not only interest but also low illiteracy among the member master craftspersons) is helpful in boosting the association's membership.

GIPA is a genuine and serious informal sector association. It appears to provide an answer at the higher end of the informal sector to the inadequate provision of skills training - not only by the state (and the NGO and private sectors) but also by the informal sector itself. GIPA's activities (for example, supplementary training, regulation of traditional apprenticeship training, examinations, and awarding of certificates), and especially its forthcoming training center, are driven by a lack of adequately skilled workers for small workshops. 


\section{Appendix G}

\section{Kenya: Jua Kali Project-Micro and Small Enterprise Training and Technology}

The Jua Kali (informal sector) project was funded with a $\$ 21.8$ million credit from the International Development Association (IDA), the World Bank's soft lending window. Its objectives were to provide skills and technology upgrading for about 32,000 informal sector manufacturing workers (reduced to 24,000 during implementation); to diversify and improve the quality of about 20 public and more than 200 private sector training providers; to increase the access of informal sector entrepreneurs to services; and to improve the policy and institutional environment by removing restrictive laws and policies.

\section{Implementation}

A key feature of the project is a voucher program intended to introduce consumer choice, enabling informal sector operators to purchase the training they want wherever they want. Intermediaries-allocation agencies-were selected by competitive tender to market, allocate, and redeem vouchers in a decentralized way throughout Kenya. Allocating agencies received a fee equal to 3 percent of the value of vouchers issued. Vouchers could be used for any kind of training from any registered training provider.

\section{Results and Impact}

Over the course of the project, about 700 training providers became prequalified for providing training. By early 2001, some 18,000 training vouchers had been issued, and 13,000 had been redeemed (the difference explainable by the time lag between issuance of the vouchers and completion of the training). The impact of the project, evaluated through two tracer studies, has been highly positive for the beneficiaries. Employment among the graduates has increased by 50 percent compared with employment before training, and the income of surviving enterprises has also increased by 50 percent. According to anecdotal evidence, some participants who received a voucher for basic training have paid the full cost of more advanced training. 
Some components of the project were not implemented because of delays occasioned by, for example, delays in starting the program to upgrade formal training institutions and delays in funding to upgrade technology. Principal implementation problems included design changes, lack of capacity in the project coordinating office, and an inadequate system of financial management that prevented timely payment of training providers. The lack of an audit or supervisory function, the failure to verify providers' credentials, and the high value of the vouchers have led to concerns about fraud and market distortion. The quality of the training has also come into question.

One unexpected outcome of the voucher training program was the emergence of a new kind of training provider, the skilled master craftsperson. The strong preference of Jua Kali workers for appropriate, accessible training by master craftspersons was revealed in the first phase of the project: 85 percent of all vouchers went to pay for the services of master craftspersons, and only 15 percent went to private and public training institutions.

\section{Lessons}

The following list highlights some the most important lessons from the project:

1. The use of a voucher mechanism enabled the project to stimulate demand for training, technology, and management and marketing consultation among micro and small enterprises. A supply response has been generated and a training market established to address the needs of micro enterprises.

2. An unexpected impact of the voucher training program was the emergence of skilled craftsmen as the leading providers of training. Entrepreneurs preferred the training services of master craftspersons in the informal sector to training in formal institutions. The training by master craftspersons was usually well adapted to entrepreneurs' need for short, practical training. These training providers were previously invisible to agencies that wished to pay for training directly.

3. Implementation experience underscores the importance of appropriate management arrangements: a project for the private sector is best managed by the private sector without undue influence of government.

4. Decentralized distribution of benefits to beneficiaries requires carefully prepared financial management systems that balance legitimate concerns for proper use of funds with prompt payment of training providers. p. 157. 


\section{Appendix H}

\section{Kenya: SITE Project-Improving Traditional Apprenticeship Training}

With $\$ 320,000$ in assistance from Appropriate Technology and the United Kingdom, the Kenyan NGO SITE (Strengthening Informal Training and Enterprise) ran a project from 1996 to 1998 to improve traditional apprenticeship training. The objectives were to upgrade the technical and managerial skills of master craftspersons to enable them to diversify their production; strengthen the capacity of master craftspersons to provide quality training to their apprentices; and strengthen the capacity of selected vocational training institutes to provide ongoing training to master craftspersons.

\section{Implementation}

The project started with a market trends survey from which metalworking, woodworking, and textiles were selected as its priority subsectors, based on their potential for growth and job creation. The survey also identified entrepreneurs' skill gaps. Some 20 trainers from vocational training institutes were taught to transfer skills to the participating entrepreneurs.

The project suffered an initial setback when the master craftspersons ("host trainers") displayed little interest in upgrading their technical skills. This prompted an important change in the project approach. The training was refocused on direct business improvement for the entrepreneurs, training content and delivery were made flexible, and overall management of training was added for the master craftspersons. The master craftspersons were recruited through Jua Kali associations, a quicker and less costly route than individual recruitment. Other changes in the project design were to build up the basic training of host trainers first, then broaden it to skills and theory; to use apprentices as sales representatives for their enterprises, thus exposing them to the wider aspects of running a business; to reduce the involvement of vocational training institutes, as their reorientation was beyond the project's mandate and capability; and to de-emphasize the credit component in view of the limited capacity to follow up and recover loans through the project.

During the project, 43 courses were designed and conducted for host trainers, including 3 on teaching methods, 8 on business skills, and 20 on technical skills. In all, 420 master craftspersons and 280 apprentices were trained directly, 
and 1,400 apprentices received improved training from the project's host trainers. In addition, training materials and videos were produced. Over the project period, the costs of running the training courses were cut by between 60 percent and 90 percent. Cost recovery was increased from less than 10 percent at the start of the project to 77 percent toward the end (excluding development costs).

\section{Results and Impact}

Host trainers improved their training of apprentices by eliminating gaps in enrollment, reducing the time and costs of training, improving content and quality, and concentrating training on productive activities. The master craftspersons involved increased their number of apprentices by between 15 percent and 20 percent, and employment of the participating small and medium enterprises increased by 22 percent. In addition, 88 percent of the master craftspersons applied their new skills; 73 percent made new or improved products; and 58 percent penetrated new markets. They achieved a 57 percent increase in turnover and a 25 percent increase in profits and improved their workshop layouts and organization of production.

\section{Lessons}

The main lessons from this project intervention are as follows:

1. Master craftspersons are not immediately interested in receiving skills training and need to be "hooked." This training has to be put in the broader context of business improvement and the transfer of marketable skills into tangible gains. Training has to be delivered in a flexible manner, taking into account the opportunity cost of the labor and the time of the participating master craftspersons.

2. Master craftspersons seek training not mainly to increase fees for traditional apprenticeships but to increase income from productive aspects of the business.

3. Training interventions proved a useful entry point for upgrading the technology of small and medium enterprises.

4. Linkages with vocational training institutes proved disappointingthey did not become sustainable providers of training to Jua Kali.

5. Independent trainers could be promoted as providers of training services to the informal sector. This is probably a more sustainable approach than working through vocational training institutes, which, as now structured, appear to have little potential for promoting employment in the informal sector.

6. Collaboration with informal sector associations is of prime importance.

7. Upgrading informal sector enterprises is possible and practical through carefully targeted skills development. Application of new skills appears to result in increased growth, innovation, and productivity. 


\section{Appendix I}

\section{Senegal: FEDNAPH-A Trade Association Providing Skills Training}

In the informal sector in Senegal, textile activities (for example, tailoring and dressmaking) are well organized. In 1991 the Association des Couturiers (ACS) was set up with local chapters in various regions in the country. To complement its activities, in 1995 the Fédération National de Professionnels de l'Habillement (FEDNAPH) was started at the initiative of the clothing sector; it soon had some 6,000 members, mostly from Dakar. FEDNAPH has the following objectives:

- Research into new commercial channels for the national and the international markets

- Creation of a savings and credit union to finance production activities of members

- Training of workers in the skills required for producing modern wearing apparel, including skills required for international subcontracting

- Establishment of a housing cooperative.

FEDNAPH has now some 10,000 members; they include small garment workshops as well as small and medium enterprises. It receives support from the Friedrich Ebert Foundation as well as from the Agence Française de Développement (AFD), which is supporting the training center.

\section{Implementation}

FEDNAPH's Centre de Formation et Perfectionnement (a 220-square-meter facility) was established in 1999 in one of Dakar's industrial areas in a building that belongs to the federation's president. It employs 18 part-time instructors and has a total capacity of some 130 trainees. The trainees are apprentices or workers from small and medium workshops and newly recruited workers of modern garment factories.

The training seeks to enhance the level of skills in clothing enterprises, mostly small and medium enterprises, and improve their prospects of serving local and regional markets. The center provides both pre-employment and skills upgrading training in three modalities. 
FEDNAPH: Types of Training Provided

\begin{tabular}{llll}
\hline Type of training & Target group & Duration & Training fee \\
\hline $\begin{array}{l}\text { Bac training } \\
\text { (basic training) }\end{array}$ & $\begin{array}{l}\text { Clients selected by } \\
\text { Direction de l'Emploi }\end{array}$ & 12 months & $\$ 50 /$ month \\
\hline $\begin{array}{l}\text { Academic training } \\
\text { (extended basic } \\
\text { training) }\end{array}$ & Individuals & $2-9$ months & $\$ 30 /$ month \\
\hline $\begin{array}{l}\text { Modular training } \\
\text { (special skills } \\
\text { upgrading) }\end{array}$ & $\begin{array}{l}\text { Individuals, workers } \\
\text { from small and micro } \\
\text { enterprises }\end{array}$ & $40-80$ hours & Trainees: $\$ 1 /$ hour \\
\hline
\end{tabular}

The AFD-funded project includes the purchase of additional equipment and a period of technical assistance provided by the Académie Internationale de Coupe in Paris. The Academy has assisted in the organization of training, the training of trainers, and the development of training curricula. The total budget of the project (1999-2001) was FCFA 250 million $(\$ 350,000)$.

The center is registered with the government. It has so far issued its own certificates but is in discussion with the ministry for an official trade certificate. No statistics on the impact of the training exist, but it is thought that some 50-80 percent of graduates in the end will have their own garments workshops, while 5 percent of the training graduates will go abroad (for example, to France) for work and further studies.

The FEDNAPH training center is facing a number of operational problems, such as lack of space and inadequate equipment. They could probably be solved by increasing fees, but in this respect FEDNAPH seems to have failed to solve the ubiquitous problem of low training revenues leading to suboptimal training provision and quality, which in turn reduces the possibilities for increasing training fees. The feelings of ownership of the training facility by FEDNAPH members are apparently not strong enough to make them pay higher fees for skills training to allow further investments that would improve future training quality.

\section{Lessons}

The training center of FEDNAPH brings out a number of points:

- When faced with a shortage of skilled workers, the enterprises in a particular sector band together to set up a training facility to solve their common problems.

- The private character of the center (it has been registered as a limited company) has resulted in higher levels of organization, equipment, 
and management and probably better quality training than in most public sector training centers.

- The external assistance, and especially the link with the Paris fashion academy, seems to have resulted in low-cost, effective capacity building.

In sum, FEDNAPH shows that trade associations can be instrumental in providing skills for the informal sector under certain conditions, such as (i) clearly understood self-interest among the members to participate, (ii) leadership, and (iii) relevant financial and technical assistance.

Source: Haan and Serriere 2002, pp. 43-45. 


\section{Appendix J}

\section{Tanzania: VETA/GTZ Project-Pilot Programs for Informal Sector Training}

The Vocational Education and Training Authority (VETA), assisted by the Danish aid agency, DANIDA, and the German technical cooperation agency, GTZ, conducted a series of labor market studies in the formal and the informal sector in Tanzania between 1997 and 1998. The studies revealed that only a few sectors offer substantial employment possibilities in formal enterprises (for example, hotels and tourism, information and communication services, mining). The vast majority of job seekers will have to earn their income in the informal sector; for example, as selfemployed persons or casual laborers or as subsistence farmers in the agricultural sector.

\section{Implementation}

VETA, assisted by GTZ, designed an Integrated Training and Entrepreneurship Promotion (INTEP) program to support target groups working in the informal sector in 1998-2001. The concept was tested in about 15 pilot programs in different regions of Tanzania, with a special emphasis on female crafts workers. The fields of training included food preparation (for example, small kitchens, meat dressing), mushroom growing, carpentry finishing, vegetable and plant nursery, oil pressing, and building. These courses are based on an identification of market niches as well as of oversaturated areas.

VETA developed and tested new training approaches for the informal sector. The INTEP concept design was based on selecting target groups and analyzing their abilities, experiences, wishes, and options; assessing the local labor market; designing an integrated training program (technical and managerial skills, literacy if necessary); and finding local training providers for implementation. The implementation was undertaken by other training providers. The concept strongly recommends the establishment of links to credit and business-development service providers. VETA's role in the INTEP approach is to initiate, facilitate, coordinate, and finance the training programs to the extent that costs are not covered by fees. The concept was introduced to the VETA regions, and the regional staff was trained intensively in the process. 


\section{Results and Impact}

The curriculum reform concurrently undertaken by VETA introduced the Competency-Based Education and Training System to Tanzania. The "unitbased training approach" offers short, modular training programs so that the trainees do not have to attend long courses. This system can also be used to train some target groups in the informal sector.

Preliminary assessments indicate that the modules and courses are costeffective, provide adequate training, and are successful in introducing trainers to the informal sector. After training, the quality of goods and services produced by the informal sector companies improved, and sales and profits increased. Some 20 percent of the carpentry graduates opened their own shops.

\section{Lessons}

The main findings and lessons can be summarized as follows:

1. A participatory approach should be used in planning the training.

2. A mix of technical and business skills (record-keeping, pricing, marketing, and customer relations) and literacy (if necessary) should be provided.

3. Trainees were able to pay a small fee and cover their travel and lunch expenses, but the rest of the training costs had to be subsidized.

4. VETA should connect with credit and other providers of services to medium and small enterprises.

5. Financial sustainability remains decidedly low, with some variation between target groups.

Sources: Haan 2001, pp. 82-84; communication from Ewald Gold, chief technical adviser, GTZ, Dar Es Salaam. 


\section{Appendix K}

\section{Uganda: UNIDO/DANIDA/JICA Project- Master Craftspersons Training}

The United Nations Industrial Development Organization (UNIDO) is assisting a project to train master craftspersons in Uganda. The project seeks to provide demand-driven and sustainable advisory services to small and medium enterprises, "star" entrepreneurs operating at district level in the project's priority sectors-metalworking, carpentry and masonry, electrical installation and electronics, textiles, food processing, and leather products. The two-year budget for the project is $\$ 877,000$, funded by the Danish aid agency, DANIDA, and the Japanese aid agency, JICA. Local institutions involved are the Uganda Small-Scale Industries Association, the Gatsby Trust, two training centers of the Department of Industrial Training, and sectoral support centers.

\section{Implementation}

The project started with consultation workshops with some 600 small producers in six districts. They agreed to pay a fee of USh 5,000 to USh 10,000 per day for quality advice and skills training. The selection of candidates to be trained as advisers to small and medium enterprises was based in part on their acceptances as advisers by their peers. Since 1999, about 180 master craftspersons have been trained as trainers. Their training encompassed adult learning principles, setting of training objectives, training methods, training needs assessment, task analysis, curricula development, and demonstration techniques. Based on performance assessment and visits to workshops, the number of prospective advisers was cut to 109, who then went on for a second round of training and upgrading of technical skills. Training took a month, full time, at the participating vocational training centers. The next phase of training included "industrial extension," that is, production management and planning (product sampling, plant layout), human resource management, financial management, marketing for competitiveness, and an in-plant study of an actual enterprise. In all, some 20 advisers per district will be trained, 3 per economic sector. The advisory services are, for the time being, a sideline activity and the master craftspersons will continue their own business activities. 


\section{Results and Impact}

The master craftspersons have started their own advisory services. In addition to in-plant advice, they conduct training needs assessments with local vocational training centers and set up skills upgrading courses for local producers. As an indication of interest in such training, when there are too few participants to cover break-even costs of the course, the prospective training participants have been willing to pay more to make up the difference.

\section{Lessons}

The main lesson of the project is that master craftspersons trained as advisers to small and medium enterprises have grasped the idea that those businesses can improve their operations and that they, the trainers, can help them do it.

Source: Haan 2001, pp. 110-11. 


\section{Appendix L}

\section{Zimbabwe: ISTARN—Traditional Apprenticeship Program}

The Informal Sector Training and Resources Network (ISTARN) project aims to improve the effectiveness of traditional apprenticeship programs by providing (i) short pre-apprenticeship training, (ii) a short follow-up training series, and (iii) access to various posttraining support services. It explicitly seeks to limit outside interventions in the existing practices so as not to upset the subtle balance that has grown with the apprenticeship system between the master craftspersons and the apprentice. Initial market surveys were conducted to ensure that training would not result in saturation of the market.

\section{Implementation}

The program began with a few trades (welding, carpentry), but was expanded to its current 19 trades, including some untraditional trades such as interior decorating, fiberglass products manufacture, and solar energy installation (linked to World Bank subsidies for teachers and other ruralbased civil servants who install photovoltaic solar panels and household electric systems). It was also recognized that not all interested masters are effective trainers. The apprenticeships vary in length by occupation (tailoring, 9 months; motor mechanics, 18 months). The block training, alternating between work and periods of training, is one of the program's most innovative aspects. The master craftspersons particularly appreciate the preapprenticeship training because it increases their students' immediate productive usefulness, reduces the risks of damage to tools, and shortens the apprenticeship period. Short-term training in business skills is also offered. Upon completion of their training, graduates are given access to small business advisory services and the chance to participate in a rentalpurchase scheme.

\section{Results and Impact}

Between the start of the program in 1996 up to 2001 a total of 1,160 apprentices graduated from the program (Billing and others 2001). Almost threequarters of them were men, mostly found in motorcycle repair, welding, 
and carpentry (together responsible for two-thirds of all male graduates). More than two-thirds of the female graduates were trained in dressmaking, childcare, and hairdressing.

Tracer studies found that the graduates of the apprenticeship training program were consistently successful in finding employment, mainly in the informal sector: on average, more than three-quarters (75-87 percent) of the graduated apprentices found employment, mainly self-employment. While many graduates of VTCs, who received much more expensive training, remain unemployed (59-78 percent), those who found employment got wage jobs. Female apprentices have made some inroads in male-dominated trades such as welding and carpentry.

\section{Lessons}

The intensive monitoring of the ISTARN program has resulted in important lessons learned:

\section{Recruitment and selection}

- Incentives originally offered to masters (free business training and advisory services) were discontinued because they led to a commercialization alien to the apprenticeship system.

- Similarly, apprentices initially received a subsistence allowance, and placements with masters were negotiated for them. This "handholding" gave the first intake group unrealistic expectations and resulted in endless complaints. Now would-be apprentices must find their own masters and no longer receive funds from the program for their food and lodging. Apprentices now also must pay a contribution to cover the costs of training materials for courses at technical training colleges.

- Using mass media to advertise training opportunities was not effective and was replaced with using informal sector associations and NGOs to recruit prospective apprentices.

- Concentrating attachments for the apprentices within a reasonable geographical area increases efficiency on the part of the implementing organization or provider.

- Instead of the training program finding attachments for the apprentices, the apprentices should do so, to prove their ability to take initiative and negotiate the terms and conditions for their apprenticeship.

- Interviewing the applicants is important to ensure that they are "job creators" rather than "job hunters."

\section{Technical training}

- A wide variety of training offerings and involvement of different training providers helps to avoid oversupplying the market with a particular set of skills. 
- The use of instructors from the technical training colleges, accustomed to teaching trainees who have much higher levels of previous education, proved not to be effective. It resulted in instruction over the heads of the target group, that is, content and level of instruction above and beyond the needs and capacity of the target group. These instructors need at least a one-week orientation course on the specific training needs of informal sector producers and on special training approaches for informal sector operators.

- More attention should be paid to the suitability of the masters-they do not always understand their mentoring role and training function. They are in need of subtle guidance.

\section{Graduation and follow-up}

- Master craftspersons have only limited business knowledge to transfer, so apprentices require complementary business training. No capacity for business training existed in the project area; hence, there was a need for building up the capacity of providers to render complementary business development services.

- Graduates need access to capital to set up their own businesses, for which task micro credit organizations were attracted.

- Graduates also need marketing assistance, for which marketing intermediaries were set up.

\section{Broader Program Issues}

One of the main success factors of the ISTARN program has been its flexibility to respond to opportunities that arise and to experiment with solutions for problems encountered. The program also tried to become self-sustainable. Costs were cut, for example, by limiting workshop visits by program staff members to one a month. At the same time, training fees were introduced. Gradually a measure of self-financing has been reached, at the expense of reduced access by the poor and those from rural areas. The experiences so far make it clear that full cost-recovery is unlikely.

ISTARN shows that apprenticeship training can be a cost-effective form of TVE and follow-up services. Its cost containment is a major achievement. It is of short duration and uses underutilized infrastructure at the technical training colleges over holidays and weekends. The program builds on the strong points of traditional apprenticeship training without undue intervention that could upset the intricate equilibrium developed over decades. The total cost of creating a job in the informal sector, from training through self-employment (including tools for the venture), is only a tenth of the estimated cost of training alone for a formal sector job. Success stems from two factors: the preparation of the unemployed through pre-apprenticeship training and the availability of a wide range of follow-up assistance. 


\section{Appendix M}

\section{Training Funds in Selected Sub-Saharan African Countries}

\begin{tabular}{|c|c|c|c|c|}
\hline Country & Organization & Funding source & $\begin{array}{l}\text { Objectives } \\
\text { (sectors covered) }\end{array}$ & $\begin{array}{l}\text { Comments on } \\
\text { the working of } \\
\text { the scheme }\end{array}$ \\
\hline $\begin{array}{l}\text { Angola } \\
\text { (planned) }\end{array}$ & $\begin{array}{l}\text { National } \\
\text { Vocational } \\
\text { Training Agency } \\
\text { (INAFOP); } \\
\text { Employment } \\
\text { and Training } \\
\text { Fund (planned) }\end{array}$ & n.a. & $\begin{array}{l}\text { Place unemployed; } \\
\text { improve worker } \\
\text { productivity through } \\
\text { enterprise-based } \\
\text { training (aimed at } \\
\text { the skill needs of } \\
\text { the enterprise sector) }\end{array}$ & n.a. \\
\hline Benin & $\begin{array}{l}\text { Planned project to } \\
\text { put into action the } \\
\text { National Vocational } \\
\text { Training Policy of } \\
\text { 1998; training fund } \\
\text { to be established }\end{array}$ & $\begin{array}{l}\text { Two-thirds } \\
\text { International } \\
\text { Development } \\
\text { Association (IDA), } \\
\text { one-third } \\
\text { government }\end{array}$ & $\begin{array}{l}\text { Provide training for } \\
25,000 \text { workers } \\
\text { (modern, informal, } \\
\text { agricultural, and } \\
\text { unemployed) }\end{array}$ & n.a. \\
\hline Cape Verde & $\begin{array}{l}\text { Training support } \\
\text { fund, overseen } \\
\text { by Executive } \\
\text { Committee and } \\
\text { administered } \\
\text { by Project } \\
\text { Coordination Unit }\end{array}$ & $\begin{array}{l}\text { World Bank and } \\
\text { government }\end{array}$ & $\begin{array}{l}\text { Develop market- } \\
\text { oriented training } \\
\text { courses, training } \\
\text { institutions, and } \\
\text { enterprises }\end{array}$ & n.a. \\
\hline $\begin{array}{l}\text { Côte } \\
\text { d'Ivoire }\end{array}$ & $\begin{array}{l}\text { Fonds de } \\
\text { Développement } \\
\text { de la Formation } \\
\text { Professionnelle } \\
\text { (established 1991), } \\
\text { a merging of the } \\
\text { Apprenticeship Fund } \\
\text { (established 1959) } \\
\text { and the Continuing } \\
\text { Vocational Training } \\
\text { Fund (established } \\
\text { 1977) }\end{array}$ & $\begin{array}{l}\text { Apprenticeship } \\
\text { tax ( } 0.4 \text { percent } \\
\text { of payroll), } \\
\text { continuing } \\
\text { vocational } \\
\text { training tax (net } \\
1.2 \text { percent } \\
\text { payroll), donor } \\
\text { funding }\end{array}$ & $\begin{array}{l}\text { Apprenticeship } \\
\text { training and } \\
\text { continuing in-service } \\
\text { training; support of } \\
\text { training programs for } \\
\text { informal sector } \\
\text { (sectoral cross- } \\
\text { subsidization) }\end{array}$ & $\begin{array}{l}\text { Problem of } \\
\text { nontransfer of } \\
\text { levy proceeds } \\
\text { by Treasury to } \\
\text { the fund } \\
\text { (particularly in } \\
\text { early 1990s) } \\
\text { largely solved } \\
\text { by establishing } \\
\text { special fund } \\
\text { account }\end{array}$ \\
\hline
\end{tabular}




\begin{tabular}{|c|c|c|c|c|}
\hline Country & Organization & Funding source & $\begin{array}{l}\text { Objectives } \\
\text { (sectors covered) }\end{array}$ & $\begin{array}{l}\text { Comments on } \\
\text { the working of } \\
\text { the scheme }\end{array}$ \\
\hline Djibouti & $\begin{array}{l}\text { National Council } \\
\text { for Training and } \\
\text { Employment } \\
\text { (planned-never } \\
\text { operational) }\end{array}$ & n.a. & n.a. & n.a. \\
\hline Gambia & $\begin{array}{l}\text { National Council } \\
\text { for Technical } \\
\text { Education and } \\
\text { Vocational } \\
\text { Training }\end{array}$ & n.a. & n.a. & $\begin{array}{l}\text { Levy assessed } \\
\text { on companies } \\
\text { but collected } \\
\text { and deposited } \\
\text { in Treasury- } \\
\text { never used for } \\
\text { training }\end{array}$ \\
\hline Kenya & $\begin{array}{l}\text { Industrial Training } \\
\text { Levy Fund } \\
\text { (established 1997) }\end{array}$ & $\begin{array}{l}\text { Sectoral training } \\
\text { levies (not } \\
\text { payroll based) }\end{array}$ & $\begin{array}{l}\text { Indentured } \\
\text { learnerships and } \\
\text { apprenticeships, skills } \\
\text { upgrading, and } \\
\text { management courses } \\
\text { (mainly formal sector) }\end{array}$ & $\begin{array}{l}\text { Levy collection } \\
\text { and fund } \\
\text { administration } \\
\text { by Directorate } \\
\text { of Industrial } \\
\text { Training; fall in } \\
\text { numbers of } \\
\text { apprentices } \\
\text { over time; poor } \\
\text { quality public } \\
\text { sector training } \\
\text { (National } \\
\text { Industrial } \\
\text { Vocational } \\
\text { Training Center } \\
\text { (NIVTC), } \\
\text { Nairobi) }\end{array}$ \\
\hline Lesotho & $\begin{array}{l}\text { Tripartite structure } \\
\text { to oversee } \\
\text { establishment of } \\
\text { national guidelines } \\
\text { and TVET reform }\end{array}$ & n.a. & n.a. & n.a. \\
\hline Madagascar & $\begin{array}{l}\text { National Council } \\
\text { of Technical and } \\
\text { Vocational } \\
\text { Education and } \\
\text { Training manages } \\
\text { Fund of } \\
\text { Intervention for } \\
\text { Vocational Training }\end{array}$ & $\begin{array}{l}\text { International } \\
\text { Development } \\
\text { Association and } \\
\text { government }\end{array}$ & n.a. & $\begin{array}{l}\text { Payroll levy } \\
\text { planned } \\
\text { for future } \\
\text { implementation; } \\
\text { regional and } \\
\text { subregional } \\
\text { training boards }\end{array}$ \\
\hline
\end{tabular}


Appendix M (continued)

\begin{tabular}{|c|c|c|c|c|}
\hline Country & Organization & Funding source & $\begin{array}{l}\text { Objectives } \\
\text { (sectors covered) }\end{array}$ & $\begin{array}{l}\text { Comments on } \\
\text { the working of } \\
\text { the scheme }\end{array}$ \\
\hline $\begin{array}{l}\text { Malawi } \\
\text { (to be } \\
\text { restructured) }\end{array}$ & $\begin{array}{l}\text { Industrial Training } \\
\text { Fund (ITF) } \\
\text { (established 1973) }\end{array}$ & $\begin{array}{l}\text { Differential head } \\
\text { tax (on skilled } \\
\text { workers), by skill } \\
\text { category, in } \\
\text { government and } \\
\text { private sector }\end{array}$ & $\begin{array}{l}\text { Finance of national } \\
\text { apprenticeship scheme; } \\
\text { reimbursement of } \\
\text { apprenticeship wages } \\
\text { grants to technical } \\
\text { colleges providing } \\
\text { formal courses }\end{array}$ & $\begin{array}{l}\text { If tax is shifted } \\
\text { onto skilled } \\
\text { workers, they } \\
\text { finance the } \\
\text { costs of training } \\
\text { apprentices }\end{array}$ \\
\hline Mali & $\begin{array}{l}\text { Fond d'Appui } \\
\text { à la Formation } \\
\text { Professionnelle et } \\
\text { de l'Apprentissage } \\
\text { (FAFPA) }\end{array}$ & $\begin{array}{l}0.5 \text { percent } \\
\text { payroll levy }\end{array}$ & $\begin{array}{l}\text { Fund to develop } \\
\text { demand-driven, } \\
\text { employer-financed, } \\
\text { skills upgrading and } \\
\text { apprenticeship training, } \\
\text { both formal (public } \\
\text { sector) and informal } \\
\text { (private sector) }\end{array}$ & $\begin{array}{l}\text { Fund finances } \\
75-90 \text { percent } \\
\text { of initial } \\
\text { training costs, } \\
\text { depending on } \\
\text { age of trainees }\end{array}$ \\
\hline Mauritania & $\begin{array}{l}\text { Institutional } \\
\text { Support Fund } \\
\text { (ISF); Training } \\
\text { Support Fund } \\
\text { (TSF) }\end{array}$ & $\begin{array}{l}\text { ISF financed by } \\
\text { Aid and } \\
\text { Cooperation } \\
\text { Fund (FAC); TSF } \\
\text { financed by } \\
\text { International } \\
\text { Development } \\
\text { Association } \\
\text { (IDA) }\end{array}$ & $\begin{array}{l}\text { ISF-to fund quality } \\
\text { improvements } \\
\text { developed by training } \\
\text { institutions; TSF_-to } \\
\text { finance training } \\
\text { initiated by micro } \\
\text { enterprises; TSF-for } \\
\text { training needs of } \\
\text { entrepreneurs and } \\
\text { small businesses, } \\
\text { mainly in the informal } \\
\text { sector }\end{array}$ & n.a. \\
\hline Mauritius & $\begin{array}{l}\text { Industrial } \\
\text { Vocational Training } \\
\text { Board (IVTB) } \\
\text { (established 1988) }\end{array}$ & $\begin{array}{l}1 \text { percent payroll } \\
\text { levy and } \\
\text { government }\end{array}$ & $\begin{array}{l}\text { IVTB training centers } \\
\text { focus on pre- } \\
\text { employment training; } \\
\text { levy-grant scheme } \\
\text { directed to in-service } \\
\text { training }\end{array}$ & n.a. \\
\hline Nigeria & $\begin{array}{l}\text { Industrial Training } \\
\text { Fund: Governing } \\
\text { Council fulfills } \\
\text { role of national } \\
\text { training authority: } \\
\text { Industrial and } \\
\text { Vocational Training } \\
\text { Board }\end{array}$ & $\begin{array}{l}1 \text { percent payroll } \\
\text { levy plus annual } \\
\text { budget from } \\
\text { government }\end{array}$ & $\begin{array}{l}\text { Promoting employer- } \\
\text { based training via levy } \\
\text { reimbursement (up to } \\
\text { about } 60 \text { percent of } \\
\text { levy contribution). } \\
\text { Some course provision } \\
\text { at ITF training centers. } \\
\text { Formal sector }\end{array}$ & n.a. \\
\hline
\end{tabular}




\begin{tabular}{|c|c|c|c|c|}
\hline Country & Organization & Funding source & $\begin{array}{l}\text { Objectives } \\
\text { (sectors covered) }\end{array}$ & $\begin{array}{l}\text { Comments on } \\
\text { the working of } \\
\text { the scheme }\end{array}$ \\
\hline Senegal & $\begin{array}{l}\text { National Agency } \\
\text { for Vocational } \\
\text { Training } \\
\text { (established 1988) }\end{array}$ & $\begin{array}{l}5 \text { percent of fixed } \\
\text { contribution } \\
\text { (includes } \\
\text { employer tax of } \\
3 \text { percent of gross } \\
\text { salaries), state } \\
\text { grants }\end{array}$ & $\begin{array}{l}\text { Formal sector } \\
\text { training }\end{array}$ & $\begin{array}{l}\text { Fully fledged } \\
\text { fund envisaged } \\
\text { in Ten-Year } \\
\text { Plan for } \\
\text { Education and } \\
\text { Training }\end{array}$ \\
\hline South Africa & $\begin{array}{l}\text { National Skills } \\
\text { Fund (established } \\
\text { 1999) }\end{array}$ & $\begin{array}{l}\text { A fifth of the } \\
\text { proceeds of } 1 \\
\text { percent payroll } \\
\text { levy (government } \\
\text { contribution } \\
\text { planned); sectoral } \\
\text { training funds } \\
\text { financed by } 80 \\
\text { percent of levy } \\
\text { proceeds }\end{array}$ & $\begin{array}{l}\text { Meet national strategic } \\
\text { objectives, especially } \\
\text { long-term for } \\
\text { unemployed and other } \\
\text { targeted special-needs } \\
\text { groups and sectors }\end{array}$ & $\begin{array}{l}\text { Fund largely } \\
\text { controlled by } \\
\text { Treasury }\end{array}$ \\
\hline Tanzania & $\begin{array}{l}\text { Vocational } \\
\text { Education and } \\
\text { Training Authority } \\
\text { (VETA) }\end{array}$ & $\begin{array}{l}2 \text { percent payroll } \\
\text { levy }\end{array}$ & $\begin{array}{l}\text { Finance of formal } \\
\text { (mainly VETA-owned) } \\
\text { training institutions }\end{array}$ & $\begin{array}{l}\text { Regional } \\
\text { training } \\
\text { boards }\end{array}$ \\
\hline Togo & $\begin{array}{l}\text { National Training } \\
\text { Fund }\end{array}$ & $\begin{array}{l}\text { Donors, } \\
\text { government }\end{array}$ & $\begin{array}{l}\text { Fund available for } \\
\text { projects in public, } \\
\text { private, and informal } \\
\text { sectors }\end{array}$ & $\begin{array}{l}\text { Payroll levy } \\
\text { remains in } \\
\text { treasury }\end{array}$ \\
\hline Zambia & $\begin{array}{l}\text { Technical } \\
\text { Education, } \\
\text { Vocational and } \\
\text { Entrepreneurship } \\
\text { Authority }\end{array}$ & $\begin{array}{l}2 \text { percent } \\
\text { (suggested) }\end{array}$ & n.a. & $\begin{array}{l}\text { Payroll levy } \\
\text { planned } \\
\text { for future } \\
\text { implementation }\end{array}$ \\
\hline Zaire & $\begin{array}{l}\text { A national } \\
\text { training agency }\end{array}$ & $\begin{array}{l}\text { Earmarked } \\
\text { payroll tax }\end{array}$ & n.a. & n.a. \\
\hline Zimbabwe & $\begin{array}{l}\text { Zimbabwe } \\
\text { Manpower } \\
\text { Development } \\
\text { Fund (ZIMDEF), } \\
\text { Vocational Training } \\
\text { Fund }\end{array}$ & $\begin{array}{l}1 \text { percent payroll } \\
\text { levy on private } \\
\text { and parastatal } \\
\text { companies }\end{array}$ & $\begin{array}{l}\text { Finance of } \\
\text { apprenticeship and } \\
\text { and other approved, } \\
\text { mainly professional, } \\
\text { formal sector training }\end{array}$ & $\begin{array}{l}\text { Leakage to other } \\
\text { uses: tertiary } \\
\text { education, real } \\
\text { estate, and so } \\
\text { forth; payroll } \\
\text { levy collected } \\
\text { by ZIMDEF }\end{array}$ \\
\hline
\end{tabular}

n.a. not available.

Note: Cameroon, Central African Republic, Chad, Republic of Congo, and Gabon also have training funds. Source: Ziderman 2003, p. 83. 


\section{Principal Sources}

The following reports were commissioned for the Review of Vocational Skills Development in Sub-Saharan Africa:

Atchoarena, David, and André Marcel Delluc. 2001. Revisiting Technical and Vocational Education in Sub-Saharan Africa: An Update on Trends, Innovations, and Challenges. IIEP/Prg.DA/01.320. Paris: International Institute for Educational Planning.

Atchoarena, David, and Paul Esquieu, eds. 2002. Private Technical and Vocational Education in Sub-Saharan Africa: Provision, Patterns, and Policy Issues. IIEP/Prg.DA/01.300. Paris: International Institute for Educational Planning.

Dabalen, Andrew, Helena Skyt Nielsen, and Michel Rosholm. 2002. “Enterprise Training in African Manufacturing." World Bank, Washington, D.C. Processed.

Farstad, Halfdan. 2002. “Integrated Entrepreneurship Education in Botswana, Uganda, and Kenya." National Institute of Technology, Oslo. Processed.

Fluitman, Fred. 2001. Working, But Not Well: Notes on the Nature and Extent of Employment Problems in Sub-Saharan Africa. Turin, Italy: International Training Center, International Labour Organisation.

Grierson, John, ed. 2002. Formal Sector Enterprise-Based Training in Africa: Case Studies from Kenya and Zambia. Turin, Italy: International Training Center, International Labour Organisation.

Haan, Hans Christian. 2001. Training for Work in the Informal Sector: Fresh Evidence from Eastern and Southern Africa. Turin, Italy: International Training Center, International Labour Organisation.

Haan, Hans Christian, and Nicholas Serriere. 2002. Training for Work in the Informal Sector: Fresh Evidence from West and Central Africa. Turin, Italy: International Training Center, International Labour Organisation.

Johanson, Richard. 2002. "Sub-Saharan Africa: Regional Response to Bank TVET Policy in the 1990s." AFTH4. World Bank, Washington, D.C.

Kitaev, Igor, with contributions from T. Coleman, J. Glover, and B. Kaluba. 2002. "Synthesis of Main Findings from Two Studies on Private Technical-Vocational Education and Training in Ghana and Zambia. (Phase II)." Draft IIEP/Prg.DA/02.365. International Institute for Educational Planning, Paris.

Lauglo, Jon, Albert K. Akyeampong, Kilemi Mwiria, and Sheldon G. Weeks. 2002. "Vocationalized Secondary Education Revisited." World Bank, Washington, D.C. Processed.

Oxenham, John, Abdoul Hamid Diallo, Anne Katahoire, Anna Petrovika-Mwangi, and Oumar Sall. 2001. Skills and Literacy Training for Better Livelihoods: A Review of Approaches and Experiences. Africa Region Human Development Working Paper Series. World Bank, Washington, D.C. 
Stevens, Geoff. 2001. "Distance Learning for Technical Vocational Education in SubSaharan Africa: Challenges and Opportunities." AFTH4. World Bank, Washington, D.C.

Ziderman, Adrian. 2003. Financing Vocational Training in Sub-Saharan Africa. Africa Region Human Development Series. Washington, D.C.: World Bank. 


\section{References and Selected Bibliography}

Acemoglu, Daron, and Jorn-Steffen Pischke. 1998. "Why Do Firms Train? Theory and Evidence." Quarterly Journal of Economics 108(1): 79-120.

. 1999. "Beyond Becker: Training in Imperfect Labour Markets." Economic Journal 109(453):F112-42.

Adams, Arvil V. June 2001. "Assessment of the Jua Kali Pilot Voucher Program." World Bank, Washington, D.C. Processed.

Afenyadu, Dela, Kenneth King, Simon Mcgrath, Henry Oketch, Christian Rogerson, and Kobus Visser. 1999. "Learning to Compete: Education, Training and Enterprise in Ghana, Kenya and South Africa." Prepared for the U.K. Department for International Development by the Center of African Studies. University of Edinburgh, Edinburgh.

African Development Bank. 1999. "Education Sector Policy Paper." Abidjan.

Altonji, Joseph G., and James R. Spletzer. 1991. "Worker Characteristics, Job Characteristics, and the Receipt of On-the-Job Training." Industrial and Labor Relations Review 45(1): 58-79.

Appleton, Simon, Paul Collier, and Paul Horsnell. 1990. Gender, Education, and Employment in Côte d'Ivoire: Social Dimensions of Adjustment in Sub-Saharan Africa. Washington, D.C.: World Bank.

Arndt, Channing. February 2003. "HIV/AIDS, Human Capital, and Economic Growth Prospects for Mozambique." Africa Region Working Paper Series 48, World Bank, Washington, D.C.

Atchoarena, David, and André Marcel Delluc. 2001. Revisiting Technical and Vocational Education in Sub-Saharan Africa: An Update on Trends, Innovations, and Challenges. IIEP/Prg.DA/01.320. Paris: International Institute for Educational Planning.

Atchoarena, David, and Paul Esquieu, eds. 2002. Private Technical and Vocational Education in Sub-Saharan Africa: Provision, Patterns, and Policy Issues. IIEP/Prg.DA/01.300. Paris: International Institute for Educational Planning.

Atchoarena, David, and Steven Hite. 1999. Training Poorly-Educated People in Africa. IIEP/Prg.DA/99.071. Paris: International Institute for Educational Planning.

Aventin, Laurent, and Pierre Huard. 2000. "The Cost of AIDS to Three Manufacturing Firms in Côte d'Ivoire," Journal of African Economies 9(2): 161-88.

Barron, J., M. Berger, and D. Black. 1997. On-the-Job Training. Kalamazoo, Mich.: W. E. Upjohn Institute for Employment Research.

Bartel, Ann P., and Nachum Sicherman. 1998. "Technological Change and the Skill Acquisition of Young Workers." Journal of Labor Economics 16(4): 718-55.

Becker, Gary. 1962. "Investment in Human Capital: A Theoretical Analysis." Journal of Political Economy 70(5, part 2): 9-49. 
1964. Human Capital. Chicago: University of Chicago Press.

Bennell, Paul. 1993. "The Cost-Effectiveness of Alternative Training Modes in Zimbabwe." Comparative Education Review 37(4): 434-53.

-1996a. "General versus Vocational Secondary Education in Developing Countries: A Review of the Rates of Return Evidence." Journal of Development Studies 33(2): 230-47.

_ 1996b. "Privatization, Choice and Competition: The World Bank's Reform Agenda for Vocational Education and Training in Sub-Saharan Africa." Journal of International Development 8(3): 467-87.

_. 1996c. "Rates of Return to Education: Does the Conventional Pattern Prevail in Sub-Saharan Africa." World Development 24(1): 183-99.

- July 1997. "Vocational Education and Training in Zimbabwe: The Role of Private Sector Provision in the Context of Economic Reform." London: U.K. Department for International Development.

-1999. Learning to Change: Skills Development among the Economically Vulnerable and Socially Excluded in Developing Countries. Geneva: International Labour Office.

Betcherman, Gordon. 2001. "Overview of Labor Markets World Wide: Key Trends and Major Policy Issues." Paper prepared for World Bank Institute course, Labor Market Policies, April 23-May 4. World Bank, Washington, D.C.

Bhaskar, V., A. Manning, and T. To. 2002. "Oligopsony and Monopsonistic Competition in Labor Markets," Journal of Economic Perspectives 16(2): 155-74.

Biggs, Tyler, Manju Shah, and Pradeep Srivastava. 1995a. "Technological Capabilities and Learning for African Enterprises." Technical Paper No. 288. Africa Technical Department Series. World Bank, Washington, D.C.

1995b. "Training and Productivity in African Manufacturing Enterprises." Regional Program on Enterprise Development, Discussion Paper. World Bank, Washington, D.C.

- 1997. "The Impact of the AIDS Epidemic on African Firms." RPED Discussion Paper 72. Africa Region, World Bank, Washington, D.C.

Bigsten, Arne, P. Collier, Stefan Dercon, Marcel Fafchamps, B. Gauthier, J. W. Gunning, A. Isaksson, A. Oduro, R. Oostendorp, C. Pattillo, M. Soderbom, F. Teal, and A. Zeufack. 2000. "Rates of Return on Physical and Human Capital in Africa's Manufacturing Sector." Economic Development and Cultural Change 48(4): 801-26.

Billing, K., P. Chitiyo, G. Kuchocha, and C. Mutiwanyuka. 2001. "Is Technical/ Vocational Training Alone Sufficient for Small Enterprise Start-Up? Practical Experiences from the Informal Sector Training and Resources Network (ISTARN) Program Zimbabwe." Paper presented at the IVETA Annual Conference 2001: Improving VET Systems, August 2, 2001, Montego Bay, Jamaica.

Bishop, John H. 1987. "The Recognition and Reward of Employee Performance." Journal of Labor Economics 5: S35-56.

- 1991. "On-the-Job Training of New Hires." In David Stern and Joseph Ritzen, Market Failure in Training? New Economic Analysis and Training of Adult Employees. Berlin: Springer-Verlag, pp. 61-98.

Black, Niel. 1997. "Technical and Vocational Education for Rural Development: Delivery Patterns." UNEVOC Info 9: 1-5. 
Bloom, David E., Lakshmi Reddy Bloom, and River Path Associates. 2000. "AIDS, Business, and Africa." In Africa Competitiveness Report 2000/2001. New York: Oxford University Press, pp. 26-37.

Bloom, David E., Ajay Mahal, and River Path Associates. January 2002. "HIV/AIDS and the Private Sector-A Literature Review." Dorset, U.K.: River Path Associates.

Boehm, Ullrich. 1991. "Education in Production Processes: Apprenticeship as a Means of Transition from Education to Work." Education with Production 12(1): 53-69.

Bonnell, R. 2000. "HIV/AIDS: Does it Increase or Decrease Growth in Africa?" Washington, D.C.: World Bank.

Bosch, Gerhard. 1992. Retraining-Not Redundancy: Innovative Approaches to Industrial Restructuring in Germany and France. Geneva: International Labour Organisation.

Brown, Charles, and James Medoff. 1989. "The Employer Size-Wage Effect." Journal of Political Economy 97: 1027-59.

Byram, Martin L., and Lawrence Pringle. 2003. "Training for Employment: A Case Study on the Community Skills Development Centres (COSDECs)," Annex 9 in "Vocational Skills Development in Namibia," Report No. 03/05/03, World Bank Education Sector Survey, "Human Capital and Knowledge Development for Economic Growth and Equity," EW-PO78682-ESW. World Bank, Washington, D.C.

Canagarajah, Sudharshan, and S. V. Sethuraman. 2001. Social Protection and the Informal Sector in Developing Countries: Challenges and Opportunities. Employment Policy Primer. Washington, D.C.: World Bank.

Canagarajah, Sudharshan, Dipak Mazumdar, and Xiao Ye. 1998. The Structure and Determinants of Inequality and Poverty reduction in Ghana, 1988-92. Washington, D.C.: World Bank.

Castro, Claudio de Maura. 1999. "Proyecto Joven: New Solutions and Some Surprises." Washington, D.C.: Inter-American Development Bank.

—. 2000. “When Employers Control Training Many Things Can Happen." Paper presented to the Working Group on International Cooperation for Skills Development, March, Washington, D.C.

Castro, Claudio de Maura, and Aimée Verdisco. 1998. "Training Unemployed Youth in Latin America: Same Old Sad Story?" Washington, D.C.: Inter-American Development Bank.

Castro, Claudio de Maura, Martin Carnoy, and Laurence Wolff. 2000. Secondary Schools and the Transition to Work in Latin America and the Caribbean. Washington, D.C.: Inter-American Development Bank.

Center for Workforce Development. 1998. "Investing in Tomorrow's Workforce." Funded by the Center for Human Capacity Development, U.S. Agency for International Development, Washington, D.C.

Chang, Chun, and Yijiang Wang. 1996. "Human Capital Investment under Asymmetric Information: The Pigovian Conjecture Revisited." Journal of Labor Economics 14: 505-19.

Coowar, Feroze. 1998. "Beyond the Formal Sector in Mauritius." In Under the Sun or in the Shade? Jua Kali in African Countries. Berlin: UNEVOC.

Crouch, Luis A. 1996. "Public Education Equity and Efficiency in South Africa: Lessons for Other Countries." Economics of Education Review 15(2): 125-37. 
Dabalen, Andrew, Helena Skyt Nielsen, and Michel Rosholm. 2002. "Enterprise Training in African Manufacturing." World Bank, Washington, D.C. Processed.

Dabalen, Andrew, Taye Mengistae, Dorte Verner, Helena Skyt Nielsen, and Michael Rosholm. 2000. "Employment and Wages during the Reform Period in Sub-Saharan Africa: A Synthesis." AFTH4. World Bank, Washington, D.C.

DANIDA (Danish International Development Agency). 2002. "Evaluation Report: Danish Assistance to Vocational Education and Training." Ministry of Foreign Affairs, Copenhagen.

Dar, Amit. 2000. “Tanzania." In Indermit S. Gill, Fred Fluitman, and Amit Dar, eds., Vocational Education and Training Reform: Matching Skills to Markets and Budgets. Washington, D.C., and Geneva: World Bank and International Labour Organisation.

Dar, Amit, and Zafiris Tzannatos. 1999. World Bank Lending for Labor Markets: 1991-1998. Washington, D.C.: World Bank.

De Nadaillac, Arnauld. 1999. "Initial Vocational Education Post 16 Years in France: Evolution and Future Trend." Paper prepared for the Office of the National Education Commission of Thailand and the World Bank. Thai French Innovation Centre, Bangkok.

Deloitte \& Touche Human Capital Corporation. May 2002. "Evaluation of Workplace Responses to HIV/AIDS in South Africa." Paper prepared for the U.K. Department for International Development.

Development Alternatives, Inc. 2001. "Analytical Summary of Nine Voucher Programs." U.S. Agency for International Development, Washington, D.C.

Dougherty, Christopher. 1989. "The Cost-Effectiveness of National Training Systems in Developing Countries." WPS. Population and Human Resources Department, World Bank, Washington, D.C.

Dougherty, Christopher, and Jee-Peng Tan. 1991. "Financing Training: Issues and Options." Population and Human Resources Department Working Paper Series No. 716. The World Bank, Washington, D.C.

Eberlein, R. 1995. "South Africa: The National Training Strategy Initiative." In Establishing Partnership in Technical and Vocational Education, Berlin: UNEVOC.

Farstad, Halfdan. 2002. "Integrated Entrepreneurship Education in Botswana, Uganda, and Kenya." National Institute of Technology, Oslo. Processed.

Fluitman, Fred. 1992. "Traditional Apprenticeship in West Africa: Recent Evidence and Policy Options." Discussion Paper 34. International Labour Organisation Publications, Geneva.

- 1999. "The Roots and Nature of Reforms in Vocational Education and Training: An Analytical Framework and Some Examples." Prospects 29(1).

- 2001. Working, But Not Well: Notes on the Nature and Extent of Employment Problems in Sub-Saharan Africa. Turin, Italy: International Training Center, International Labour Organisation.

Fluitman, Fred, and Wim Alberts. 2000. "Zambia." In Indermit S. Gill, Fred Fluitman, and Amit Dar, eds., Vocational Education and Training Reform: Matching Skills to Markets and Budgets. Washington, D.C., and Geneva: World Bank and International Labour Organisation.

Fluitman, Fred, and Xavier Oudin. 1991. "Skill Acquisitions and Work in MicroEnterprises: Evidence from Lomé, Togo." A joint study by the World Bank, the 
International Labour Organisation, and the Organisation for Economic Cooperation and Development, Geneva.

Forsythe, Steven. 2002. "How Does HIV/AIDS Affect African Businesses?" In International AIDS Economics Network, "State of the Art: AIDS and Economics." Prepared for the Barcelona Conference, June 2002. U.S. Agency for International Development, Washington, D.C.

Foster, Philip. 1992. "Vocational Education and Training: A Major Shift in World Bank Policy." Prospects 22(2): 149-55.

Fougère, Denis, Francis Kramarz, and Thierry Magnac. 2000. Youth Employment Policies in France. London: Centre for Economic Policy Research.

Gallart, Maria Antonia. 1996. "Poverty, Youth and Training in Latin America." Paper prepared for the Oxford International Conference on Education and Development, September 9-13.

- 1999. "Restructuring, Education and Training." In Víctor E. Tokman and Guillermo O'Donnell, eds., Poverty and Inequality in Latin America: Issues and New Challenges. Notre Dame, Ind.: University of Notre Dame Press.

German Foundation for International Development. 2002. International Cooperation in Human Resource Development for TVET Systems. Mannheim, Germany: Industrial Occupations Promotion Center.

Gill, Indermit S. 2003. Mexico: Technical Education and Training: Issues and Options. Vols. I and II. Washington, D.C.: World Bank.

Gill, Indermit S., Fred Fluitman, and Amit Dar, eds. 2000. Vocational Education and Training Reform: Matching Skills to Markets and Budgets. Washington, D.C., and Geneva: World Bank and International Labour Organisation.

Grierson, John P. 1997. "Where There Is No Job." Sponsored by Swiss Centre for Development Cooperation in Technology and Management (SKAT). Center of African Studies, University of Edinburgh, and Swiss Agency for Development and Cooperation (SDC), Berne, Switzerland.

ed. 2002. Formal Sector Enterprise-Based Training in Africa: Case Studies from Kenya and Zambia. Turin, Italy: International Training Center, International Labour Organisation.

Grierson, John P., and Iaian McKenzie, eds. 1996. Training for Self Employment through Vocational Training Institutions. Geneva and Turin, Italy: International Labour Organisation.

Grubb, Norton. 1999. "Lessons from Education and Training for Youth: Five Precepts." In Proceedings of Preparing Youth for the 21st Century: The Policy Lessons from the Past Two Decades. Conference organized jointly by the Organisation for Economic Co-operation and Development and the U.S. Department of Labor and Education, Washington, D.C. February 24-26, 1999, Paris.

Haan, Hans Christian. 2001. Training for Work in the Informal Sector: Fresh Evidence from Eastern and Southern Africa. Turin, Italy: International Training Center, International Labour Organisation.

Haan, Hans Christian, and Nicholas Serriere. 2002. Training for Work in the Informal Sector: Fresh Evidence from West and Central Africa. Turin, Italy: International Training Center, International Labour Organisation. 
Haltiwanger, John C., Julia I. Lane, and James R. Spletzer. 1999. "Productivity Differences across Employers: The Roles of Employer Size, Age, and Human Capital." American Economic Review 89(2): 94-98.

Hoppers, Wim. 1994. "The Promotion of Self-Employment in Education and Training Institutions: Perspectives in East and Southern Africa." Discussion paper. International Labour Organisation, Geneva. Processed.

- 1996. Searching for Relevance: The Development of Work Orientation in Basic Education. Paris: International Institute for Educational Planning.

Hoppers, Wim, and Donatus Komba, eds. 1993. Productive Work in Education and Training: A State-of-the-Art Review in Eastern Africa. The Hague, Netherlands: Centre for the Study of Education in Developing Countries.

Human Sciences Research Council. 1995. Ways of Seeing the National Qualifications Framework. Johannesburg: Human Sciences Research Council.

IDB (Inter-American Development Bank). 1999. "Study of the Impact of HIV / AIDS in Small Businesses: Case Studies of Suba and Isiolu Districts in Kenya." November. International Labour Organisation, Geneva.

- 2000. Vocational and Technical Training: A Strategy for the IDB. Washington, D.C.: IDB.

Idson, T., and W. Oi. 1999. "Workers Are More Productive in Large Firms." American Economic Review 89(2): 104-08.

ILO (International Labour Organisation). 1991. "Proceedings of the International Round Table on Vocational Training and Employment." Conference proceedings from Turin, Italy, June 17-20, 1991.

- 1998. World Employment Report 1998/9: Employability in the Global EconomyHow Training Matters. Geneva: International Labour Organisation.

- 1999. Jobs for Africa. Geneva: United Nations Development Programme and International Labour Organisation.

James, E. 1991. "Private Finance and Management of Education in Developing Countries: Major Policy and Research Issues. In Issues and Methodologies in Educational Development: An IIEP Series for Orientation and Training. Paris: UNESCO/ International Institute for Educational Planning.

Johanson, Richard. 2001. "Education and Health in Sub-Saharan Africa: A Review of Sector-Wide Approaches." Africa Region: Human Development Series, World Bank, Washington, D.C.

- 2002. "Sub-Saharan Africa: Regional Response to Bank TVET Policy in the 1990s." AFTH4. World Bank, Washington, D.C.

Katisson, Jenni. 1997. Partnerships in Current Government Education and Training Policy and Practice. Durban, South Africa: University of Natal.

Katz, Eliakim, and Adrian Ziderman. 1990. "Investment in General Training: The Role of Information and Labour Mobility." Economic Journal 100: 1147-58.

Kerre, B. Wanjala. 1995. "Kenya: Co-operation and Vocational Education." In Establishing Partnership in Technical and Vocational Education. Berlin: UNEVOC.

- 1998. "A Position Paper." In Under the Sun or in the Shade? Jua Kali in African Countries. Berlin: UNEVOC. 
Kewagamang, M. M., and K. Kabecha. 1998. "TVET beyond the Formal Sector in Botswana." In Under the Sun or in the Shade? Jua Kali in African Countries. Berlin: UNEVOC.

Kibera, Lucy. 1993. “Vocationalising Kenya's Secondary School Curriculum: Career and Educational Aspirations of Boys and Girls." Nairobi: University of Nairobi, Institute for Development Studies.

Kinyondo, Godbertha K. 1998. “Tanzania Workforce Development: Current Conditions and Opportunities." In Investing in Tomorrow's Workforce. Center for Workforce Development, U.S. Agency for International Development, Washington, D.C.

Kitaev, Igor, with contributions from T. Coleman, J. Glover, and B. Kaluba. 2002. "Synthesis of Main Findings from Two Studies on Private Technical-Vocational Education and Training in Ghana and Zambia. (Phase II)." Draft IIEP/Prg.DA/02.365. International Institute for Educational Planning, Paris.

Kogoe, Akrima. 1990. “The Diploma Disease and Unemployment in Francophone West Africa." Lomé.

Kraak, André. 1991. "Making the Hidden Curriculum the Formal Curriculum: Vocational Training in South Africa." Comparative Education Review 35(3): 406-29.

LaRocque, Norman. 1999. "Regulatory Framework Issues in Education." Paper prepared for the Investment Opportunities in Private Education in Africa Conference, Abidjan, November 30, 1999. World Bank, Washington, D.C.

Lauglo, Jon, and Anders Närman. 1987. "The Status of Practical Subjects and Their Uses After School: Diversified Secondary Education in Kenya." International Journal of Educational Development 7(2).

Lauglo, Jon, Albert K. Akyeampong, Kilemi Mwiria, and Sheldon G. Weeks. 2002. “Vocationalized Secondary Education Revisited." World Bank, Washington, D.C. Processed.

Law, Song Seng. 1996. Dynamics and Challenges of a Vocational Training System-The Singapore Experience. Singapore: Institute of Technical Education.

Leigh-Doyle, Sue. 1992. Increasing Women's Participation in Technical Fields: A Pilot Project in Africa. Geneva: International Labour Office.

Loewenstein, Mark A., and James R. Spletzer. 1998. "Dividing the Costs and Returns to General Training." Journal of Labor Economics 16: 142-71.

- 2000. "General and Specific Training: Evidence and Implications." Journal of Human Resources 34(4): 710-33.

Lugujjo, E., and B. M. Manyindo. 1995. “Uganda: Co-operation Links." In Establishing Partnership in Technical and Vocational Education. Berlin: UNEVOC.

Lukhele, Leonard. 1995. "Swaziland: Co-operation." In Establishing Partnership in Technical and Vocational Education. Berlin: UNEVOC.

Lynch, L., ed. 1994. Training and the Private Sector. National Bureau of Economic Research Comparative Labor Market Series. Chicago: University of Chicago Press.

McEwan, Patrick, and Martin Carnoy. 1997. "The Effectiveness and Efficiency of Private Schools in Chile's Voucher System." Stanford University, Stanford, Calif. Processed. 
McGrath, Simon, ed. 1996. "Donor Policies on Technical and Vocational Education and Training: Presentation of the Working Group and Comparative Analysis and Main Issues of the Sector Policies." Working Group for International Cooperation in Vocational and Technical Skills Development, Geneva.

— 1997. "Donor Policies in Skills Development." Geneva: Working Group for International Co-operation in Vocational and Technical Skills Development.

— 1998. "Donor Policies in Skills Development: Reforming Education and Training Policies and Systems." Geneva: Working Group for International Cooperation in Vocational and Technical Skills Development.

— 1999. "Debates in Skills Development: Sector Program Support and Human and Institutional Development in Skills Development." Geneva: Working Group for International Co-operation in Vocational and Technical Skills Development.

McNab, Christine. 2002. "Review of SIDA Support to Post-Basic Education in the Partner Countries." Final Report, August. Swedish International Development Authority, Stockholm.

Mahomed, Nisaar. 1996. The Integration of Education and Training in South Africa within the Context of Labor Market Theories and Globalisation. Durban, South Africa: University of Natal.

Manyindo, Ben M. "A Case for Uganda." In Under the Sun or in the Shade? Jua Kali in African Countries. Berlin: UNEVOC.

Mbugua, G. K. N. 1998. "Brief Description of the Jua Kali Movement in Kenya." In Under the Sun or in the Shade? Jua Kali in African Countries. Berlin: UNEVOC.

Middleton, John, Adrian Ziderman, and Arvil Van Adams. 1993. Skills for Productivity: Vocational Education and Training in Developing Countries. New York: Oxford University Press.

Miller, Juliet, and Louise Vetter. 1996. Vocational Guidance for Equal Access and Opportunity for Girls and Women in Technical and Vocational Education. Paris: UNEVOC, International Project on Technical and Vocational Education.

Mincer, Jacob. 1962. "On the Job Training: Costs, Returns, and Some Implications." Journal of Political Economy 70(2): 50-79.

- 1974. Schooling, Experience and Earnings. New York: Columbia University Press.

Mukuni, Joseph S., and Joseph P. Kalunga. 1989. "Training for the Informal Sector in Zambia." In Under the Sun or in the Shade? Jua Kali in African Countries. Berlin: UNEVOC.

Mullei, Andrew, and Crispin Bokea, eds. 1999. Micro and Small Enterprises in Kenya: Agenda for Improving the Policy Environment. Nairobi: International Center for Economic Growth.

Murnane, Richard, and Frank Levy. 1996. Teaching the New Basic Skills: Principles for Educating Children to Thrive in a Changing Economy. New York: Free Press.

Närman, Anders. 1992. "Trainees at Moshi National Vocational Training CentreInternal Achievements and Labour Market Adoption." Education Division Documents 56. Swedish International Development Authority, Stockholm.

Nell, Marian, Janet Shapiro, and Edda Grunwald. 2002. Projects/Programmes Aimed at Economic Improvement and Poverty Alleviation through Non-Formal and Non-Traditional 
Training in Sub-Saharan Africa. Frankfurt, Germany: Deutsche Gesellschaft für Technische Zusammenarbeit (GTZ).

Nestler, Katja, and Emmanuel Kailis. 2002. "Continuing Vocational Training in Enterprises in the European Union and Norway." Statistics in Focus, Theme 3, March. Brussels: Eurostat, European Communities.

“The New Partnership for Africa's Development (NEPAD)." 2000. Abuja, Nigeria.

Nielsen, Helena Skyt, and Michel Rosholm. 2002. "Evaluation of Training in African Enterprises." World Bank, Washington, D.C. Processed.

Odugbesan, Felicia A. 1990. “Women in Technical Education, Training and Jobs Africa: Western Regional Report." Discussion Paper 58. International Labour Organisation, Geneva.

- 1995. "Nigeria: The Perspective of an Educational Institution." In Establishing Partnership in Technical and Vocational Education. Berlin: UNEVOC.

OECD (Organisation for Economic Co-operation and Development). 1998. "Thematic Review of the Transition from Initial Education to Working Life, Interim Comparative Report." Paris.

- 1994. Apprenticeship: Which Way Forward? Paris.

Ogbu, Osita M., and Mark Gallagher. 1991. "On Public Expenditures and Delivery of Education in Sub-Saharan Africa." Comparative Education Review 35(2): 295-318.

Okaka, Peter O. 1998. "Technical and Vocational Education and Training Policy in Kenya." In Under the Sun or in the Shade? Jua Kali in African Countries. Berlin: UNEVOC.

Oxenham, John, Abdoul Hamid Diallo, Anne Katahoire, Anna Petrovika-Mwangi, and Oumar Sall. 2002. "Skills and Literacy Training for Better Livelihoods: A Review of Approaches and Experiences." Africa Region Human Development Working Paper Series. World Bank, Washington, D.C.

Pack, H. 1993. "Productivity and Industrial Development in Sub-Saharan Africa." World Development 21(January): 1-16.

Parker, Ronald L., Randall Riopelle, and William F. Steel. 1995. Small Enterprises Adjusting to Liberalization in Five African Countries. Washington, D.C.: World Bank.

Phekani, Joyce, and Maston M. Mtambo. 1998. "The National Policy Definition in Malawi." In Under the Sun or in the Shade? Jua Kali in African Countries. Berlin: UNEVOC.

Phiri, Christine C. M. 1990. “Women in Technical Education, Training and Jobs Africa: Southern/Central Regional Report." Discussion Paper 53. International Labour Organisation, Geneva.

Psacharopoulos, George, and William Loxley. 1985. Diversified Secondary Education and Development: Evidence from Colombia and Tanzania. Baltimore, Md.: Johns Hopkins University Press.

Rau, B., and M. Roberts, eds. 1996. Private Sector AIDS Policy: Businesses Managing HIV/AIDS. Arlington, Va.: AIDSCAP/Family Health International.

Republic of Mozambique. 2001. Professional Technical Education Strategy in Mozambique: More Technicians, New Professions and Better Quality (2002-2011). Maputo: Council of Ministers. 
2003. "The Cost and External Effectiveness of Present Provision for Vocational Training in Mozambique." Austral Consulting for the Ministry of Education, Maputo. Processed.

Richards, P., and R. Amjad, eds. 1994. New Approaches to Manpower Planning and Analysis. Geneva: International Labor Office.

Riley, Thyra, and William Steel. 1999 "Kenya Voucher Program for Training and Business Development Services." World Bank, Washington, D.C. Processed.

Rosen, Sherwin. 1976. "A Theory of Life Earnings." Journal of Political Economy 84(2):S45-S68.

Rumble, Greville, and João Oliveira. 1992. Vocational Education at a Distance: International Perspectives. Sterling, Va.: Stylus Publishing.

Sakafu, Lunogelo. 1989. "TVET at Mwanza Rural Housing Programme in Tanzania." In Under the Sun or in the Shade? Jua Kali in African Countries. Berlin: UNEVOC.

Sanyal, Bikas, Ulla Kann, N. V. Varghese, and B. Camara. 1990. “Education, Employment and Work: Report on an Intensive Training Course." International Institute for Educational Planning, Paris.

Sekonyela, Mota. 1998. "Non-government Organizations and Enterprise in Lesotho." In Under the Sun or in the Shade? Jua Kali in African Countries. Berlin: UNEVOC.

Sekwao, Cathleen. 1990. "Women in Technical Education, Training, and Jobs Africa: Eastern Regional Report." Discussion Paper 54. International Labour Organisation, Geneva.

Shongwe, William A. S. 1989. "Essential Features of the Non-formal Sector in Swaziland." In Under the Sun or in the Shade? Jua Kali in African Countries. Berlin: UNEVOC.

Sifuna, Daniel N. 1992. "Diversifying the Secondary School Curriculum: The African Experience." International Review of Education 38(1): 1-18. Hamburg, Germany: UNESCO Institute of Education.

Simon, Jonathan, Sidney Rosen, Alan Whiteside, Jeffrey Vincent, and Donald Thea. 2000. "The Response of African Businesses to HIV/AIDS." In HIV/AIDS in the Commonwealth 2000/01. London: Kensington Publications.

South African Government. April 2002. Report of the Study Team on the Implementation of the National Qualifications Framework. Department of Education and Department of Labor.

Stevens, Geoff. 2001. "Distance Learning for Technical Vocational Education in SubSaharan Africa: Challenges and Opportunities." AFTH4. Washington, D.C.: World Bank.

Stevens, Margaret. 1999. "Should Firms Be Required to Pay for Vocational Training?" Discussion Paper 2099. Centre for Economic Policy Research.

Tan, Hong W., and Geeta Batra. 1995. "Enterprise Training in Developing Countries: Incidence, Productivity Effects, and Policy Implications." Private Sector Development Department. World Bank, Washington, D.C.

Teichler, Ulrich. 1999. "The Contribution of Education and Training to the Employability of Youth: Changing Concerns, Debates, and Measures." In Preparing Youth for the 21st Century: The Policy Lessons from the Past Two Decades. Conference organized jointly by the Organisation for Economic Co-operation and Development 
and the U.S. Department of Labor and Education, Washington, February 24-26, 1999. Paris: OECD.

Terefe, Mesfin. 1998. "Existing Set-Up in Ethiopia." In Under the Sun or in the Shade? Jua Kali in African Countries. Berlin: UNEVOC.

Troske, Kenneth R. 1999. "Evidence on the Employer Size-Wage Premium from Worker-Establishment Matched Data." Review of Economics and Statistics 81(1): 15-26.

U.K. Department for International Development. 2000. "Meeting the Challenge: Skills Development, Capacity Building, and Widening Access to Education and Training in the Developing World." Skills for Development Team Education Department Strategy Paper. Education Department, Department for International Development, London. Processed.

UNAIDS (United Nations AIDS Prevention Agency). 1998. "Putting HIV/AIDS on the Business Agenda." Geneva.

UNDP (United Nations Development Programme). 2000. Human Development Report 2000. New York: Oxford University Press.

UNEVOC (International Project on Technical and Vocational Education, UNESCO). 1995. Establishing Partnership in Technical and Vocational Education. Berlin.

- 1996. The Development of Technical and Vocational Education in Africa. Dakar: UNESCO.

- 1998. Under the Sun or in the Shade? Jua Kali in African Countries. Berlin.

Vaughn, Roger. 1990. "Education, Training, and Labor Markets: A Policy Perspective." NCEE Brief 8, August. National Center on Education and Employment, Columbus.

Vawda, Ayesha Yaqub, and Harry Anthony Patrinos. 1999. Private Education in West Africa: The Technological Imperative. Washington, D.C.: World Bank.

Velenchik, Ann D. 1997. “Government Intervention, Efficiency Wages, and Employer Size Wage Effects in Zimbabwe." Journal of Development Economics 53(2): 305-38.

Verner, Dorte. 1999. "Are Wages and Productivity in Zimbabwe Affected by Human Capital Investment in International Trade?" Policy Research Working Paper 2101. World Bank, Washington, D.C.

Verner, Dorte, and Mette Verner. 2002. Economic Impacts of Professional Training in the Informal Sector of Côte d'Ivoire: Evaluation of the PAFPA. Washington, D.C.: World Bank.

Verster, Ryno. 1995. "South Africa: The ESKOM Approach." In Establishing Partnership in Technical and Vocational Education. Berlin: UNEVOC.

VETA (Vocational Education and Training Authority). 2002. "Competence-Based Education and Training: A Practitioner's Guide to VET Competence-Based Education and Training in Tanzania." Dar es Salaam.

Washi, Sidiga, and Sunita Pitamber. 1994. "Overcoming Structural Adjustment Policies in Africa: Strategies for Vocational Education and Training in the Sudan." Paper presented at the American Vocational Association Convention, December 9-13, 1994, Dallas.

Wilson, David N. 1993. "The Effectiveness of National Training Boards." Training Discussion Paper 110. International Labour Office, Geneva. 
Wolff, Laurence, and Claudio de Maura Castro. 2000. Secondary Education in Latin America and the Caribbean: The Challenge of Growth and Reform. Washington, D.C.: Inter-American Development Bank.

Working Group for International Cooperation in Skills Development. 2001. "Debates in Skills Development: Linking Work, Skills and Knowledge." Paper 6. Interlaken, Switzerland.

World Bank. 1991. Vocational and Technical Education and Training: A World Bank Policy Paper. Washington, D.C.: World Bank.

. 1999a. An Assessment of the Private Education Sector in Côte d'Ivoire. Washington, D.C.

-1999b. An Assessment of the Private Education Sector in The Gambia. Washington, D.C.

-1999c. An Assessment of the Private Education Sector in Mauritania. Washington, D.C.

-1999d. An Assessment of the Private Education Sector in Senegal. Washington, D.C.

- 2000. Can Africa Claim the 21st Century? Washington, D.C.

- 2001. "Project Appraisal Document on a Proposed Credit to the Republic of Zambia for a Technical Education Vocational and Entrepreneurship Training (TEVET)." Development Program Support Project. Report 21417-ZA. Washington, D.C.

- 2002. “Eritrea: Education and Training Sector Note.” Human Development I, Africa Region. Report 24448-ERI. Washington, D.C.

World Bank and the Turkish Employment Organization. 1997. "Synthesis Report of the International Conference on Employment and Training Funds," Antalya, Turkey, April 1-3. World Bank, Economic Development Institute, Washington, D.C. "The Worst Way to Lose Talent." 2001. The Economist, February 8.

Xulu, Siphamandla. 1989. "An Effective System for Non-formal TVET in South Africa." In Under the Sun or in the Shade? Jua Kali in African Countries. Berlin: UNEVOC.

Yates, Elizabeth. 1998. "Workforce Development in Namibia: Current Conditions and Opportunities." In Investing in Tomorrow's Workforce. Center for Workforce Development, U.S. Agency for International Development, Washington, D.C.

Ziderman, Adrian. 2003. Financing Vocational Training in Sub-Saharan Africa. Africa Region Human Development Series. Washington, D.C.: World Bank.

Ziderman, Adrian, and Arvil Van Adams. 2000. "South Africa." In Indermit S. Gill, Fred Fluitman, and Amit Dar, eds., Vocational Education and Training Reform: Matching Skills to Markets and Budgets. Washington, D.C., and Geneva: World Bank and International Labour Organisation. 


\section{Index}

abilities, innate and acquired, 31

accountability, 162

administrative controls, 104

Africa Regional Review of Skills and

Development, 32-37

approach, 33-35

country and case studies, distribution, 35

financing, 34

limitations, 36

report organization, 36-37

scope, 33

studies included, 34

African Development Bank (ADB), 24, $37 n .8$

agriculture, 47

percentage by country, 49

aid effectiveness, 25-26

allocation mechanisms, 11, 162-176

direct, 167-171

Angola, training funds, 220

APME, 200-203

apprenticeship training, 121-122, 126n.4, 129-135, 189

advantages and disadvantages, 133-134

allowances, 171-172

Benin, 197-199

costs, 198

enhancing, 146

fees, 156

image, 145

Kenya, 208-209

Malawi, 172

organization and implementation, 197-198

Senegal, 132

shortcomings, 139-140

strategy to improve, 145-147

strengths and weaknesses, 132, 182

Zimbabwe, 217-219

Argentina, training, 89n.5

artisanat, 52

autonomy, training, 78

Zambia, 79 barriers, removal, 10, 12

Benin

apprenticeship training, 131, 197-199

employment, 51

time use, 45

training funds, 220

bilateral assistance, 26

Botswana

public sector, $61 n .4$

training, 78-79

Botswana Brigades, 78-79, 176n.1

brain drain, 43-44

Brazil, employer-owned and managed, 78

budget practices, traditional, 167 Zambia, 168

budgeting norms, $10-11$

business planning, 89

business profitability, 41

business skills, 139

Cameroon

apprenticeship, 131

employment, 51

entrepreneurship, 55

nongovernment training, 94

unemployment, 50

Cape Verde, training funds, 220

capital, lack of, 56

Center for Workforce Development, 26

certification, 104, 144, 146

civil service, 68,70

collective support services, $124-125$

community contributions, 160

Community Skills Development Centers, 60

company size, 111, 153

competency-based training, 4-5, 80-82

qualifications systems, 188

competition, 16

micro and small enterprises, 56

competitive bidding, 166-167

composite formula funding, 168-169

CONFEMEN framework, 73-75

conflict of interest, training funds, 165

contracting, 125 
contracts, 29-30

cost-effectiveness, 19, 20

costs

apprenticeship, 133

business, 42

enterprise-based training, 203

HIV / AIDS and, 41-43

informal training, 141

nongovernment training, 96-99

per trainee, 98

production, 41

recovery, $176 n .2$

redistribution, 173

reimbursement, 173

cost sharing, 10, 183

fees, 155-156

Côte d'Ivoire

formal sector, 47,48

labor market information, 58, 59

nongovernment training, 94

training, 64, 80

training funds, 220

course length, 139

crafts, 52

craftspersons, 136

skills, 146

training, Uganda, 215-216

cross-subsidization, 153, 176n. 3

Danish International Development

Agency (DANIDA), 24, 25, 26, 76, 79,

89 n. $3,138,188$

demand-side financing, 25

Department for International

Development (DfID), 26

Deutsche Gesellschaft für Technische

Zusammenarbeit (GTZ), 24

diploma types, Senegal, 101

disincentives for training, 30

distance learning and teaching, 84, 123

Djibouti, training funds, 221

donor community, 20-22

approach, 25

downsizing, 17

economic output, increasing, 15-16

economy

analysis, 20-21

reforms, 39

understanding, 184-185

education, 1, 31, 32, 64, 99

basic, $86-87,145-146$

informal sector, 54 school enrollment, 44, 46-47

training and, 111, 123, 139

vocationalizing, 87-89

Education for All, 22

effectiveness, nongovernment training institutions, 99-103

efficiency, internal, training, 71-72

employer buy-in, 154

employer-owned and managed training, Brazil, 78

employer-sponsored training, 109

employment, 3,25

characteristics, 31

enrollment, 108n.2

enterprise-based training, 7, 36, 171-175, 190

Cameroon, 55, 200-205

financing, strengths and weaknesses, 174,175

Kenya, 206-207

new generation, 54

strengths and weaknesses, 182

enterprises

characteristics, 31

efficiency, determinants, 119

role, 32

trainers, 180-181

entrepreneurship, teaching, 88-89

environmental issues, 39

equity

apprenticeship, 133

fees and, 157

training and, 69

Eritrea, training, 68

Ethiopia

school enrollment, 46

training, 71

unemployment, 50

evaluation, 146

evening classes, 82

examinations

Mali, 100

performance, 100

Zambia, 102

export orientation, training and, 116, 118

external agencies, role of, 148

external approach, 174

failure rate, informal sector, 54

farmers, 33

HIV / AIDS, 42

FEDNAPH, 210-212

training types provided, 211 
fees, 96

apprenticeship, 156

centrally or locally established, 157

cost-sharing, 155-156

equity implications, 157

issues, 156-159

Senegal, 159

training, 77

tuition, 156

use of, 157-160

Zambia, 158

fertility rate, 44

finance, 190

allocation mechanisms, 162-176

promoting reforms with training

finance, $149-188$

reform and, 181, 183

resource mobilization, 150-161

financial sustainability, 141, 148

financing, 20

apprenticeship, 133, 145

diversification, 183

enterprise-based training, 203

government's role, 184

nongovernment training, 96-99

reforms, 9-11

strategy, 10, 12

trends, 162

follow-up, 219

formal sector, $47-48$

urban, 48

see also wage employment

formal sector enterprises as trainers, 109-126

benefits, 118-120

collective support services, $124-125$

firms' characteristics, 115-118

HIV / AIDS, 125

importance of, 111

incidence, 112-113

international comparisons, 113-114

pattern and determinants, 111-118

public-private partnerships, 124

recruitment practices, $120-121$

training types, 121-124

formal sector training, 7

strengths and weaknesses, 182

France, 24, 37n.9

funding diversification mechanisms, advantages and risks, 161

funds, 10, 142

competition for, $165-167$

Gabon, training, 71

Gambia, training funds, 221 gender equity, training, 69

Germany, 24, 25, 26

Ghana

employment, 51

informal sector, 128

informal training, 136

labor market information, 58, 60

nongovernment training, 94, 95, 106

training, 67, 72, 76, 77, 83

training follow-up, 141

training vouchers, 170-171

unemployment, 50

wage employment, 48

globalization, 16

governance, training funds, 164-165

government

role, 5, 12, 20, 183-186

recognition of nongovernment training, 106

support for nongovernment training, $104,108 n .1$

government-owned training institutions, strengths and weaknesses, 182

graduation, 219

Grierson study, 110

gross national product, 40

HIV / AIDS and, 40-41

Groupement Interprofessionnel des Artisans (GIPA), 204-205

harassment, 56

HIV / AIDS, 17, 40-43, 178, 188

formal sector enterprises, as trainers, 125

human capital, 16, 41

ILO, 33

incentives, worker, 29

income, 21, 25, 40-44

income-generating activities, 144-145

indirect financing, 169-171

individual training, 4

industry, percentage by country, 49

informal economy, 11, 178-179

demand, 128-129

external agencies and, 148

initiatives to support training markets, 135-142

issues, $147-148$

needs, 130

policies, 142

skills building, 8-9, 127-148

training strategies, 142-147

training supply, 129 


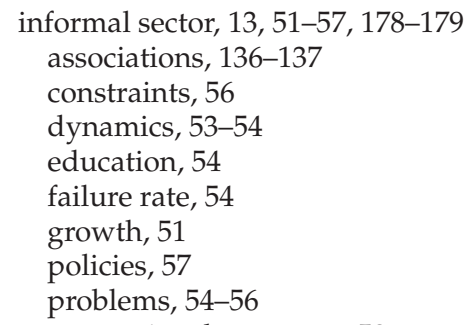

informal training, 138

manufacturing, 16

public sector, $61 n .4$

trade, small-scale, 55-56

training, 73

training funds, 221

training vouchers, 171

knowledge gaps, 13

proportion, by country, 53

labor

size and structure, 51-53

strategies, 57

support, 25

urban, 48

informal sector training, 189

firm size, by, 115

government role, 143

ownership, by, 117

Tanzania, 213-214

information and communication technologies (ICT), 84

infrastructure, inadequate, 56

initial training, 121

innovations, 188

input-based financing, 167-168

in-service training, 25, 30-31

institutional capacity, development, 185-186

institutional management, 77-79

institutional sources, 15

institutional sustainability, 141

institution-based providers of training, 36

institutions, 4

instructors. See teachers

INTEP, 141

international assistance, 21-26

International Development Bank, 27-28

international partners and assistance, 13

potential areas, 13

role, 186-187

International Project on Technical and Vocational Education (UNEVOC), 26

investment, 123-124

ISTARN project, 138, 217-219

issues, 219

IVTB, 76

Jobs for Africa Program, 33

Kenya

apprenticeship training, 208-209

employment, 51-52

enterprise-based training, 206-207

formal sector enterprises as trainers, 110-126

demand, 47-51

supply, $44-47$

labor force, 3-4

participation rates, 44,45

planning, 18

quality, 44

structure, 49

labor market information systems (LMIS), $18,20,57-61$

Namibia, 60-61

labor market, 3-4, 39-61, 178

analysis, 57, 58

imperfections, 29-30

linkage, 144

observatories, 58, 59

signaling, 18

structural adjustment programs, 50-51

trends, $14 n .1$

understanding, 184-185

legislation, 12

lending, 21-23

Lesotho, training funds, 221

level playing field, 107

Zambia, 107

levies

collection, 153-154

exemption, 174

proceeds, security of, 154

rate, 153

see also training levies

levy-grant schemes, 173-174

weaknesses, 175

levy-rebate schemes, 26

literacy, 8, 130, 140

rates, 46

literature, 26-28

macroeconomic frameworks, $37 n .10$

Madagascar

labor market information, 60

nongovernment training, 94

school enrollment, 46

training, 68, 70, 72, 77

training funds, 221 


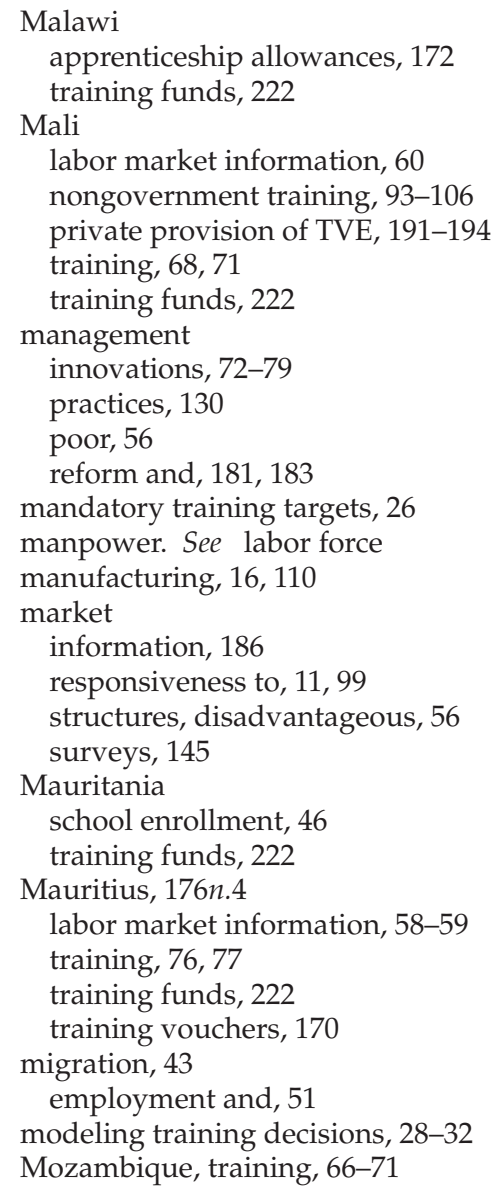

NACVET, 76

Namibia, labor market information, 60-61

national coordinating and consultative bodies, training, 75

national qualification framework (NQF), 80-81, 188

Ghana, 83

Report of the Study Team on the Implementation of the National Qualifications Framework, 81-82 South Africa, 80-81

New Economic Program for African Development (NPAD), 22

Nigeria training funds, 222 unemployment, 50

nonfarm sector, 33 employment, informal sector, 52 non-government training, 96, 180-181

effectiveness, 99-103

financing and costs, 96-99

issues, 106-108

markets for, 91-108

obstacles, 97

providers, 91,92

regulation, 104-106

scope and characteristics, 93-96

strengths and weaknesses, 182

Tanzania, 93

Zambia, 94

normative financing, South Africa, 169

numeracy, 130

occupation, training by, 116, 118

occupational requirements, 32

on-the-job training, 41-42, 111

open unemployment, 50

output, 41

apprenticeship, 134

ownership, training by, 117

partnerships, training, 75-76

payroll tax schemes, 151, 173

performance and outcomes, 5

criteria, 10-11

placement rates, 99-100

policies, 56, 57, 73

informal sector training, 142

policy framework, 183-184

Policy Paper, 24

Policy Study, 19-21, 25

population, 39

growth, 44

posttraining support, 147

poverty, $40-44$

reduction, 17

Poverty Reduction Strategy Programs

(PRSPs), 22

preservice training, 30

private sector

growth, 48

role, 18-19, 20

private sector training, 189

Mali, 191-194

Senegal, 191-192, 195-196

strengthening, 21

production costs, 41

productivity, 1, 16, 110, 125n.3

public-private partnerships, formal sector enterprises, as trainers, 124 
public sector growth, 48 role in training, 18-19, 28-30, 84-86 wage employment, by country, 49

public sector training, 180 effectiveness, 21

purchasing power, 56, 146

push factors, 54

quality

apprenticeship, 134

training, 69-71

rate of return, 30-31

analysis, 18, 20, 37n.3

recruitment, 120-121, 218

formal sector enterprises, as trainers, 120-121

reforms, 11

assessment, 177-183

government's role, 183-186

international partners' role, 186-187

making reforms work, 72-84

moving forward, 177-188

ownership, management, and structure, 63-64

priorities and policy issues, $84-89$

promoting, 9-11

public sector training, 63-89

research agenda, 187-188

trends, 179-180

refugees, 43

regional employer associations, 60

Regional Program on Enterprise

Development (RPED), 110, 125n.2

registration, 106

regulation, 56

frameworks, 105

nongovernment training, 104-106

regulatory environment, 106-107

regulatory framework, 21

relevance, training, 65-68

renting institutional premises, Togo, 160

requirements forecasting, 18

research agenda, 187-188

resources

allocation, 10-11

mobilization, 9-10, 150-161

sources, 150-159

responsibilities, delegation, $77-78$

return of investment, 43

salaries, TVE instructors, 98-99

sale of good and services, 9-10, 159-161 scaling up, 147

scholastic affairs, regulations of, 104

school enrollment, 44, 46-47

sectoral coverage, 153

sectorwide approaches (SWAPs), 25

sectorwide expenditure frameworks, $37 n .10$

self-employment, 35, 39, 47, 144-145

teaching, 88-89

Senegal

apprenticeship, 131, 132

fees, 159

labor market information, public sector, $61 n .5$

non-government training, 93-101, 105

private provision of TVE, 191-192, 195-196

trade-association training, 210-212

training, 65, 72, 82-83

training funds, 223

service delivery, innovations, 79-84

SITE project, 138, 208-209

skilled workers, loss, 41-42

skills, 1

demand for, 128-129

general vs specific, 29

skills development, 4

Africa regional review, 32-37

questions regarding Sub-Saharan Africa, 32

questions, 2-3

reduced attention to, 24

reforms, 21, 179-180

two-stage approach, 21

Skills for Productivity: Vocational Education and Training in Developing Countries.

See Policy Study

small workshop employment, 144

social objectives, 19

South Africa

normative financing experiment, 169

public sector, $61 n .4$

training, 81-82

training funds, 223

TVET reforms, 179-180

unemployment, 50

spending, 71

stakeholder participation, 184

state-sponsored training, 65-72

equity, 69

internal efficiency, 71-72

quality, 69-71

relevance, $65-68$

structural adjustments, 17 
student enterprises, 89

subsidies, 107-108

direct, 171-172

indirect, 172

supplementary training, 146

supply and demand, 17-18

sustainability, training funds, 165

Swaziland, unemployment, 50

Swiss Agency for Development

Cooperation, 25

system management, training, 74-79

systems approach, 174

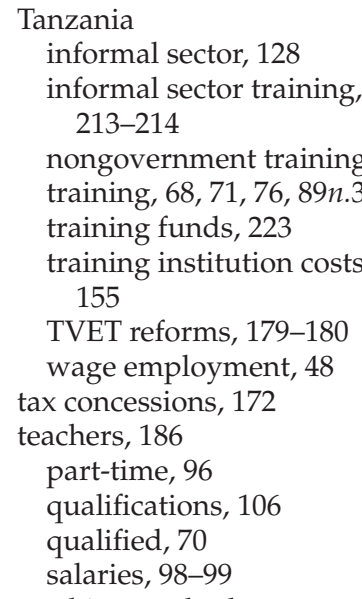

teaching methods, apprenticeship, 134

Technical and Vocational Education and

Training (TVET), 2, 15, 19, 20, 24,

$37 n .1,65-71$

isolation, 67

issues surrounding, 17-19

Policy Paper, 1-2

research on, 26-28

statistics, $89 n .1$

supply driven, 67

systems, 24

systems management, 4

World Bank lending, 21-22

technical personnel, 124

technical skills, 56, 130

technical training, 218-219

technological change, 17,31

technological efficiency, 110

technology, $37 n .2$

inadequate, 56

investment and training, 111

TEVETA, 76, 102-103

textile industry, $37 n .2$

thematic studies, 2, 14n.1

time use, Benin, 45
Togo

labor market information, 58

renting institutional premises, 160

training funds, 223

trade associations, 60

Senegal, 210-212

trade liberalization, 110

trading, small-scale, 52-53, 55-56

trainers, for-profit, 6

training, 63

boards, 76

content, 134, 144

decisions, modeling, 28-32

delivery, 139, 144

determinants, 30-32

development of the 1990s, 19-21

direct, 189-190

dual modes, 80

economic relevance, 87

expanded services, 82-83

follow-up, 141, 144

Ghana, 141

importance, $16-17$

job category, by, 120

management, 72-79

materials, 144

needs, informal sector, 130

organizations, 76-77

quality, 6

rationale, 15-16

service delivery, 79-84

state-sponsored, reforms, 4-5

strategies, 27-28, 142-145

strengths and weaknesses, 182

types, formal sector, 121-124

variation, 64

see also nongovernment training

training funds, $162-165,183,220-223$

conditions for success, 166

income sources, 163

issues, 164-165

training institutions

nongovernment, 6

raising revenues, 154-155

type and standards, by, 103

Zambia, 103

training levies, 9, 11, 151-154

advantages and disadvantages, 152

design and implementation, 153-154

premature introduction, 154

training markets, 6,12

formal sector enterprises, 7

improving, 185-186

tuition, 9, 96, 105, 156

see also fees 
UFAE, $89 n .4$

Uganda

craftspersons training, 215-216

employment, 51

formal sector, 47

informal sector, 128

nongovernment training, 95, 99

training, 67

U.K., 26

unemployment, 5

open, 50

urban, 48

rural, 48

UNIDO/DANIDA/JICA project, 215-216

Units for Training and Support to

Enterprises (UFAE), 82-83

upgrading training, 122-124

U.S. Agency for International

Development (USAID), 26

VETA/GTZ project, 213-214

Vocational and Technical Education and

Training: A World Bank Policy Paper, 19

Vocational Education and Training Reform, 26-27

vocationalization, general education, 87-89

vocational skills, light, 95

vocational training institutes, 138 reorientation, 147

vouchers, 169-171, 207

Mauritius, 170

wage employment, 35,47

public sector, by country, 49

stagnation, 127, 188

TVET and, 68

see also formal sector

wage premiums, 31 wages, 29-30, 178

training and, 119

women

informal sector, 53

time use, 45

training, 69

work placement, 89

Working Group for International

Cooperation in Skills Development, 24, 25, 26

World Bank-International Labour

Organisation study, 26, 27-28

youth, unemployment, 50

Zaire, training funds, 223

Zambia

fees, 158

formal sector, 48

formal sector enterprises as trainers, 112-126

nongovernment training, 93-107

trade, small-scale, 55

traditional budgeting, 168

training, 66-79

training funds, 223

TVET reforms, 179-180

Zimbabwe

apprenticeship training program, 217-219

formal sector, 47,48

formal sector enterprises as trainers,

112-126

informal training, 138

levy-grant schemes, 174

nongovernment training, 93-94, 99

trade, small-scale, 55

training, 68

training funds, 223 
The development of the African workforce is at a critical moment. Wage employment in the modern sector is largely stagnant, with those unable to find these jobs left to pursue self-employment in the informal sector. Unemployment among urban youth is substantial and increasing. Much of the impact of HIV/AIDS has fallen on the educated and the skilled. What can African governments do to ensure that the workplace skills needed for growth and equity are taught and developed in a cost-effective way?

Skills Development in Sub-Saharan Africa provides relevant and useful knowledge that should help African leaders and donor agencies find answers to this question. An update of a World Bank Policy Paper on technical and vocational education and training (TVET), this review assesses a decade's progress on TVET development and reform. The study puts into an African context the Bank's earlier work on TVET, explores issues and recent developments, and reviews recent literature and policy studies. Without being prescriptive, the book provides a comprehensive review of the challenges facing skills development in Africa today and the lessons learned over the past decade.

Based upon 14 thematic studies covering 20 countries and 70 case studies, the volume provides a good starting point for the development of country policies and programs, including a strategic role for governments. The wealth of information specific to training in Africa should be of value not only to African leaders but also to countries in other regions that are facing similar challenges. Skills Development in Sub-Saharan Africa will be of great interest to policymakers, leaders, and international donors with a stake in skills development in the region. 